San Jose State University

SJSU ScholarWorks

Dissertations

Master's Theses and Graduate Research

Summer 2019

\title{
Students of Black or African American Ancestry in Grades 10th -12th Perceptions of Their Schooling Experiences
}

Annette Renee Kennedy

San Jose State University

Follow this and additional works at: https://scholarworks.sjsu.edu/etd_dissertations

\section{Recommended Citation}

Kennedy, Annette Renee, "Students of Black or African American Ancestry in Grades 10th -12th

Perceptions of Their Schooling Experiences" (2019). Dissertations. 33.

DOI: https://doi.org/10.31979/etd.3cq8-v2sg

https://scholarworks.sjsu.edu/etd_dissertations/33

This Dissertation is brought to you for free and open access by the Master's Theses and Graduate Research at SJSU ScholarWorks. It has been accepted for inclusion in Dissertations by an authorized administrator of SJSU ScholarWorks. For more information, please contact scholarworks@sjsu.edu. 


\title{
STUDENTS OF BLACK OR AFRICAN AMERICAN ANCESTRY IN GRADES $10^{\mathrm{TH}}$ - $12^{\mathrm{TH}}$ PERCEPTIONS OF THEIR SCHOOLING EXPERIENCES
}

\author{
A Dissertation \\ Presented to \\ The Faculty of the Educational Doctoral Program in Educational Leadership \\ San José State University \\ In Partial Fulfillment \\ of the Requirements for the Degree \\ Doctor of Education \\ by \\ Annette Kennedy
}

Summer 2019 
(C) 2019

Annette Kennedy

ALL RIGHTS RESERVED 
The Designated Dissertation Committee Approves the Dissertation Titled STUDENTS OF BLACK OR AFRICAN AMERICAN ANCESTRY IN GRADES $10^{\mathrm{TH}}$ -
$12^{\mathrm{TH}}$ PERCEPTIONS OF THEIR SCHOOLING EXPERIENCES

\author{
By \\ Annette Kennedy \\ APPROVED FOR THE EDUCATIONAL DOCTORAL PROGRAM IN \\ EDUCATIONAL LEADERSHIP
}

SAN JOSÉ STATE UNIVERSITY

Summer 2019

Amy Leisenring, Ph.D.

Director - ACCESS, Professor, Department of Sociology and Interdisciplinary Social Sciences

Megan Thiele, Ph.D.

Professor, Department of Sociology and Interdisciplinary Social Sciences

Thomas Moriarty, Ph.D.

Director - Writing Across the Curriculum, Professor, Department of English and Comparative Literature 


\begin{abstract}
STUDENTS OF BLACK OR AFRICAN AMERICAN ANCESTRY IN GRADES $10^{\mathrm{TH}}$ $12^{\mathrm{TH}}$ PERCEPTIONS OF THEIR SCHOOLING EXPERIENCES
\end{abstract}

by Annette Kennedy

California continues to tackle blatant racist acts within school systems across the state as recent headlines read, "Deeply offensive blackface video of California high school student sparks backlash" (Yancey-Bragg, Guynn, \& Rhor, 2019, n.p.) and "Four teachers and their principal placed on leave after cheerfully posing for photo with noose" (Lunning, 2019, n.p.). Gaining a greater awareness of the non-headlining actions that take place on a day-to-day basis that have an equally powerful adverse effect on the school experiences of black learners was the focus of this study. Microaggressions are "subtle, stunning, often automatic, and non-verbal exchanges which are put downs" classified as microassaults, microinsults, and microinvalidations. For this study, emphasis was on race-based microaggressions. The presence of racial microaggressions impacted student participants' perceptions of their schooling experiences. Microassaults were the most experienced racial microaggressions generally instigated by peers followed by microinsults, equally exhibited by teachers and peers. Microinvalidations were not as common but when they did occur peers were often the perpetrator. 


\section{Acknowledgments}

Luke 1:28 And having come in, the angel said to her, "Rejoice, highly favored one, the Lord is with you; blessed are you among women!" (NKJV)

- Dear Dissertation Committee, thank you for agreeing to embark on this journey with me!! Dr. Amy Leisenring and Dr. Megan Thiele who served as Co-Chairs, you both have inspired me to do my best work and to find a balance between staying true to my passion for the topic while using ethical research practices to guide the undertaking of it. You challenged me to be explicit and focused on my research topic and design and your feedback has been priceless in moving the work along a productive path. I want to give a special thank you to Dr. Thomas Moriarty for reading through the chapters and providing insights and suggestions as this work came into being. Also I am greatly appreciative of your willingness to serve as my third committee member.

- I want to thank Dr. Arnold Danzig, Director, Ed.D. Program and the faculty and staff of SJSU Educational Leadership Program for the opportunity to be apart of the Cohort 3 experience.

- I want to thank my family, with a special recognition to my son Tréjan Sun Kennedy, my heartbeat who motivates me to be the best me I can be for him and all of the young people I serve in my day-to-day interactions. To my mother, Mrs. Jean Bates, who has always encouraged me to go as far as I can in my educational endeavors. In loving memory of my father, the late Mr. Arthur Bates, who instilled in me a strong work ethic and to my extended family and friends for their love and support. 
- I want to thank the high school district that entrusted me to undertake this district wide study with their precious commodities: $10^{\text {th }}-12^{\text {th }}$ grade students of Black or African American ancestry. The intent was to uncover the root causes that have led many Black students to feel disengaged from the district. The results will serve as a catalyst for district wide, on-going Courageous Conversations on topics of implicit biases, inequities, and racial microaggressions' that impact the achievement and engagement level for students of color. The work will help to spring forth intentional implementation of initiatives addressing these ills while being constantly reflective in practice in support of the district's efforts of promoting a relationship-centered, inclusive learning environment that provides equitable access for all students.

- This work is dedicated to the 72 brave students who took part in this survey to stand in the gap for their peers, not only locally but nationally, to voice their lived experiences in unjust educational systems. It is the hope this study will contribute not only to the body of educational leadership in the K-12 setting but transcend to the greater good of humanity in creating equitable spaces throughout the nation in all social institutions.

- My Edifice: Philippians 4:13 I can do all things through Christ who strengthens me (NKJV). Always giving honor and praise to the Heavenly Father for I recognize and acknowledge that in all my doings they are only possible because God has allowed it to be. I've prayed that 2019 be the catalyst year that will allow me to become famous in my field. Not for a conceited, egotistical, self-centered 
gratification, but, to serve as a vessel for the glorification and magnification of God's transformative power to change the negative trajectory that has been placed on many students of color in this nation and around the world. Too many young people have been educationally oppressed at the hands of adults who hold subpar dispositions toward them that manifest into policy and practice. It is time to shake the comfort zone like never before and remove the status quo for a New Normal in the K-12 public school experience. I pledge a lifelong conviction and commitment of service to this human rights and social justice work at empowering and magnifying the voices in the margins. 
Table of Contents

List of Tables ................................................................................................. xii

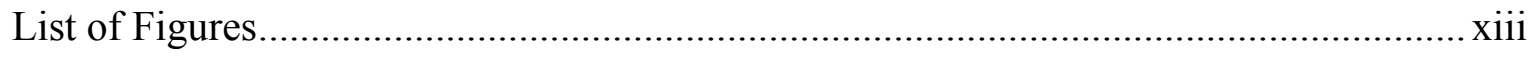

Chapter 1 Introduction and Statement of the Problem..............................15

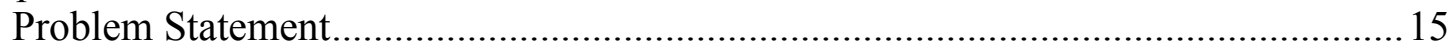

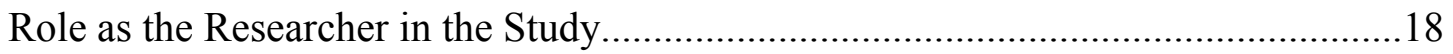

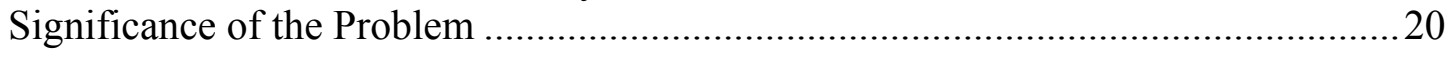

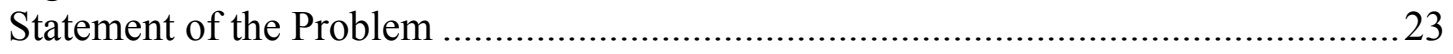

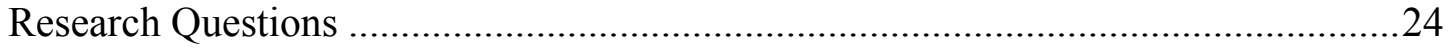

Site Selection and Sample ................................................. 24

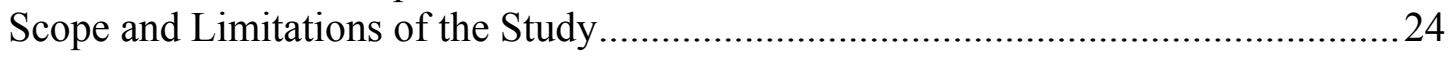

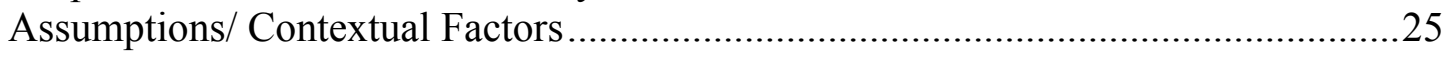

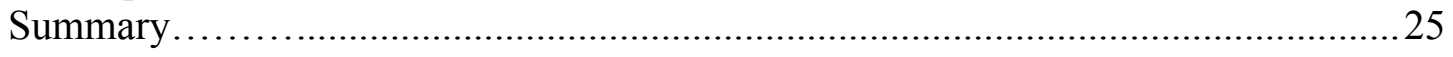

Chapter 2 Literature Review............................................. 27

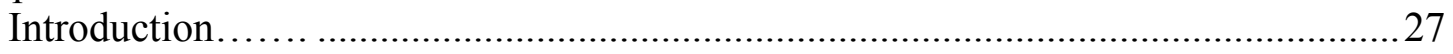

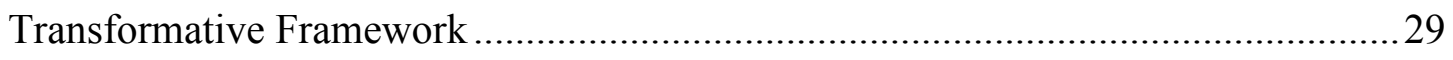

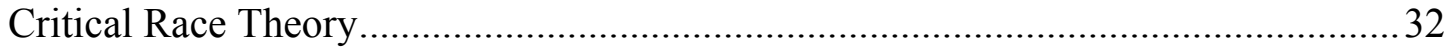

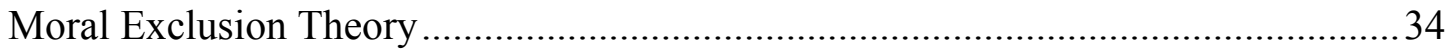

Critical Race and Moral Exclusion Theories in the Classroom ..................................36

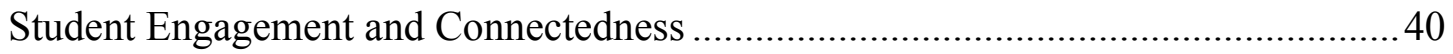

Marginalization of black student engagement ............................................... 42

Teacher dissonance: beliefs and classroom practices......................................44

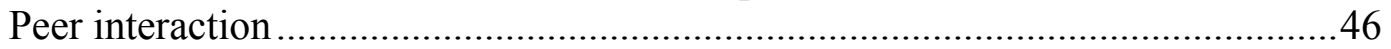

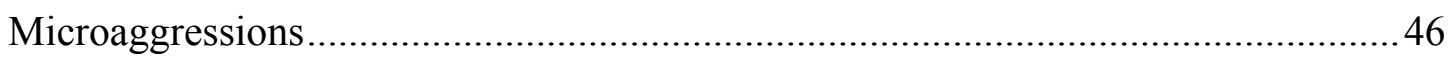

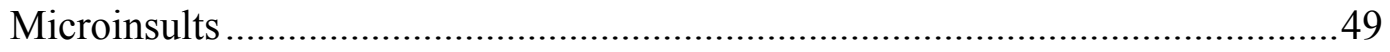

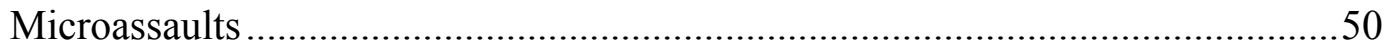

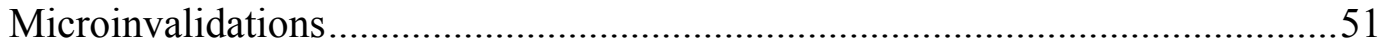

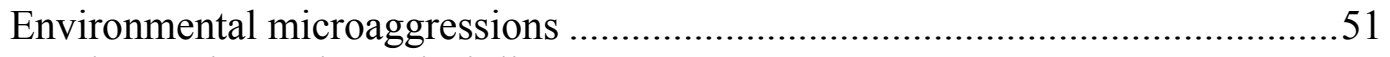

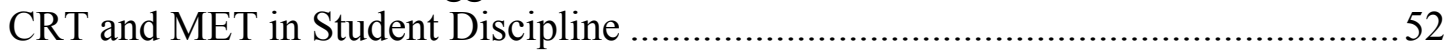

Objective v. subjective discipline practices..............................................52

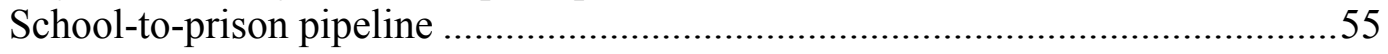

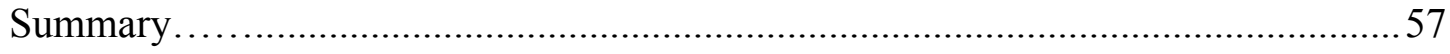

Chapter 3 Methods........................................................59

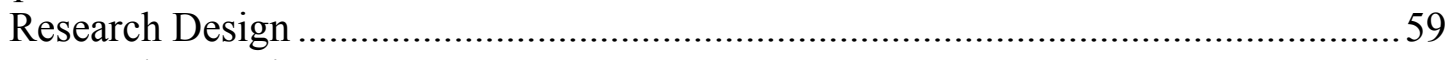

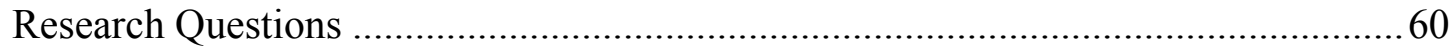

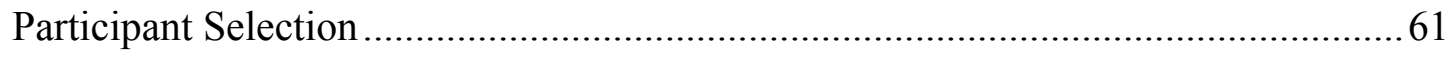

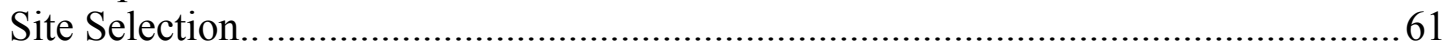

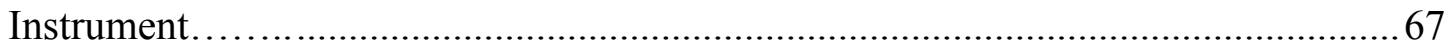




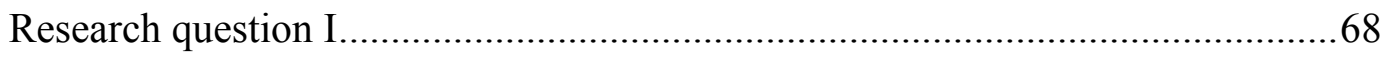

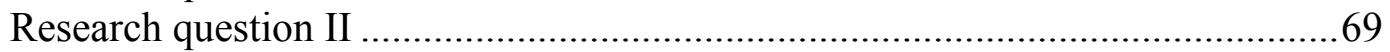

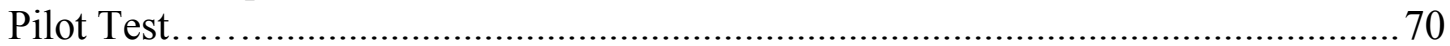

Research Timeline and Security Approaches ......................................................... 71

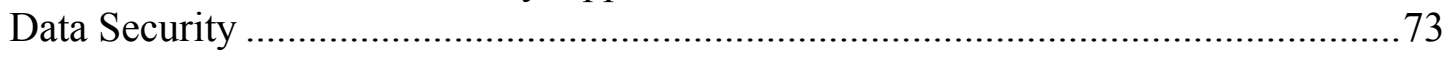

Sample Size and Analyzing Data ..........................................................................

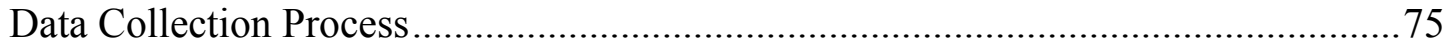

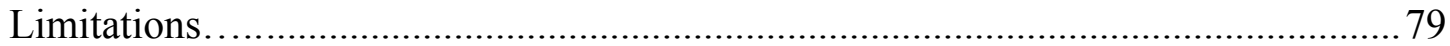

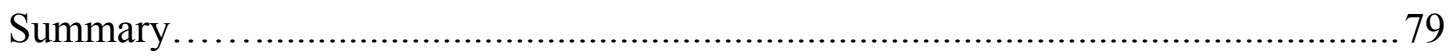

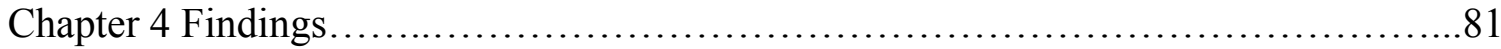

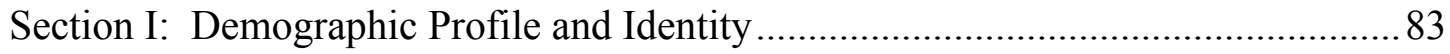

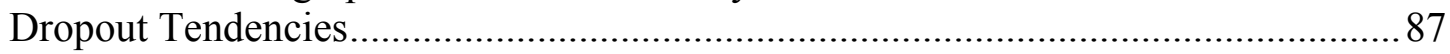

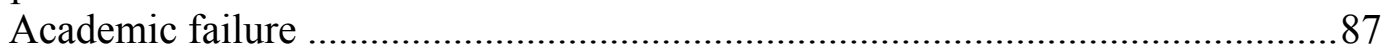

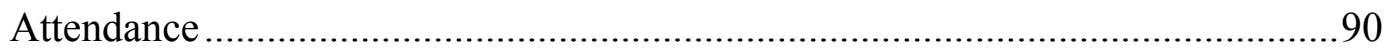

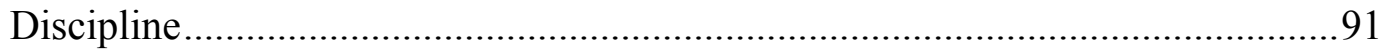

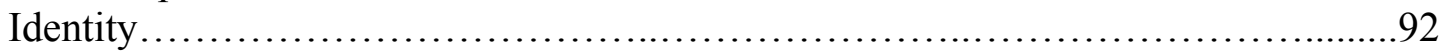

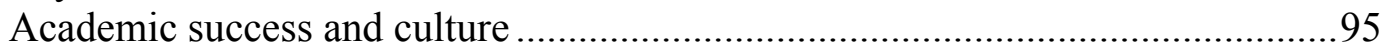

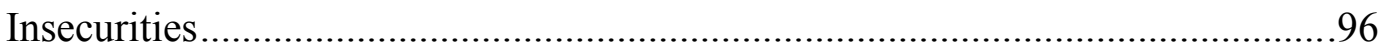

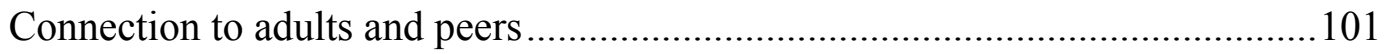

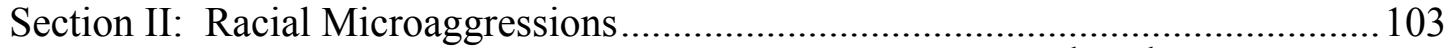

RQ1: to what extent do Black and/or African-American $10^{\text {th }}-12^{\text {th }}$ grade students experience racially-based microaggressions? what types of raciallybased microaggressions do they experience? from whom do they do they experience these racially-based microaggressions? ............................................103

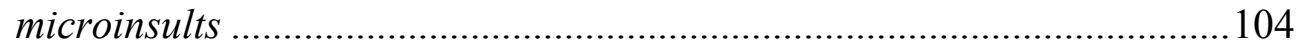

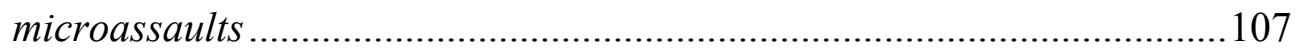

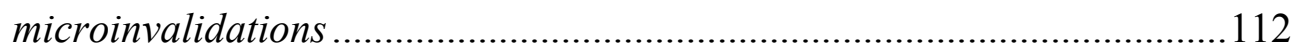

environmental microaggressions .....................................114

Section III: Raising the Level of Cultural Consciousness........................................115

RQ2: what suggestions do students have for restructuring the learning

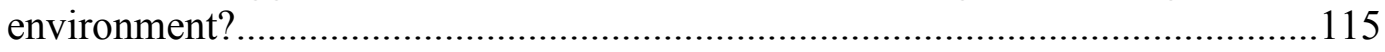

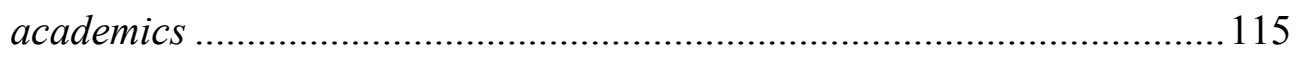

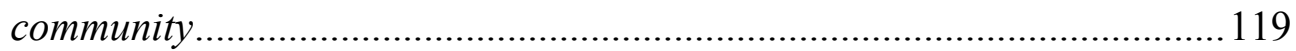

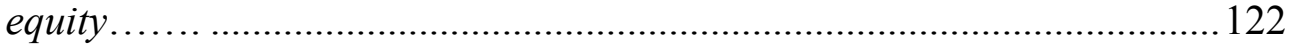

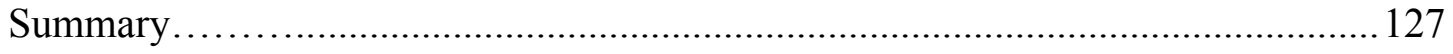

Chapter 5 Conclusions............................................................ 130

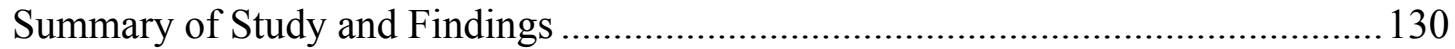

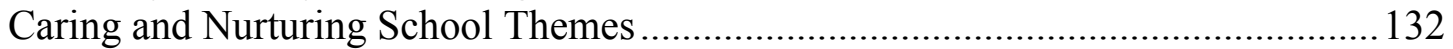

student-teacher relationships and student-student relationships............................132

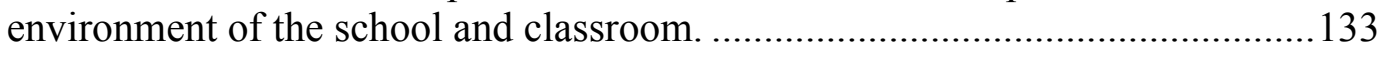

students' feelings about themselves. ...................................................................133 
Explanation of Black Students' Schooling Experience............................. 134

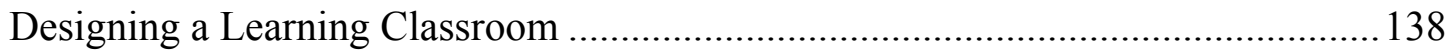

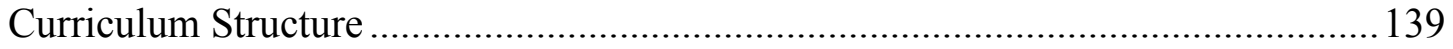

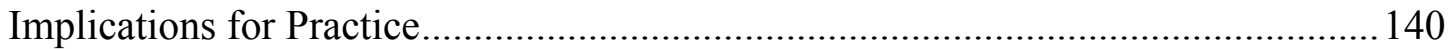

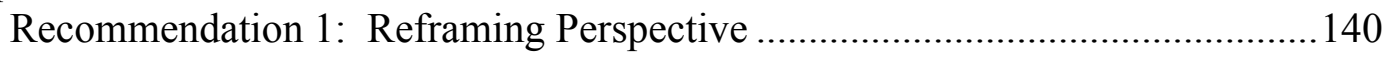

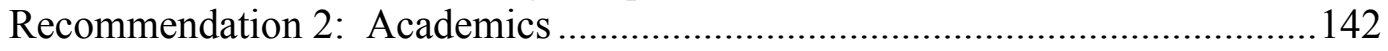

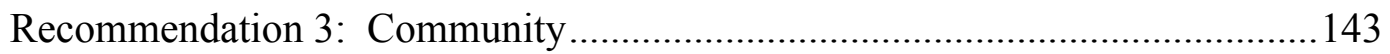

Recommendation 4: Equity ………………………....................................... 145

Recommendation 5: Professional Discourse .................................................... 148

Urgency for Whole System Change …………………....................................... 150

Change Through Effective Communication.......................................................... 152

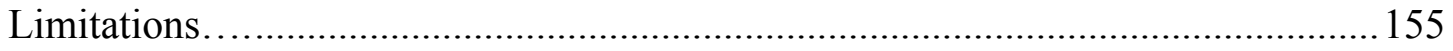

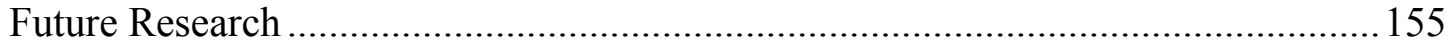

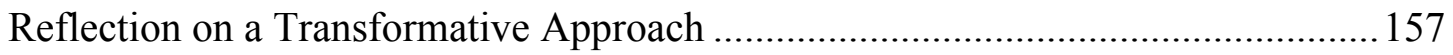

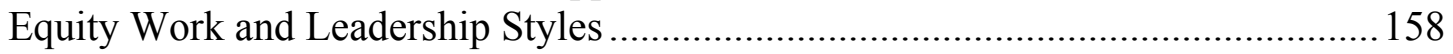

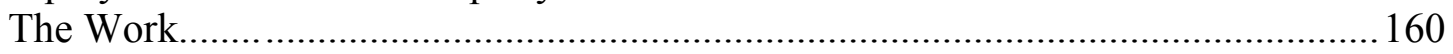

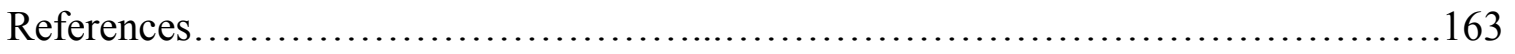

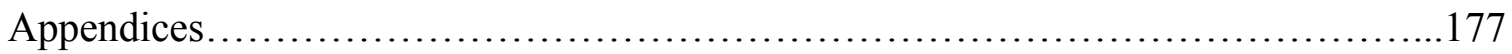

Appendix A: CITI Program Completion Certificate ………………….....................177

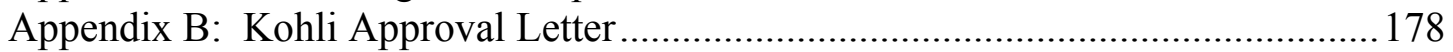

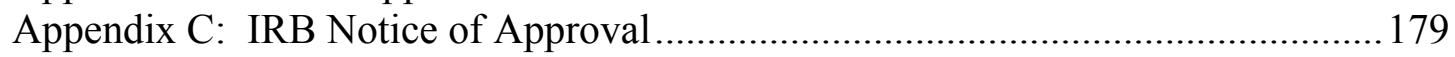

Appendix D: Principal Introduction Email Letter ................................................... 181

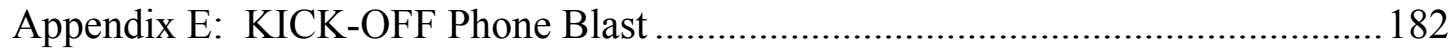

Appendix F: Parent/Guardian Informational Flyer .................................................183

Appendix G: Student Infographic .................................................................... 184

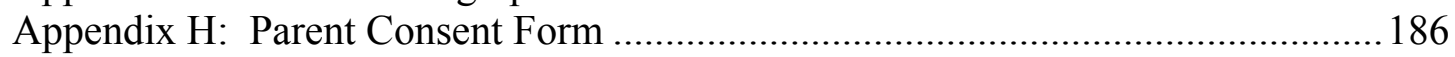

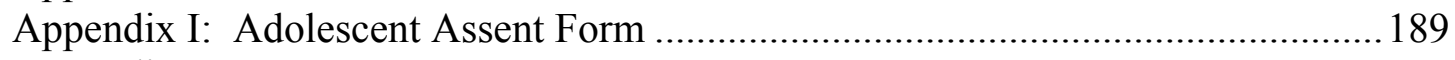

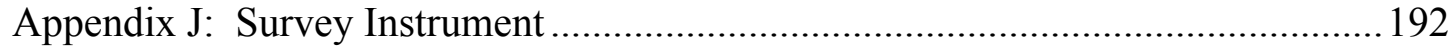

Appendix K: Staff Paper Survey Directions.................................... 202

Appendix L: Student Paper Survey Directions........................................ 203

Appendix M: Desire to Leave Current School Open Responses ..............................2204

Appendix N: Like About Self Open Responses ....................................................220

Appendix O: Feeling Judged Open Responses ………………………………...2215

Appendix P: Microinsults Open Responses ........................................................218

Appendix Q: Microassaults Open Responses........................................................222

Appendix R: Microinvalidations Open Responses...................................................222

Appendix S: Males Desired Instructional Strategies Open Responses .....................2227

Appendix T: Females Desired Instructional Strategies Open Responses .................229

Appendix U: Course Preferences ………………………...............................2232

Appendix V: Ideal Peer-to-Peer Interactions in the Classroom ................................236

Appendix W: COMMUNITY - Ideas to Include Black Families and Student 
Integration.

Appendix X: EQUITY - What are Some Ideas/Ways on How Black or African American Student Voices can be Empowered in the Classroom and School. 244 Appendix Y: EQUITY - What Would Discipline Look Like in the Classroom/ School? 248

Appendix Z: EQUITY - How Would Students be Made to Feel Cared for in the

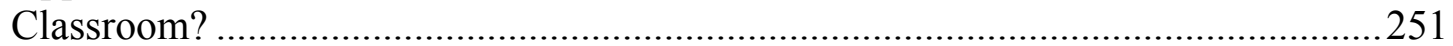

Appendix AA: Researcher Epistemology ..................................254

Appendix BB: Response: Kindezi Inspired Structured Schools (K.I.S.S. Model).. 264 


\section{List of Tables}

Table 1. Study District Demographics......................................62

Table 2. Frequencies of Student Demographic Profile, $(\mathrm{N}=72) \ldots \ldots \ldots \ldots \ldots . \ldots 8$

Table 3. Frequencies of Parent Educational Attainment, $(\mathrm{N}=71) \ldots \ldots \ldots \ldots \ldots . . . .64$

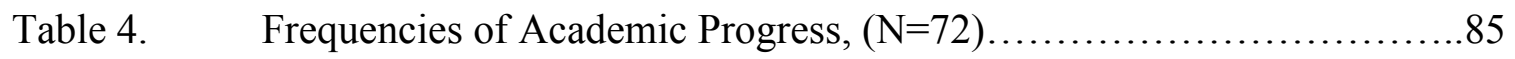

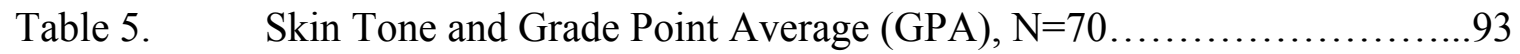




\section{List of Figures}

Figure 1. A model for understanding racial microagressions [sic]. Adapted with permission from from Khohli, R. \& Solórzano, D.G. (2012). Teachers please learn our names!: Racial microagressions [sic] and the k-12 classroom, Race Ethnicity and Education, 15(4), 441-462.

Figure 2. Conceptual model for examining, analyzing, and explaining schooling experiences of Black or African American students.

Figure 3. Black students favorability of sense of belonging/ connectedness

construct.....................................................65

Figure 4. Paper survey packet....................................... 78

Figure 5. Black student participation per school site..........................82

Figure $6 . \quad$ Self-reported school challenges................................ 88

Figure $7 . \quad$ Course repeated for credit..................................... 89

Figure $8 . \quad$ Attendance challenges..............................................

Figure 9. Suspension and expulsion record $\quad$ S...........................92

Figure 10. Hairstyle preferences..................................... 95

Figure 11. Friendships outside of racial/ethnic group........................ 102

Figure 12. Trusting relationships with staff............................... 103

Figure 13. Microinsults open-ended response types, $(\mathrm{N}=44) \ldots \ldots \ldots \ldots \ldots \ldots \ldots \ldots$

Figure 14. Microinsults received from teachers and peers.......................106

Figure 15. Microassaults open-ended response types, $(\mathrm{N}=51) \ldots \ldots \ldots \ldots \ldots \ldots \ldots$

Figure 16. Microassaults received from teachers and peers................... 110

Figure 17. Microinvalidations open-ended response types, $(\mathrm{N}=24) \ldots \ldots \ldots \ldots \ldots \ldots 112$

Figure 18. Microinvalidations received from teachers and peers.................114 


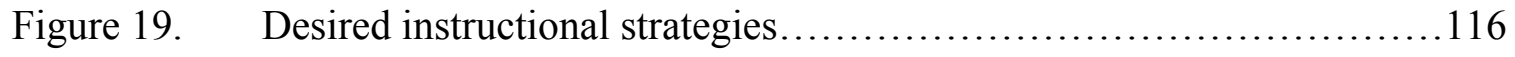

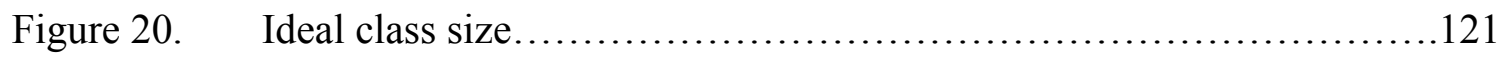

Figure 21. Black or African American student value exclusion model

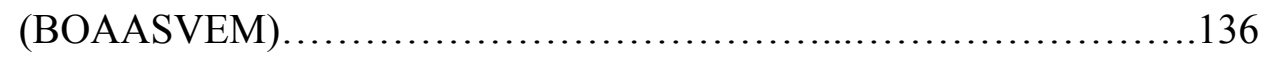

Figure 22. Conceptual model of an equity-minded leader........................158

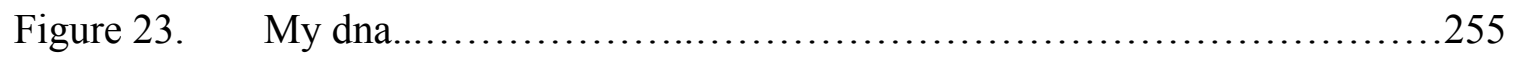

Figure 24. Seesaw imbalance effect......................................... 264

Figure 25. Kindezi - a process of collectively nurturing and rearing a child for success. Adapted and modified from Fu-Kiau and Lukondo-Waamba (2000). KINDEZI: The Kôngo art of babysitting (p. 32). Baltimore,

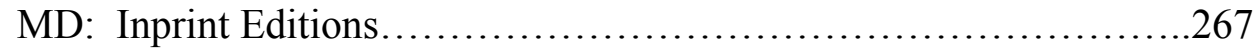

Figure 26. Framework and self-sustaining model of kindezi inspired structured schools (K.I.S.S.) core values........................................270

Figure 27. Roles within K.I.S.S. core values................................271

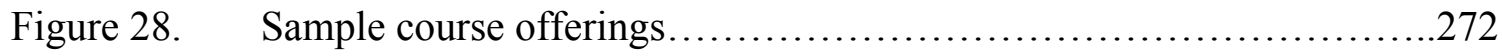




\section{Chapter 1 Introduction and Statement of the Problem}

\section{Problem Statement}

A high school diploma is a gateway to adulthood livelihood. Unfortunately, the pathway to this credential is filled with obstacles for many students of color. In a recent study Rumberger \& Losen (2017), used longitudinal data for the 2013-2014 cohort in 401 school districts in California. They followed 10th graders through to their senior year of high school (2015-2016). Controlling for other dropout predictors, they found that students who never had a suspension had an $83 \%$ graduation rate while students who experienced one suspension had a significant drop in graduation rate to $60 \%$. Racial disparities continue to fester in California school discipline systems impacting graduation rates of Black students and ultimately their adult livelihood.

According to the California Department of Finance, in 2018, statewide Black and African American (AFAM) students in grades $9^{\text {th }}-12^{\text {th }}$ represent a very small segment of the total student population $(\mathrm{N}=485,175 ; 5.5 \%)$. An even smaller number of seniors were Black or AFAM. In the 2015-2016 school year, at the close of Rumberger \& Losen (2017)'s study, AFAM/Black seniors represented $1.5 \%$ or roughly 32,000 students in California schools. Yet, they had a suspension rate of nearly $30 \%$, essentially twice the statewide average of $14.9 \%$ and 20 times their student population enrollment percentage. Ideally, in an equitable world, suspension rates should model student population percentages. Unfortunately for Black students, disparate discipline practices in schools often push them out of the class and further jeopardize their likelihood of graduating. Lee \& Cornell (2011) utilized secondary data collected from 306 comprehensive high 
schools in Virginia. Schools served as the unit of analysis. They found the racial suspension gap was highly correlated with the Black suspension rate and that Black students in Virginia high schools were twice as likely to be suspended than their white counterparts. Zero tolerance practices toward Black students was evident with a large percentage being suspended for subjective reasons (classroom disruption and defiance) and receiving referrals to law enforcement for minor infractions. High suspension rates were associated with high dropout rates and involvement with juvenile crime. Arguably, as a student's number of suspensions increases, his or her chance of earning a high school diploma decreases impairing life chances/ outcomes.

Black and African American students were the subgroup with the highest percentage of dropout rates and suspensions and tied with American Indian or Alaska Native as having the largest percentage of expulsions in California (California Longitudinal Pupil Achievement Data System (CALPADS), 2017; DataQuest, 2018; NCES, 2018). Research has shown that high school dropouts are more susceptible to experience poverty and interaction with the criminal justice system in adulthood (Leone, Nelson, Skiba, Frey, \& Jolivette, 2003; Sweeten, 2006). According to Christle, Jolivette, \& Nelson (2005), “(a)cademic failure, exclusionary discipline practices, and dropout have been identified as key elements in a "school to prison pipeline" (p. 69). Younger offenders return to prison more quickly than older offenders. The recidivism rate of offenders ages 18-19 is the highest rate $(59.1 \%)$ of any age group in the state of California (California Department of Corrections and Rehabilitation (CDCR), 2016). 
Lee \& Cornell (2011) also found the black student dropout rate was statistically significant if they were eligible for free or reduced-price meals. The finding suggests poverty induced trauma and socioeconomic status are important aspects to consider in schools with high percentages of low-income Black or African American students. Schools serving large populations of low-income students need to invest in providing a free breakfast program and weekend backpacks of nonperishable foods for students who suffer from inadequate access for this essential, basic need.

Nationally, the majority of teachers are white females and they teach a large proportion of minority students with growing subgroups of students with special needs and English language learners (National Center for Education Statistics (NCES, 2013); (United States Department of Education's Office for Civil Rights (OCR), 2014). In American high schools, white teachers teach most black students. Additionally, students of color are segregated in our current educational infrastructure. Most black students go to school with other black students and in most schools where white students are the majority, students of color are often sparse. Unfortunately, conscious or unconscious bias on the behalf of white teachers leads black students to be hyper visible and overrepresented in terms of reprimanded behavior. Within the schooling system, there are many other racialized patterns of engagement that increase the chances a black student feels invisible to educational opportunities, yet leave the same student unfairly targeted for discipline and a transition to the school-to-prison pipeline. Many black students experience teachers who hold deficit thinking (which includes a view that hold lower academic expectations for black students). In the 2015-2016 school year, 
nationally Black students had the lowest graduation rate (76\%) in comparison to their non-black counterparts except for American Indian youth (84\% All; Asian=91\%, American Indian $=72 \%$, Hispanic $=79 \%$, and White $=88 \%$ ) and had the lowest graduation rate among all ethnic and racial groups in California at 72.9\% (83.8\% ALL; Asian $=93.7 \%$, American Indian $=74 \%$, Hispanic $=80.5 \%$, and White $=88.9 \%$ ).

\section{Role as the Researcher in the Study}

I recognize that my lived experience embodies how I respond to inequities in my present role as a school administrator. As an African American student, throughout my K-12 experience, I witnessed discriminatory practices by white educators towards black peers through tracking practices. In elementary school, I was restricted to accessing opportunities for educational enrichment by being denied evaluation of the gifted and talented program in third grade. It was not until the summer prior to my freshman year of high school that I was finally assessed and qualified for the program. In my professional career I have worked with white colleagues who held low expectations of students of color; these views are generally accepted and enabled by administrators. As a high school administrator using a transformative paradigm approach, my epistemology enables me to be mindful of disparate academic and disciplinary practices. It propels me to be critically conscious and culturally responsive in my daily duties. In my role of overseeing discipline and special education, both of which have historically disproportionately overrepresented Black students, being equity-minded and having a social justice lens is critical. 
I too have played a role in having to suspend students for various education code violations. However, I do believe in being consistent and fair in practice and providing students with due process. As the leader of the discipline in my school, I am empowered to set the course of how we do discipline in the school and I strongly believe in progressive discipline methods. There is so much more we can do to keep students in the classroom instead of pushing them further into the school-to-prison pipeline. It is the hope and desire that this work will help to bring about a cultural shift in the study district. I hope my research-based suggestions can serve as a model for the district to restructure their learning environments in order to meet the needs of students who are at-risk of classroom push out and to dismantle racist, disparate academic and discipline practices.

I have always considered myself to be an advocate for the voices less heard. My research focuses on students who are disenfranchised due to the color of their skin/ ethnicity, special needs, language barriers, economic status, orientation or whatever the need. I believe in inclusive practices: considering alternative curriculum pedagogy, reducing class sizes and overall restructuring school learning environments to reach all students. What makes me angriest in education undoubtedly is the school-to-prison pipeline, disparate discipline practices with harsher punishments often for the minority and special needs populations, exclusion practices toward special needs population, the pre-labeling of African Americans students (males in particular) as menaces to society at an early age (Maddern, 2009; Skiba, et al., 2002; Togut, 2011). The fundamental structure of the public school comprehensive high school does not ensure equity of voice and cultural freedom of expression for all students. 
As a high school administrator, I do believe discipline is important and necessary for ensuring a safe and orderly school environment. It is one of the five dimensions of student-centered learning that does have a direct impact on student outcomes (Robinson, 2011). In particular, I have implemented discipline in relation to the Big Five safety offenses EC 48915(c) (i.e., firearm, brandishing a knife to another student, selling a controlled substance unlawfully, committing or attempting to commit sexual assault or sexual battery, and possession of an explosive) which are mandatory offenses that require a zero tolerance response such as a suspension and/or expulsion. However, a concern of mine has always been how do we effectively re-integrate students who have been suspended or expelled back into a classroom setting where they can meet with success. I still believe people can right their wrongs and that their life's contribution and value should not automatically be outcasted as a juvenile delinquent or menace discounting their potential worth to society. The majority of suspension cases in the study district are misdemeanor in nature and are state coded as 511 defiance/disruption which tend to be based on bias and subjective inferences (Infinite Campus, 2018). As I pursue this work, I will 'pay careful attention to [my] own and others' racialized and cultural systems of coming to know, knowing, and experiencing the world" (Milner, 2007, p.388).

\section{Significance of the Problem}

In general, there are a number of pull factors due to outside of school influencers that attribute to student dropout such as needing to work, becoming pregnant, caring for a family member, etc. The purpose of this study is to focus on the Black or AFAM experience of push out reasons inside of school influencers such as not getting along with 
teachers and peers, disparate discipline practices, not feeling a sense of belonging, and academic failure stemming from within school walls (Bradley \& Renzulli, 2011). Whether alienated due to race-based microaggressions (e.g. unfairly treated by teachers and/or peers, graded differently, etc.) or ostracized through suspensions, the root of these factors traces back to the dynamics that occur in the classroom setting affecting the level of engagement and academic success of a student. Implicit bias is defined as, "the attitudes or stereotypes that affect our understanding, actions, and decisions in an unconscious manner" (Safir, 2017, p. 311). Teachers and peers who have racialized negative attitudes that manifest into discriminatory behavioral practices in the classroom discount and traumatize students of color.

The Local Control and Accountability Plan (LCAP) is a tool for local educational agencies to set goals, plan actions, and leverage resources to meet those goals to improve student outcomes (CDE, 2018). As part of the eight areas assessed, data for Priority 5: Student Engagement and Priority 6: School Climate, are assessed through school climate indicators. California State Indicator Priority 5: Pupil Engagement is measured by a school's attendance rates, chronic absenteeism rates; middle school dropout rates; high school dropout rates; and high school graduation rates (California Department of Education, (CDE), 2018). Engagement is viewed as a multi-dimensional construct comprised of four subtypes: academic, behavioral, cognitive, and psychological (Appleton, Christenson, Kim, \& Reschly, 2006, p. 429). The State Indicators focuses on the "academic" and "behavioral" [participation] subtypes of student engagement [outward signs of engagement] which are the outcomes based on the internalized attitudes 
and beliefs students have reflected in their "cognitive" and "psychological" engagement. Engagement is described as "energy in action," the connection between a person and activity (Russell, Ainley, \& Frydenberg, 2005, p. 1). Engagement thus reflects a person's active involvement in a task or activity (Reeve, Jang, Carrell, Jeon, \& Barch, 2004, p. 147). Engagement has emerged as the primary theoretical model for understanding school dropout (Finn, 1989) and as the most promising approach for interventions to prevent this phenomenon (Reschly \& Christenson, 2006). Based on the definition of student engagement, one could infer that Black or African American students are being conditioned by their schooling experience to have low graduation rates and high dropout rates with respect to both White and other non-White peers.

School climate, California State Indicator 6, is defined in terms of the rates of suspensions and expulsions. Specifically, the district under study utilizes four measures from their climate survey to operationalize school climate, which are: school connectedness, support for academic learning, knowledge and fairness of discipline rules and norms, and safety (California School Dashboard, 2018). Green (1998) identified 13 characteristics categorized into four themes that exist in nurturing schools. The themes are student-teacher relationships, professionalism among administration, faculty, and staff, the environment of the school and classroom, and students' feelings about themselves. Using Spearman Correlation Tests, Green (1998) found that nurturing schools had a positive effect on student success and teacher morale. The more students and teachers perceived their environment as nurturing, the less the rate of suspension and increase in attendance. The emphasis for this study will focus on three of the four themes: 
student-teacher relationships/ (including peer relationships), environment of the classroom, and students' feelings about themselves to determine if Black or African American students perceive their learning environment as engaging and nurturing. The intent of the study is to inform teaching practices and intervention strategies on how best to meet the needs of Black or African American students in the classroom and school setting.

\section{Statement of the Problem}

Negative school experiences including truancy, dropping out, suspension, expulsion, and other forms of academic failure (Mathur \& Schoenfeld, 2010) often find their roots in the classroom setting. Trauma-informed care practices often focus on outside of school maltreatment ills such as poverty, neglect or abuse students deal with that educators and support personnel try to help diffuse once they enter school grounds (Gurwitch et al., 2016; Walkley \& Cox, 2013). But what happens when the school classroom is not a safe space but rather a place where Black or African American students are harassed and pushed out? The current study focuses on understanding to what extent and types of racially-based experiences Black or African American high school students have encountered in the school setting and from whom. A secondary objective is to use the data from this study to inform how to restructure the classroom into a more welcoming and student-centered learning environment that promotes excellence and implements equitable practices for Black/African American youth. 


\section{Research Questions}

The following research questions guided this study:

RQ1. To what extent do Black and/or African-American $10^{\text {th }}-12^{\text {th }}$-grade students experience racially-based microaggressions? What types of racially-based microaggressions do they experience? From whom do they experience these raciallybased microaggressions?

RQ2. What suggestions do students have for restructuring the learning environment?

\section{Site Selection and Sample}

The data for this study were collected in the fall of the 2018-2019 school

year. Because the study focused on students' perceptions of their high school classroom and overall schooling experiences, it was important for students to have had at least one year of high school from which to reference. Thus, for this study, African American or Black high school students in grades $10^{\text {th }}-12^{\text {th }}$ were the unit of analysis. The students were recruited from eleven comprehensive high schools in a large high school district located in Northern California.

\section{Scope and Limitations of the Study}

The current study focuses on understanding how racially-based experiences of high school Black or African American students relate to their level of engagement, participation, and persistence in high school. Because the study was limited to only 1012th graders who were of Black or African American descent, the viewpoints of beginning high school students (9th graders) were excluded. Although freshmen were 
not apart of the study, it was anticipated that the study's participants would share

experiences from their first year of high school.

\section{Assumptions/ Contextual Factors}

The following must be established before conducting this study with fidelity to gain an understanding of students ' perceptions of their interactions in the classroom from student-adult and student-to-student relationships:

A. The School District's Associate Superintendent who oversaw the Assessment and Research Departments needed to grant approval for the research topic.

B. The 10-12th grade Black, African American, or any student of mixed heritage or Hispanic having Black or African ancestry and their parents needed to be willing to participate. Students were provided with breakfast or lunch as a thank you for their participation.

C. The students took a 30-40 minute long online survey to assess level of engagement, experience with microaggressions, and their affinity toward dropping out of school.

D. The Researcher coordinated with the 11 high school Principals' to determine a date to be able to use a computer lab or classroom with access to chromebooks for students to complete the survey.

\section{Summary}

Merriam-Webster Dictionary (2018) defines value as "relative worth, utility, or importance." It appears that Black and African American students have suffered from a value gap in the classroom by teachers (and peers). An intended outcome of this project is to help educators reflect consciously on their practices by acknowledging that the implicit biases they hold deny the presence of the rich cultural capital and value that Black / African American students bring to the classroom. Not only in California but, in the nation as a whole, a large segment of the K-12 public school system are students of 
color. It is necessary that race is explicitly examined and centered as part of the conversation when discussing how best to meet the needs of the students we serve if we are to see real change in creating learning environments that nurture all students' success. 


\section{Introduction}

\section{Chapter 2 Literature Review}

The nature of human beings is to be social and desire to belong. Carl Rogers' humanistic psychological approach states:

(F)or a person to "grow" they need an environment that provides them with genuineness (openness and self-disclosure), acceptance (being seen with unconditional positive regard), and empathy (being listened to and understood). Without these, relationships and healthy personalities will not develop as they should, much like a tree will not grow without sunlight and water" (as cited in McLeod, 2014, para. 1).

Students are purposefully introduced to the educational system at a very early age to learn how to develop academic (cognitive), behavioral, and social skills to become productive citizens in society. Teacher and student relationships are instrumental in fostering a nurturing, learning environment (Esquivel, 1995; Green, 1998). Although all students have an equal right to a free appropriate public education throughout the United States of America, the inequitable interactions students have with teachers and peers ultimately set the course for who successfully navigates or fails the K-12 system. To a greater extent, the interactions dictate who enters a life of poverty, poor health, and the criminal justice system.

Green (1998) provides a working definition of a nurturing school as one “...where there is trust and caring among all individuals; supportive relationships exist in a positive environment. There is a sense of community where all individuals are valued and participate in the decision-making process, and the self one brings into the environment is respected and nourished with everyone accepting responsibility for student success" (pp. 8-9). Just as students learn academic subjects like reading and mathematics they also 
learn socially acceptable behavioral and relational skills in the classroom environment. However, the latter tends to be ignored or assumed that students already have mastery in conduct and self-management. According to Valenzuela (1999) "relations with school personnel, especially with teachers, play a decisive role in determining the extent to which youth finds the school to be a welcoming or an alienating place" (p.7). Authentic caring requires a holistic approach to educating a student. To foster a pro-school orientation, it is expected that “...teachers' authentic caring accepts and embraces...diversity disposition unconditionally...[and] call for attention to the total person and the withholding of judgment" (p. 141). Unfortunately, because teachers are inundated with external demands outside of the classroom, some tend to care aesthetically or only invested for a means to an end (e.g. paycheck). Some teachers appear to be more concerned with getting students to pass state and other achievement tests rather than to truly invest in the development and quality of students they teach. For some students who are viewed as having nothing or very little to offer, they are not invested in by teachers or peers, despite the level of diligence they may possess (Valenzuela, 1999).

To frame this research, a conceptual model consisting of Critical Race Theory (CRT) and Moral Exclusion Theory (MET) infused through a social justice, Transformative framework will be used to ascertain a better understanding of how African American students are alienated within the classroom finding themselves feeling devalued and voiceless. The theories will provide a premise for the undertaking of this study's intent to know to what extent Black students' level of school engagement is mediated by race- 
based microaggressive behaviors in the classroom and propelling the responsive action steps needed to change the trajectory.

\section{Transformative Framework}

Considered an umbrella encapsulating this study, the Transformative Paradigm was introduced by Donna Mertens (2010) as a framework for changing thinking through addressing issues below the surface. The paradigm allows for a social justice and human rights approach to research root causes with the goal of a social transformation through the empowerment of voices of the marginalized population or community under study. As with any paradigm, it is derived based on four assumptions: axiology, ontology, epistemology, and methodology. The two key assumptions that center this study include epistemology and methodology.

In the video entitled, Introduction to the Transformative Paradigm: Axiology and Ontology, Mertens (2017b) defined the Transformative Paradigm as a "meta-physical umbrella that brings together many dimensions of diversity that are used as a basis of discrimination and oppression." Diversity can be related to a number of ills in society that extend to marginalize a group of people whether it is with respect to age, class, race, sex, identity, etc. that must remain at the center of the work that is undertaken in a study. The first assumption to guide this paradigm is axiology or ethics surrounding the study. The ultimate goal of this assumption is to consider the benefit to the community beyond the scope of the study. Specifically, Mertens (2017c) stated, "the need to be culturally aware, culturally responsive" is intuitive that the researcher be conscious and respectful of the diversity that exists in the communities they study. The design of the study must 
therefore assume an ethical responsibility, since the approach must be culturally respectful to bring about sustainable change. The recognition and awareness of positionality regarding instances of power imbalance based on racism, classism, and sexism are important aspects that need to be considered at the forefront and throughout the process of research. Mertens (2017a) further stressed the importance of the researcher to establish authentic relationships and not see themselves as estranged from the work by doing a study on or about a group but rather working in partnership with the group to conduct research. She identified four transformative ethics leading to methodological implications:

Identify major stakeholder groups Identify the cultural norms Identify relevant elements of history Identify dimensions of diversity (Mertens, 2017a)

According to Mertens (2017a), the researcher must move away from an objectifying lens of deficit thinking to one that is humane and inclusive by recognizing the knowledge and strengths that exists within the community. An awareness and respect of cultural capital is critical to gaining trust and understanding by shedding light on fundamental human rights issues in need of change that are deemed as relevant and what actions need to occur to benefit the community. The transformative paradigm empowers the community to voice their issues and provide solutions to the problems they face rather than automatically assuming they do not have the capacity and are in need of rescue by others.

Ontology is the reality or realities that exist to explain why a phenomenon is occurring. Mertens (2017b) defined ontology as "multi-faceted, consequences of 
privilege." In other words, people in privilege tend to believe they already have the diagnosis of the marginalized group without ever considering their input in acknowledging the nature of the problem. Four questions that the researcher should ask themselves:

Who needs to be included?

How do we include them appropriately?

How do we listen respectfully?

How do we challenge versions of reality which are harmful? (Mertens, 2017b)

Mertens (2012b) noted that ontology was “...reflective of different power positionalities in society. Consequences of accepting different versions of reality over another are evaluated in terms of their ability to challenge oppressive systems" (p. 256).

Epistemology is about how the researcher connects to the community that is under study. With respect to the epistemological assumption, Mertens (2017a) noted that it was important for the researcher or an essential member of the team to be reflective of the communities under study. Whether it is identifying based on race/ethnicity, gender, disability, or experience it is important that the researcher or team builds trust within the community they study. Consequently, the cultural relevance of the researcher's life is not excluded in relation to having experienced being on the margins as the subjects under study. The assumption promotes the use of contextual analysis.

Methodology is concerned with how the study is designed. According to Mertens (2017a) the methodological assumption traditionally used in transformative work is mixed methods with a cyclic approach. For this phenomenological study three of the four guiding questions typically used to guide the traditional design underpin this study:

How do we engage appropriately with diverse stakeholders? 
How do we use earlier research findings to develop effective interventions? How do we facilitate the use of our findings to contribute to transformative change (in programs and policy)?

The study started with a literature review to gain an understanding of what was studied about black students and their schooling experiences in order to determine what gaps still need further exploration. The findings of this study will be used to develop interventions and programs in the district under study to change policies and practices in terms of how they support their Black / African American students ' needs.

\section{Critical Race Theory}

The social construction of race, particularly in the United States has long served to justify, not only the separation of people based on race, but also the privileges of whites and the oppression of nonwhites. There is a history of institutionalization; discriminatory laws and policies deemed to demoralize and enslave people of color. Critical Race Theory (CRT) sets out to retell the stories of people of color whose voices have long been dispelled or silenced by the ethos of the normative white status. Every societal aspect, from education to health care to legal proceedings, non-Whites are always viewed and evaluated in relation to and in terms of a white standard. The framework was born of the 1970s from the critical legal studies work of law professors Derrick Bell and Alan Freeman. Bell (1995) defined it as, "a body of legal scholarship" and noted that "...a majority of members are both existentially people of color and ideologically committed to the struggle against racism, particularly as institutionalized in and by law" (p. 898). 
He further noted that white critical race theorists recognized their white privilege and are willing to rescind and overthrow it.

Ladson-Billings \& Tate (1995) shows how the same principles can transcend and serve as a theoretical approach to the deconstruction, reconstruction, and construction of colored people's stories and narratives in the educational environment. Although CRT can serve as an independent framework as part of this study's triangulation, it will serve as a lens for empowering the voices of black students' experiences and perspectives on different facets of their secondary education. Three essential themes emerged from the framework to include:

1. Racism is a normal daily fact of life in U.S. society and the ideology and assumptions of racism are so ingrained in the political and legal structures as to be almost unrecognizable.

2. As a form of oppositional scholarship, CRT challenges the experience of white European Americans as the normative standard...CRT grounds its conceptual framework in the distinctive contextual experiences of people of color and racial oppression through the use of literary narrative knowledge and story-telling to challenge the existing social construction of race.

3. CRT attacks liberalism and the inherent belief in the law to create an equitable [and] just society. (Lerma, Linick, Warren-Grice, \& Parker, 2013, p. 36)

African Americans in the United States are often defined or stereotyped into objective, demeaning race-based statuses that attempt to marginalize their mere existence and reduce their opportunity to challenge and participate in White-dominated power structures. Critical Race Theory allows a person to speak their truth through a firsthand perspective (lived experiences) in which they see themselves situated in social institutional chasms (e.g. economy, education, health care) that exists in greater society. 
CRT acts as a catalyst to mobilize and challenge the status quo to promote directed cultural changes in formally organized systems through transformative measures. The social reality in which we live continues to keep race and racism alive and viable and must continue to be discussed with the intersectional ties to both individual and group identities (e.g., class, disability, gender, generational status, language, and sexual orientation). This study understands CRT as, "the work of scholars who are developing an explanatory framework that accounts for the role of race and racism in education" (UC Davis School of Education \& Solórzano, 2014).

Research has shown that Black students are far more likely than their peer groups to experience suspension and expulsions and interaction with juvenile justice systems (Skiba et al., 2011) and less likely than their peers to take advanced high school classes or graduate with a high school diploma (Rumberger \& Losen, 2017; Solórano \& Ornelas, 2004). Race plays a major role in schooling outcomes for Black students and should not be denied as Carter Andrews (2012) challenges educators to ensure that it is an on-going part of the conversation as she noted, "when Whites are perceived to enact behaviors toward[s] Black students based on racial assumptions, race matters" (p. 12). Townsend Walker (2014) points out how "CRT challenges racial stereotyping and cultural deficit thinking," which are two elements that continue to impede equitable access for African American students in a classroom setting.

\section{Moral Exclusion Theory}

Coined by Ervin Staub in 1987, "moral exclusion occurs when individuals or groups are perceived as outside the boundary in which moral values, rules, and considerations of 
fairness apply" (as cited in Opotow, 1990, p. 1). All people have prejudice or beliefs about other groups that they consider different from themselves. However, it is prejudice plus power that leads to racist practices and discriminatory laws to segregate, devalue, and deem inferior those who have less or no power to maintain the privilege of those in power. Historically, there have been many blatant, mass instances where people were morally excluded and treated as less than human. Examples of moral exclusion are the holocaust of the Jews by Hitler and his Nazi regime, the diaspora of Black African bodies sold into chattel slavery through Mid-Atlantic Slave Trade, and the segregation practices of Jim Crowism enforced on Black American citizens.

Moral exclusion practices and policies were indoctrinated into laws affecting and impeding Black's educational attainment since slavery and the Separate But Equal doctrine which continued to be practiced well after the 1954 Brown v. Board of Topeka, Kansas Supreme Court ruling. Modern day exclusionary practices include federal legislation of zero tolerance in the early 1990s, over-representation of African American students in special education (Blanchett, 2006; Harry \& Anderson, 1994; Patton, 1998), high rates of suspension and expulsion (Fenning \& Rose, 2007; Townsend, 2000), and low rates of high school graduation (Storer et al., 2012) that not just trail behind White peers, but other student groups of color. Textbooks that promote stereotypes or group exclusion also serve in schools as an example of moral exclusion. Bullying, tracking, and inequity in education are all forms of moral exclusion from within the classroom (Opotow, Gerson, \& Woodside, 2005, p. 304). 


\section{Critical Race and Moral Exclusion Theories in the Classroom}

Regardless of whether a black student is being educated in a predominantly white school or a majority minority school, the academic gap in comparison to their white peers persists (Pringle et al., 2010). The majority of all students in the United States, including black students are taught by white teachers. The pattern of students of color being taught by white teachers is often referred to as a mismatch effect. The consequences of this mismatch include racial stereotyping, such as when white teachers perceive African American students as less favorable compared to their white peers in the classroom. Using data from the Education Longitudinal Study (ELS), McGrady \& Reynolds (2013) examined white English and Math teacher perceptions of $10^{\text {th }}$-grade students of color classroom behavior which consisted of the following: working hard for grades, relating to peers, attentiveness, and disruptiveness (pp. 7-8). A key element in the success of a student in the classroom is teacher expectation (Pringle et al., 2010). White English and Math teachers rated black students significantly lower in being attentive in the classroom than their white counterparts. They were further perceived as having less scholastic aptitude. Specifically, white teachers felt black students used poor grammar, had difficulty organizing ideas in class, and more likely to have difficulty managing math problems (p.13).

Racial inequality goes deeper for African American students who face colorism, inequality by skin tone (Hunter, 2016). The stratification of black bodies by skin color in the classroom leads some students to further experience negative bias practices by both their teachers and peers. This type of treatment is referred to as the halo effect. The halo 
effect leads to lighter skin students receiving privileges based on skin color biases that enable some students to be viewed favorably and others to be excluded ultimately contributing to academic inequalities and negative outcomes of life chances (Monroe, 2016; Thompson \& McDonald, 2016). Hunter (2016) states "lighter-skinned children of color are more likely to experience the halo effect with their teachers, fostering positive relationships [and] leading to more positive schooling experiences overall" (p. 56).

Utilizing secondary data from the National Longitudinal Study of Adolescent Health (NLSAH) and the Adolescent Health and Academic Achievement (AHAA) to understand the impact of racism and colorism on educational attainment, Thompson \& McDonald (2016) found skin tone effects grade point average (GPA). The results revealed darker skinned Black or African American students had GPAs lower (by .4 points on average) than light-skinned students. When looking at race alone, African Americans as a whole had lower GPAs than their white peers (and Asian students). However, when considering race and colorism effects together, both remained statistically significant factors for black students as "...the achievement disparity relative to whites decline in magnitude for blacks, Hispanics, Native Americans, and multiracial respondents. The most pronounced of these reductions is observed for the black coefficient, which drops from .280 points on the GPA scale to .144 points after controlling for skin tone " (p. 101). Based on the combined model results, it affirms that being a lighter skin Black or African American student opens the door to hierarchy and privilege for some students who are traditionally apart of a group considered racially marginalized in the school setting. 
Color complexities have long historical roots. Slave owners divided and separated slaves into houseworkers or fieldworkers based on skin tone. Slaves who were more Eurocentric in feature had a greater probability of obtaining favor and privileges from the owner; lighter skinned, more white looking slaves were required to do less manual labor. In the same vein, this division through racial coloring, which served as a powerful tool for slavery, continues to emerge in modern day Black communities and other communities of color as a means of separation and status differentiation.

Contemporary music and media also note the effects of colorism that has long served to divide the Black community. The melodious lyrics from his album To Pimp A Butterfly (Duckworth, Bruner, Spears, \& Evans, 2015, track 12) in Kendrick Lamar's Complexion (A Zulu Love) referred to the Willie Lynch myth of a fictional slave owner who allegedly began dividing dark and light-skinned slaves. The modern-day television series called Black $\bullet$ ish, is known for addressing the elephant in the room with discussing sensitive topics such as the ending of enslavement of Blacks in the United States in season 4 episode 1 Juneteenth (Saji \& Cropper, 2017). Season five tackles the oppressive nature of colorism and light-skinned privilege in episode 10 Black Like Us (Saji \& Richardson-Whitfield, 2019). Colorism as a topic has played a pivotal role for generations as an exclusionary tactic and has relevance in how Black people interact internally as a collective body and externally in the greater community.

The school classroom also perpetuates the inferiority of the color complex adding potential stress and detrimental impact on the educational achievement of darker skinned Black or African American students who are being treated differently and excluded at 
higher rates than other classroom students. According to Thompson \& McDonald (2016) students who received higher grades perceived teachers were fair and had positive relationships with them. However, students who experienced exclusion through suspension or expulsion, “....received grades that were approximately half a point lower than students who never received such discipline" (p. 103).

Even asking black students how they believe their teachers perceive them, they are sadly aware of the biases against them and the role double consciousness that Du Bois (2014/1903) defined as, “...always looking at one's self through the eyes of others...one ever feels his twoness, --an American [and] a Negro" (p. 5). Sparks (2016) indicates low expectations perceived by Black students from their interactions with teachers and peers may lead to stereotype threat which she defines as, "the fear that one's actions could confirm a negative stereotype about his or her group" (p. 17). Pringle et al., (2010) interviewed 48 African American high school students. Two themes emerged: teacher expectations (with emphasis on race and race relations within the high schools) and qualities of teacher instruction (course difficulty). With regard to the first theme, the perceived expectations of students were based on whether or not teachers cared for and liked them as a person and also if they felt the teacher's unfairness leading them to believe that the teacher had low expectations of them. Additionally, $75 \%$ of the participants reported perceptions of lower expectations for them to graduate and attend college. In essence, the findings revealed race or ethnicity was a factor in how teachers perceived and treated black students. However, the students indicated their most challenging and fair teachers were in the foreign languages and mathematics departments. 
I do not think White teachers enter the profession wanting to harm children of color, but they will hurt a child who whose culture is viewed as an afterthought.

Bettina Love (March 18, 2019)

\section{Student Engagement and Connectedness}

Dr. Love is a University of Georgia Associate Professor of Educational Theory \& Practice. She is a published professor who created a Hip Hop Based Education (HHBE) curriculum. The purpose of the curriculum is to create social consciousness in English/ language arts classrooms by bringing "... awareness to the social and political concerns of one's community, or critical voice [using] hip hop to promote civic education and engagement" (Love, 2014, p. 53). Dr. Love also serves as Chairperson of the Kindezi Schools Board of Directors, a charter system in Atlanta, Georgia that serves a large, urban black student body using small, family-like classrooms and alternative pedagogy to maximize academic success. She noted that culturally relevant pedagogy (CRP) is an important part of instruction in the school and teachers are expected to teach from that framework (B. Love, personal communication, July 19, 2016). In a recent Education Week commentary, Love (2019) stressed the importance of white teachers genuinely getting to know their black students and their culture to authentically care for them. In doing so, she highlights the need for white teachers to recognize the role that racism plays in diminishing and eradicating people of color contributions. Love (2019) states that, "teachers who disregard the impact of racism on Black children's schooling experiences, resources, communities, and parent interactions will do harm to children of color" (para. 7). In schools with black and brown children, she further states that racism serves as a "superpredator" reinforcing societal norms of white supremacy (para. 7). 
Recommendations offered include, "future teachers should be required to take classes such as African studies, African-American studies, Latinx studies, Caribbean studies, Chicana/o studies, Asian and Southeast Asian studies, and Native American studies" as a way to begin bridging the cultural gap between white teachers and their students color in urban communities (para. 8).

School identification is an affective form of engagement comprised of students' sense of belonging in school and feeling that school is valuable (Voelkl, 2012,p. 223). In a study by Sirin \& Rogers-Sirin (2004) using survey data from middle-class African American middle and high schools' the National Longitudinal Study of Adolescent Health (ADD Health), they found that the individual student engagement factor had a positive relationship with self-esteem and educational expectations. They defined educational expectations as a measure of a student's perceptions about their future opportunities (p. 326). Multi-regression analyses further revealed all three (student engagement, self-esteem, and educational expectations) had a significant impact on academic achievement. For these middle-class black students, the three strongest predictors that emerged as keys to academic success were educational expectations, school engagement, and parent-adolescent relationship.

Finn's (1989) Participation-Identification Model provides a perspective for understanding why some students withdraw and ultimately may dropout from school. Specifically, identification refers to a sense of belongingness and the perceived worth of schooling. Participation is comprised of four distinct components: respond to requirements (directions and questions initiated by the teacher), class-related initiative 
(initiating questions and dialogue with the teacher and taking part in tutoring, academic clubs/ competitions), extracurricular activities (participation in social milieu such as clubs or sports), and decision making (academic goal setting and other forms of decision making such as student government member). The model suggests that the more students are involved/participate with school activities with respect to the four components, the more successful performance results lead to greater school identification (p.130). Finn (1989) also noted the model is strengthened by parent involvement in the schooling process.

Marginalization of black student engagement. Whose culture has capital? Using a CRT framework, Yosso (2005) describes six capitals that compose the community of cultural wealth that students of color bring into the classroom, which is: aspirational, linguistic, familial, social, navigational, and resistant. However, as it appears middleclass white students lead the pack particularly among black and brown students as the achievement gap continues to widen. Valenzuela's (1999) Subtractive Schooling implies for many students of color in the U.S., your culture and identity takes a back seat to the "white norm" standards and in order to have a chance to meet success in this society who you are outside of class stops when you enter the classroom door. Even then, masking your racial, ethnic, and other identity forms does not lead to any assurance that your teachers or peers will accept and hold you to high expectations. According to Solórzano (1997), "the cultural deficit model contends that minority cultural values, as transmitted through the family, are dysfunctional, and therefore the reason for low educational and later occupational attainment“" (p. 13). 
According to Kunjufu (2002), African Americans are classified as involuntary minorities and they see school as a majority meaning the academic achievement it promotes often serves to challenge their group loyalties and ethnic identities. He recommends cooperative learning classrooms because it is student centered and encourages students to work together promoting confidence and self-esteem as well as academically enhancing student learning. Kunjufu (2002) further noted competitive, grade oriented classrooms leave many low achieving and disadvantaged students to finish last and to feel demoralized. This sentiment is echoed by Ford (2012) who pointed out that African Americans are involuntary minorities because their ancestors were brought to this country as slaves for the financial benefit of the slave-owners and were stripped from their culture and had Western culture impressed upon them unlike other immigrant groups who have come to the United States freely to pursue economic and educational opportunities.

Ladson-Billings \& Tate (1995) coined the phrase culturally relevant pedagogy as a way to train new teachers how to use best practices that value the African American learner. Academic success (intellectual growth), cultural competence (appreciation of one's culture), and sociopolitical consciousness were the defining domains. LadsonBillings (2014) pointed out that over the years teachers have been successful at implementing the first two but were failing at raising the consciousness of students. She defined sociopolitical consciousness as "the ability to take learning beyond the confines of the classroom using school knowledge and skills to identify, analyze, and solve realworld problems" (p. 75). Teachers need to create and seek out opportunities to engage 
students in learning beyond the textbook or worksheet by utilizing real-world, meaningful issues and topics by which students can become action oriented thinkers and doers as well as take part in service learning projects and other meaningful learning opportunities.

Teacher dissonance: beliefs and classroom practices. Irizarry (2015) found that non-White Latino and Black students are about twice as likely to be rated far below average as White, Asian, and White Latino students, while non-White Latino and Black students are less likely to receive far above average ratings. The overall distributions of teacher perceptions show that the majority of White, Asian and White Latino receive either average or above average literacy ratings, while for non-White Latino and Black students are weighted more heavily toward the lower end of the distribution (p. 527-528). Their findings support the idea that as grade levels increase, the feeling of being excluded also increases. This feeling intensifies when there is no positive relationship between a student and their teachers and/or peers.

Neal, McCray, Webb-Johnson, \& Bridges (2003) examined the perceptions of 136 middle school teachers of African American males based on cultural movement styles. They found that most teachers automatically perceived students with African American movement styles as having lower achievement levels, higher aggression levels, and more likely to require special education services. In turn, students behaved more defiantly and less cooperatively with teachers perceived as having untrustworthy authority (Gregory \& Weinstein, 2008).

Fundamentally, educators should hold the belief that all children can learn. Implicit biases, however, tend toward an affinity of an Implicit Mental Model of Human Potential, 
result in students being tracked and labeled as "advanced" or "disadvantaged" and others as "dumb" creating a culture of "winners and losers" (Senge et al., 2012). The classroom reality is that Teachers listen differently to different students. Some students are allowed a chance to think as they speak, while others are interrupted. This type of behavior is referred to as the Discount Revenge Cycle often done subtly using either body language (rolling one's eyes) or verbal comments (whispering to others while someone is talking) to essentially slight or devalue the speaker.

Teacher bullying that McEvoy (2014) defined as "a pattern of conduct, rooted in a power differential, that threatens, harms, humiliates, induces fear in or causes students substantial emotional stress" is a frequently unspoken or inadequately addressed reality for many schools across the nation. The passive response to this type of behavior has, unfortunately, created a culture in which mistreatment of students is an acceptable part of the schooling experience as a result of being:

- Rationalized by offenders.

- Normalized by students.

- Minimized or ignored by colleagues who remain silent.

- Enabled by inaction of school systems.

- Undetected by outsiders (p. 52).

According to Pringle et al. (2010), Black students are left with feelings of dread at attending class, low morale, and a lack of motivation from having low expectations held of them. Students perceived a direct association between a negative interpersonal relationship with certain teachers and their decreased feelings of belongingness in the classroom setting. Students further felt race or ethnicity was a factor in the way they were treated by their teachers--many had few or no non-white teachers. 
Peer interaction. Socialization not only requires students to have positive interactions with adults but with peers as well. The impact of being accepted (liked or disliked) by your peers and developing friendships is necessary for students to practice social skills (in contextual settings such as the classroom and playground), develop social ties, and promote a healthy attitude towards social identity (Gifford-Smith \& Brownell, 2003; Sheridan, Buhs, \& Warnes, 2003). Classroom structure plays a critical role in the development of friends as argued by Pellegrini \& Blatchford (2000) (as cited in GiffordSmith \& Brownell, 2003) that “...in traditionally organized classrooms, there are more isolated, friendless children, whereas in less traditional, more open classrooms there are more frequent, more stable, and more reciprocated friendships" (p. 258).

You've givin' a name to my Pain--Detroit High School Student 2001 (as cited in UC Davis School of Education \& Solórzano, 2014)

\section{Microaggressions}

Solórzano (2014) noted in a presentation he gave at UC Davis School of Education that he once gave a speech at a high school in Detroit, Michigan about microaggressions. When the audience was given an opportunity to speak, he recalled a young, black female high school student in tears who stood at the microphone and stated those words. It was the first time she was able to name what she had been encountering in her schooling experience. Microaggressions are commonly found in society and can be based on a person's age, disability, gender, race, and/or sexual orientation that can be covert and overt in nature. Microaggressive acts tend to be commonplace in the classroom. The focus of this study will be to understand what race-based microaggressions Black or African American students encounter on a daily basis in the classroom and school setting. 
Racial Microaggressions first coined by the late Harvard Psychiatrist, Dr. Chester Pierce in $1970, \ldots$ refers to "subtle, stunning, often automatic, and non-verbal exchanges which are put downs" as he specifically related actions done to Black people by non-Blacks (Sue et al., 2007). Classified as microassaults, microinsults, and microinvalidations, microaggressions can lead to lowered teacher expectations and intentional and unintentional bias acts and comments creating a hostile learning environment for students of color (Sue, 2010).

Sue et al. (2007) define racial microaggressions as "brief and commonplace daily verbal, behavioral, or environmental indignities, whether intentional or unintentional, that communicates hostile, derogatory, or negative racial slights and insults toward people of color" (p. 271). From a sociological perspective, "racial microaggressions are one form of systemic everyday racism used to keep those at the racial margins in their place." They are both manifested through verbal and nonverbal behavior (UC Davis School of Education \& Solórzano, 2014). Figure 1. A model for understanding racial microaggressions by Kohli \& Solórzano (2012) depicts the types as well as the context in which racial microaggressions take place can lead to various effects or internalization of it by the receiver/ target. In return the response or reaction indicates how the receiver choose to deal with the experience(s) received from the perpetrator. 


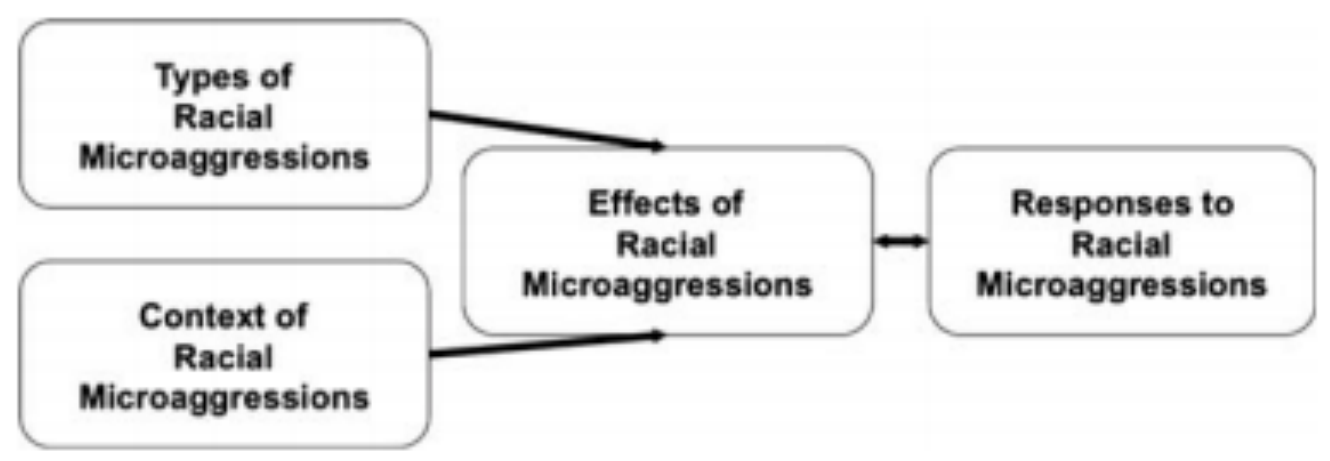

Figure 1. A model for understanding racial microagressions [sic]. Adapted with permission from Kohli, R. \& Solórzano, D.G. (2012). Teachers, please learn our names!: racial microagressions [sic] and the K-12 classroom, Race Ethnicity and Education, 15(4), 441-462.

Goldstein, Young, \& Boyd (2008) examined how exposure to relational aggression at school is associated with adolescents' perceptions of, and participation in, a hostile school environment. Using a sample of 1,335 African American and European American adolescents in grades 7-12 (52\% female, 49\% African American) results indicated that exposure to relational aggression is associated with several components of adolescents' perceptions of the school climate. Adolescent exposure to high levels of relational aggression perceived their school to be less safe, and was less pleased with the general social atmosphere at school. They further found that males were more prone to carry a weapon to school due to relational aggression. Gregory \& Weinstein's (2008) review of a high school's discipline record found African American students were over-represented in disciplinary referrals with defiance as the most frequent reason for sanctioning adolescents. Referrals were from one or several classroom teachers suggesting referrals are specific to the classroom situation. The students' variability in defiant behavior may be related to their perceptions of teacher behavior. 
The contextual setting that is the focal point of this study is the classroom where racial insults and slurs are manifested by White teachers and peers who serve as perpetrators onto Black or African American Students who serve as targets. The three racial microaggressions to be examined are: microinsults, microassaults, and microinvalidations. Environmental microaggressions will also be explored in greater depth to determine the impact these behaviors have on students and the way they internalize their engagement level in the schooling experience. Black or African American students will either respond through persistence or yield to pushout.

Microinsults. Microinsults are "behavioral/verbal remarks or comments that convey rudeness, insensitivity and demean a person's racial heritage or identity (Sue et. al., 2007, p. 278). Common themes include questioning one's intelligence, being treated like a second-class citizen, purposeful devaluation of the power of one's name through mispronunciation or complete negation of a person's name despite being informed of the correct way to say it, and making assumptions about behavior (Allen, 2013; Kohli \& Solórzano, 2012). According to Allen (2013), “...Black students experience invisibility, differential treatment by school teachers, and the feeling of being stereotyped" (p. 175). Pringle et al. (2010) points out a common assumption that black students are from low income homes with uneducated parents as a student shared, "Teachers "appearing shocked" that a black student could be from an affluent family and do well” (p. 37). Kohli \& Solórzano (2012) further add that internalized racism can lead to feelings of embarrassment and shame and at times can produce a self-hatred for one's cultural heritage and identity leading to feelings of insecurity throughout life concerning their 
traumatic experience of having their name repeatedly disrespected during their schooling years.

Microassaults. Microassaults are "explicit racial derogations characterized primarily by a violent verbal or nonverbal attack meant to hurt the intended victim through namecalling, avoidant behavior or purposeful discriminatory actions (Sue et. al., p. 278). In a qualitative study of African American high school students' perceptions of teacher expectations, Pringle et al. (2010) noted a racial microaggression that occurred in a classroom by a teacher who used derogatory terms to describe a student: "He told me that I had a ghetto black girl mentality" (p. 36). Microaggressions can also occur from peer to peer. Winstead's (2016):

(Asian American, Male): Black people have more melanin. (White Male): Blacks have more melon in them? (p. 11)

The white male student engaged in making a racial joke based on racist stereotypes of black people eating watermelon as depicted in anti-black, sambo caricature. An additional example of how a microassault can manifest by being treated as invisible as noted by a student from the Pringle et al. (2010) study "students being purposely marked absent when present and having their work thrown in the trash" (p. 36). Receiving subjective disciplinary actions for minor defiance events are common ways students are excluded from class. White teachers may perceive African Americans as more defiant and rule-breaking than other groups (Gregory \& Weinstein, 2008). Often excessive and unnecessary force is used against Black and African American students. Kohli, Pizarro, \& Nevárez (2017) recount the instance of a high school aged black female being 
slammed to the floor in a classroom by police officers. As is shown by research, microassaults vary greatly in their intensity.

Microinvalidations. Microinvalidations are "verbal comments or behaviors that exclude, negate, or nullify the psychological thoughts, feelings, or experiential reality of a person of color (Sue et. al., p. 278). The type of behavior is manifested in a multitude of ways and can include invalidating comments such as "we live in a colorblind society," not being validated for one's thoughts and opinions, and/or otherwise treated as untrustworthy. Students report experiencing physical symptoms, such as headaches or nausea from such experience. In a case study of three adolescent girls, Spegel (2016) gains a greater understanding of the students prior schooling experience as they were currently transitioning back into the community from a juvenile correctional facility. One female student indicated that she had issues with peers in school prior to her incarceration, which resulted in the charges that led to her stay at the facility. She reported that she got into multiple fights in school and that other students were treating her poorly. In her words, "the bullying had gotten out of hand" (p. 72). She also reported that she frequently avoided school, stating, "I would skip, tell my mom I was sick, pretend to be sick, stick the thermometer under hot running water" (p. 72).

Environmental microaggressions. School structure plays a major part in how connected a student feels in the classroom. Environmental microaggressions can be considered an extension of microassaults on a macro-level. Seeing positive images of people and cultural relics in the classroom and school setting are important in developing a healthy social identity. However, the reality is that African American students often 
feel unwelcomed and invisible in the classroom. Worn textbooks, broken desks, poor lighting, holes in the wall and peeling paint further embody separate and unequal learning environment. This environment influences the mentality of African American students who are more likely to attend predominantly black and high impoverished school settings than other students of color.

He who opens a school door, closes a prison--Victor Hugo

\section{CRT and MET in Student Discipline}

Ford (2012) pointed out "behavior is context bound and riddled with subjectivity and polemic opinions" (p. 395). Teacher and administrator bias often influence how students are disciplined in relation to subjective (e.g., defiance and noncompliance) and objective (e.g., alcohol and fighting) reasons. It is well known that African American and Latinx students receive harsher punishments for similar infractions compared to their white peers. Cultural and racial differences appear to play a major role in the perceptions of teachers assessing student behavior.

Objective v. subjective discipline practices. Although teachers have the power to make referrals for various behavioral infractions, in and out-of-suspensions are ultimately the decisions of the school administrator. However, teachers heavily influence the outcome and initiate the majority of referrals. African Americans are overrepresented in office referrals in relation to their population size in the school from elementary onward while Hispanic/Latino students start to experience similar overrepresentation of discipline referrals during the middle school years (Skiba et al., 2011; Wallace, Jr., Goodkind, Wallace, \& Bachman, 2008). Looking at racial disparities in school discipline, Skiba et 
al. (2011) used regression analyses on elementary and middle school data from the School-Wide Information System (SWIS), which revealed African Americans were more likely than their white peers to receive out of school suspensions regardless of the type of infraction.

In a similar study using data from the University of Michigan's Monitoring the Future project, Wallace et.al. (2008) examined the differences and similarities in school discipline among high school $10^{\text {th }}$ graders. Their findings indicate that African Americans and Latino students were consistently more likely than their white or Asian peers to be disciplined in school. They further noted Black, Hispanic, and American Indian students were more likely to be sent to the office or detained after school. All racial and ethnic groups saw a decline in the early 2000's in discipline rates, except African American students who experienced an increase in suspensions and expulsions as part of the Zero Tolerance reform movement in schools which involved the presence of heavy policing of black students by referring large percentages to law enforcement for infractions that could have been resolved by school officials and suspending black students for minor infractions. Skiba et al. (2011) further pointed out that African American students were, "less likely to receive in-school suspension for minor misbehavior disruption, noncompliance ... or detention" indicating harsher (out of school suspension) punishment for minor offenses (p.95). Possible reasons for the disparity are attributed to socioeconomic status and communication affect differences (Monroe, 2006; Peguero \& Shekarkhar, 2011; Skiba et al., 2011; Wallace et al., 2008). 
To help further understand why discipline often takes on a biased effect may lie in the understanding of Intergroup Threat Theory. Stephan, Ybarra, \& Morrison (2009) state intergroup threat is when members of one group perceive that another group is in a position to cause them harm" (p. 43). They further note that the threat between groups can be perceived as realistic or symbolic in nature and define as:

(R)ealistic group threats are threats to a group's power, resources, and general welfare. Symbolic group threats are threats to a group's religion, values, belief system, ideology, philosophy, morality, or worldview. Realistic individual threats concern actual physical or material harm to an individual group member such as pain, torture, or death, as well as economic loss, deprivation of valued resources, and threats to health or personal security. Symbolic individual threats concern loss of face or honor and the undermining of an individual's self-identity or self-esteem. (p. 44)

In the school the imbalance of power in the classroom would be teachers over students. Often those in power tend to use fear and other preconceived notions or stereotypical beliefs as justifications to treat some students with care and others without care. Thus, this imbalance of power may lead to students of color being treated as second class citizens in the classroom by their teachers and peers (Opotow, 1990).

If perception of reality is what drives some people to treat others differently and to have ill-will toward members of out groups due to fear or perceived threat in the greater society, it is not surprising that the same dynamic plays out in the classroom setting between teachers and students. Obviously a power imbalance exists between the two groups (teachers [high power] and students [low power]). As it has been noted that although low power groups tend to experience more threats it is the high power group that reacts more harshly to the threats because they often control the means or resources. Stephan et al, (2009) share an example of “...low power racial and ethnic groups (e.g. 
Black Americans, Native Canadians) perceive higher levels of threat from higher power groups (e.g. European Americans, Anglo Canadians) than high power groups perceive from low power groups (p.45). Some teachers may perceive threats from African American students leading to exclusionary discipline practices.

School-to-prison pipeline. The school-to-prison pipeline, which has been coined as "death by education," can attribute much of its momentum to zero-tolerance discipline policies, which have led to the pushing out of black and brown students from the educational setting into the juvenile system (Fasching-Varner, Mitchell, Martin, \& Bennett-Haron, 2014, p. 410). Heilbrun, Cornell, \& Lovegrove (2015) point out how black students are suspended twice as much as white students due to such policies and often more for behavioral related offenses such as disruptive behavior, which often can been view from a subjective lens, versus whites who are more likely to be suspended for objective reasons such as an alcohol or drug-related offense.

Nance (2016) points out, "a police officer's regular presence at a school is predictive of greater odds that school officials refer students to law enforcement for committing various offenses, including lower-level offenses" (p. 919). He further found that SRO's weekly presence on school campuses increases the number of students who will be involved in the justice system. As a result, the rate of referrals for lower-level offenses, such as fighting without using a weapon or making a threat without using a weapon, increases more than twofold when a school has regular contact with an SRO (p. 968). According to OCR (2016), nationally black students comprise $16 \%$ of student enrollment yet $27 \%$ of them are referred to law enforcement and $31 \%$ are subjected to a school- 
related arrest unlike their White counterpart who represents $51 \%$ in enrollment and 29\% with school-related arrests. OCR (2016) further notes that special needs students who constitute $12 \%$ of the student population $25 \%$ of these students are arrested and referred to law enforcement. Accordingly, students with disabilities, a subgroup who benefits from more contact with teachers, face twice as much out of school suspension days $(13 \%)$ in comparison to their non-disabled peers $(6 \%)$ (p. 1). Thus, the criminalizing of school misconduct opens the pathway to the juvenile justice system.

For some students, the classroom is the breeding ground for their induction to the School-to-Prison Pipeline. All states have educational code policies that serve as the guiding body by which school districts function. School discipline is one of the entities that conform to the regulations of education code and has often appeared to push some students away from receiving educational opportunity into a life of crime and poverty. Unfortunately, the realities of the dropout-hidden cost factors are manifested through the implementation of disparate, exclusionary discipline practices. Often leading to suspensions and expulsions, this pattern of practice has shown to be negatively skewed at the intersections of race and ethnicity, gender, and disability. Many minority and disabled youth in California face the brunt of both objective and subjective discipline practices.

For example, in California secondary school settings, African American high school students who are disabled are suspended from school twice as many times as their white counterparts. Furthermore, those with disabilities suspension rates increase to more than three times as much as their white counterparts (UCLA Civil Rights Project, 2017). Unfortunately, this crisis of disparate discipline practices not only has long-term negative 
ramifications for the suspended student but has an even greater economical and sociological impact on all of California's citizens.

The $14^{\text {th }}$ Amendment's Due Process and Equal Protection of the Law clause ascertains that students are to receive a fair and objective discipline process if they are charged with being in violation of school rules. However, discipline practices often reveal that when an individual is African American or Hispanic/Latino, a biased perspective often overshadows the likelihood of receiving fair treatment. Research studies (Skiba et al., 2011; Skiba, Michael, Nardo, \& Peterson, 2002) indicate that not only is the infraction itself important when deciding upon the type of discipline that will be given, but the chance for a more severe punishment increases for minority students. Thus, Zero Tolerance-like discipline practices fuels the school-to-prison pipeline for children of color and students with disabilities.

In general females tend to fair better than their male counterparts with respect to discipline. In Subtractive Schooling, Valenzuela (1999) noted, "ironically, it may be girls' lifelong experience with stronger social control mechanisms that results in their ability to provide "safe spaces" for potentially wayward males" (p. 148). Unfortunately, too many educators often devalue the cultural identity and often deflect toward a subjective rather than objective affinity for African American and Latino males.

\section{Summary}

The purpose of this literature review was to use a guiding conceptual framework to examine the alienating effects from racial microaggressions and preconceived stereotypes and biases on the schooling experiences of Black and/or African American students 
inside of the classroom. These dehumanizing behaviors lead to interactions with adults as well as peers that factor into a series of push out tactics to include low expectations, disparate discipline and grading practices igniting the school-to-prison pipeline. The reality that some African American youth face inside the classroom makes dropping out of school a viable option.

Teachers and administrators should refrain from using punitive measures such as suspensions and expulsions on a regular basis as a classroom management tool unless it is a violation of one of the five mandatory federal offenses categorized under EC 48915(c). Zero tolerance and subjectively biased discipline practices serve to rob students of color of their educational benefit and opportunity. Instead of schools providing an inviting and nurturing learning environment for all students, they often serve to alienate and push out African American students. The trajectory must change and it is through the voices of students of color that will be the catalyst for restructuring the classroom learning environment to be a caring and nurturing place for all students to maximize their potential and have a chance at becoming contributing and productive members of society. 


\section{Chapter 3 Methods}

Merriam-Webster's online dictionary defined value as "relative worth, utility, or importance" (2018, Def. 3). From the review of literature, it is clear that far too long Black and African American students have suffered from a value gap in the classroom by teachers and peers. The ethical, moral, and social implication of this project is to help educators see the value in Black and African American students because what happens in the classroom manifests in all other aspects of their schooling experience and postsecondary life chances. It is necessary that race be apart of the conversation when discussing how best to meet the needs of the students served if there is to be systemic change in creating learning environments that nurture all students' success.

\section{Research Design}

To frame this phenomenological research, a conceptual model (see Figure 2) consisting of Critical Race Theory (CRT) and Moral Exclusion Theory (MET) were infused within a Transformative Paradigm research approach to ascertain a better understanding of how Black or African American students perceive their classroom and school learning environment experiences. The theory of change for this study consists of surveying Black or African American high school students to gain an understanding of their schooling experience, with respect to their encounter with race-based microaggressions. By understanding how students perceive their experiences with microaggressions and the impact it has on them, I will be able to better advocate for students by making specific recommendations to the study district with regards to designing professional development for staff, trainings for students, as well as 
intervention programs explicitly addressing the needs of Black or African American students in the classrooms and schools.

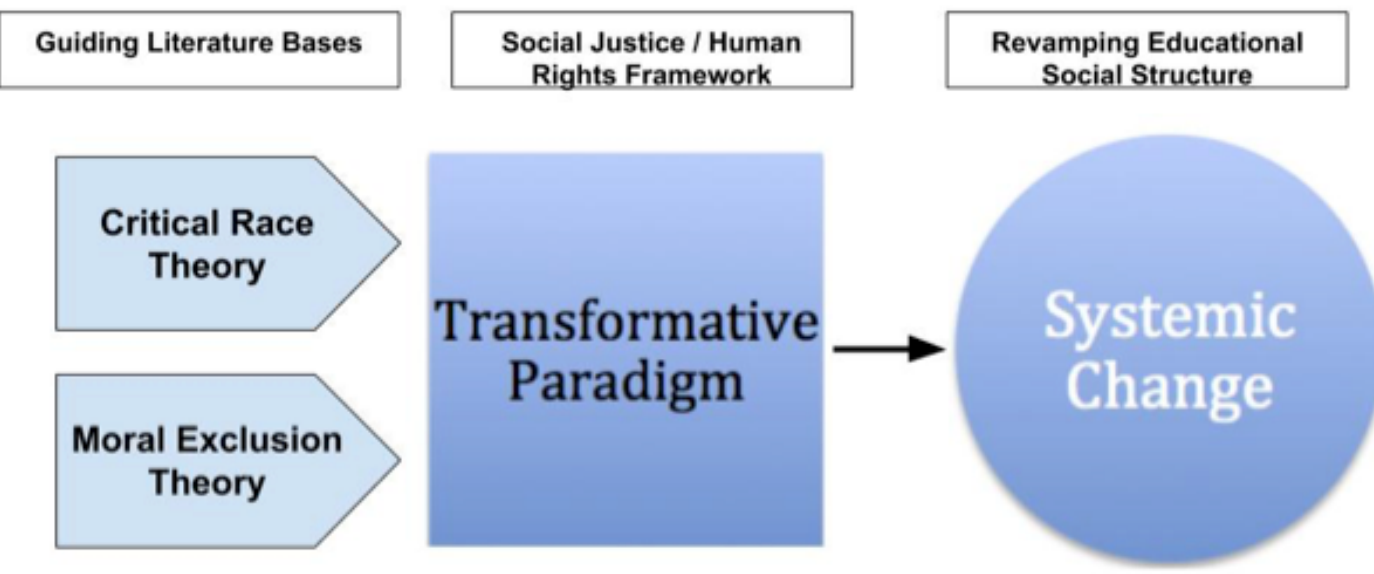

Figure 2. Conceptual model for examining, analyzing, and explaining schooling experiences of Black or African American students.

Visually, the thinking process of the conceptual model for this research study centered the transformative framework as core for "[shaping] how [the] researcher sees the world as well as interprets and acts within it" seeking to uproot and spring forth the inequities in the schooling experiences of Black or African American students (Kivunja \& Kuyini, 2017, p. 26). The contextual lens infused in the perspective to examine, analyze, and explain their experiences draws from two literature bases-critical race and moral exclusion theories to advocate systemic changes in restructuring the schooling environment to promote and support positive learning experiences for Black or African American students.

\section{Research Questions}

The following two research questions guided this study: 
RQ1. To what extent do Black and/or African-American 10th-12th grade students experience racially-based microaggressions? What types of racially-based microaggressions do they experience? From whom do they experience these raciallybased microaggressions?

RQ2. What suggestions do students have for restructuring the learning environment?

\section{Participant Selection}

The 72 participants for this study had at least one year of high school experience to reference. The unit of analysis for this study was high school students who were enrolled in grades 10th-12th within the 11 comprehensive high schools in the study district. These students were identified by Federal (Code 4) and State (600) race codes as Black or African American. The study included Federal Code 7: Two or more races if one of the racial groups is Black or African American and students who identify ethnically as Hispanic and racially as Black or African American.

\section{Site Selection}

The students were recruited from eleven comprehensive high schools in a high school district located in Northern California. Fall 2018 the study district had a collective student body of 23,336 students spread across 11 traditional high schools, four small but necessary schools (SBNs), and one alternative high school (CDE, 2017). The district has affiliation with one nonpublic school and 10 charter schools. For the purpose of this study, only the 11 comprehensive high schools were included.

With respect to the demographic composition of the study district, it has a minority majority student population (see Table 1). The district's student body racial/ethnic 
makeup consists mostly of Hispanic/Latino (44.4\%) and Asian students (36.9\%). The Black or African American student body continues to see a decline from $2.7 \%$ the previous school year to $2.5 \%$ the current school year. More than half $(55.1 \%)$ of the student body is considered socioeconomically disadvantaged which increased from $53.5 \%$ the previous school year. With respect to gender, the district is composed of 51.7\% male and 48.3\% female. Students with Limited English Proficiency (LEP) constitute $16.8 \%$ of the study body, which grew by one percentage point from the previous school year. Students with disabilities in the district have also seen an increase from $9.8 \%$ to $10.5 \%$ (CDE, Fall 2018 Dashboard Report, 2018).

African American students graduation rate (83.7\%) is higher than other student subgroups of color such as American Indian (66.7\%) and Hispanic (79.3\%) peers. However, their graduation rates fall below their white peers $(86.5 \%)$.

Table 1

Study District Demographics $(N=23,336)$

\begin{tabular}{lrrr}
\hline Student Group & Total & Percentage 2018 Graduation Rate \\
\hline English Learners & 3,911 & $16.8 \%$ & $74.2 \%(\mathrm{n}=1,260)$ \\
Foster Youth & 65 & $0.3 \%$ & $51.1 \%(\mathrm{n}=47)$ \\
Homeless & 198 & $0.8 \%$ & $56.5 \%(\mathrm{n}=108)$ \\
Socioeconomically Disadvantaged & 12,862 & $55.1 \%$ & $82.4 \%(\mathrm{n}=3,940)$ \\
Students with Disabilities & 2,454 & $10.5 \%$ & $64.6 \%(\mathrm{n}=534)$ \\
TOTAL & $\mathbf{1 9 , 4 9 0}$ & $\mathbf{8 3 . 5 \%}$ & \\
Race/Ethnicity & & & \\
Black or African American & 581 & $2.5 \%$ & $83.7 \%(\mathrm{n}=166)$ \\
American Indian & 58 & $0.2 \%$ & $66.7 \%(\mathrm{n}=18)$ \\
Asian & 8,612 & $36.9 \%$ & $93.3 \%(\mathrm{n}=2,283)$ \\
Filipino & 1,836 & $7.9 \%$ & $92 \%(\mathrm{n}=486)$ \\
Hispanic & 10,368 & $44.4 \%$ & $79.3 \%(\mathrm{n}=2,623)$
\end{tabular}


Table 1 (continued).

Two or More Races

Pacific Islander

Note. Data collected from CA Dashboard, Fall 2018 report

However, in this student minority majority district, nearly half of all teachers are White (49.3\%). Twenty-three percent of the teaching staff are of Latin descent, $14.5 \%$ are Asian. African American teachers constitute $4.1 \%$ of the district teaching staff (DataQuest, 2017).

Each year a district wide school climate survey is administered to gather the perceptions students have with respect to sense of school connectedness, safety, and social emotional needs. The findings of this study addressed two key areas reported to the state through the Local Control Accountability Plan (LCAP). LCAP is part of California's accountability instrument for local school districts to discuss and write about how areas of concern, in this case, Priority 5: Student Engagement and Priority 6: School Climate, will be addressed for the following school year. Spring 2018 the study district administered the survey with over $60 \%$ of students $(n=14,289)$ responding. In general, the results revealed that a systemic problem concerning sense of belonging and school connectedness existed throughout the district as a whole with slightly more than half $(52 \%)$ of the students respondents indicating feeling connected to their school. Thus, $48 \%$ of student respondents in the district appeared to feel estranged from their school. With respect to student racial and ethnic breakdown, when compared to the all students 
who took the survey, African American students felt the least connected to school at $46 \%$. Five questions were asked to measure the sense of belonging/school connectedness construct. In four of five areas, Black students felt the most disconnected from the school district compared to all other racial/ethnic groups (Panorama Education, 2018).

The district recently completed the Fall, 2018 Panorama Student Survey and the results were similar with roughly $60 \%$ of the district wide total student enrollment responding to the study climate survey. There was no change overall in how students responded across the board with respect to sense of belonging/ school connectedness (remained 52\% from Spring, 2018 to Fall, 2018). Once again, Black students who constitute two percent of the total district population felt least connected with a $45 \%$ favorability rate and continued to be the most disconnected from school on four out of five areas assessed for that construct. The questions, "The teachers at this school treat students fairly" (37\%) and "I feel like I am apart of this school" (41\%) were some of the measures Black students felt most estranged from in the district (see Figure 3). 


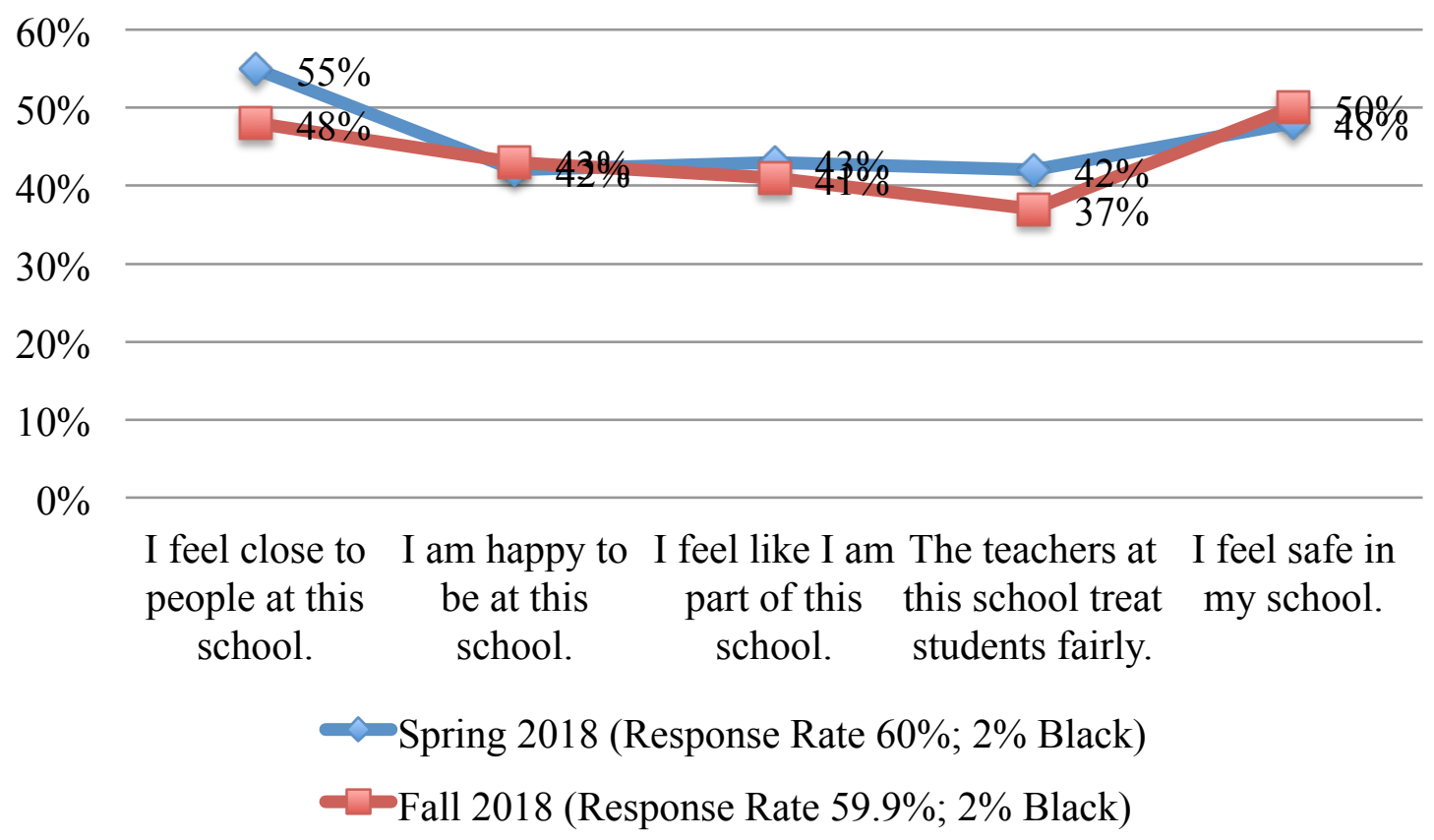

Figure 3. Black students favorability of sense of belonging/connectedness.

In comparison to the CORE Districts nationwide who also took the same school climate assessment, this district ranked in the low $20^{\text {th }}$ percentile for student sense of belonging and school connectedness. Overall, the results indicate, especially items three and four, a critical need of developing nurturing, positive teacher-student relationships across the board for all students. All student racial groups except Asian (50\%) and Multiracial (50\%) ranked under 50\% feeling favorable for item number three. All students racial groups were under $50 \%$ feeling favorable for item number four. Black and African American students appeared to feel the most estranged from their high schools (Panorama Education, 2018).

In the 2013-2014 school year, the study district had 5,979 students in their 10 cohort. Of those students, 690 were suspended yielding an $11.5 \%$ suspension rate. The graduation rate for all the students in the study district was $80.1 \%$, while the graduation 
rate of non-suspended students was $84.4 \%$. However, a significant decline to $44.3 \%$ graduate rate for students who had been suspended indicating a 40.5 point difference in the two types of students. The number of non-graduates for this cohort was $n=1,188$. Thirty-two percent $(n=384)$ of the non-graduates were of students who had received at least one suspension or more. An additional 37 students were currently suspended when the cohort graduated in the 2015-2016 school year. When adding the fiscal $(\$ 67 \mathrm{M}+$ $\$ 6 \mathrm{M})$ and social loss $(\$ 223 \mathrm{M}+\$ 21 \mathrm{M})$ you get a combined loss of $\$ 317,000,000$ attributed to school discipline practices for this cohort that graduated in Spring 2016 from the district (Rumberger \& Losen, 2017).

For 2018, the district had a total of 6,053 graduates with a 4-year graduation rate of 86.2\%, which increased by 2.6 percentage points from 2017. African American students had a graduation rate of $83.7 \%$ who were apart of the district's senior class $(n=166)$, a decline of 4.6 percentage points from 2017. It is unclear if this data only reflects students who had no suspensions. Generally when students have one or more suspensions, their chance of graduating from high school greatly reduces (Rumberger \& Losen, 2017). Unfortunately the district does have a high suspension rate for the small percentage of African Americans students currently enrolled in the system. Fall 2017 data indicated Black students were categorized as being very high with an $11.8 \%$ suspension rate showing a significant increase by 3.2\%. Black or African American students were suspended nearly 4.5 times their enrollment rate in the district, which speaks to both disparate discipline practices and disparate loss of instructional minutes. Fall 2018 data continued to see Black or African American student group with the highest rate of 
suspension than any other group in the district. Of the 643 students, $13.1 \%$ had been suspended at least once (CA Dashboard, 2018). Under new administrative leadership, the district is slowly but surely making headway from the once zero tolerance- - heavy police involvement mindset to a relationship-centered focus and has proposed the following suggestive action, "Identify lead for developing positive school presence and incorporating student voice in planning for African American and other students" (Superintendent, 5/17/18).

\section{Instrument}

The survey instrument was comprised of 35 questions with some questions having multi-question, likert-scale response categories as well as closed and open-ended questions. The survey was divided into three parts: student engagement, classroom and school experiences, and designing a learning classroom. The survey was administered electronically to 52 participants. The remaining 20 participants received a secured paper version of the survey that will be discussed later in this chapter. Web-based surveys can be more aesthetically appealing to respondents providing motivation for them to complete the questionnaire (Berends, 2006, p. 631). SJSU Google Forms was the program used to construct the survey for this study and was setup to allow for automated coding of the data minimizing errors in the data collection process and provided real-time data to assist in monitoring the survey administration. However a downfall of using online surveys was the risk of data leakage as well as the unknown ability of the user to engage technology (Berends, 2006; Merriam \& Tisdell, 2016). 
Research question I. To what extent do Black and/or African-American 10th-12th grade students experience racially-based microaggressions? What types of racially-based microaggressions do they experience? From whom do they experience these raciallybased microaggressions? RQ1 will be answered by the results found in part two of the survey. The second section of the survey was entitled, "Classroom and School Experiences." It consisted of 16 questions. The purpose of this section was to determine the extent and from whom (teacher and/or peer) a student had experienced racial microaggressions based on race in the classroom setting. Question 12 measured the construct microinsults which was composed of six items related to: repeatedly having name mispronounced, low expectations held of them by others, and being treated like a second class citizen in the classroom. Question 13 allowed for the capture of qualitative data by providing an open-ended question for the student to give an example of the behavior or incident they experienced from that part of the survey.

Question 14 addressed microassualts in the classroom. It was composed of five items to measure the construct. Questions included: having hand raised in class first to answer but student of a different race is called on instead, being called a derogatory term or racial slur, and being referred to the office for subjective reasons such as disruption and defiance. Question 15 was an open-ended question to allow the student to write an example of this type of behavior or incident they experienced.

Question 16 focused on microinvalidations in the classroom. The construct was measured using five items which included: Hearing the term colorblind being used in class, made to feel not trusted or believed, and experiencing a physical reaction to a race 
targeted behavior or comment. Question 17 was an open-ended question to allow the participant to expand on the behavior or incident experienced in the classroom.

Question 18 focused on environmental microaggressions within the classroom and school as a whole. It was composed of 12 items to measure this type of microaggression occurrence in the classroom or school environment using a scale with "never," "rarely," "sometimes," and "often" as response categories. Questions in this section included: Do you see pictures or posters in the classroom of role models from their racial/ethnic group, been suspended in class (e.g. in school suspension or benched in office), and if they have classrooms with peeling paint or damage to the walls.

Research question II. What suggestions do students have for restructuring the learning environment? RQ2 was answered by the final section of the survey entitled, "Designing a Learning Classroom." It consisted of three areas: academics, community, and equity to determine learning strategies and instructional practices most beneficial for the learning needs of Black or African American students. All of the eight questions were open-ended to provide students an opportunity to empower their voice by sharing what an ideal school model for them would look like. The purpose was to gain insight on best practice recommendations for educators on how the Black or African American high school age students learn best.

Academics looked at course and instructional practices. The questions (28-30) were: What types of courses would you like to see offered that you are interested in taking not currently offered at your school? How would teachers teach their lessons? Grading 
Practices? How do students interact with one another inside the classroom? How do they help each other learn?

Community considered the physical structure of the school and classrooms and strategies for promoting a sense of belonging/ connectedness for Black and African American students. Questions (31-32) included: What is the maximum number of students in an ideal classroom? How would the classroom be arranged/setup? How would Black or African American culture be included in the classroom? How would Black or African American families feel welcomed and integrated into the school?

Equity (fairness) is captured in the final three questions of the survey. Questions (3335) included: What are some ideas/ways on how Black or African American students' voices can be empowered in the classroom and school? What would discipline look like in the classroom/ school? How would students be made to feel cared for in the classroom?

\section{Pilot Test}

A recent high school graduate residing on the east coast pilot tested the survey instrument. Although he did not provide responses to the follow up questions that included asking how long the survey took, he appeared to have no difficulty with understanding the questions or responding to them. Answers provided for many of the open-ended questions were brief. However, there were some interesting noted points. For instance, question 21 under part II of the survey asked the student to identify three adults in roles at his school he trusted to talk to for emotional support and/or academic encouragement. He identified three supports as a teacher, coach, and custodian. This 
was valuable data because it denoted the importance of relationship building by all adults in the school whether in a certified or classified position as they have the power to serve as role models and influence student outcomes. With respect to experiencing microaggressions, he noted both teachers and peers repeatedly mispronounced his name however, in regards to environmental microaggressions, in class he saw instances of posters and other relics of role models that looked like him indicating teachers were utilized culturally responsive teaching practices to make all students feel included in the classroom.

\section{Research Timeline and Security Approaches}

The researcher took extra care to review the district's school calendars' as to avoid any conflict with testing and to give 60 days or more advance notice of the expected collection window to the district. The data collection window spanned the months of September and October of the Fall, 2018 semester. The week of September 4-7th was used to announce the study and recruit participants. Week 2, September 10-14th, was the collection window of Parent Consent and Student Assent Forms. Weeks 3 and 4, September 17-28th, was when the online survey was administered to the participants at their respective school site. The month of October was used to obtain responses via a paper survey for students who missed the administration date for their school. The arrangement of dates, locations, and times were made with local school site administrations.

The researcher sent an email to the 11 Principals' informing them of the study and expectations which included: 
A. The Principal would provide the researcher with the contact information for the Black Student Union (BSU) Advisor. If the campus did not have such an Advisor, the researcher requested the contact information for the Head School Counselor to work with directly in recruiting students for the study. Principals were informed of the $\$ 100$ incentive that would be given to schools that had $80 \%$ of the students meeting the criteria participating from their school. The money was to be used to support Black Student Union (BSU) projects or for a school diversity activity during the school year.

B. The Principal or designee provided a list of their Black or AFAM students who were enrolled in $10^{\text {th }}-12^{\text {th }}$ grades to the researcher. They were identified by Federal Code 4 and State Code 600 as Black or African American. Also, including Federal Code 7: Two or more races if one of the racial groups is Black or African American and students who identify ethnically as Hispanic and racially as Black or African American. [Date: 8/27/18] The researcher sent a reminder email to Principals who have not provided the researcher with their list by the designated afternoon.

C. The researcher coordinated with the principal or designee a date and time between September $17^{\text {th }}-28^{\text {th }}$ to be able to use a computer lab, large space with tables and chairs, or classroom with access to chromebooks for student participants to complete the online survey. [Scheduled Week of 8/13/18]

The researcher, an Associate Principal at one of the 11 comprehensive school sites, oversaw attendance and discipline as well as other areas that may have had minimal impact on the target population at that particular school site. All schools were expected to follow the same procedure of having a certified staff member (e.g. BSU Advisor or Head 
Counselor) as their initial point of contact. Unlike the remaining 10 schools, the researcher served as the contact person for her school site. The target population at the researcher's site had a slight advantage of being able to speak with the researcher in person concerning the study than other participants who were limited to email or phone access. No additional advertising of the program was done at the researcher's site that was not done at the other 10 comprehensive high schools during the recruitment of students, collection of consent/assent forms, and administration of the survey. Students were not coerced or under duress to participate in the survey.

\section{Data Security}

Security measures were implemented to ensure confidentiality of study participants. The researcher requested through Information Technology (IT) Support a generic/ dummy login for students to use to avoid having to use their school email logins to minimize risk of identification. Further, no student names or personal student identification numbers were asked on the survey instrument. Participants were given specialized survey ID codes to enter on the online survey that was crossed reference from a separate, secured source that contains confidential information of the research participant. The researcher used Random.org's Random String Generator to create a list of unique survey ID codes five characters long composed of letters and numbers that the participants used to login into the online survey (Haahr \& Haahr, 2018).

Paper copies were made available to participants if they had difficulty manipulating a computer, personally request a hard copy, or in the event of a technological failure resulting in a need to switch to paper-based administration, later entered into the online 
database by the researcher and destroyed afterwards. Students received breakfast or lunch catered by the researcher for their participation in the study. They were free to withdraw from the study at anytime without penalty. Any data collected at that point were used in the analyses. No demographic data was asked directly on the survey because the Researcher had district level access to all students in the district demographic data. The Researcher added demographic descriptors such as age, gender, grade level, etc. once the survey administration window ended.

No names or student ID numbers were included and the unique survey ID number was removed from each participant's responses during the data mining process in order to prepare the data to be analyzed in SPSS. Once the survey window closed each school site's student participation was tallied. No school met the criteria of having $80 \%$ or more of their Black or African American student body complete the survey, therefore no school was rewarded $\$ 100$ for their BSU Club or towards a student diversity inspired activity.

\section{Sample Size and Analyzing Data}

A total of 72 students participated in the opt-in survey yielding a $14 \%$ completion rate of the total students $(\mathrm{N}=515)$ who met the requirements in the study district. Statistical Package for the Social Sciences (SPSS), a common software package used in educational research, was used to perform quantitative analysis. Qualitative analysis methods were used to find patterns/ themes that emerged within open-ended responses (Clandinin \& Connelly, 2000; Muijs, 2004). The open-ended responses were included to give students a chance to give specific examples/ experiences as well as opportunity to denote what they felt were best practices to help Black students meet with success in school. 


\section{Data Collection Process}

The researcher worked with school site administrators to recruit students in order to maximize participation. With the assistance from district office staff, the researcher sent out a KICK-OFF study robocall and email. This went out to all potential families with students who were eligible to participate. It informed them that their student would receive a package that provided more information concerning the study. It also included a flyer addressed to parents/guardians, an infographic postcard for the student, and the consent and assent forms for both.

The KICK-OFF letter served to initiate communication between parents/ guardians and researcher. The researcher shared background information about herself and role in the study to establish trust. According to Mertens (2017c), "the participants" perceptions of the researcher is a crucial piece of the puzzle and will determine the quality of relationships that are developed, as well as the data that will be collected" (p. 20). Due to historical and cultural injustices from dishonest research practices (e.g. Tuskegee Study of Untreated Syphilis in the Negro Male), some Black and African Americans may be reluctant to participate in research studies because they may fear being exploited and objectified and see little transparency in the researcher's agenda which may lacks no true investment in working with the community to promote change.

At the very beginning of the KICK-OFF phone blast (see Appendix E) it was important to establish a connection with the community by informing families of my role in education, my racial identity, and making it known that I was invested in their child's educational attainment. Parents/guardians were informed of the intent of the research 
study to dig deeper as to why our students felt disconnected to their schools and district as a whole by understanding from their perspective what their schooling experience was like. At the end of the letter families were informed that the data collected would be confidential and no names of participants would be disseminated in any reports.

I worked with a variety of staff at each school site: advisors of the Black Student Union (BSU), counselors, student advisors, and parent liaisons as a school base point of contact during the recruitment phase. I further worked with district IT staff to create a guest/dummy login to be used by study participants so no student had to use their school email address to login into the computer to minimize risk of identification. Each school received packets to be disseminated to each identified student at their school. Students were directed to turn in their consent and assent forms to the designated staff member.

During week 2, I focused on the collection of Parent Consent and Student Assent Forms. Additional flyers, postcards, consent, and assent forms were made available at each school site for students to take if they misplace their original copy. I collected the consent and assent forms from the designated staff member that served as point of contact from each of the 11 school contacts on Friday, September 14, 2018 and Monday, September 17, 2018. By request of many of the school sites, the collection window of consent and assent forms were extended through September 21, 2018 in order to give more students an opportunity to submit their forms.

During week 3 and 4 the online survey was administered to participants. Each of the 11 schools had a designated date, time, and location for the survey to be administrated to students. Arrangements included the use of a computer lab, classrooms, conference 
rooms, libraries, etc. along with the use of chromecarts for students to access the survey. Upon entry into the assessment location students were instructed to sign in by their name on the roster. After students signed in, I provided the student with an index card containing a specialized survey ID code and dummy login instructions for the computer in order to access the SJSU Google Forms online survey. Prior to the start of the survey administration, I formally introduced myself, restated the purpose of the survey, answered questions posed by the participants, and thanked them for taking part in the study. Food was provided to the participants as stated in the assent and consent forms. The index card contained a question that asked the participant to identify the highest level of educational obtained by their parent/guardian. I collected the index card once the student began the survey. It was used to cross-reference a secured, separate source that contained confidential information of the research participant. Students' time ranged from 20 - 60 minutes to complete the survey which was based on their comfort level with technology, level of negative experiences, and depth of their responses to the open-ended questions.

The online version of the survey ended September 28, 2018 with 52 students who completed it. However, a number of schools had low turnout. Several students who submitted consent forms to participate were absent the day it was administered at their site. To ensure these students had an opportunity to participate, I sent specific instructions to the school contact (see Appendix K) and special paper versions of the survey to the school site for students to complete (see Appendix L). Because of the survey's nature, they were glued shut and only the student listed on the packet was to 
open the packet upon receipt. If the student was unavailable, the school contact person was instructed to return the packet unopened in its original state along with the completed surveys that were sealed in envelopes with the student's signature across the seal (see Figure 4). The survey was not allowed to be given to another student or opened by school staff. The survey had to be completed at school in a quiet space. It could not be taken home or contents shared with others.

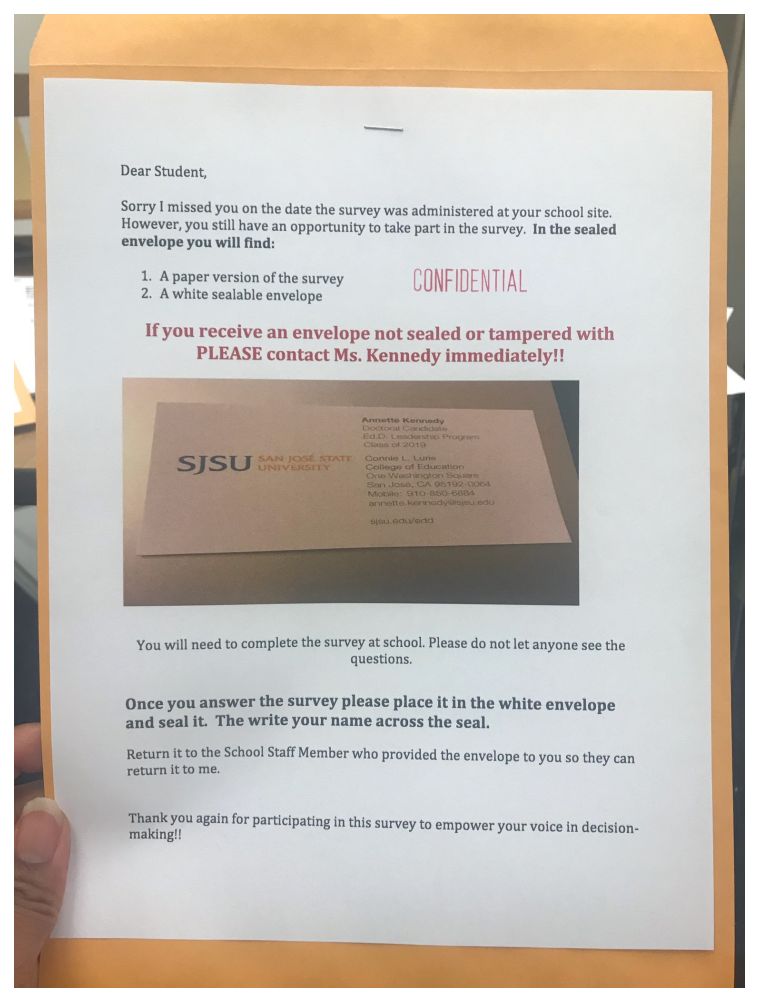

Figure 4. Paper survey packet.

Packets were sent to the schools in the intra-district mail. The package to the school staff contact included the roster of students who submitted their forms but were unavailable to take the survey the day it was administered at their site along with a confidential packet for the student. Each packet had the name of the intended student on it. The initial request was for the completed surveys to be returned by October 5 , 
2018. However, due to various unforeseen activities occurring at each school site, the paper survey collection was extended through October 31,2018. The paper version led to the completion of 20 surveys that were entered into the online survey database by me yielding a total sample size of 72 student participants.

\section{Limitations}

Black or African American students made up less than three percent of the total student population of the study district. Limiting the sample to 10th-12th grades in the 11 comprehensive schools makes the pool even smaller; the target population was estimated to be a little more than 500 students. Although the results will be beneficial for the study district, it will be difficult for results to be generalizable due to the small sample size.

\section{Summary}

The phenomenological study allowed students the opportunity to share first-hand accounts of their schooling experiences through survey. Constraints for when the data

could be collected based on the district calendar of events prevented the inclusion of $9^{\text {th }}$ graders who had not had sufficient time to experience attending high school. Alternative paper surveys had to be used for 20 students due to some students being absent at the time the survey was administered at their school site. The paper surveys were securely packaged and sent to the respective schools for students to complete in order to give them an opportunity to have their voices heard. Various parts of the survey instrument captured usage of school resources, extent experienced negative schooling, and opportunities for students to voice how they learn best. 
All school districts in the state of California as well as throughout the nation who desire to improve the educational outcomes of Black or African American students may benefit from this study. The cleaned data may be shared with the study district upon request. Also, the data may be used in subsequent white papers and publications. The collective responses of the participants schooling experiences will impact decisionmaking. The study's findings will contribute to the District's LCAP Priority 5 (Pupil Engagement) and Priority 6 (School Climate) measures. Using the input/voices of current Black or African American students will be instrumental in all areas of strategic and scenario planning to drive professional development, curriculum needs assessments, and interventions/models/programs that will be most effective for school leaders, teachers, and students at all levels within the district. Ultimately, the intent of this study was to maximize implementation of best practices that are beneficial to all students in the classroom setting by enhancing the learning needs and life chances through receiving culturally conscious instruction in a caring and nurturing environment. 


\section{Chapter 4 Findings}

This phenomenological study used several different lenses, the critical theory of race (CRT), the narrative of the oppressed (Bell, 1995; Ladson-Billings \& Tate, 1995) and the theory of moral exclusion (MET), the oppressive dialectical policy/practice (Opotow, 1990), to explore the extent of racial microaggressions experienced by black students' in school. This work also used a student-centered approach to explore what students want from school. In these veins, this study offers a transformative paradigm: my social justice lens created research that is culturally responsive and empowering to the oppressed and marginalized community studied (Mertens, 2003, 2007, 2010). By empowering the voices of black youth, we gain a better understanding of their perceptions of their schooling experiences.

The sampling frame, a 2018-2019 list of the Black students enrolled in 11 comprehensive high schools in the district of study, indicated there were 375 such students in grades $10^{\text {th }}-12^{\text {th }}$. Subsequently, the study district IT department located an additional 169 students. In total, 544 students met the criteria of the study as of August 28, 2018. During the study's implementation period the number of students meeting the criteria was reduced to 515. All schools in the district had at minimum one participant and four of the eleven schools accounted for approximately half (51.2\%) of the study participants. The participation rate was $14 \%$. Figure 5 provides the number of students per school who participated in the study. 


\begin{tabular}{|r|r|r|}
\hline School & Number Participants & \% Total Study Participation \\
\hline 1 & 9 & 12.5 \\
\hline 2 & 4 & 5.6 \\
\hline 3 & 12 & 16.7 \\
\hline 4 & 6 & 8.3 \\
\hline 5 & 13 & 18.1 \\
\hline 6 & 10 & 13.9 \\
\hline 7 & 1 & 1.4 \\
\hline 8 & 5 & 6.9 \\
\hline 9 & 7 & 9.7 \\
\hline 10 & 1 & 1.4 \\
\hline 11 & 4 & 5.6 \\
\hline TOTAL & 72 & $\mathbf{1 0 0 . 1}$ \\
\hline
\end{tabular}

Figure 5. Black student participation per school site.

The results are divided into three sections. First, I discuss the demographic profile and identity of the participants. The section, demographic profile and identity, explores how latent factors such as racial identity and colorism in school fuels the presence of racial microaggressions. The section on racial microaggressions offers an in-depth look at the frequencies and types of racial microaggressions students encounter in their interactions with both peers and teachers. Section Three, Raising the Level of Cultural Consciousness, reflects on the perceptions of students among three realms: pedagogy, community, and equity. Each section begins with summary statistics followed by an analysis of how these findings move forward our understanding of the lived experiences of black students. 


\section{Section I: Demographic Profile and Identity}

Forty-three females and 29 males participated in this study. Forty-six percent of the students $(\mathrm{N}=33)$ were sophomores, and $38 \%(\mathrm{~N}=27)$ were juniors. Seventeen percent $(\mathrm{N}=12)$ were from the senior class. Table 2 further includes information on the communication and learning support services needs of the participants.

Table 2

Frequencies of Student Demographic Profile, (N=72)

\begin{tabular}{lccr}
\hline Characteristic & Category & F & $\%$ \\
\hline Gender & Female & 43 & 59.7 \\
& Male & 29 & 40.3 \\
\hline Grade Level & $10^{\text {th }}$ & 33 & 45.8 \\
& $11^{\text {th }}$ & 27 & 37.5 \\
& $12^{\text {th }}$ & 12 & 16.7 \\
\hline Multiracial & No & 58 & 80.6 \\
& Yes & 14 & 19.4 \\
\hline Hispanic & No & 61 & 84.7 \\
& Yes & 11 & 15.3 \\
\hline RFEP $^{\text {a }}$ & No & 66 & 91.7 \\
& Yes & 6 & 8.3 \\
\hline EL $^{\text {b }}$ & No & 68 & 94.4 \\
& Yes & 4 & 5.6 \\
\hline 504 Plan & No & 66 & 91.7 \\
& Yes & 6 & 8.3 \\
\hline SPED & No & 60 & 83.3 \\
& Yes & 12 & 16.7 \\
\hline
\end{tabular}

a. Reclassified Fluent English Proficient (RFEP)

b. English Learner (EL)

The student participants included 19\% identified as multi-racial and 15\% identified as Hispanic/Latinx. Six students' primary language was not English however; they had been reclassified as fluent in English (RFEP) based on passing the California English 
Language Development Test (CELDT). The CELDT is required for students whose primary language is not English. This state test assesses proficiency in listening, speaking, reading, and writing the English language. An additional four students identified as English Learners (EL), meaning they are still working on becoming proficient in English and were receiving services through an English Language Development (ELD) program at their school site. Students with federally recognized disabilities received academic support through accommodations from a 504 Plan $(n=6)$ in the general education setting or from an individualized education plan (IEP) $(n=12)$ with specially designed instruction (SDI) through the Special Education program.

Thirty-seven percent of the students reported the highest level of education of their parent/guardian was high school (see Table 3). Twenty-eight percent reported the highest level of education of their parent/guardian was a 4-year college degree. The level of parental education has been associated with pursuing post-secondary education opportunities, especially if it is the father who has the highest level of education in the home (Schlechter \& Milevsky, 2010).

Table 3

Frequencies of Parent Educational Attainment, $(N=71)$

\begin{tabular}{lcr}
\hline Parent Education Level & F & $\%$ \\
\hline High School or Equivalent & 26 & $36.62 \%$ \\
4-Year College/University Degree & 20 & $28.17 \%$ \\
Community College/Vocational & 11 & $15.49 \%$ \\
Professional Degree/ Graduate School & 8 & $11.27 \%$ \\
Junior High/Middle & 5 & $7.04 \%$ \\
Elementary & 1 & $1.41 \%$ \\
\hline
\end{tabular}


Students must earn 220 credits to graduate with a diploma from the traditional high school setting in this northern California high school district. For a student to be on track for graduation, they need to earn 60 credits in designated course areas each year. Thus, a sophomore should start the school year with 60 credits, a junior with 120 credits, and a senior would start the year with 180 credits. By the end of the senior year, students on track for graduation would have earned 240 credits. According to the data (see Table 4), 10 students earned less than 60 credits, 25 students were off-track for graduation, and fully sixty-five percent of participants were on track for graduation. Three out of four student participants were not enrolled in an Advanced Placement (AP) course. At the end of the first grading period, $33 \%(n=24)$ of students had at least one " $D$ " and $19 \%(n=14)$ of students had received at least one "F" on their report card signaling a need for early academic intervention for some of the participants.

\section{Table 4}

Frequencies of Academic Progress, $(N=72)$

\begin{tabular}{lccr}
\hline Characteristic & Category & F & $\%$ \\
AP Classes & None & 54 & $75 \%$ \\
& 1 & 10 & $13.89 \%$ \\
2 & 6 & $8.33 \%$ \\
& 3 & 1 & $1.39 \%$ \\
Report Card D's* & 4 & 1 & $1.39 \%$ \\
& None & 39 & $54.17 \%$ \\
& 1 D & 24 & $33.33 \%$ \\
& 2 Ds & 7 & $9.72 \%$ \\
& 3 Ds & 1 & $1.39 \%$ \\
& 4 Ds & 1 & $1.39 \%$ \\
\hline
\end{tabular}


Table 4 (continued).

\begin{tabular}{lccr} 
Report Card F's* & None & 49 & $68.06 \%$ \\
1 F & 14 & $19.44 \%$ \\
2 Fs & 5 & $6.94 \%$ \\
3 Fs & 2 & $2.78 \%$ \\
4 Fs & 1 & $1.39 \%$ \\
& 5 Fs & 0 & $0.00 \%$ \\
Credits Earned & 6 Fs & 1 & $1.39 \%$ \\
& $60-119$ & 35 & $48.61 \%$ \\
& $120-179$ & 17 & $23.61 \%$ \\
\hline \multirow{2}{*}{ Graduation Progress } & $180-240$ & 10 & $13.89 \%$ \\
& $0-59$ & 10 & $13.89 \%$ \\
\hline
\end{tabular}

Note: Ds and Fs based on $1^{\text {st }}$ marking period grades for Fall, 2018. 


\section{Dropout Tendencies}

Student engagement embodies feelings of belonging and connectedness to school. It is associated with a number of variables including academic success, good attendance, and healthy relationships with teachers and peers. The absences of these factors increases students' propensity to leave high school without a diploma. Nasir, McLaughlin, \& Jones (2009) operationalized the connection as "solid relationships with teachers and peers" and disconnected as students who felt they could risk for dropping out (p. 81). Several questions on the survey were asked to explore school dropout tendencies students held in relation to academic failure, attendance, and discipline. Christle et al. (2005) found “(a)cademic failure, exclusionary discipline practices, and dropout as key elements in a "school to prison pipeline" (p. 69). Thus, to further understand the engagement level of students, it is necessary to see how these variables impact their presence in school.

Academic failure. Eleven items were asked in relation to students' propensity to leave school. In regards to academic failure (see Figure 6), questions pertaining to school challenges and courses repeated for credit were asked. Students who reported considering dropping out gave the following reasons: not liking the school (51\%), not liking the teachers (48\%), and not seeing the value in the work being asked to complete (42\%). All 72 student participants responded to the course repeated question (see Figure 7). Thirty-eight percent $(n=27)$ respondents stated they had repeated a course for credit and $26 \%(n=19)$ suspected they will be repeating a course taken during the current school year. 


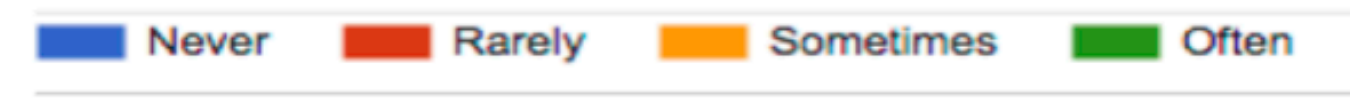

\section{0}

40

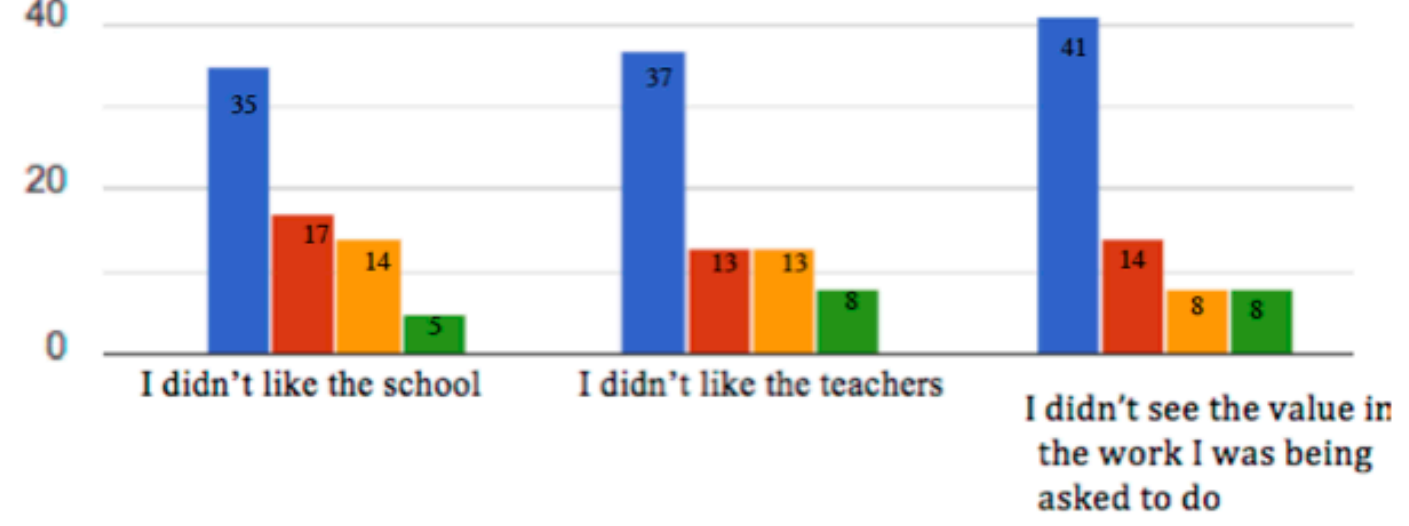

Figure 6. Self-reported school challenges.

Nearly $30 \%$ of black students surveyed believed they will have to repeat a course before the first grading period ended (see Figure 7) reinforcing the need for schools to have early warning systems in place to support students who are struggling. The district under study is in the elementary stages of developing district wide protocols through an accountable school-based multidisciplinary group serving as the gatekeeper for intervention support. A recent audit (11/2015) by the California Department of Education (CDE) revealed the study district was not providing enough interventions to support students to stay in their least restrictive setting as much as possible before referring students for a special education assessment. In Spring 2016 the district hired a Multi-Tiered Systems of Support (MTSS) Coordinator to develop a pre-referral process and to set in motion a comprehensive system that encompasses Response to Intervention (RTI) practices. California Department of Education defines Multi-Tiered 
Systems of Support (MTSS) as, "an integrated, comprehensive framework that focuses on [Common Core State Standards (CCSS)], core instruction, differentiated learning, student-centered learning, individualized student needs, and the alignment of systems necessary for all students' academic, behavioral, and social success (2016). The component of the MTSS process that the district is beginning to implement for the corrective action is Instructional Support Teams (IST) at each school site to change the district's culture of premature special education assessment.

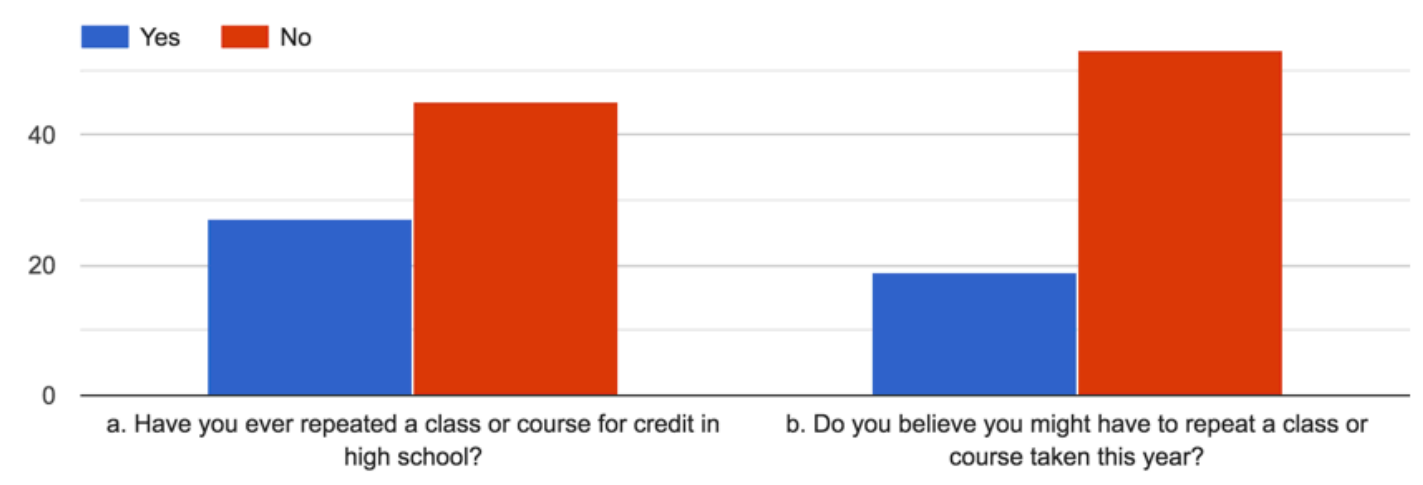

Figure 7. Course repeated for credit.

Students who have to repeat courses often fall behind their peers and risk not graduating on time. They often have to take full course loads their senior year or have to remain in school for a $5^{\text {th }}$ year. Based on the number of credits that may be missing, will determine whether remaining in the traditional setting is feasible or an alternative school enrollment is needed to recover the lost credits to earn their degree. In turn this may result in not graduating from the school the student attended the majority of their high school career causing a sense of alienation or sentimental loss. The goal of IST is to catch students 
early on who are struggling and to work with them and their teacher on instructional practices that help the student meet with success.

Attendance. The majority (88\%) of the 72 student participants indicated they have been 5-10 minutes tardy to class in their high school career (see Figure 8). Forty-seven percent of students indicated they had skipped school, faked an illness to stay home, or deliberately came to school late because of disinterest in school (see Figure 8). Additionally, $40 \%$ of the respondents reported some level of (rarely, sometimes, often) truancy (habitual absence from school/ skipping school or repeated absences from class). The attending habits findings are important for educators to be aware of because anytime a student does not report to class on time, there is a critical need to gain an understanding of why or what is occurring in the environment serving to push them away. According to Infinite Campus, Inc. (2018), the management system utilized for attendance and grades, in the first month and a half of school (attendance collected 8/14/18 through 9/28/18) student participants' period absences (excused or unexcused) ranged from 0 to 122 and tardies ranged from 0 to 36 . Of the 689 period absences shared between the 72 participants, nearly half $(\mathrm{n}=343)$ were considered excused due to illness or other excused (OTE) reasons. Eleven students made up missed days by attending Saturday School Attendance Recovery. There were 521 tardies from the first day of school to the end of the data collection window. However, less than two percent $(\mathrm{n}=10)$ of those tardies had been considered excused. Only eight (11\%) student respondents had zero period absences and zero tardies for the start of the school year. 


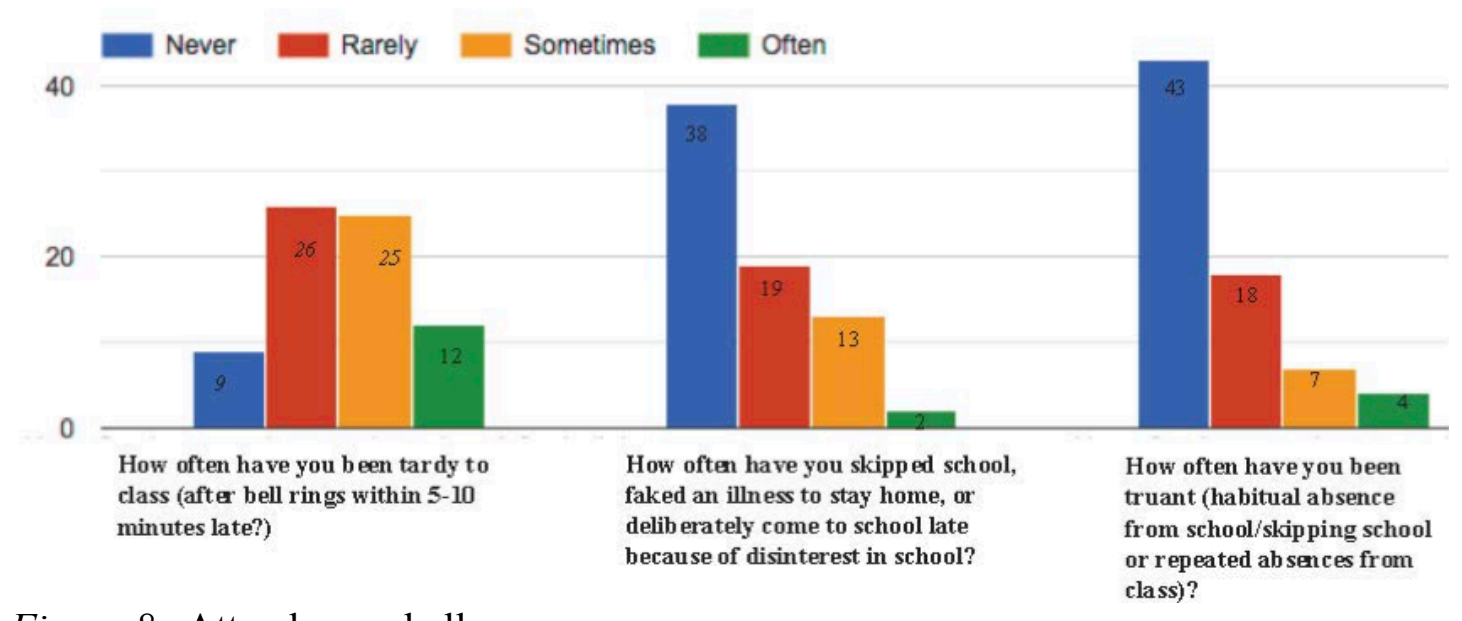

Figure 8. Attendance challenges.

According to the California Department of Education (CDE) (2018 chronic absenteeism is defined as missing $10 \%$ or more of school in an academic year both excused and unexcused absences. Most of the students who took part in the study had six periods a day. Students who had 18 period absences or more $(15 \%, n=11)$ met the threshold of being chronically absent during the window the survey was administered. In a full 180 day school year missing 18 days of school equates to be chronically absent for the year. One student with 122 period absences ( $\sim 20$ days) exceeded the yearly marker.

Discipline. The majority $(84.7 \%)$ of student participants did not have a discipline referral that resulted in being suspended from school (see Figure 9). Only $12.5 \%(n=9)$ noted having received a suspension once and $2.7 \%(n=2)$ indicated having received more than one suspension during their high school career. One student responded that they had been referred for expulsion. According to Infinite Campus, Inc. (2018), during the data collection window, five students had received one discipline related referral. The majority of students $(65 \%, n=47)$ did not have a past history of behavior referrals. However, one student had had 21 office referrals. Discipline action involving removal 


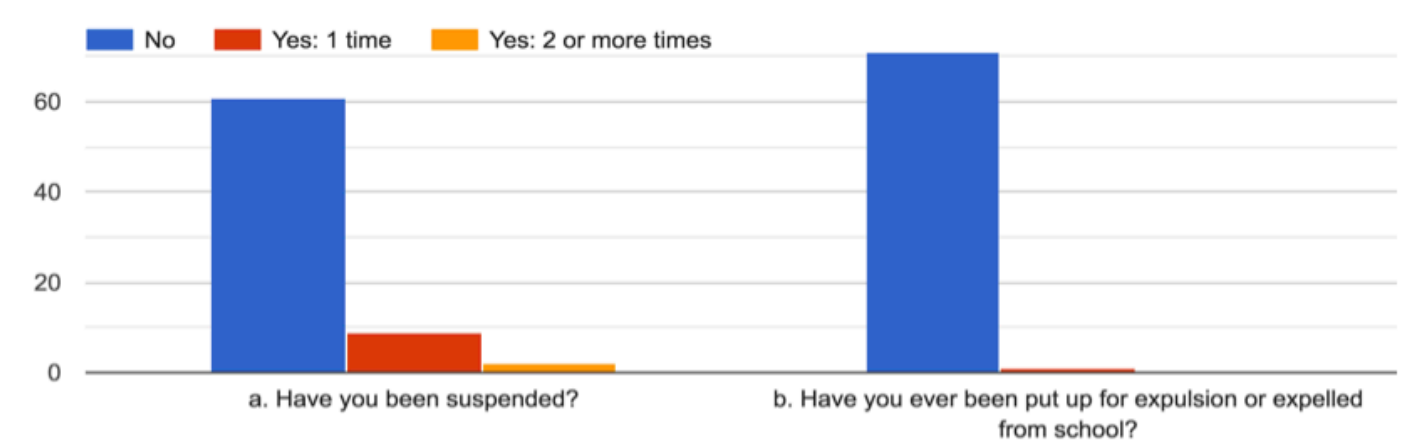

Figure 9. Suspension and expulsion record.

from school appears to only be a concern for a select few of the students surveyed indicating the school-to-prison pipeline is not a major concern in the schooling experiences of this group of students.

\section{Identity}

As discussed in depth in Chapter 2, Black students racial identity is historically rooted in color complexities. Color complexity is an important element in understanding how black youth see themselves as well as understanding how others view them (Birts, 2017). The assertion is the lighter the skin tone the better chance a black person will have in being accepted in arenas that view blackness as inferior. The latent attitudes of colorism intersect with covert and overt racial microaggressions encountered through physical interactions with others. With respect to skin tone, the majority $(59.2 \%)$ of the students identified as having a medium complexion. Eleven males and 12 females (32.4\%) self reported having a dark skin complexion and one male and five females reported having a light skin complexion $(8.5 \%)$. Students provide examples of how they perceive skin tone matters in school:

I felt like just because I had a darker complexion than other people that I was considered "ugly or too dark". It made me seem unwanted in the classroom. I just ignored it and never addressed it. 
They think its funny to have very dark skin and full lips. I'm relatively light but my friends who are dark get teased sometimes.

Students perceived that darker skinned students fared worse than lighter skinned students in the classroom. Although students perceived a difference in treatment based on skin tone in the classroom, colorism did not appear to impede the academic performance of darker skinned students. Regarding academic performance outcomes, darker skinned students actually had a higher average GPA than the lighter and medium skin-toned students as noted in Table 5 .

Table 5

Skin Tone and Grade Point Average (GPA), N=70

Skin Tone $\quad$ GPA
Light
2.18

Medium

Dark

A one-way between groups ANOVA was performed to compare the impact of skin tone on grade point average. Participants were divided into three groups based upon their skin tone (Group 1: light; Group 2: medium; Group 3: dark). The outcome variable was found to be of unequal distribution so a harmonic mean of the group sizes was used. Although there were no statistically significant differences in grade point average 
between the three groups means as determined by one-way ANOVA $(\mathrm{F}(2,67)=.882, \mathrm{p}$ $=.419$ ), a caveat is that the findings may be impacted by the fact that most students reported being the same skin tone. It may be likely that skin tone still affects these outcomes but due to lack of variability in the data it was not captured. With regards to a halo effect, students perceived skin tone mattered in classroom treatment.

Color complexities not only embodies skin tone but also the maintenance and quality of hair. The ideology of good hair or bad hair has a long standing presence in the black community to the point where a coding system of natural hair curl pattern types was created to distinguish between the quality of strands ranging from $3 \mathrm{~A}$ loose curl to $4 \mathrm{C}$ the most kinky type of curl (Anonymous, n.d.). Some blacks with lighter skin tones or those who may be mixed with European descent often have what is referred to as good hair because it is easier to manage without the need for chemical processing treatments to relax or loosen the curls. Like skin color, the straighter the hair strands, the greater the chance of being accepted in spaces that view Afrocentric hair styles as inferior. School handbook rules across this nation have led to the targeting and reprimanding black students because of their natural hairstyle choices (e.g. afro, braids, locs). The following visual (see Figure 10) displays the results for hairstyle preference. Students wear a variety of hairstyles typically common in the Black or African American community. Most students indicated they tend to wear their hair in a natural state (e.g. afro, braids, locks, twists) indicating a preference for a more Afrocentric affinity. Because they are less likely to display hairstyles that take on a more European texture, it may increase their 
tendency to be discriminated against by their teachers and peers.

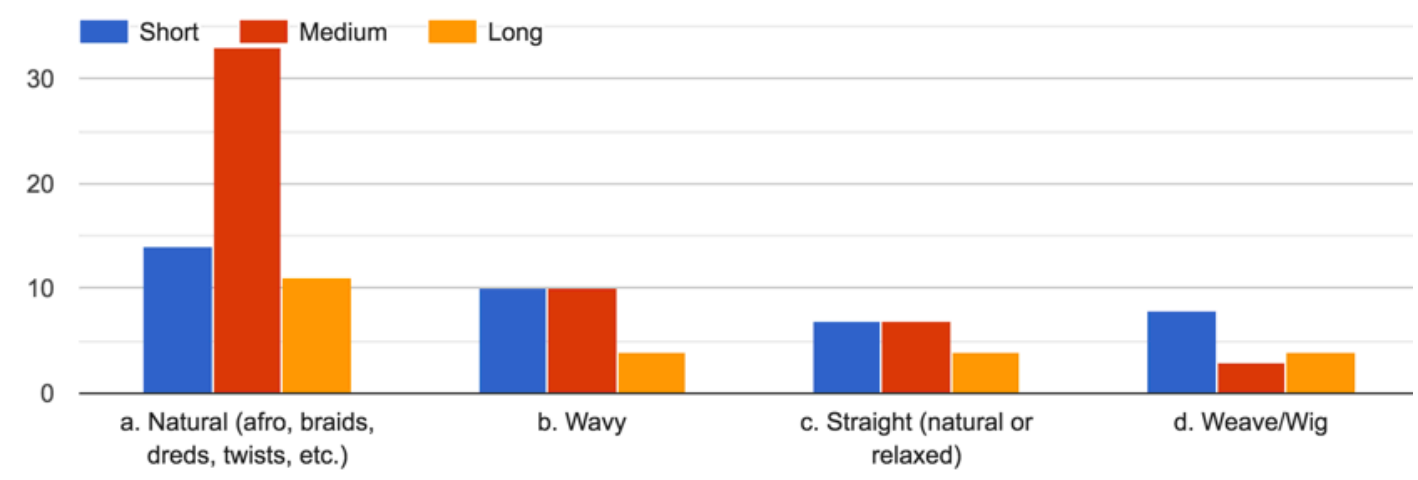

Figure 10. Hairstyle preferences.

With respect to measures on social identity, themes emerged to include academic success and culture, insecurities, and connection to adults and peers.

Academic success and culture. Many students responded that they were proud of their culture, their hair and their academic success. Students reported positive selfimages about their racial identity and expressed self-love for their hair, skin color, and being of multi-heritage. Oftentimes, students grouped seemingly separate categories together, demonstrating the fluidity of racial identity for students. As an example, consider the following:

Knowing i'm doing well in class and taking pride in my hair and ethnic background.

However, not all comments were positive. Several students indicated that they realize that greater society does not appreciate and value their blackness. For example, consider the following: 
Knowing who I am and what I stand for. I am proud of my ethnic backgrounds and I want justice/peace for both of them. I love my hair and when people praise me for showing it off. I think my skin is very pretty but it is a shame others don't.

Many of the comments (see Appendix N) about feeling good centered on having a strong racial/ethnic identity along with caring and supportive family and friends. Many students also expressed making good grades and being acknowledged or praised for their efforts.

Insecurities. Thirty-six insecurities were expressed by students (see Appendix O). The five main themes included: academic failure, alienation, criminalization, racial identity, and racism. Consider the following student comments which relates to feelings of exclusion:

Sometimes when I am one of, or the only, African American students in my class I am very aware of that.

The student recognizes that they serve as the only black face in the classroom that can put a lot of pressure on them to constantly ward off negative stereotypes believed about black people. Also, they have to serve as the voice designated for the whole black community. The student below not only fears being ostracized by peers because of race but also because of preference:

Being judged I feel if I was born in a different ethnic group I'd be treated differently because I'm not only black but I'm also gay and Ive [sic] been told that those are 2 taboos.

The student sees himself affected by a double negative of identities in the eyes of a larger society. He is black fighting against white supremacy and homosexual fighting 
against a heterosexual normative.

Several students expressed this theme of feeling very aware of their race. Others expressed feeling isolated by their racial identity. Many students expressed a desire to feel connected with others who share their racial background. Others expressed problems they felt were brought on by their racial identity. As an example, consider the following:

They always follow me $\mathrm{n}$ [sic] my brother around campus after school and just watch us the whole time (kinda find it disturbing).

Black students are often perceived to be a threat. They are stereotyped as untrustworthy and thus they are seen to be in need of constant supervision. This racial profiling heightens their chance of experiencing discipline. Nasir et al., (2009) noted a type of black racial identity in school is street savvy. A black student perceived as having a street savvy persona is often the targets of this type of policing in school and viewed as a thug because of their style of dress which may include wearing sagging pants, oversized tee-shirts, and/or using Black English/ Ebonics. Biases based on racial identity impacts various other aspects of the schooling experience as noted by the three students statements:

I used to be very insecure about my skin and hair, people always made fun of it and i've always felt excluded for it.

People think that I can't get good grades because of my race; they think i'm a bad student.

Modern day science has shared there are more differences within groups than across them. Black or African Americans phenotypic characteristics are often treated as 
counter culture to what society values as beautiful and thus students experience negative comments about their skin color and hairstyle choices. The perception students hold about colorism further adds an additional layer of disadvantage for the darker-skinned student in the learning environment. Not only does race impress upon the physical characteristics but also impede students who hold other social identities that are often seen as counter to the status quo or norm. The young male stated the struggle he faces with both racism and sexual orientation. White supremacy have long used race to downgrade the intellectual abilities of Blacks in the United States. The assumption that Blacks are not as smart as their white counterparts or they are automatically distrusted and deemed to be an outcast in the classroom is echoed in the third student's comment.

Subjection to daily racism and racist behaviors with little regard to the damaging effects it has on the learning environment were noted in the comments below:

One of my biggest insecurities is how little the racial problem is adressed [sic]. The amount of students who say the "N word" is disparaging.

not rally [sic] just racist comments around school

Race and racism are rarely discussed in many schools because of the contentious nature that surrounds it. Racism has been deemed as an individual characteristic, which places people in a combative, defensive mode impeding progress for change rather than approaching it as a system that weakens the overall core of the school body. Jones (2018) provided a restructured way of defining racism:

Racism is a system of structuring opportunity and assigning value based on the social interpretation of how one looks (which is what we call "race"), that unfairly disadvantages some individuals and communities, unfairly advantages other individuals and communities, and saps the strength of the 
whole society through the waste of human resources. (p. 231)

Racism approached as a system does not divide and target individuals into groups of who is racist and who is not but allows all people of the system to become aware of and recognize the ill exists through data and discussion in a safe space thereby providing a segue for reflective practice leading to transformational changes in programming and policy.

More than half, $54.9 \%$ of students indicated they believed people at their school treated other people differently based on skin color. As researchers have documented "light skin tone constitutes a form of social capital" (Thompson \& McDonald, 2016, p. 93). Students who identified as having a medium skin tone were more likely $(62.8 \%)$ than any other group to believe that people at their school treated other people based on the color of their skin followed by darker skin students (43.5\%). Light skinned students were least likely $(33.3 \%)$ to perceive skin color was a factor in how people treat others supporting the Halo Effect (Hunter, 2016) that lighter skin student perceive receiving better treatment than their darker skinned peers.

According to Thompson \& McDonald (2016), "the color line refers to the social construction of racial boundaries defined chiefly by skin tone and hair texture" (p. 91). In their study, findings emphasized the need to include skin tone as an ascribed socially constructed status characteristic to be included as a vital part of the diversity conversation due to it being one of the most observable characteristics used to define and evaluate differences (p. 107). The color line also appeared to be a factor based on how students responded to feeling like they were judged based on skin color and/or hair style in the 
classroom. Twenty-one respondents indicated yes with $24 \%$ by teachers and $43 \%$ from peers. Thirty-two students provided open-ended responses (see Appendix M) about feeling judged based on skin color and hairstyle. Three dominating themes emerged were: enduring negative comments of beauty/body images, low expectations, racial stereotyping. Negative comments related to beauty/body images included:

[I] felt judged by my hair [I] have a Afro and [I] dont [sic] like my curly natural hair sometimes because kids can be means and say its ugly or your big ugly hair is in the way.

I get weird looks because my hair type and skin tone don't match. Sometimes people touch my hair without asking even if I tell them to ask first.

Although some students expressed a positive self-image concerning their racial identity in the survey section on what makes them feel good, others did not share that outlook. External reactions toward their blackness, especially as it relates to hair and skin color, is often criticized and scrutinized by their peers who attempt to dehumanize and objectify them. Non-black peers see violations of personal space boundaries as acceptable behavior toward black students.

Student respondents noted feeling objectified from having low expectations assumed of them by others as stated below:

They told me when they first seen me, they didn't think I cared about school \& grades.

[B]ecause [I] was black she did not think [I] wanted education

Black adolescents are placed in positions to prove themselves as serious-minded students unlike their white counterparts who are generally assumed to be apt to 
wanting to learn and academically succeed in class. The presence of racial stereotyping in sports included:

My [f]riends picked me to be on there team because they think all black people are good at sports.

Its just jokes[,] like for example when we did the swimming unit, some of my peers wondered if I could swim.

Students express a sense that they are constantly viewed through the racial tokenism lens and treated as different or viewed as an other. Stereotypical depictions are often fostered by social media such as being seen as a Stephen Curry or LeBron James super athlete in basketball. However, black students are questioned in their ability to perform other sports generally not seen as commonly participated in such as swimming. Students used coping strategies such as self-talk to address and deflect the negative comments and behaviors.

Connection to adults and peers. Education has been described as a "socially engaged process" (Rose, Joe, Shields, \& Caldwell, 2014, p. 57). The need for a caring and nurturing environment includes having healthy and positive relationships with adults and peers in the school. For Black or African American students, race plays a major role in how they identify socially and integrate in the school setting. Birts' (2017) Black/ African American Racial Tapestry identified four key elements in how racial identity is formulated. Particularly, the fourth thread looked at the impact of how interpersonal school relationships and close associations may lead to race-related negative interactions as she noted: 
Interpersonal relationships consist of youth strong or close connections or acquaintances with individuals in their environment that trigger the onset of racerelated episodes (e.g. negative stereotypes or marginalization in the classroom). (p. 116)

Despite the level of racism students face in school, the majority $(91.5 \%)$ of the student participants indicated they have friends who belong to racial groups other than their own racial group (see Figure 11). This is important data because black students comprise a small percentage of the total district student body making it a physical challenge for mechanical solidary to occur. Although students may experience implicit biases and race-based microaggressions, they still are able to develop allies or friendships with other ethnicities. Nearly all $(n=71)$ respondents indicated they had friends of different ethnic and racial backgrounds as indicated in Figure 11.

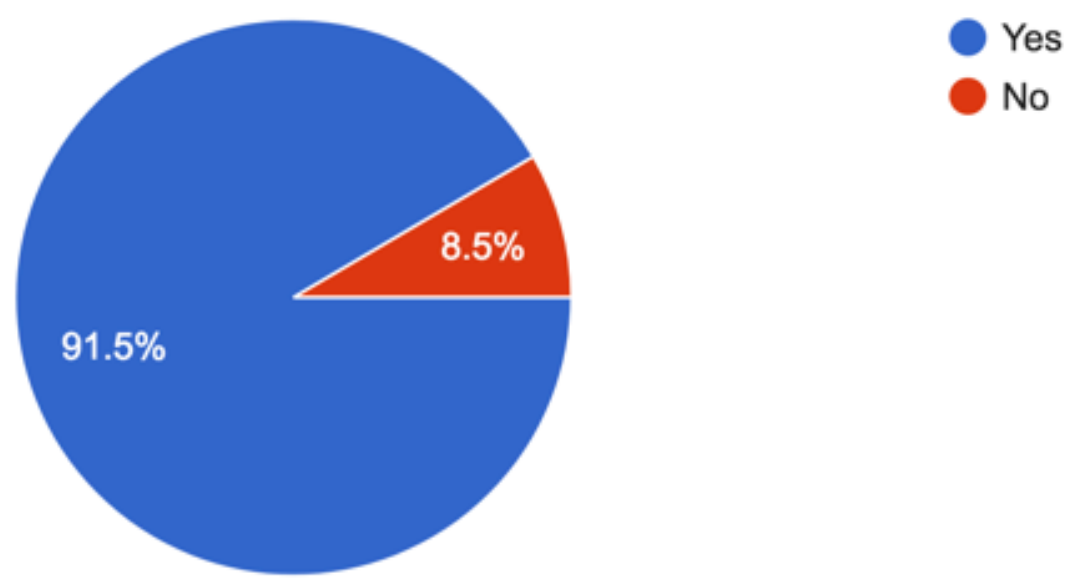

Figure 11. Friendships outside of race/ ethnic group.

Students were asked to identify the top school staff members who they felt they could talk to for emotional and/or academic encouragement (see Figure 12). Of the 71 student responses, $20 \%(n=14)$ of students indicated they did not have an adult in their school 
that they felt they could trust to share personal information with or served as a motivator during the previous 2017-2018 school year. However, many students had at least one teacher who they had a trusting relationship with in the previous school year. Students also identified coaches and parent/community specialists as people they could turn to. None of the students identified custodial staff or librarians as academic motivators or confidants.

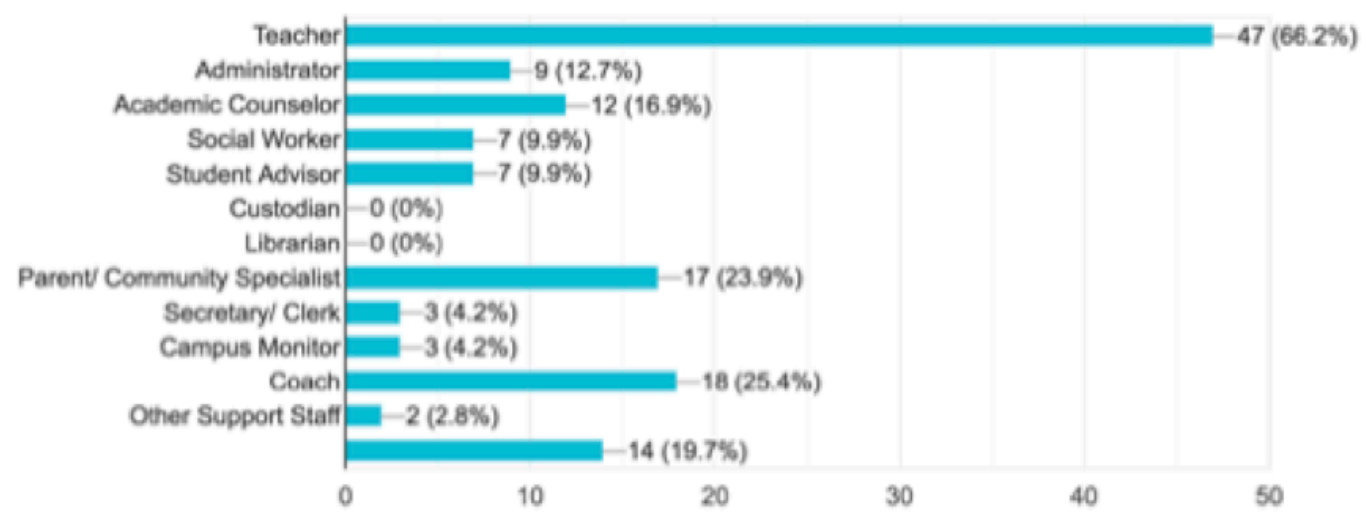

Figure 12. Trusting relationships with staff, by type.

\section{Section II: Racial Microaggressions}

RQ1: to what extent do Black and/or African American 10th-12th grade students experience racially-based microaggressions? what types of racially-based microaggressions do they experience? from whom do they experience these raciallybased microaggressions? The most frequent racial microaggressions reported were microassaults ( $\mathrm{n}=40)$ and microinsults $(\mathrm{n}=38)$. Microinvalidations $(\mathrm{n}=29)$ were less reported. In total there were 107 student reports of these three types of microaggressions. Students often experienced more than one type of microaggression on a regular basis and generally, microassaults were apart of that combination. 
microinsults. Students report the following microinsults: having their name mispronounced, experiencing low expectations by others, being singled out in the classroom, and negative comments about immigrants (see Figure 13).

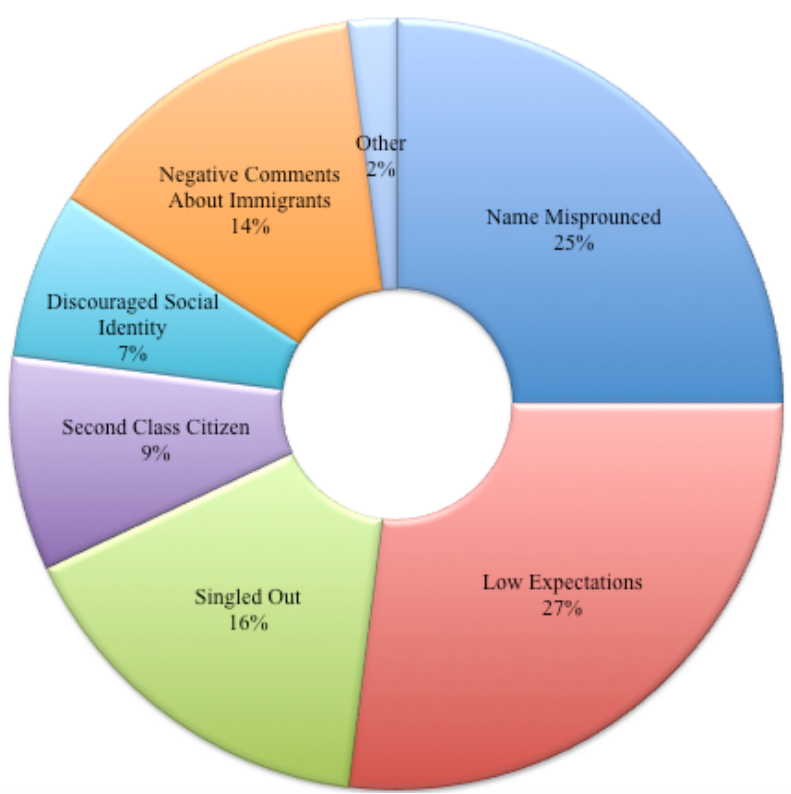

Figure 13. Microinsults open-ended response types, $(\mathrm{N}=44)$.

In their written comments (see Appendix P), students provided a number of examples of having their names mispronounced. The following comment is indicative of what students report:

[W]hen I first came here my name was mispronounced thousands of times, sometimes [I] would tell them to call me any way they like.

Other comments support the work of Kohli \& Solórzano (2012), who demonstrated that educators and peers often purposely mispronounce the names black students as a way to discount their existence. "Peers sometimes mispronounce my name on purpose." These microinsults can have traumatizing effects on students. 
The presence of low expectations continue to fester. Students shared:

My math teacher last year automatically thought [I] would sit in the very back of the class where the students who didn't do anything productive with the class time sat. When my first test was graded she was in disbelief that [I] produced work that was on the test and was hesitant to give it back to me due to it. So [I] took it from her hand.

I felt like my teacher didn't expect much of me because I was the only black person in the class and once I started not doing great she seems more validated as well as my classmates.

Research has shown that predominantly white teachers assume that black students do not value education and that they are unable or unwilling to produce high quality work. These teacher mindsets act as barriers to black students' academic success. Singled out was also a highly experienced microinsult by students as they stated: It is weird talking about slves [sic] in the class because everyone looks at you Anytime the subject of black lives matter or our history of African Americans is brought up, I get starred [sic] at by both the teacher and my peers and often when we talk about it, my voice is shut out.

Like when we talk about black people stuff, everybodys [sic] always asking me stuff, and looking at me, and I get it, but its [sic] just uncomfortable.

Black or African American students often find themselves having to serve as the resident spokesperson for all black related issues regardless if it is a topic they have familiarity with or not. The assumption that students must be all knowing on topics pertaining to Black peoples or that all black people are descendants of slaves is manifested by both teachers and peers.

The sentiment that blacks who have recently relocated to the United States from the continent of Africa are uncivilized savages who lived in the jungle. Negative comments 
about immigrants noted below include:

I'm African so people say stuff to me like how was the jungle or Wakanda or just make "African" gestures most of the places they ask about i've never been there or most of the things they've asked me if i've seen like lions, [I] haven't and it's mostly students.

Often such inaccuracies are sensationalized and commercialized by Hollywood and social media as in found in books such as the Heart of Darkness written by Joseph Conrad in 1899 that was based on the Congo area of Africa where black inhabitants were being hunted like animals by white men. A recent movie, Black Panther, released in 2018 written by Ryan Coogler and Joe Robert Cole also portrayed negative images about the African continent. In the movie, Wakanda is a fictional nation on the continent of Africa that is filled with a rare and highly valued element that has high-tech capabilities. The black inhabitants are referred to as savages by whites who seek to gain control of the element.

According to students who have encountered racialized microinsults, the majority in this category are done by both teachers and peers--especially with respect to the mispronunciation of names (see Figure 14).

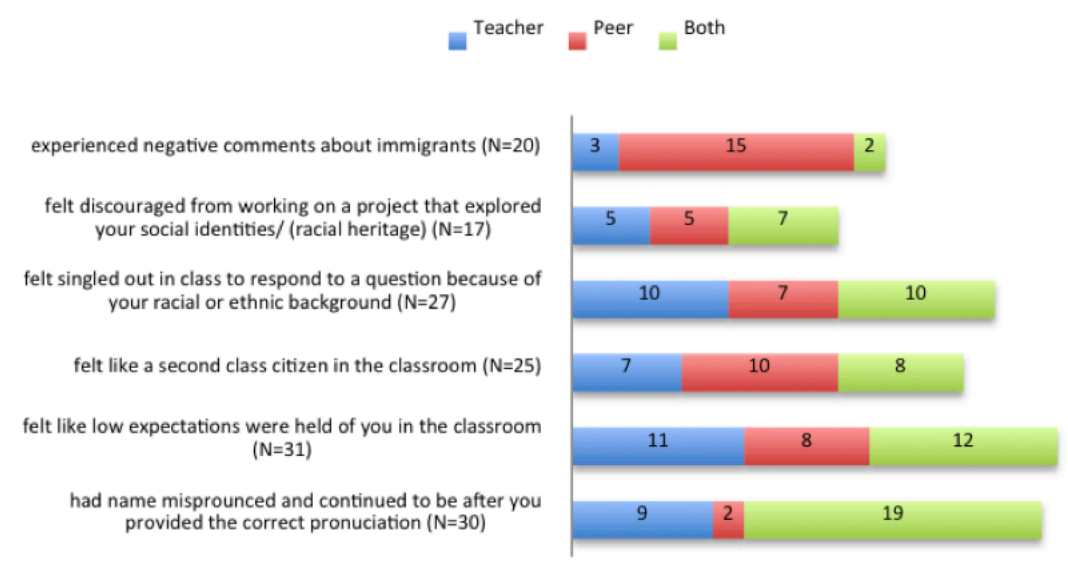

Figure 14. Microinsults received from teachers and peers. 
Students expressed teachers held low expectations of them and singled them out in class. With respect to peers, they often experienced negative comments about immigrants and made to feel like they were second-class citizens to them in the classroom.

microassaults. Seventy-six percent of the microassaults comments (see Appendix Q) by students were in relation to being called a derogatory term/ racial slur and experiencing inappropriate racial/ethnic jokes in the classroom as noted by Figure 15.

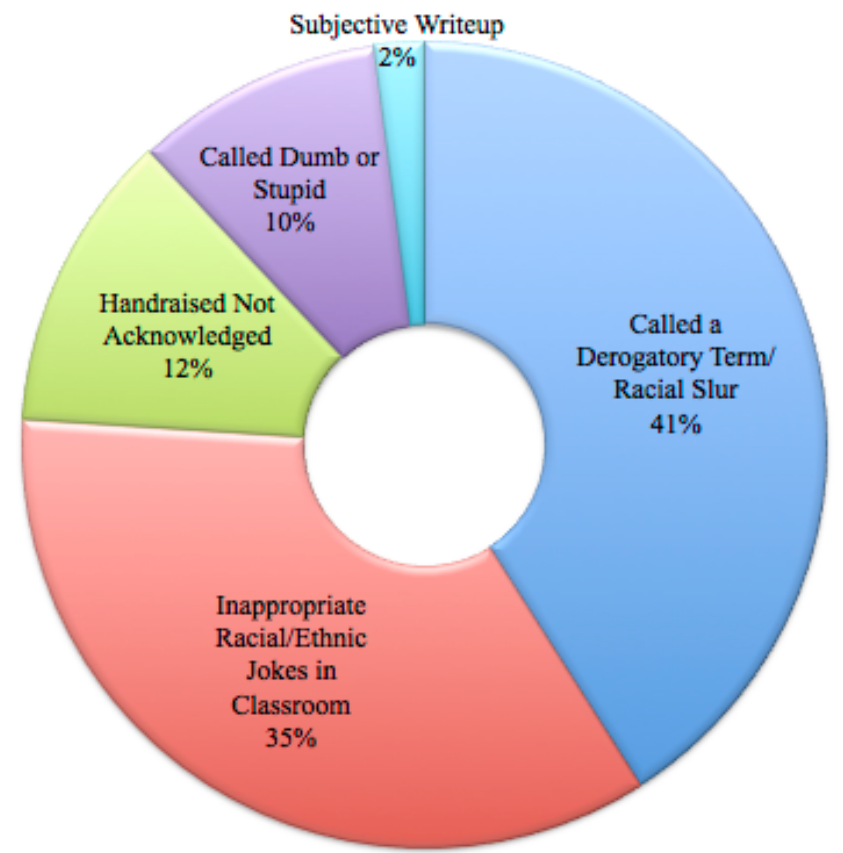

Figure 15. Microassaults open-ended response types, $(\mathrm{N}=51)$.

Several students noted being blatantly called the $\mathrm{N}$-word by peers and other racial slurs on a regular basis to include:

"Nigger" was written on a desk, a baby dolls head was snapped and the caption was, "a typical day in the South" The N word is constantly utilized.

Unfortunately, the use of the $\mathrm{N}$-word as a derogatory term towards blacks has had a long existence in the history of this country since the institution of slavery. Not only is it an ill of the South's past but also a present day reality for student participants attending 
high school in a northern California school district. Reverend Hosea Easton, an

abolitionist and a multi-racial man of African ancestry captured it best in his 1837 book,

"Treatise on the Intellectual Character, and the Civil and Political Condition of the

Colored People of the United States," prior to his death:

Negro or nigger, is an approbrious [sic] term, employed to impose contempt upon them as an inferior race, and also to express their deformity of person. Nigger lips, nigger shins, and nigger heels, are phrases universally common among the juvenile class of society, and full well understood by them; they are early learned to think of these expressions, as they are intended to apply to colored people, and as being expressive or descriptive of the odious qualities of their mind and body... it flows from the fountain of purpose to injure...sown in the tender soil of youthful minds, and there cultivated by the hand of a corrupt immoral policy. ( $\mathrm{p}$. 40)

Easton (1837) further noted how schools promoted racialized stereotypical tactics during adolescent years as a way of encouraging white youth to be successful instead of being "ignorant as a nigger." Also, to instill a segregated mindset and practice in the classroom, teachers would designate a seating area known as the "nigger-seat" or threaten the white student of "being made to sit with the niggers" (p. 41). Although modern day teachers may not be as explicit with frequently using the "N-word" in the classroom, the adage of separating or encouraging similar exclusionary practices continue to manifest in a number of ways from seating arrangements to discipline referrals.

From the narratives of the youth in this study, it appears that when an overt, derogatory remark from peer-to-peer is made, many educators often turn the other cheek instead of correcting the behavior. Inappropriate racial/ethnic jokes noted in the classroom included the following:

There was a time were [sic] the "_" teacher was talking about slavery and racism. and when he talked about how whites and blacks couldn't be in the same 
schools or bathrooms and stuff like that a student behind me leaned to his friend and tried to whisper- "No niggas allowed"

Me and some former friends (also [A]frican [A]merican) were a few minutes late to class and the teacher said," oh looks like the three black girls are late" and that made me really upset.

Not only are peers taking part in race-based jokes but teachers as well as noted by the second comment with the teacher deliberately race shaming the students entering class late. Experiencing blatant racist jokes is an ongoing concern for students who find themselves targeted by peers who persist in continuing to uphold longstanding historical stereotypes of black people. Examples shared by study participants include:

Students always have the reaction of, "You have Ebola! Don't touch me," when told that I went to Africa.

My peers always say the various $\mathrm{N}$ words that are used towards African Americans. The [sic] always ask or say that black people like watermelon grape soda and fried chicken to me or any other black student.

The student comments speak to the continued perception that Africa is a continent plagued with disease and destitute. Images of racist caricatures comes to mind with stereotypes of African Americans depicted as child-like and unkempt eating a diet consisting of fried chicken and watermelon. Also, echoed is the sentiment that people with dark skin are somehow viewed as comical and deserving recipients of nonsensical jokes. Unfortunately these stereotypes have been recycled for generations in this country. Nearly 200 years after the publication of Easton's (1837) book, the quote holds true and resonates with the experiences black students encounter providing a strong indication that much has not changed in the $21^{\text {st }}$ century concerning topics of race and racism in this 
nation. Black youth are still being oppressed with persistent, overt racial discrimination in schools initiated by both teachers and peers.

The majority of microassaults were received from peers. Peers were more than twice as likely than teachers to commit this type of offensive behavior. Particularly, most noted being called a derogatory term or racial slur (e.g. N-word) and experiencing inappropriate racist jokes made by peers in class (see Figure 16).

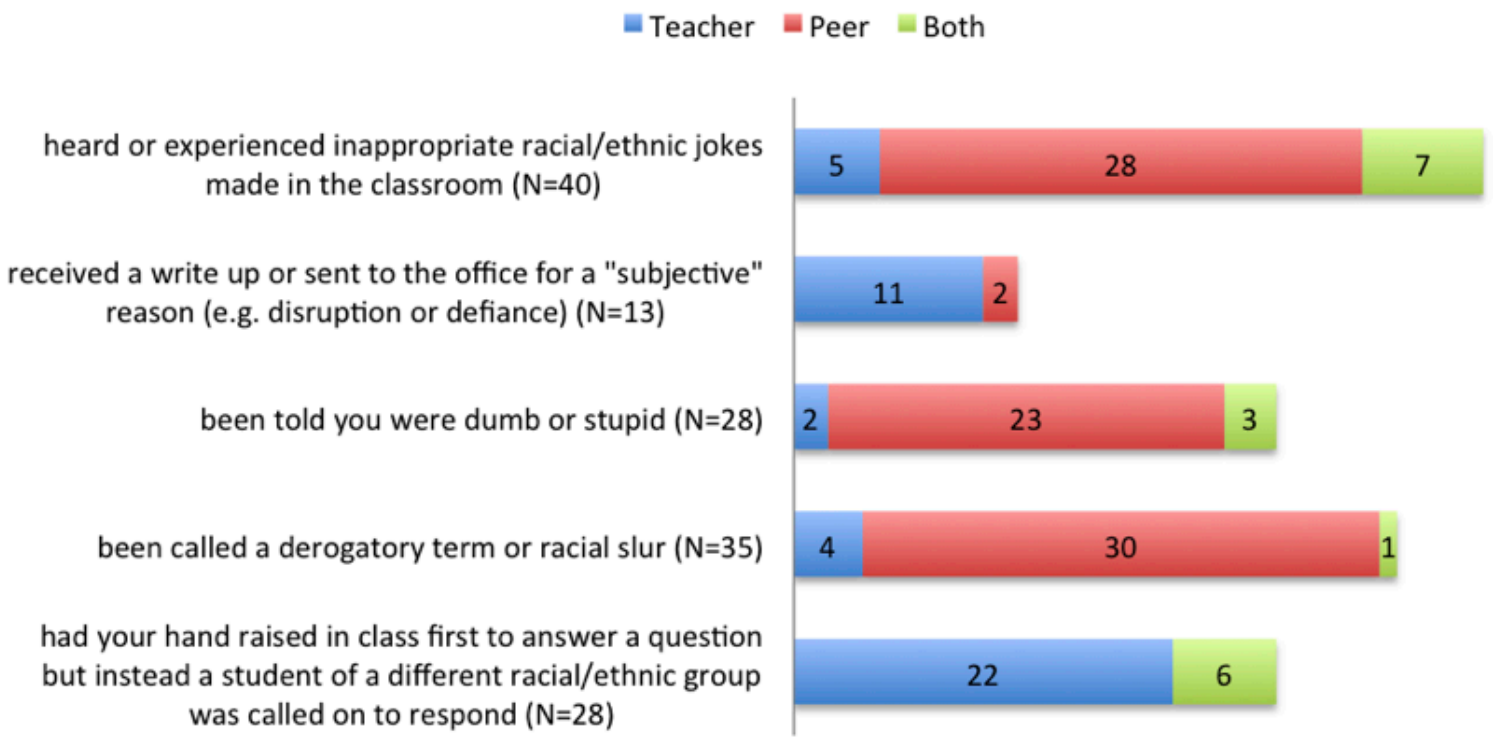

Figure 16. Microassaults received from teachers and peers.

Several students noted they were overlooked by their teachers while attempting to participate when raising their hands to answer a question as noted by these student responses:

One time when [I] raised my hand [I] had it up for about 30-45 seconds and than another student raised their hand and the teacher called them instantly after ive [sic] been waiting for almost 1 minute.

[W]hen [I] was in class that used to happen to me a lot [I] raise my hand first and they go too [sic] the white kid.

The comments speak to the feeling of being treated as if you are invisible and that your voice does not matter academically in the educational arena when you are a black 
student. Black and African American students are often treated as if they are dumb or stupid by both teacher and peers as noted by these two comments:

One of my teachers on the first day of school said they didnt [sic] have time to teach stupid kids or something like that and they looked directly at me.

Students have literally said to my face "What are you doing in this math class, you're black." Insinuating that I'm dumb because I'm black

Again, the notion of being less than in ability and capacity is echoed through the comments expressed by the students experiences in the classroom setting. Also, a few students indicated receiving subjective discipline write-ups by teachers as noted by this statement:

[T]he teacher would always write me and my friend up for "being disruptive" when we didnt [sic] sit near each other, never talked to each other in class, and when other students were being loud and running around the teacher wouldn't do anything. [M]e and my friend were the only black people in the class. [A]lso when my mom would email the teacher about it the teacher would never respond.

The comment speaks to the hyper-visibility experienced by black students. Often treated as untrustworthy and perceived as a threat fueling the image of a menace to society mentality. The statement shows a quickness of some teachers who with little evidence to justify their actions are frank to chastise a black child as a result of their negative personally held biases towards them. Such inconsistent disciplinary practices seek to bring division among students creating a hostile learning environment. The statement further speaks to the concern of the demission of parents of black students who seek to take an active stance in their child's performance yet, are not acknowledged and disrespected by the teacher. 
microinvalidations. Student responses (see Appendix R) were nearly equally divided up among the four areas assessed for microinvalidations as represented by Figure 17.

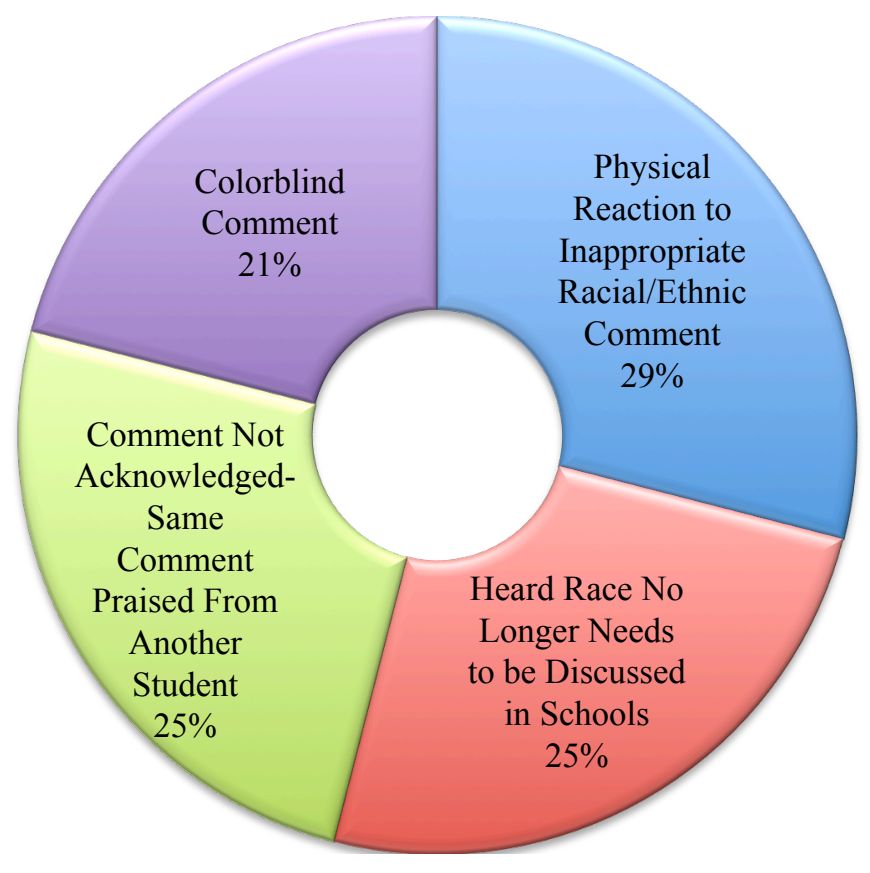

Figure 17. Microinvalidations open-ended response types, $(\mathrm{N}=24)$.

With respect to having a physical reaction to an inappropriate racial/ ethnic comment students stated:

Anytime someone would mention the $\mathrm{N}$ word and their interpretation of it, I would get upset because they never knew what they were talking about and assumed I was "over-exaggerating"

I have felt underestimated by a teacher junior year and [I] felt she treated me differently. There was also this incident where students had to do satire comedy and my teacher played the role of the white supremacist and there was a black man being shot on the screen and my class thought it would be funny to laugh. Where being the only black girl in the class did not find it funny at all.

I have had peers and once a teacher make racial jokes and slurs that made me cry and gave me a headache. 
Feeling of nausea, upset, and being brought to tears by the actions of peers and teachers are common reactionary themes experienced by students in this study. The teacher, who is bound by ethical and moral standards of professionalism playing the role of a white supremacist shows total disregard of how such negative behavior impacts all of their students and reinforces segregation ideology of fear and servitude in this nation.

Microinvalidations include actions and behaviors that devalue the thoughts and opinions of a person. Carter Andrews (2012) referred to this type of invisible treatment encountered by black students in the classroom as racial ignoring. Study participants experienced lack of acknowledgement when attempting to contribute to classroom discussions as seen in the examples below:

It is hard to be African-American/Mexican-American and be dismissed when topics involving your race are being ignored. I have asked teachers if we could talk about these things and they have the audacity to tell me no and that it isn't worth it.

Sometimes I would say something out loud repeatedly and then another student will say the same thing then (in one incidence) they got extra credit!

The multi-racial student, apart of two racial/ethnicities of color, is further marginalized by a teacher who does not see the value in recognizing the important contributions members from their ancestry have contributed to this nation. The second student expresses the concern where racial ignoring impedes academic performance with being denied an opportunity to gain extra credit.

Microinvalidations also appear to be heavily (twice as likely) received from peers 
than teachers (see Figure 18).

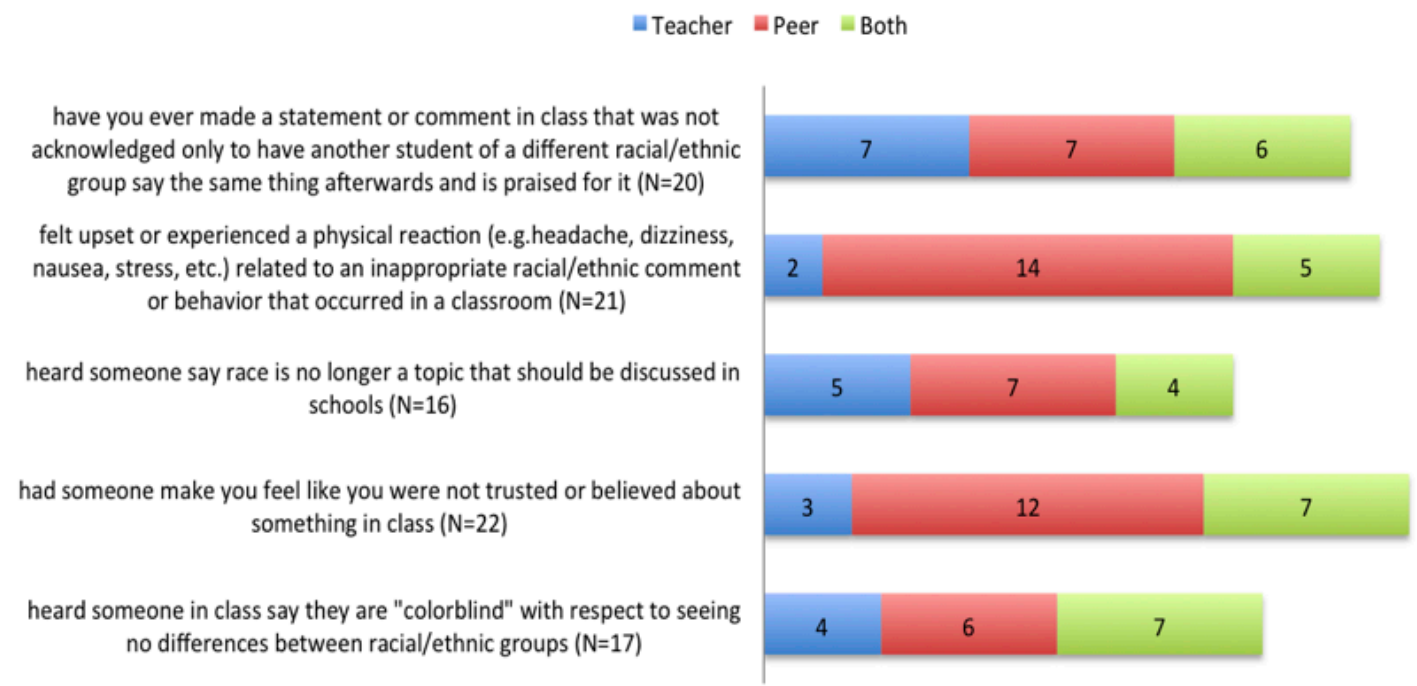

Figure 18. Microinvalidations received from teachers and peers.

The two areas students noted the most received invalidations by peers were: felt upset or experienced another physical reaction (e.g. cried, nauseated, stressed) and felt like they were not trusted or believed in class. Both teacher and peers have contributed to students feeling unacknowledged for their contribution to classroom discussions.

environmental microaggressions. Because students spend a considerable amount of time in the classroom, the learning environment (human interaction and facility upkeep) in which they receive instruction is critical to how they feel they are perceived or valued as students. The areas of most concern were rarely seeing peers in the classroom or adults in the school that look like them. The majority of the participants never received In-School Suspension or Benched in the Office with respect to a discipline resolution and in general felt discipline was fair in the classroom. Most students indicated feeling teachers graded all students fairly in class. With respect to the physical structure 
and overall facility maintenance, student responses indicated classrooms were maintained and had good lighting.

\section{Section III: Raising the Level of Cultural Consciousness}

RQ2: what suggestions do students have for restructuring the learning environment? Section three of the survey was entitled Designing a Learning Classroom.

The purpose was to gain insight on best practice recommendations for educators by asking Black or African American high school students how they learn best. The areas assessed were academics, community, and equity. A number of themes concerning educational practices with respect to the three areas emerged as most beneficial for the learning needs of Black and African American students that will be further elaborated on in this section.

academics. Academic preferences were relayed through three questions. The first question, "What types of courses would you like to see offered that you are interested in taking not currently offered at your school?" Forty-nine students provided information on course interests they would like to see offered at their high schools. The top five areas where students would like to see increases in choice offerings were in the following subject areas: life skills/vocational (e.g. cooking and driving), foreign language (e.g. American Sign Language and French), art (e.g. Cinematography, Dance), culture/history (African American Studies and African History), and STEM (e.g. animation and engineering). Appendix U: Course Preferences provides additional details with respect to course preferences students expressed a desire to take.

The second question (see Figure 19) asked in reference to academics was "How would teachers teach their lessons (Think about your learning style--e.g. more hands-on, 
direct instruction, etc.)? Grading Practices? How would technology be incorporated?" Grading Practices? How would technology be incorporated?" Students overwhelming desired instructional practices that included using hands-on learning. They also had a strong affinity for the incorporation of technology. More females than males expressed a strong affinity for direct instructional practices (e.g. teacher being exact and clear in explaining content). One area that females noted that was absent from the male comments was the need to have exposure to authentic learning experiences to include having guest speakers or taking field trips to engage learning. Ladson-Billings (2014) described this as sociopolitical consciousness with instruction and learning transcending the four walls of a classroom by using the world in which we live to gain knowledge through advocacy and inquiry. A caveat to the findings is that due to the inclusion of the phrases "hands-on" and "direct instruction" the question can be considered leading.

Male $\mathbf{N}=\mathbf{2 2}$

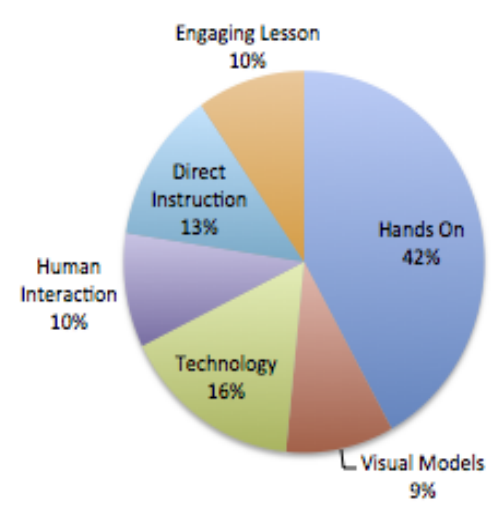

\section{Female $\mathbf{N}=\mathbf{3 6}$}

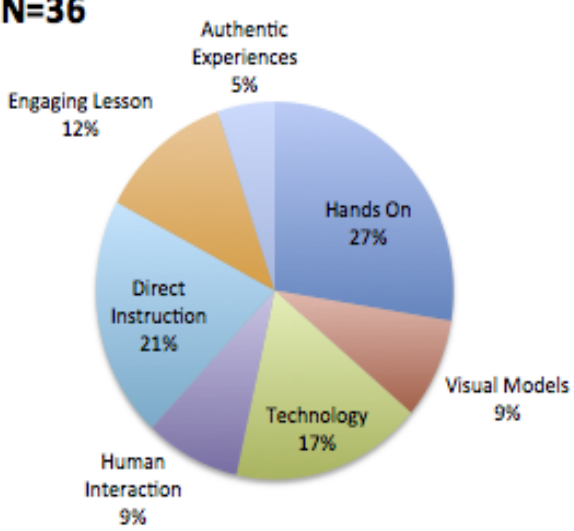

Figure 19. Desired instructional strategies.

The idea of creating instructional spaces for students of color to be apart of the conversation versus the object of the conversation is the next wave of culturally relevant pedagogy that Ladson-Billings (2014) coined as culturally sustaining pedagogy. Freire 
(2000/1970) whose work in propelling freedom through critical consciousness discourse advocated that students needed to be active in their own learning, not just vessels to be filled with knowledge. In his proposition, Freire (2000/1970) advocated the movement from a linear teacher transfer knowledge through a student banking concept of learning to a student-centered, problem-posing education / humanistic approach. Critical pedagogy encourages inquiry-based learning and active discourse between teacher and student who learn from each other. Students are expected to be active thinkers and doers in their learning experience. It is obvious the current method of teaching is not effectively reaching all learners and actually pushes many African American students further away from graduating as career and college ready. The most desired learning style modalities centered on tactile and audiovisual learning preferences. Thus, teachers need to be intentional at including on a regular basis lesson activities that encourage hands-on learning opportunities, explicit directions when instructing, and technology use to enhance comprehension of the lessons.

The third academic-related question asked, "How do students interact with one another inside the classroom? Describe how they help each other learn?" With respect to peer interaction, comments centered on the following themes: academic support, group work and discussion, cooperative learning, and racial identity. In general, in an ideal classroom setting, most students saw the benefits of learning from and gaining an understanding of content material when working with their peers which supports the concept of Black or African American students having a strong desire for cooperative, 
relational connections with peers in the classroom (Ford, 2012; Kunjufu, 2002) as stated in the responses:

They help each other by sharing their ideas and dictating mistakes

They support each other by creating study groups.

Black students express the need to learn and work with peers, which gives the learning process a sense of support. With regard to racial identity, a sense of unity is provided by working with other students who looked like them as well as being accepted by peers who are non-Black or African American descent captured in the comments below:

Students would interact simply be connecting with other students of their ethnicity it is much easier that way because we struggle with the same thing and problems in this society because of our color differences and racial backgrounds. We'd help each other learn simply by interacting with one another.

Students see no difference in one another. They are all treated equally by teachers and all staff members. It would be a calm and collected community and environment.

The need to create and ensure spaces for black affinity groups is important for students to feel connected to each other and to discuss ways on improving school climate for the betterment of all students. The idea of community learning among peers resonates in the students' responses with many seeing value in peers supporting each other in the learning process. Students also stressed the need for a family-like feeling environment as noted in the following comments:

[W]e interact like a family. we always help each other out with school work

In this class, we are a family...there is not much [A]frican [A]merican students at this school so we made a promise to always look out for each other.

These findings support the work of Ford (2012) who found that black students often 
have a communal orientation rather than a competitive, individualistic approach to learning.

community. In order for a school to act as a nurturing, learning community it is necessary for the leader to devote time and attention to the physical structure of the school, the individuals who serve the school, and their relationships with students, as well as with each other. To become more family-like, the physical structure of the classroom setting has to be revamped. Nationally, as the student population continues to grow, the number of schools serving them has remained consistent creating large class sizes with $30+$ students that do not allow a teacher to provide students with individualized instruction but results in teaching to the middle, which is the reality of many classrooms in today's society. For African American students to maximize their academic and socioemotional success, the classroom must take on several of the nine traits characteristic of the African American learner which include: Spirituality, harmony, affect, communalism, movement, verve, expressive individualism, orality [sic], and social time orientation (Ford, 2012).

Reduction in class size is often a twofold debate. Some view it as a cost saving mechanism for school districts to have larger classrooms and often denounce that smaller classes make a difference in academic gains. Others argue that reduction in classroom size does make a difference in student academic success and is worth the cost of increasing the number of teachers, materials, and space, given the beneficial outcomes it has for students (Berliner \& Glass, 2014). Berliner \& Glass' (2014) work with metaanalyses supports the argument that smaller classes do contribute to academic success. 
They noted several cases such as the controlled experiment, Project STAR in Tennessee, which incorporated a small class size design at the elementary level with less than 18 students per teacher leading to significant gains on standardized tests as well as fostered continued improvement through latter grades. It was further found that minority students success rate in small group was nearly doubled in comparison to their peers (p. 90-91).

However, weary of a potential Hawthorne Effect from the Tennessee experiment's large gains due to class size reduction, Bosworth (2014) used secondary data taken from the North Carolina Education Research Data Center (NCERDC), to further assess the impact that reduction of class size had on the outcomes for fourth and fifth graders by controlling for classroom composition (e.g. race/ethnicity, gender, free/reduced lunch, and parent education level). Using chi-square analyses he found that most of the classrooms in the study were created randomly with respect to the race/ethnicity of students in the classroom. However, he found that with respect to gender, schools appeared to ensure that there was a balance of male to females in the classroom setting.

The results of the study indicated benefits on a small scale based on the reduction of classroom sizes. Although the results did not explicitly indicate that African Americans necessarily performed better in small group, results did indicate that small class sizes have a positive impact for female students and students who struggle in school. Smaller classes also encouraged teachers to change instructional practices from less whole group instruction to more individualized instruction (Bosworth, 2014).

Weiss, Carolan, \& Baker-Smith (2010) study looked at the big school and small school debate and its impact at the high school level. The study focused on effects of 
class size for student math academic outcomes and engagement levels. Their study revealed that student engagement was effected by school size but math performance was not. They further found that African American students were not different in their level of engagement from white peers. In the current study, the student perception of class size was derived from 58 students who indicated their ideal class size. The sizes included as few as 15 to as many as 40 with a spread of 25 . The mean number per class was approximately 27 and the median was 29.5 students. The box-and-whisper plot (Figure 20) provides a visual representation of the ideal class sizes. Several responses perceived $30(N=16)$ students per class as the ideal size with $20(\mathrm{~N}=10)$ being the next desired class size of students.

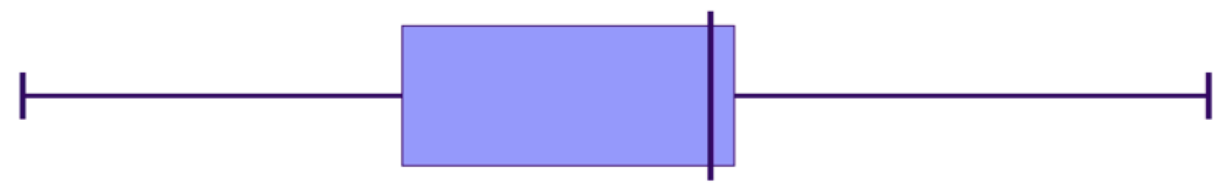

\section{$\begin{array}{llllllllllllll}14 & 16 & 18 & 20 & 22 & 24 & 26 & 28 & 30 & 32 & 34 & 36 & 38 & 40\end{array}$}

Figure 20. Ideal class size.

A class size composed of 20-30 students is ideal, according to the study participants. Smaller class sizes are aligned with learning environments that promote a hands-on teaching approach as indicated by many students as their preferred learning mode.

Students expressed wanting their families to be treated fairly and with the same type of respect as other families such as to be welcomed into the school and be treated with kindness. Also, to recognize and have an awareness of the diversity that exists within 
Black and African American students served within the district to include the variety of languages spoken at home as noted in the comment by the student:

Just treated with kindness and equality like all the other families should be. Check beforehand if a translator is needed so there's no stress put on their child.

Also, to incorporate more cultural presence in topics and events that would encourage Black and African American family participation to advocate on their students behalf such as suggested by the student comment:

have meetings with just black families and a black administrator and discuss school issues or events. make sure there [sic] student is welcomed and adjusting properly

The need for early mechanical solidarity in school is an important component not only for students, but also for their families. It is critical to have someone in school leadership that looks like them to help build confidence among black families.

equity. In The Effects of Education as an Institution, Meyer (1977) states, "education is a central element in the public biography of individuals greatly affecting their life chances" (p. 55). He notes that educational allocation often creates the basis of the social structure in education because it ensure that the "rules" of socializing students are in place from the teacher's credentials to the hierarchical structures imposed upon students directing them into their classified role/ place in society in order to maintained the institution. Educational allocation states, "adult success is assigned to persons on the basis of duration and type of education, holding constant what they have learned in school" (p. 59). In other words social class in education along with the hidden curriculum advantages some students and disadvantages others. 
An example would be a high school student who barely graduates from an elite independent school can expect to experience greater career status later in adulthood versus a high preforming graduate of a public, turnaround school simply because of the connection and value of receiving a degree from an institution that is seen as favorable and marketable. The education system is structured into elites and members. Based on a number of contributing factors, the educational/ schooling experiences of two students in the state of California being conferred with the same high school degree can expect very different postsecondary opportunities and outcomes.

Even within the same institution tracking tactics matter. Tracking is defined as, "the process whereby students are divided into categories so that they can be assigned to groups in different kinds of classes” (Turner \& Spain, 2016, p. 3). For example, Student A who took Advanced Placement English courses throughout high school and was considered college-track versus Student B who took taking Basic English course all four years of high school and sorted into the vocational track leads to inequitable life chance disadvantages for Student B. Although both fulfilled California's graduation requirements, Student A's pathway opens the doorway to more rigorous coursework, access to social networking and opportunity, and potential gain of college credit through AP exams reducing cost of college. Student A fulfills the requirement of graduating A-G which is required for admission to UCs and CSUs. Student B does not obtain A-G status and is at best prepared for a community college, trade school, or entering the workforce. It will take more money and time to be invested in education in adulthood to reach a 
status similar to that of Student A had at the time of high school graduation. Ultimately, for these socialization processes to sustain, there has to be a way to legitimize the different educational attainments of students. Thus, allocation is encompassed by legitimation theory. In the classroom teachers, counselors, and administrators, and other personnel in the educational setting serve as "social gate keepers" for their students' potential economic knowledge and classification in society fostering a culture of winners and losers in the system with race subconsciously factored in and often serving as a qualifier for which pathway a student is stirred toward. Ways to combat inequitable ills in the school setting are addressed in this section of Designing a Learning Classroom.

What are some ideas/ways on how Black or African American student voices can be empowered in the classroom and school? Four themes emerged with respect to this question (see Appendix V). The themes were: incorporating social media, speaking up in class, need for affinity clubs and organizations, and other items of concern. The theme with the most responses was speaking up $(\mathrm{N}=29)$. The overall essence of this theme was to create less a safe space where students could feel acknowledged, have their voice heard without interruption or being overlooked, and to be taken seriously when voicing their opinions. In terms of clubs and organizations $(\mathrm{N}=13)$ several students saw the need for Associated Student Body (ASB) and Leadership to be revamped due to lacking a representative body as most school site ASB Leadership members are mostly Asian with little representation of other racial/ethnic groups and little to no Black and African Americans students. Students also expressed a need to have more affinity-based groups such as a larger Black Student Union (BSU) or a Black Study Body government to 
address the specific needs of Black students. The incorporation of social media $(\mathrm{N}=5)$ included using tools such as creating a talk show, making posters to promote Black or African American causes, and using art and music as outlets to reach a greater audience. The other theme centered on the removal of negative stereotyping of Black or African American students, to be treated fairly, and to incorporate more African American content imbedded in course selections.

What would discipline look like in the classroom/school? For many students who provided a response to this question saw three key elements as necessary to be incorporated into discipline practices. The respondents indicated the need to have a student be provided with a warning $(\mathrm{N}=12)$, treated respectfully $(\mathrm{N}=10)$, and fairness $(\mathrm{N}=9)$ in the discipline process. Students expressed the need to receive a warning and having someone actually talk with them to understand why they may be exhibiting the behavior as echoed in the student comment:

Discipline won't be harsh and it would just have the student sit out and someone can talk to the student to understand how they actually feel.

Students further expressed the need for respect by teachers as well as peers (see Appendix Y). Students noted fairness both in punishment and reward. An example of how students saw the importance for fairness to be apart of the process:

Discipline would be fair and equal, and no student would feel singled out. Frequent troublemakers would get the necessary things they need to help them be successful.

How would students be made to feel cared for in the classroom? Essentially students desire to be treated kindly/welcomed $(\mathrm{N}=24)$ and listened to $(\mathrm{N}=15)$ (see Appendix $\mathrm{Z})$. 
Having teachers who are benevolent and invest in them as a person as a running theme for this are as noted in the following student comments:

Teachers who take the time to make their students feel cared for and treated fairly. Teachers who make the effort to be kind and find out about students' lives would produce happier and more caring students.

Receiving less insults and teachers having more patience was the essence of the student responses.

The importance of creating a family-like environment and listening to students were areas of importance for Black or African American students who responded to this questions as noted in the comments:

[C]lass will feel like a family making strong relationships with the teachers and students. That being said teachers will not accept all late work because the students should know there expectations and the teachers should know if the students have something going on that will get in the way of school work

[T] eachers should make sure they contact every student and parent to ask about the well being of the family.

I would hope that they would see me or other instructors as a source of advice and an open person to consult with for anything. I'm a pretty unbiased person and [I] genuinely love listening to the concerns of others and helping them.

As in any family there are expectations and rules to follow. Black students also desire consistency and structure to be present in the classroom and to feel their voice is important. The other $(\mathrm{N}=8)$ items in relation to feeling cared for included feeling safe, more interaction with peers, being trusted, and the desire to have more Black or African American teachers. 


\section{Summary}

The results revealed that Black or African American students' were not as socially integrated with respect to accessing school resources such as meeting with a counselor for postsecondary planning, taking advantage of tutoring, or enrolling in more rigorous course work such as advance placement classes. For students who considered transferring to another school either within or outside of the school district, push out factors were due to feeling alienated, safety concerns, sporting opportunities, and seeking programs or magnets geared toward a specific academic focus or special interest.

Dropout tendencies with regards to academics, discipline, and repeating courses for credit were due to students not liking the school or their teachers as well as not see the work assigned as relevant or connected to their life. Four themes that comprised disengagement were due to material being too difficult, coursework not interesting, and teaching methods not engaging.

Colorism and racial identity were intertwined in how student participants socially identified in the school. In general, meeting with academic success, strong sense of support from family and friends, being proud of their cultural and ethnic heritage, as well as being creative or talented in an area such as art or sports were the key areas identified that made students feel good about themselves. Insecurities with their schooling experiences were due to concerns for academic failure, feeling alienated and criminalized as well as having their racial identity disrespected and the overall feeling of racism and racist behaviors particularly exhibited by peers with having to constantly be called racial slurs such as called the N-word or called dumb because they are Black. Colorism further 
was an area student felt were prominent in how they were perceived by both peers and teachers with respect to skin color and hairstyle choices. They noted receiving negative comments in reference to beauty/ body imagine, having low expectations held of them and racial stereotyping.

The findings for racial microaggressions revealed several reoccurring themes. Being singled out, having low expectations held of them, and constantly having name mispronounced by peers and teachers were the dominant microinsults that emerged. Microasaults were most frequently experienced from student-to-student centered around three major themes which being called a derogatory slurs and experiencing inappropriate racial jokes in the class not only of Black students but of other students of color such as Hispanic/Latino or Asian. Being overlooked and ignored by teachers while attempting to participate when raising their hand was also experienced by several of the participants. Microinvalidations experienced were due to experiencing a physical reaction (e.g. stress, upset, sick) due to experiencing inappropriate racial/ethnic comments, lack of acknowledgement of in classroom discussion, and felt like they were not trusted or believed in the classroom. Two thirds of the racial microaggressions (i.e. microassaults and microinvalidations) were mostly dominated by peers. Microinsults received were balanced between teachers and peers. Microassaults $(\mathrm{N}=40)$ were the most frequently noted as being experienced by the student respondents and microinsults $(\mathrm{N}=38)$ and microinvalidations $(\mathrm{N}=29)$. Microassaults overlapped with microinsults 66 items and fifty times with microinvalidations indicating a high presence of microassaults experienced in tandem with the other two racial microaggressions. However, it was 
seldom that students who experienced a microinsult also experienced a microinvalidation as the results indicated that they only co-occurred four times together. In general for students who experienced racial microaggressions, they usually experienced more than one type on a regular basis and microassaults were often apart of that combination.

With respect to Designing a Learning Classroom, academically, students desired more culturally diverse course selections to include African American Studies and American Sign Language, and cooking courses. The need for more hands on opportunities, increased use of technology imbedded in lesson activities, and explicit instruction/clarity from their teachers were some of the instructional strategies provided in the open-ended responses. Many students desired to work collaboratively in groups with peers to learn from each other and for the classroom to have a family feel to it. To promote community, students desired more integration of parents in the school and to have more affinity groups that were responsive to the needs of Black or African American Students. In regards to equity, students wanted to be treated fairly and to have their voices heard in the class and a strong desire to have teachers really invest in getting to know them. 


\section{Chapter 5 Conclusions}

\section{Summary of Study and Findings}

In 2012, as part of Common Core State Standards (CCSS), the CDE required all school districts to report educational progress utilizing a standardized template called the Local Control and Accountability Plan (LCAP). LCAP is a tool for local educational agencies (LEA) to set goals, plan actions, and leverage resources to meet those goals to improve student outcomes (CDE, 2018). As part of the eight areas assessed, data for

Priority 5: Student Engagement and Priority 6: School Climate, are assessed in the study district through the use of a research based assessment created by Panorama Education. Specifically, according to the website, "Panorama Student Survey gathers feedback from students about their classroom experience" (Panorama Education, 2018). The experiences include sense of belonging and connectedness.

In Spring, 2018, Black or African American students felt the least connected to their school than any other group of students with a $46 \%$ favorability rate. The recent Fall, 2018 Panorama Student Survey results echoed similar outcome with 45\% of Black students feeling favorable about having a sense of belonging/school connectedness and continued to be the most disconnected group of students in comparison to peers of other racial and ethnic backgrounds (Panorama Education, 2018).

Thus, the purpose of this study was to examine with a closer, critical lens the "whys" or root causes that have led black students to feel disengaged in their learning environments. The conceptual model for this study was composed of Critical Race Theory (CRT) to empower voice by using the firsthand narrative of Black and African 
American high school students and Moral Exclusion Theory (MET) to gain an understanding of specific actions and ways in which students experience feeling estranged/ morally excluded in the classroom. A transformative paradigm is centered on promoting human rights and social justice by propelling systemic changes in unjust systems. The paradigm encapsulated the process in order to shed light on the daily interactions students of Black or African American ancestry have with teachers and peers and the extent the presence of racial microaggressions have on impacting classroom experiences leading to a push out/ disengagement effect for students. Based on the results, a social constructivist explanation for examining, analyzing, and explaining the schooling experiences of black students was proposed. The data will further be used to promote transformative, systemic changes in practice and policy within the study district through best practice methods offered from the participant narratives in the Designing a Learning Classroom, the final section of the survey, in which students share several key implementable strategies as to how they learn best.

This chapter consists of five parts. It begins by analyzing the key themes that emerged from the data to determine if Black or African American high school students in the study district were experiencing a nurturing learning environment or traumatizing effect in the classroom and school. Second, based on findings utilizing the conceptual model that guided this study, the researcher constructed a social theoretical explanation to provide an understanding of how Black or African American students' values are often excluded in the schooling experience. Third, Designing a Learning Classroom is based on what the students stated were the most effective means of maximizing their schooling 
experience with respect to academics, community, and equity and a school

model/framework response is proposed. Fourth, the study offers five key

recommendations, limitations, and future research suggestions. Finally, the chapter

concludes with a reflection on the study's effectiveness at implementing a transformative framework that centers and nurtures the work that lies ahead.

\section{Caring and Nurturing School Themes}

A nurturing school is defined as:

A school where there is trust and caring among all individuals; supportive relationships exist in a positive environment. There is a sense of community where all individuals are valued and participate in the decision-making process, and the self one brings into the environment is respected and nourished with everyone accepting responsibility for student success. (Green, 1998)

This study utilizes Green's (1998) themes of a nurturing school: student-teacher relationships, peer-to-peer relationships, environment of the classroom, and students' feelings about themselves to determine if Black or African American students perceive their learning environment as nurturing. The intent of the study was to inform teaching practices and intervention strategies on how best to meet the needs of Black or African American students in the classroom and school setting.

student-teacher relationships and student-student relationships. The results indicated that racial microaggressions had a negative impact on a student's level of engagement/integration in the classroom. Particularly for this group of participants, the most common form of racial microaggression experienced was microinsults (e.g. mispronunciation of name) received almost equally from teachers and peers. Microassaults (e.g. called the $\mathrm{N}$-word) were also a common racial microaggression most 
heavily received from peers. Microinvalidations (such as not trusted/believed) were not as frequent as microinsults and microassaults but when they were noted, peers were identified as the main aggressor.

environment of the school and classroom. In regards to the upkeep of the school facilities with respect to their physical structure and maintenance, student responses indicated classrooms were clean and had good lighting. Rarely did students' witness peeling paint or damage (e.g. holes in the wall or graffiti) indicating custodians across the district do an excellent job at maintaining the current structures. The majority of student respondents' answered "never" to "rarely" having seen people in prominent roles (e.g. teacher, counselor, administrator) in the school who were of the same race or having peers of the same racial or ethnic background in their classes. However, more than half $(\mathrm{N}=42)$ of the student participants indicated they saw pictures or posters in their classrooms with a frequency from sometimes of images of role models from their racial/ethnic group. The presence of such artifacts in the classroom supports the earlier finding by Ladson-Billings (2014) that teachers have increased in cultural competence (appreciation of one's culture) of their diverse student body.

students' feelings about themselves. With respect to school engagement, a number of sub themes emerged as key factors to why students desired to transfer to another school, held dropout tendencies, and experienced disengagement in the classroom. School transfer themes were related to feeling alienated, safety concerns, playing on a higher-ranking sports team, and the desire to participate in specific interest programs not currently available at their school. Three themes emerged regarding dropout tendencies 
(i.e. academic failure, discipline, course repeated for credit), which included: not liking the school, not liking the teachers, and not seeing the value in the work being asked to complete. The key disengagement themes included: work too difficult, material not interesting, teaching methods not interesting, and not feeling the material was relevant to their lives.

Social Identity themes emerged regarding what students felt made them feel good about themselves, insecurities they held about school, and if they believed they were judged based on skin color and hair style. Students felt good about academic successes, being creative, support received from family and friends, pride in their cultural heritage, and participating in sports. However, insecurities about school centered on concern for academic failure, feeling alienated (e.g. being the only black student in the class or singled out when a topic of a black person is mentioned), treated like a criminal (e.g. not trusted, followed around the school), disrespect of racial identity, and experiencing racism and racist behaviors (e.g. called the N-Word, dumb). Majority of the student participants identified hair preferences were akin to traditional Black/ African American styles such as wearing their hair in braids, afro, twists, or locks. Three themes emerged: negative comments related to beauty/body image, low expectations held of them, and racial stereotyping (e.g. picked by peers to be on a team because they believed black people are good at sports).

\section{Explanation of Black Students' Schooling Experience}

As we meet at the intersections of CRT, MET, and cultural capital we find the gap in the literature is value. In essence, the root of all gaps (academic, discipline, and 
opportunity) is the VALUE GAP with devaluation serving as core. Students disengage from school because they feel devalued through being downgraded, demeaned, and distance in the classroom. Schools utilize various prediction models such as SAS's Education Value-Added Assessment System (EVASS) to talk about value-added data with respect to educators' impact on instructional quality leading to student growth. However, we speak very little about educators' appreciation of what the students, especially Black or African American students, bring to class and add to it. To authentically care for someone, you first have to see his or her value, relevance, and worth.

To explain the negative schooling effects the perception of colorism and racial microaggressions have on the participation and engagement level of black students, the researcher offers an explanation as to how the devaluation ensues. The Black or African American Student Value Exclusion Model (BOAASVEM) pronounced "Boa" “As" "Vem" is composed of three themes: downgrade, demean, and distance leading to a devaluation effect (see Figure 21):

Devaluation Themes: Downgrade, Demean, Distance

1. Downgrade through Low Expectations

2. Demean in the learning environment by fostering a climate where racial microaggressions manifest through implicit bias actions that are covert and overt in nature

3. Distance through perceived threat and discipline referral 


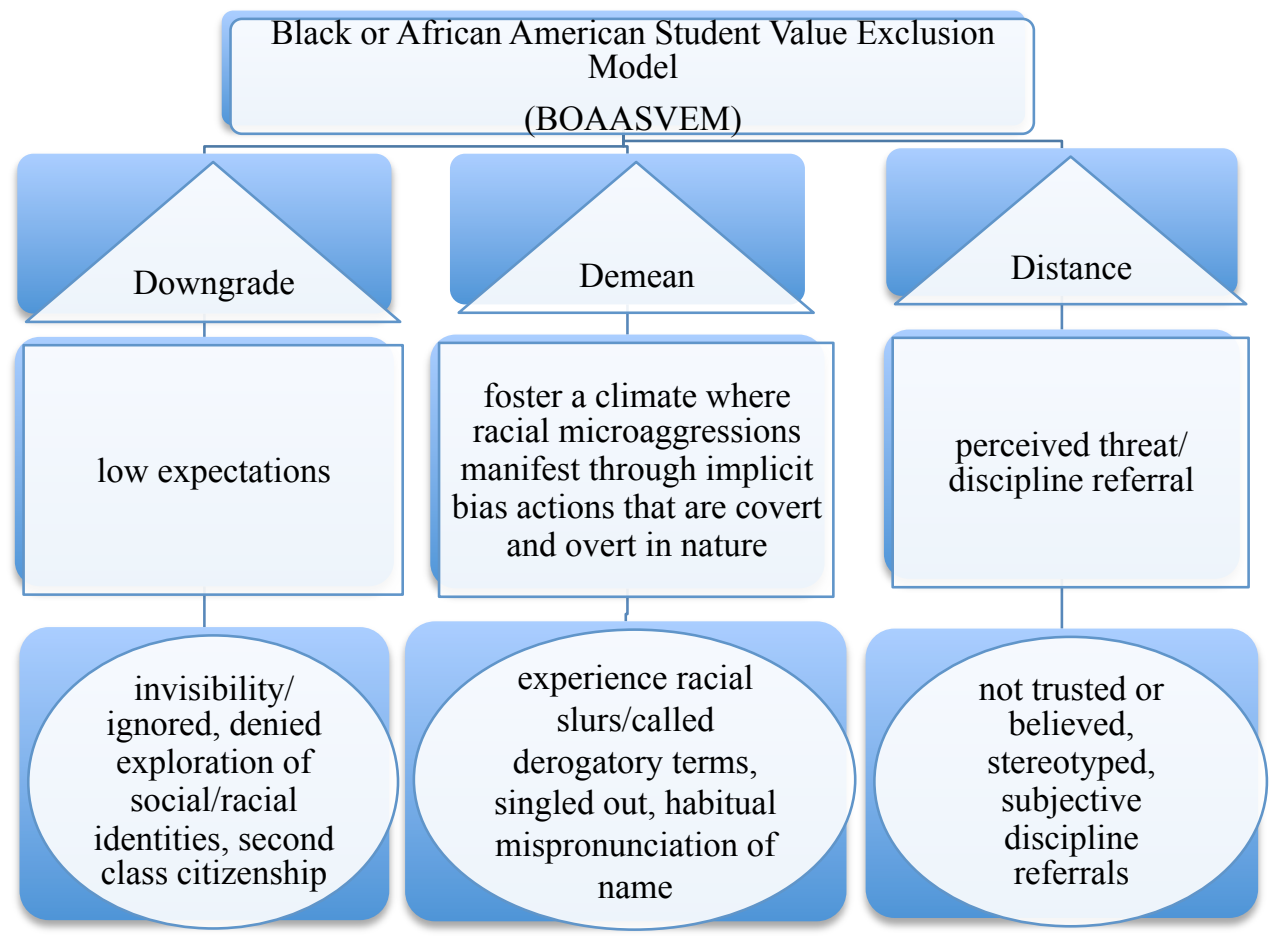

Figure 21. Black or African American student value exclusion model (BOAASVEM).

The Black or African American Student Value Exclusion Model (BOAASVEM) is centered on a recurring theme throughout the findings of the study, which was the feeling of alienation. Education has been described as a "socially engaged process" or a collective consciousness that binds people together (Rose, Joe, Shields, \& Caldwell, 2014, p. 57). The need for a caring and nurturing environment includes having healthy and positive relationships with adults and peers in the school who value each other's cultural norms. For Black or African American students, race plays a major role in how they identify socially and integrate in the school setting. In Merriam-Webster's online dictionary, alienation is defined as, the state or experience of being isolated from a group or an activity to which one should belong or in which one should be involved. Black and African American students only constitute roughly 2.7\% (CDE, 2017) of the total student 
body population in the study district. They are often the only black student in the classroom, making it difficult or impossible for these students to form close connections with others who share their racial or ethnic ancestry. Absence of this bonding opportunity in their classes often makes them feel invisible or ignored as a result of having low expectations held of them by both teachers and peers which sparks the feeling of being downgraded to a second class citizenship status.

Second, Black or African American students are further alienated by a classroom climate where stress inducers through negative stereotypes, implicit biases, and other forms of racial microaggressions harbor. The behaviors are fostered and serve to demean blacks through racial slurs and derogatory terms heavily induced by peers as well as teachers. Described as the pink poodle syndrome, "you are standing among a crowd of people and you are almost a mascot or a wild one" (Kelly, 2007, p. 237) often includes being singled out and disrespected because of one's racial identity (Malcolm X, 1965). Instead of forming healthy, productive relationships through organic solidarity they often find themselves being demoralized through a distancing, push out effect inducing feelings of disconnection and disengagement. Black and/or African American students are often treated as a threat, whether due to excellence and rising above their initial low expectations or due to their physiological makeup (skin color, physical characteristics, hair and clothing style), which can serve as a catalyst to be treated in a criminalized, untrustworthy manner often opening the doorway to subjection. 


\section{Designing a Learning Classroom}

People have the power to solve their own social problems, which is crucial when using a transformative framework, which is about working with the community to bring about change. The final portion of the survey was entitled, Designing a Learning Classroom. It consisted of three focus areas: academics, community, and equity. It allowed students the opportunity to offer suggestions and solutions concerning educational practices with respect to academics, community, and equity as most beneficial for their learning needs. The eight questions were open-ended to provide students an opportunity to empower their voice by sharing what an ideal school model for them would look like. The purpose was to gain critical insights at implementing best practice recommendations for educators on how Black or African American high school aged students learn best.

The section on academics looked at course and instructional practices. The questions (28-30) were: What types of courses would you like to see offered that you are interested in taking not currently offered at your school? How would teachers teach their lessons? Grading Practices? How do students interact with one another inside the classroom? How do they help each other learn?

Community was about examining the physical structure of the school and classrooms and promoting a sense of belonging/connectedness for Black and African American students. Questions (31-32) included: What is the maximum number of students in an ideal classroom? How would the classroom be arranged/setup? How would Black or 
African American culture be included in the classroom? How would Black or African American families feel welcomed and integrated into the school?

Equity (fairness) and advocacy promotion within the school were captured in the final three questions of the survey. Questions (33-35) included: What are some ideas/ways on how Black or African American students' voices can be empowered in the classroom and school? What would discipline look like in the classroom/school? How would students be made to feel cared for in the classroom?

\section{Curriculum Structure}

Culturally responsive teaching is the current push for teachers to develop more inclusive and engaging lessons and practices that encompass the learning styles and diversity that exists in today's classrooms. In order to move away from teaching to the middle to a more culturally and behaviorally driven method of teaching, educators need to be conscious of their own biases and values as well as the impact it has on student learning. Ford (2012) pointed out several cultural nuances that exist within minority populations that are essential elements in understanding how students learn. For African American students he notes various factors should be considered such as spirituality (belief in a higher power), harmony (desire connections/sensitivity to situational and nonverbal cues), affective communication (reactive or impulsive expression), and communalism (need for sense of family-like structure) should be recognized and incorporated into the classroom as best practice strategies to impact student learning (p. 396). 


\section{Implications for Practice}

To promote student engagement and increase the level of family involvement supports need to be provided in academics (e.g. tutoring, after-school programs), school community building (e.g. mentoring, group or individual counseling), and equity of Black or African American student and family involvement through voice empowerment and presents in the school that extends into building community pride by advocating for literacy programs, community restoration, and cultural enrichment activities within their neighborhoods (Brandes \& Green, 1999; Reimer \& Dimock, 2005). The success of all students, particularly Black or African American youth who are often the objects of marginalization in schools, is critical for educators to understand how to design learning environments that maximize the potential and value all of its students. Based on the results of this study, several recommendations are made to circumvent the elements that make up the Black or African American Student Value Exclusion Model (BOAASVEM). They must be done intentionally and with fidelity to change the negative trajectory of Black or African American student schooling experiences and increase the projection of positive postsecondary outcomes.

Recommendation 1: Reframing Perspective. The consensus from the student participants in this study is that they would prefer to stay within the District. They would like to have more options with respect to school choice. Incorporation of a school model that promotes diversity and equity for students who desire a social justice lens in a project based learning atmosphere to maximize the learning needs of Black students should be considered. A potential model in draft format presented by the researcher entitled, 
Kindezi Inspired Structured Schools (K.I.S.S. Model) can be found in Appendix BB. Darling-Hammond, Ross, \& Miliken (2006) found that students who are low-SES and students of color are often poorly served by the comprehensive high school model but have achieved at higher levels in schools that foster opportunities of developing strong, supportive relationships for learning.

To promote equity and achievement the district needs to recognize the importance of being agile and flexible in addressing the deficiencies revealed within their data. Requiring the implementation of research-based strategies that centers on cultural responsiveness, reviewing outcomes of successful campaigns and models of similar situated systems, and input of the voices from this study to intentionally launch a systemic initiative to promote positive enrollment experiences and inclusionary practices for black students will be essential to seeing real changes in future school climate reports. As a system that is undergoing declining enrollment due to both financial affordability concerns for families to live in the area as well as nonfinancial reasons such as families leaving to public charter schools for choice options, the district has to learn the power of reinventing or rebranding themselves as a desired system to attend as they compete against rivalry entities or the negative trend in enrollment will continue. Developing a special study team of diverse stakeholders to make a concerted effort to investigate (i.e. study their models, make contacts, visit sites and classrooms, talk to their attendance base to find out why they chose it and what makes them stay, etc.) and lead this effort is necessary to design a model that truly embodies the study district's core values. To be transformative in nature, the 
core values must be lived and modeled daily in instruction and reinforced by all in the system through their actions not just pseudo posted on a powerpoint presentation or wall to fill space. Individual schools in California (public, private, and charter) have sustainable success with diverse populations that may serve as a starting reference include June Jordan School of Equity in San Francisco, The Nueva School in Hillsborough and San Mateo, and The Envision Schools in Oakland all embody a social justice, equity inspired, inclusive practices creating a caring and nurturing environment.

Recommendation 2: Academics. In addition to the need for assessment changes, course offerings in the traditional high school setting need to be expanded to include courses that focus on appreciation of cultural diversity such as a African American Studies, African Art and Culture, and American Sign Language. There is a strong need to include a social justice oriented course that regularly incorporate engaging issues and topics that are relevant and promotes a consciousness for advocacy through projective based and collaborative learning on topics related to ethnicity, identity, and race. The creation of an independent studies course centered on service learning with the opportunity for action research projects working toward solutions for ills that serve to marginalize communities of color would increase awareness and appreciation of diversity in the school and greater community. Also, including courses that allow for tactile/hands-on learning such as projects, demonstrations, and labs will maximize use of hands-on and technology integration. Offering extended learning opportunities through vocational and STEM courses such ask auto mechanics, cooking, and engineering often 
allow for tactile learners to express and engage with learning. Service learning opportunities combine community exposure with academics to promote personal and social growth, career development, and civic responsibility further authenticating the learning experience (Dynarski et al., 2008).

Results from Chapter 4 indicated students were highly likely not to engage school counselors limiting both current course planning and postsecondary planning opportunities. In order to ensure Black or African American high school students are on track for success, Counselors need to be required to check-in at minimum once a grading period with Black students to discuss grades, progress in coursework, and inform students of opportunities that will enhance learning and long term goal outcomes (e.g. shadowing, mentorship, preparation for AP coursework, scholarship opportunities). Using tools such as Naviance will be helpful to monitor interactions and ensure that students are progressing in building a portfolio of activities throughout their high school career that will increase their competitiveness in being prepared for postsecondary college and career options. Creating a Gradation Coach position to work with specific caseloads of potential first generation college students and students most at risk of not graduating for a more comprehensive academic and mentoring outreach support in high needs schools within the study district is highly recommended.

Recommendation 3: Community. In general, students expressed desire to be in classrooms that promoted empowerment of voice, encouraged collaboration on classwork, and treated all students fairly with a diverse set of instructional methods utilized to provide a more effective learning environment for students. The physical 
classroom arrangement should allow for more pairing, group work opportunities while creating a family feel in the classroom where everyone is accepted. Visuals need to be included in the classroom and throughout the school that represent the diversity of the student body as well as ensure equity of voice in the classroom. Grayson (2017) pointed out, "despite the workings of institutional racism on our students' lives, there are too few opportunities for young people to discuss their experiences with racism or the social and cultural ideologies these experiences represent" (p. 144). It is important that schools are intentionally creating opportunities for students to engage in critical discourse. Utilizing a town hall or restorative practice in the classroom to promote positive classroom climate. A school wide initiative may include instituting a monthly Real Talk seminar to raise the level of consciousness among the student body on topics that are important and relevant to their lives in a safe, structured environment to serve as a platform for discourse on race and other topics.

With respect to, "How would Black or African American families feel welcomed and integrated into the school?" Most students expressed the need for families to be treated fairly like other families of different racial/ethnic groups, invited to various school events, and to have opportunities to express their racial identity/empowerment of voice as part of the school environment (see Appendix U). The student below stressed the importance in having Black parents actively be apart of the decision making process within the District:

If they are invited to events that doesn't exclude them from any thing, or they are put on boards of school and any other decision making group when it comes to school activities 
Also, several comments related back to the theme of feeling alienated and isolated and the desire to see more Black and African Americans in their schools. The suggestion by a study participant offers a student-centered integration strategy to create a safe space to develop racial/cultural bonding opportunity with other students who look like them:

BSU Welcome Day- First Week of School, call all black students in and tell them what to expect, get them to join BSU, etc. Also, upper class-man-lower class-man buddy/mentor system that help new students make friends and feel more comfortable navigating and enjoying the school.

The student expresses a desire and need for more black affinity groups like the Black Student Union (BSU) to take a leading role in new student onboarding. In particular, BSU could serve new and existing black students by creating a safe space to facilitate and enhance bonding so that they do not feel marginalized on school campuses. Many of the district's traditional high schools offer a week of summer activities to guide new students. Including BSU in the planning of that onboarding process is critical early on in the success of black students.

Recommendation 4: Equity. Equity is about being fair and impartial in practice. Specifically, educational equity is defined as "raising the achievement of all students while narrowing the gaps between the highest- and lowest-performing students; and eliminating the racial predictability and disproportionality of which student groups occupy the highest and lowest achievement categories" (Singleton \& Linton 2006, p. 46). In California, the Local Control Funding Formula (LCFF) determines how schools will be financed under the new accountability system for public education. It is composed of eight priorities as measured through the LCAP. The need to align current system to meet the needs of Common Core State Standards brings more variables into focus such as 
parent involvement, student engagement, and school climate when considering the needs of local education authorities (LEAs). The full effect of LCFF is not expected to be felt until the 2020-2021 school year when additional monies are expected to be given to high needs schools (concentration grant— to promote equity). It has been noted that "at the core the debate regarding these regulations is how to strike a critical balance: ensuring that LCFF dollars are spent to support the disadvantaged students for whom they are intended while providing school districts more authority over how to spend those dollars" (Kaplan, 2013, para. 1).

Imbedded in the rubric used with the revised accountability system includes the unveiling of the new California Dashboard. Instead of using a 1-5 number rating it is now a color scale rating of schools. On the surface it appears to take into consideration more items than just test scores as unlike its predecessor, No Child Left Behind. Ideally, it is a push toward a more formative approach for a more holistic look at the needs of schools however time will tell if it truly pans out to be viewed by the greater society as such an instrument that ultimately will allow a more leveled playing field for disadvantaged schools or if it will become corrupted and misused to further divide and widen the gaps it set out to close.

As Darling-Hammond (1997) so eloquently stated, "in order to create a cohesive community and a consensus on how to proceed, school people must have the occasion to engage in democratic discourse about the real stuff of teaching and learning" ( $p$. 336 as cited in Singleton \& Linton, 2006). Race and racism in schools is the real stuff that has too long been negated. The creation of BOAASVEM addresses the 3-D 
effect (downgrade, demean, distance) at explaining the schooling devaluing experiences of Black students. Using the model will be helpful when having courageous conversations explicitly and intentionally talking about race. It is important that it is embedded in a profound way into the culture of schools and the study district as a whole.

Singleton \& Linton (2006) note the second condition of courageous conversations is to, "isolate race while acknowledging the broader scope of diversity and the variety of factors that contribute to a racialized problem" (p. 88). In order to begin the process of de-institutionalizing racism in schools the creation of active Equity Teams within schools to include a variety of stakeholders with a special representative student focus group apart of that Team as well as the formation of a cohort of Administrators of color within the District that meet frequently to candidly discuss challenges to race-based equity-related topics without fear of recourse against them is needed as part of the fundamental core at moving schools to equitable communities.

Equity Teams are in the developmental stages of a select few schools within the study district. E-Teams need to be present on all school campuses. The group should be diverse in nature racially/ethnically and consists of not only school staff (certified and classified) but also of students, parents, and community partners who lead the charge at looking at their respective school data with an honest eye of how historical and present day practices (globally and locally) have led students of color to face disproportionalities' in academics and discipline. Those courageous conversations and other tools and resources utilized need to manifest into initiatives that are implemented with fidelity and 
progress monitored on a regular basis. E-Teams must serve as a watchdog agency to ensure that all in the school environment are held accountable with the standards that are put forth by the team and are serious about the work if true change is to emerge in the racial/ethnic divide.

Recommendation 5: Professional Discourse. Principals are trendsetters of culture for their respective school community and they have to take a proactive, equity-centered stance using a transformative mindset when leading the work of equity in the school. In order to promote a prosocial school climate, School Administrators need to intentionally create safe space opportunities where staff meet regularly to discuss professional norms by explicitly addressing issues of bullying, microggressive acts, and race. McEvoy and Smith (2018) in their study of teachers who have observed other teachers bullying students, noted two key findings necessary to begin to shift the culture and reduce this type of unprofessional behavior:

1. School policy includes specific language about teacher conduct

2. Schools provide professional development about teachers who bully students

McEvoy and Smith (2018) further found that students of color, English Learners, and students of the LGBTQ+ community were the heaviest targeted groups of students by teacher bullying behavior and experiencing negative stereotyping and devaluation. Thus, "training teachers about unprofessional conduct reinforces professional codes of ethics and lessens punitive treatment of students" by acknowledging that such behavior will not be tolerated or allowed to continue to be passively acceptable for our students (p. 34). 
CDE's (2018) mission of schools is to provide an equal education to all. The state of California is not leaving it to chance that districts will voluntarily shift to more equitable communities and thus have set forth policy to ensure districts began making necessary changes in how bullying is dealt with in the school whether initiated by adult or peer. Accordingly, CDE's general education code Chapter 2 Educational Equity [200-262.4] consists of 14 articles specifically designed to address inequities in school districts throughout the State that serve to deny students of color and others from receiving a quality education. Articles address topics from the use of racial mascots to providing safe places to learn. Article 5.5 Safe Place to Learn Act [234.4] will require all districts across the state to adhere to the following, "a local educational agency [LEA] shall adopt, on or before December 31, 2019 procedures for preventing acts of bullying, including cyberbullying." (CDE, 2018). A LEA is defined as, "a school district, a county office of education, or a charter school” (Added by Stats. 2018, Ch. 491, Sec.1. (AB 2291), effective January 1, 2019).

Professional development must not only center on dispelling implicit biases with the adults in the school environment but within the students as well. To begin this work, the E-Team needs to complete an equity audit to serve as a roadmap to know where the school currently stands and the direction it needs to go with respect for trainings and implementation needs of staff and students to truly make it inclusive of all school community members. The praxis must include reading and discussing current research literature via articles and books to serve as guides to the conversations as well as hosting in-house and guest speakers specializing in different areas of the discourse. PD must be 
designed to include strategically structured group processes/practices that implore action research methodology through a transformative, social justice lens. In other words, the discussions that derive should be the catalyst that manifest into real, embedded, sustainable changes in various areas of the system with constant reflection of practice.

\section{Urgency for Whole System Change}

Bartunek, Balogun, \& Do (2011) state that Large Group Interventions are "...methods for involving the whole system, internal and external, in [a planned] change process" (p. 2). They identify the current dilemma that exists for whole system organizational change approaches. The authors discussed how to begin the dialogue between practitioners and scholars and to merge the two essential items (practice and theory) for this area of organization development (OD). Organization Development is defined as, "a systemwide application and transfer of behavioral science knowledge to the planned development, improvement, and reinforcement of the strategies, structures, and processes that lead to organization effectiveness" (p. 3). On a grand scale (macro level [district]) there is continued planning of strategizing, activities, and practice and while at the micro level (school site) the focus is on roles and experiences of the recipients of change (p. 4).

Bartunek et. al. (2011) note that there are over 60 types of Large Group Interventions. Strategizing Activities and Practices (Strategy as Practice) [SAP] provide a framework for taking a closer look a large group intervention's strengths and weaknesses using the six guiding SAP themes: Complexity of change; relationship between intended and realized strategy; social, political, and cultural processes; timing; the whole system and 
modularity; and activities, patterns, and relationships (pp. 11-12). The authors' note that although OD initially emphasized social relationships and a personal needs of workers the focus currently has shifted to focus on resistance to change.

The intent is to provide a whole system, six step approach to creating action oriented problem solving methods by putting the concern(s)/issue(s) into context, creating a space for common ground among the stakeholders and an action plan of implementation. The six steps include: participants focus on past/create timelines, focus on the present/mind map, formation of stakeholder groups, focus on the future, groups develop themes/ discussion/common ground, and action planning/implementation (p. 19).

Whole-Scale Change is used to help organizations with strategic planning, training, and culture change. A strength is that it is flexible working with both small and large groups with a variety of needs. Based off the earlier rubric created by Gleicher's formula for change ( $\mathrm{D} \times \mathrm{V} \times \mathrm{F}>\mathrm{R}$ ), where $\mathrm{D}$ is dissatisfaction, $\mathrm{V}$ is vision, $\mathrm{F}$ is future, and $\mathrm{R}$ is resistance (p. 22). The essential pieces of the process include: clear purpose, core leadership team, event planning team, and a logistic team. Ideally, “...Whole-Scale Change is that while emotions may be difficult at first, they will as a result of the process, end up being very positive" (p. 22). Change is not easy but it is necessary to get a different outcome for students of color.

Although many positive aspects occur in large group intervention models such as planned meetings and multiple levels of participation of various stakeholders, it is noted that, '...the large scale changes are under theorized" [and] "...while the change processes are very carefully designed and scripted, they also include ongoing processes that are not 
explicitly acknowledged by Large Group Intervention designers, but at almost certainly have impacts on the course of the interventions" (p. 27). Bartunek et. al. (2011) proposed several steps to help develop the communication between practitioners and scholars to help fill the void lingering from the six guiding SAP questions by encouraging forums where they can come together on a regular bases to share their experiences and encouraging every voice to be heard. Developing personal relationships with each other and avoiding stereotyping (pp. 35-36).

Many organizations today are not able to adapt to change quick enough. School Systems lean toward reactive mode rather than proactive mode when faced with change. The idea of the "new normal" is basically being able to think fast with respect to being on the cutting edge of a product/ program that is desired and marketable but also efficient and cost effective in maintaining, upgrading, or creating a new product/ program all together as the needs of the consumer changes. Thus, agility is a catalytic force that propels action from both internal and external stakeholders of an organization (Worley \& Lawler, 2010, p. 194).

\section{Change Through Effective Communication}

Tschannen-Moran \& Tschannen-Moran (2014), noted that if we “...think of morale as an organizational mood, [then] we can view a school with low morale as a school that's in a bad mood" (p. 37). The researchers' stressed the importance of neutrality, to be nonjudgmental when communicating, particularly in a school where there is high stress. Often people like to approach a situation by using "I feel..." however they strongly discourage this type of response because it causes the receiver to be defensive. 
Instead, using a "coaching" method, nonviolent communication, focuses on observing, acknowledge feelings, recognizing needs, and asking are the preferred strategies to foster an emphatic conversation (pp. 38-39). In being neutral, it is important that there is clarity when communicating with various stakeholders. Maunsell (2014) emphasized the need for clarity by, “[Ensuring] that you use simple, clear, consistent messages for all and differentiate for key audiences" (p. 64). Openness in communication is about providing access to information by giving the public opportunities to become consumers and producers of information, which often encourages integrating technological communication tools. Evans (2013) looked at five ways that education can be revamped and used for efficiently. Two of the recommendations were to "make education technology easier to use" and to "make it easier for parents to make decisions about their children's education" (p. 22).

Corda (2012) used the metaphor of Superintendent as Super Teacher. Honesty was one of the elements of communication noted and stressed honesty and reflective practice of one's own strengths in leading others. Specifically, "Superintendents must engage in their own reflection about how they see themselves in this role and ask how they intend to engage their administrative staff in identifying the critical questions about how to ensure that students learn. They can then see where the answers might lie" (p. 28). In having honest communication leads to trust building. Corda (2012) recommends Superintendents "establish trusting relationships that will enable others to engage in dialogue without fear or anxiety [and] understand how to extend themselves into the 
experience of the other individual or group in understanding the content under consideration and thus expand the knowledge" (p. 28).

Tennenbaum (2018) further noted the importance of establishing relational trust within a school organization, which consist of honesty, reliability, openness, benevolence, and competence. Particularly, among 96 high school teachers who participated in the study within an urban school district in Northern California, he found three key factors in an effective school leader were: reliability (55.96\%), competence (47.8\%), and honesty (45.0\%) (p. 71). Specifically, reliability was conceptualized as being seen as valuable both as a professional and as a person in addition to a school leader following through on actions such as “...completing a task, answering emails, or providing resources" (p. 65). A competent principal was described as “...having the knowledge and skills to lead the school [and] who follows through with action" (p. 67). Honesty was defined in terms of "being transparent" (p. 64).

Transparency is about giving information that people need in order to understand what is going on at the time that they need it. It also helps to build a trusting relationship. In the article by Riccards (2014), open lines of communication are key for the public school system to truly reform its schools. To help reduce the metaphorical Eduflack, he proposes," regular discussions about the issues to explore areas of agreement, look for areas to partner, identify educators who bring interesting ideas to the table, and create a formal advisory board to get feedback and solidify ideas (p. 25). 


\section{Limitations}

Challenges for this study included the requirement of parents and students opting-in resulted in a small percentage of participants who agreed to take part in the study. In turn, it led to the lost of voices that may have presented additional themes of schooling experiences of Black and African American high school students. Because the sample size was small the results may not be generalizable. Given time constraints with the doctoral data collection window time frame along with the restraints imposed by the school district's calendar when the survey could be administered, freshmen were excluded due to not having enough exposure to speak from an informed stance of their high school experience at the time data was collected (September, 2018). Also, because the survey was done across a district that spanned several miles between schools, distance and time posed a challenge to hold in-depth interviews or an opportunity to create a focus group to meet in a strategic local for dialogue. The length of the survey was a concern for test taker fatigue as some students took as few as 20 minutes while others took as long as 1 hour to complete the 35 -question survey.

\section{Future Research}

Based on the findings, racial microaggressions were a regular part of the lives of Black students. These conditions negatively impact the engagement level and overall schooling experiences for Black and African American students who participated in this

study. A variety of sub themes emerged from each of the racial microaggression categories in this study that would benefit from additional in-depth study. Many students stated in their open-ended responses that they had experienced racial microaggressions 
from elementary through middle school indicating a need for researchers to do more work in the K-8th years in order to determine how these types of behaviors are manifested and can be minimized early on in the school setting in order to make it a caring and nurturing environment where students can feel included and free to learn.

From negative comments noted by study participants, particularly with respect to immigrants or other ethnicities, it is apparent that other students of color such as Latino/ Hispanic students are experiencing racial microaggressions as recent research suggests they too experience feelings of being unsafe and unwelcomed leading to disengagement in schools (Vasquez, 2018). The extent and impact of racial microaggressions should be further studied to determine what overlapping themes exists between students of color as well as unique discriminatory factors that are most central to certain ethnic/ racial groups.

Peers appeared to be the main initiator of many of the racial microaggressions experienced by Black or African American students attending the study district. Perhaps a comprehensive study focused on student-to-student interactions should be undertaken to gain a better understanding of the internal and external forces that have created and allowed negative interactions to persist between peers. Although the sample size was small, the results in this study were consistent with the experiences noted by other studies in different parts of the country (Pringle et al., 2010) that found similar racial microaggressions being experienced regularly by Black or African American students. The presence of this phenomenon appears to persist regardless of location (east to west coast) or population size (small to large) of black students within a district. Future longitudinal studies in this district and across the nation need to be conducted to gain a 
greater awareness and understanding of the effects racial microaggressions have on the schooling experiences at all levels (elementary, middle, high) and postsecondary outcomes of Black or African American students.

\section{Reflection on a Transformative Approach}

Mertens (2010) stated that in order to improve a researcher's practice they must engage in "...critical self-reflection and dialogue about the philosophical assumptions that underlie their positions as researchers" (p. 16). As a researcher, I situate myself within the transformative paradigm. During the data collection process, as the researcher, I insisted on being the only adult present during the administration of the online survey at each school site to provide a face to the project, greet and welcome students directly, provide participants with food as a way of breaking bread and thanking them for their participation, to build trust in a safe space, and foster a sense of security and transparency for any questions or concerns they had as to who was the leader of the study and its intentions. 
Equity Work and Leadership Styles. Ross \& Berger (2009) recommend three leadership styles that are most effective for school leaders to implement equitable practices. The leadership styles are: transformational, distributive, and instructional. In addition to those three leadership styles, as a practicing school based administrator, I believe it is essential to include Adaptive and Culturally Responsive leadership styles to create a more in-depth conceptual model of an equity-minded school leader. With regards to my leadership identity as an equity-minded leader, I see it as a continuous process incorporating a number of styles operating in tandem in order to mesh theory and practice to bring about social justice infused work (see Figure 22).

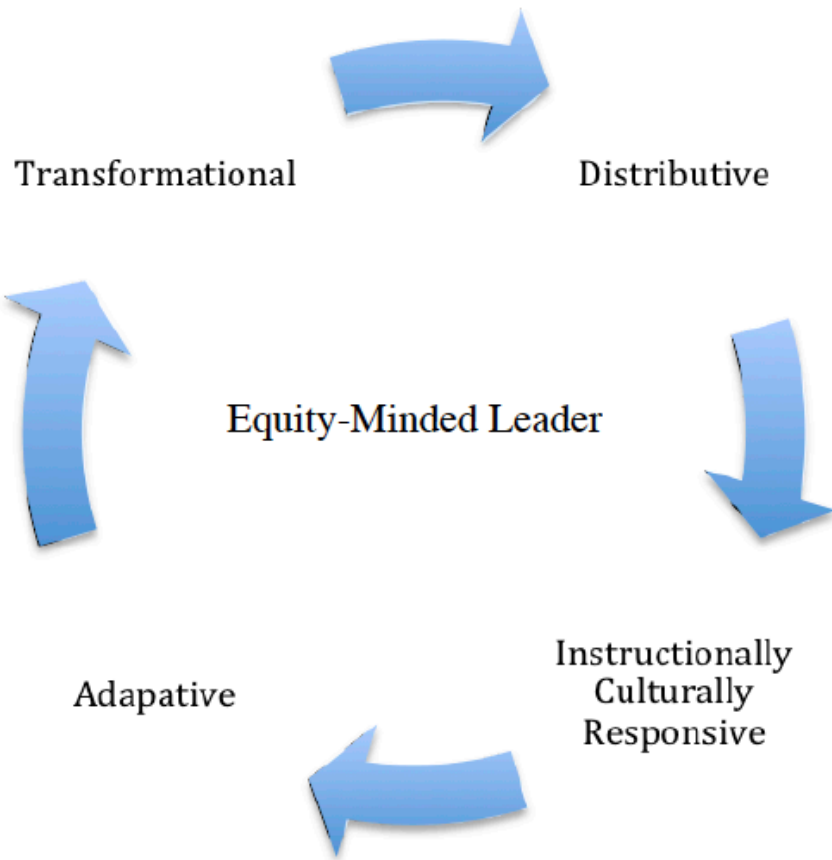

Figure 22. Conceptual model of an equity-minded leader.

In essence, Transformational Leadership is the ability to get people to want to change, improve, and be led" (Northouse, 2001). Various aspects need to be considered to include consideration for systemic change and the need to build employee morale and 
commitment (Michael-Chadwell, 2010). The work in the school often focuses on aspects such as establishing school vision and goals as well as modeling best practices and setting high student achievement expectations and educational opportunities for all in an innovative and collaborative school culture (Balyer, 2012).

Distributive leadership is about taking the big ideas introduced through the transformational reform process and recognizing that systemic change has to be collaborative through a shared purpose and responsibility embodied by the entire organization in order to maximize its capacity to collectively work through proposed initiatives and shifts in focus within the school (Goff, Salisbury, \& Blitz, 2015). Keppell, O’Dwyer, Lyon, \& Childs (2011) stated, "in the schools context it is largely used to describe a broadly disseminated pattern of leadership operating throughout a school and school community, the organization being led collaboratively by many participants rather than by a single authoritative being with the power of delegation" (p. 10). In other words, in order to propel transformational change, you need the investment of the people in the organization to move the work forward.

Culturally Responsive Leadership is a framework for school leaders to engage in praxis and bring theory to action (Lopez, 2015). Schools are expected to be places of critical thought and reflection with persistent dialog between teachers and students that seek to explore, form, and shape knowledge (Dantley, 1990 as cited by Lopez, 2015). It is considered to be an effective means of meeting both the academic and the social needs of students from diverse racial and ethnic backgrounds (Gay, 2000, Ladson-Billings, 1994). I combine it with Instructional leadership which stress the work of a principal is to 
serve as center to lead the work of setting the tone of high expectations, monitoring student progress, assessing instructional practices, and aligning curriculum which means being conscious of students needs and best practices to maximize their learning through high quality instruction (Goff, et al., 2015).

Adaptive leadership takes into consideration we work in human, social systems that require being cognizant of the greater political, social, and economic climates of society and the need to adjust to changes as the populations we serve diversify. In preparing staff to enter into transformative initiatives and to challenge the current status quo, it is important that they know the leader will protect them from the "pains of change" to mobilize them to be in position to learn new ways of doing by be an active participant in bringing change about in the organization. Heifetz \& Linksy (2017) emphasize the work of an adaptive leader is to:

Engage people in adjusting their unrealistic expectations, rather than try to satisfy them as if the situation were amendable primarily to a technical remedy. You have to counteract their exaggerated dependency and promote their resourcefulness. (p. 15)

It is critical that the leader is transparent and committed in time, and seeks creative ways to facilitate communication and builds trust among stakeholders when introducing change.

It's not about the degree, money--bump in pay. It's just the work that has to be done Marcos Pizarro (5/24/18)

\section{The Work}

Professor Marcos Pizarro spoke these words at the Spring 2018 San José State University celebration dinner for graduated doctoral Cohort 2 in educational leadership. 
He says in the statement that while there may be superficial rewards of holding a doctoral degree such as monetary compensation, the real work lies in the long-term commitment to combating injustices that exist in the field of education. Essentially, using the foundational work we started in the doctoral program should continue to propel us to be active and deliberate in contributing to the body of knowledge. We have the power to influence change and make a difference as experts in our field. The statement strongly resonates with me and how I see my role in eliminating injustices in our public school systems.

I dream of learning environments that are free from covert and overt microaggressive actions and behaviors for both staff and students. My lifelong work as a culturally responsive, transformative advocate for ending educational oppression, is to help educators see the value in Black and African American students because what happens in the classroom manifests in all other aspects of their schooling experiences and postsecondary life chances. Far too long we adults in educational leadership have allowed other adults to keep the "blinders" on through the guise of deficit thinking. Such policies and practices have translated into continual presence of institutionalized racism and racist behaviors that foster covert and overt racial microaggressions that run counter to the work we do in dispelling the inequities and injustices that feed the gaps (academic, discipline, and opportunity) and weakens the very fabric of all society. It is time to truly shake the comfort zone, dispel the oppressive status quo, and set the course for a New Normal. Race must always be apart of the educational, critical conscious conversations to be a catalyst for leading transformative, systemic changes in school districts across the 
nation because as indicated by the findings of this study and those that have preceded it, as long as racism exists, race matters. 


\section{References}

Allen, Q. (2013). "They think minority means lesser than": Black middle-class sons and fathers resisting microaggressions in the school. Urban Education, 48(2), 171-197. doi:10.1177/0042085912450575

AncestryDNA. (2019). DNA story for Annette. Retrieved January 26, 2019, from https://www.ancestry.com/dna/origins/9E3A1767-39A5-4B86-B396-B38FD 61C8D96

Appleton, J.J., Christenson, S.L., Kim, D., Reschly, A. (2006). Measuring cognitive and psychological engagement: Validation of the student engagement instrument. Journal of School Psychology, 44, 427-445.

Bartunek, J. M., Balogun, J., \& Do, B. (2011). Considering planned change anew: Stretching large group interventions strategically, emotionally, and meaningfully. The Academy of Management Annals, 5(1), 1-52. doi:10.1080/ 19416520.2011.567109

Baylor, A. (2012). Transformational leadership behaviors of school principals: A qualitative research based on teachers' perceptions. International Online Journal of Educational Sciences, 4(3), 581-591.

Bell, D. A. (1995). Who's afraid of critical race theory? University of Illinois Law Review, 1995(4), 893-910.

Berends, M. (2006). Survey methods in educational research. In J.L. Green, G. Camilli, P.B. Elmore, A. Skukauskaite, \& E. Grace (Eds.), Handbook of complementary methods in education research (pp. 623-640). New York: Routledge.

Berliner, D.C. \& G.V. Glass. (2014). 50 myths \& lies that threaten america's public schools: The real crisis in education. New York: Teachers College Press.

Birts, Angela R., "The African American/Black Racial Tapestry: Black Adolescents' Private, Independent School Experiences and Racial Identity Development" (2017). Dissertations. 3. https://scholarworks.sjsu.edu/etd_dissertations/3

Blanchett, W. J. (2006). Disproportionate representation of african american students in special education: Acknowledging the role of white privilege and racism. Educational Researcher, 35(6), 24-28. doi:10.3102/0013189X035006024

Bosworth, R. (2014). Class size, class composition, and the distribution of student achievement. Education Economics, 22(2), 141-165. 
Bradley, C. L. \& Renzulli, L. A. (2011). The complexity of non-completion: Being pushed or pulled to drop out of high school. Social Forces, 90(2), 521-545.

doi:10.1093/sf/sor003

Brandes, B. \& Green, R. (1999). Off their rockers into service. Connecting the generations through service learning. Linking learning with life. National Dropout Prevention Center, College of Health, Education, and Human Development, Clemson, SC: Clemson University. Retrieved from http://www. dropoutprevention.org

California Department of Education (2018). State priority related resources. Retrieved from https://www.cde.ca.gov/fg/aa/lc/statepriorityresources.asp

California Department Corrections and Rehabilitation. (2016a). Juvenile justice outcome evaluation report. Retrieved from http://www.ca.gov/

California Department of Finance, Race/Ethnic Population with Age and Sex Detail, 1990-1999, 2000-2010, 2010-2060 (Jan. 2018); U.S. Census Bureau, Population Estimates, Vintage 2017 (Jul. 2018). Retrieved from http://www.kidsdata.org

California Longitudinal Pupil Achievement Data System (CALPADS). (2017). Retrieved from https://www.cde.ca.gov/ds/sp/cl/

California School Dashboard. (2018). Conditions and climate. Retrieved from blob:https://caschooldashboard.org/ac8293e7-5bd1-4ff3-8cc2-6bde109de393

Carter Andrews, D. J. (2012). Black achievers' experiences with racial spotlighting and ignoring in a predominantly white high school. Teachers College Record, 114, 1-46.

Christle, C.A., Jolivette, K., \& Nelson, C.M. (2005). Breaking the school to prison pipeline: Identifying school risk and protective factors for youth delinquency. Exceptionality, 13(2), 69-88.

Clandinin, D. J. \& Connelly, F. M. (2000). Narrative inquiry: Experience and story in qualitative research. San Francisco, CA: Jossey-Bass.

Cohen, J. (1988). Statistical power analysis for the behavioral sciences. Hillsdale, NJ: Erlbaum.

Corda, S.J. (2012). Super teacher. Phi Delta Kappan, 93(6), 26-28.

Darling-Hammond, L., Ross, P., \& Milliken, M. (2006). High school size, organization, and content: What matters for student success? Brookings Papers on Education Policy, (9), 163-203. 
DataQuest. Retrieved 2017, from https://dq.cde.ca.gov/dataquest/

DataQuest. Retrieved 2018, from https://dq.cde.ca.gov/dataquest/

Du Bois, W.E.B. (2014). The souls of black folk. San Bernardino, CA: Millennium Publications. (Original work published 1903).

Duckworth, K, Bruner, S., Spears, M., \& Evans, M. (2015). Complexion (A Zulu love). [Recorded by Kendrick Lamar Duckworth and Marlanna "Rapsody" Evans ]. On To Pimp A Butterfly [CD]. Santa Monica, CA: Aftermath/Interscope (Top Dawg Entertainment).

Dynarski, M., Clarke, L., Cobb, B., Finn, J., Rumberger, R., and Smink, J. (2008). Dropout Prevention: A Practice Guide (NCEE 2008-4025). Washington, DC: National Center for Education Evaluation and Regional Assistance, Institute of Education Sciences, U.S. Department of Education. Retrieved from http://ies.ed.gov/ncee/wwc.

Easton, H. (1837). A treatise on the intellectual character, and civil and political condition of the coloured people of the U. states; and the prejudice exercised towards them; with a sermon on the duty of the church to them Isaac Knapp. Retrieved from Books on Google Play.

Esquivel, G. B. (1995). Teacher behaviors that foster creativity. Educational Psychology Review, 7(2), 185-202. doi:10.1007/BF02212493

Evans, C. (2013). Five steps to reboot American schools, Education Week, 33(10), 28. retrieved from https://www.edweek.org/ew/articles /2013/10/30 /10evans_ep. h33.html

Fasching-Varner, K., Mitchell, R. W., Martin, L. L., \& Bennett-Haron, K. (2014). Beyond school-to-prison pipeline and toward an educational and penal realism. Equity \& Excellence in Education, 47(4), 410-429. doi:10.1080 /10665684.2014.959285

Fenning, P., \& Rose, J. (2007). Overrepresentation of african american students in exclusionary discipline: The role of school policy. Urban Education, 42(6), 536-559. doi:10.1177/0042085907305039

Finn, J. (1989). Withdrawing From School. Review of Educational Research, 59(2), 117142.

Ford, D.Y. (2012). Culturally different students in special education: Looking backward to move forward. Exceptional Children, 78 (4), 391-405. 
Freire, P. (2000). Pedagogy of the oppressed. New York, NY: Bloomsbury Publishing. (Original work published 1970).

Fu-Kiau, K.K. \& A.M. Lukondo-Wamba. (2000). Kindezi: The kongo art of babysitting. Baltimore: Inprint Editions.

Gay, G. (2000). Culturally responsive teaching: Theory, research, and practice. New York: Teachers College Press.

Gifford-Smith, M. E., \& Brownell, C. A. (2003). Childhood peer relationships: Social acceptance, friendships, and peer networks doi:http://dx.doi.org/10.1016 /S0022-4405(03)00048-7

Goldstein, S.E., Young, A., \& Boyd, C. (2008). Relational aggression at school: associations with school safety and social climate. Journal of Youth and Adolescence, 37(6), 641-654. Retrieved from http://eric.ed.gov.

Golf, P., Salisbury, J., \& Blitz, M. (2015). Comparing CALL and VAL-ED: An illustrative application of a decision matrix for selecting among leadership feedback instruments (WCER Working Paper No. 2015-5). Retrieved from the University of Wisconsin-Madison, Wisconsin Center for Education Research website: http://www.wcer.wise.edu/publications/workingPapers/papers.php

Grayson, M.L. (2017). Race talk in the composition classroom: Narrative song lyrics as texts for racial literacy. TETYC, 45(2), 143-167.

Green, R. (1998). The existence of nurturing characteristics in schools and its effect on student discipline. Guidance \& Counseling, 13(4), 10.

Gregory, A., \& Weinstein, R. S. (2008). The discipline gap and african americans: Defiance or cooperation in the high school classroom. Journal of School Psychology, 46(4), 455-475. doi:10.1016/j.jsp.2007.09.001

Gurwitch, R. H., Messer, E. P., Masse, J., Olafson, E., Boat, B. W., \& Putnam, F. W. (2016). Child-Adult relationship enhancement (CARE): An evidence-informed program for children with a history of trauma and other behavioral challenges. Child Abuse \& Neglect, 53, 138-145. doi:10.1016/j.chiabu. 2015.10.016

Haahr, M. \& Haahr, S. (2018). Random Integer Generator retrieved from URL: https://www.random.org/strings 
Harry, B., \& Anderson, M. G. (1994). The disproportionate placement of african american males in special education programs: A critique of the process. The Journal of Negro Education, 63(4), 602-619. doi:10.2307/2967298

Heifetz, R \& Linsky, M. (2017). Leadership on the line: Staying alive through the dangers of change. Boston, Massachusetts: Harvard Business School Press

Heilbrun, A., Cornell, D., \& Lovegrove, P. (2015). Principal attitudes regarding zero tolerance and racial disparities in school suspensions. Psychology In The Schools, 52(5), 489-499. doi:10.1002/pits.21838

Hunter, M. (2016). Colorism in the classroom: How skin tone stratifies african american and latina/o students. Theory into Practice, 55(1), 54-61. doi:10.1080 /00405841.2016.1119019

Infinite Campus, Inc. (2018). Retrieved from www.infinite.campus.com

Irizarry, Y. (2015). Selling students short: Racial differences in teachers' evaluations of high, average, and low performing students. Social Science Research, 52, 522-538.

Jones, C.P. (2018). Toward the science and practice of anti-racism: Launching a national campaign against racism. Ethnicity \& Disease, 28(1), 231-234. doi:10.18865/ed.28.S1.231

Juvenile Law Center. (2017). Retrieved from, http://jlc.org/news-room/mediaresources/glossary/juvenile-and-criminal-justice.

Kaplan, J. (2013). Requiring clear baseline and transparency is key in crafting rules for new school funding formula. California Budget and Policy Center. Retrieved from https://calbudgetcenter.org/blog/requiring-clear-baseline-and-transparency-is-key-in -crafting-rules-for-new-school-funding-formula/

Kelly, H. (2007). Racial tokenism in the school workplace: An exploratory study of black teachers in overwhelmingly white schools. Educational Studies, 41(3), 230-254. doi:10.1080/00131940701325712

Keppell, M., O’Dwyer, C., Lyon, B., \& Childs, M. (2011). Transforming distance education curricula through distributive leadership. Journal of Asynchronous Learning Networks, 15(4), 9-21. https://doi-org.libaccess.sjlibrary.org /10.24059/olj.v15i4.202

Kivunja, C., \& Kuyini, A. (2017). Understanding and applying research paradigms in educational contexts. International Journal of Higher Education, 6(5), 26-41. 
Kohli, R., Pizarro, M., \& Nevárez, A. (2017). The "new racism" of K-12 schools: Centering critical research on racism. Review of Research in Education, 41(1), 182202.

Kohli, R. \& Solórzano, D.G. (2012). Teachers, please learn our names!: racial microagressions (sic) and the K-12 classroom, Race Ethnicity and Education, 15(4), 441-462. doi:10.1080/13613324.2012.674026

Kremelberg, D. (2011). Practical statistics: A quick and easy guide to IBM® SPSS ${ }^{\circledR}$ statistics, STATA, and other statistical software. Thousand Oaks: United States, California, Thousand Oaks: SAGE Publications, Inc. doi:10.4135/9781483385655

Kunjufu, J. (2002). Black students. Middle class teachers. New York: African American Images

Ladson-Billings, G. (2014). Culturally relevant pedagogy 2.0: A.k.a. the remix.Harvard Educational Review, 84(1), 74-84,135. Retrieved from http://search.proquest.com. libaccess.sjlibrary.org/docview/1511014412?accountid $=10361$

Ladson-Billings, G. (1994). The dreamkeepers: Successful teachers of African American children. San Francisco, CA: Jossey-Bass.

Ladson-Billings, G., \& Tate,William F.,IV. (1995). Toward a critical race theory of education. Teachers College Record, 97(1), 47-68.

Lee, T., Cornell, D. G., Gregory, A., \& Fan, X. (2011). High suspension schools and dropout rates for black and white students. Education and Treatment of Children, 34(2), 167-192. doi:10.1353/etc.2011.0014

Leone, P. E., Christle, C. A., Nelson, C. M., Skiba, R., Frey, A., \& Jolivette, K. (2003). School failure, race, and disability: Promoting positive outcomes, decreasing vulnerability for involvement with the juvenile delinquency system. ().National Center on Education, Disability, and Juvenile Justice.

Lerma, R., Linick, M., Warren-Grice, A,, \& Parker, L. (2013). The politics of education: Its development and what is needed for the future for advocacy leadership in a postracial America. In L.C. Tillman \& J.J. Scheurich (Eds.), Handbook of research on educational leadership for equity and diversity (pp. 22-42). Retrieved from ProQuest Ebook Central, https://ebookcentral-proquest-com. libaccess.sjlibrary.org/lib/sjsu /detail.action?docID $=1356208$.

LibreTexts. (2019). Free the textbook. Retrieved from https://libretexts.org 
Lopez, A.E. (2015). Navigating cultural borders in diverse contexts: Building capacity through culturally responsive leadership and critical praxis. Multicultural Education Review, 7(3), 171-184. doi:10.1080/2005615X.2015.1072080

Love, B. (2019, March 18). Dear white teachers: You can't love your black students if you don't know them. Education Week, 38(26). Retrieved March 18, 2019 from https://www.edweek.org/ew/articles/2019/03/20/dear-white-teachers-you-cant-love -your.html?cmp=soc-edit-tw\&print=1

Love, B. (2014). Urban storytelling: How storyboarding, moviemaking, and hip-hopbased education can promote students' critical voice. English Journal, 103(5), 53-58.

Maddern, K. (2009). Tsars join forces to hit out at exclusion rates of SEN pupils.(high exclusion rates of special education needs students). Times Educational Supplement, (4859), 4.

Mathur, S. R., \& Schoenfeld, N. (2010). Effective instructional practices in juvenile justice facilities. Behavioral Disorders, 36(1), 20-27. Retrieved from http://search. proquest.com.libaccess.sjlibrary.org/docview /860367165?accountid=10361

Maunsell, P. A. (2014). Communication is key to common core. Phi Delta Kappan Magazine, 95(6), 61-65. doi:10.1177/003172171409500613

McEvoy, A. (2014). Abuse of power. Teaching Tolerance, 51-53. (48), Retrieved from https://www.tolerance.org/magazine/fall-2014/abuse-of-power

McEvoy, A. \& Smith, M. (2018, January). Statistically speaking. Teaching Tolerance, (58), Retrieved from https://www.tolerance.org/magazine/spring-2018 /statistically-speaking

McGrady, P. B., \& Reynolds, J. R. (2013). Racial mismatch in the classroom: Beyond black-white differences. Sociology of Education, 86(1), 3-17. Retrieved from http://www.jstor.org.libaccess.sjlibrary.org/stable/43744615

McLeod, S. A. (2014). Carl Rogers. Retrieved from www.simplypsychology.org /carl-rogers.html

Merriam, S.B. \& Tisdell, E.J. (2016). Qualitative research: A guide to design and implementation, $4^{\text {th }}$ Edition. San Francisco, CA: Jossey-Bass.

Mertens, D.M. (2003). Mixed methods and the politics of human research: The transformative-emancipatory perspective. In A. Tashakkori, C. Teddlie, \& C.B. 
Teddie (Eds.), Handbook of mixed methods in social \& behavioral research (pp. 135162). Thousand Oaks, California: Sage Publications.

Mertens, D.M. (2017a). An introduction to the transformative paradigm: Epistemology $\&$ methodology [Streaming video]. Retrieved from SAGE Research Methods.

Mertens, D.M. (2017b). Introduction to the transformative paradigm: axiology and ontology [Streaming video]. Retrieved from SAGE Research Methods.

Mertens, D.M. (2010). Philosophy in mixed methods teaching: The transformative paradigm as illustration. International Journal of Multiple Research Approaches, 4(1), 9-18.

Mertens, D.M. (2012a). Transformative mixed methods: Addressing inequities. American Behavioral Scientist, 56(6), 802-813. doi:10.1177/0002764211433797

Mertens, D.M. (2007). Transformative paradigm: Mixed methods and social justice. Journal of Mixed Methods Research, 1(3), 212-225. doi:10.1177/15586898 07302811

Mertens, D.M. (2017c). Transformative research: personal and societal, International Journal for Transformative Research, 4(1), 18-24. doi: https://doi.org/10.15 15 /ijtr-2017-0001

Mertens, D.M. (2012b). What comes first? The paradigm or the approach? Journal of Mixed Methods Research, 6(4), 255-257.

Mertens, D.M. (2009). Youth resilience research and the transformative paradigm. In Liebenberg, L. \& Ungar, M. (Eds.), Researching Resilience (pp. 297-317). Toronto; Buffalo; London: University of Toronto Press. Retrieved from http://www.jstor.org. libaccess.sjlibrary.org/stable/10.3138/9781442697669.16

Michael-Chadwell, S. (2011). Examining the underrepresentation of underserved students in gifted programs from a transformational leadership vantage point. Journal for the Education of the Gifted, 34(1), 99-130. doi:http://dx.doi.org.libaccess.sjlibrary.org/ $10.1177 / 016235321003400105$

Milner, H. R. (2007). Race, culture, and researcher positionality: Working through dangers seen, unseen, and unforeseen. Educational Researcher, 36(7), 388-400. doi:10.3102/0013189X07309471

Mizel, M. L., Miles, J. N. V., Pedersen, E. R., Tucker, J. S., Ewing, B. A., D’Amico, E. J. (2016). To educate or to incarcerate: Factors in disproportionality in school discipline. Children and Youth Services Review, 70, 102-111. doi:10.1016 
/j.childyouth.2016.09.009

Monroe, C. (Ed.). (2016). Race and colorism in education. Retrieved from http://ebookcentral.proquest.com

MTSS. (n.d.). In California Department of Education. Retrieved November 18, 2016, from http://www.cde.ca.gov

Muijs, D. D. (2004). Doing quantitative research in education: with spss. Retrieved from http://ebookcentral.proquest.com

Nance, J. (2016). Students, police, and the school-to-prison pipeline. Washington University Open Scholarship, 93(4).

Nasir, N., McLaughlin, M. W., \& Jones, A. (2009). What does it mean to be African American? Constructions of race and academic identity in an urban public high school. American Educational Research Journal, 46(1), 73-114. https://doi.org $/ 10.3102 / 0002831208323279$

National Center for Education Statistics. (2013). Number and percentage distribution of teachers in public and private elementary and secondary schools, by selected teacher characteristics: Selected years, 1987-88 through 2011-2012. Retrieved from https://nces.ed.gov/pubs2009/2009324/tables/sass0708_2009324_t12n_02.asp.

National Clearinghouse on Supportive School Discipline. (2017). Retrieved from, http://supportiveschooldiscipline.org/learn/reference-guides/disproportionateminority-contact.

Neal, L.I., McCray, A.D., Webb-Johnson, G., \& Bridgest, S.T. (2003). The effects of African American movement styles on teachers' perceptions and reactions. Journal of Special Education, 37(1), 49-57. Retrieved from http://www.eric.ed.gov.

Northouse, P.G. 2001. Leadership theory and practice ( $2^{\text {nd }}$ ed.). Thousand Oaks, CA: Sage Publications, Inc.

Office of Civil Rights (2016). 2013-2014 Civil rights data collection: A first look. United States Department of Education. Retrieved July 11, 2016.

Opotow, S. (1990). Moral exclusion and injustice: An introduction. Oxford, UK:10.1111 /j.1540-4560.1990.tb00268.x

Opotow, S., Gerson, J., \& Woodside, S. (2005). From moral exclusion to moral inclusion: Theory for teaching peace. Theory into Practice, 44(4), 303-318. 10.1207 /s1543042 1tip4404_4 
Panorama Education. (2018). Retrieved from www.panoramaed.com

Patton, J. M. (1998). The disproportionate representation of african americans in special education. The Journal of Special Education, 32(1), 25-31. doi:10.1177 /002246699803200104

Peguero, A. A., \& Shekarkhar, Z. (2011). Latino/a student misbehavior and school punishment. Hispanic Journal of Behavioral Sciences, 33 (1), 54-70.

Pringle, B. E., Lyons, J. E., \& Booker, K. C. (2010). Perceptions of teacher expectations by african american high school students. The Journal of Negro Education, 79(1), 3340. Retrieved from http://www.jstor.org.libaccess.sjlibrary.org/stable/ 25676107

Reeve, J., Jang, H., Carrell, D., Jeon, S., \& Barch, J. (2004). Enhancing Students' Engagement by Increasing Teachers' Autonomy Support. Motivation and Emotion, 28(2), 147-169.

Reid, A., \& Allum, N. (2019). Learn about rescaling and transforming variables in survey data in SPSS with data from the general social survey (2004-2016). London: London: SAGE Publications Ltd. doi:10.4135/9781526489401

Reimer, M.S. \& Dimock, K. (2005). Best practices and model truancy programs. Truancy prevention in action. Clemson, SC: National Dropout Prevention Center/ Network (NPDC/N), Office of Juvenile Justice and Delinquency Prevention, U.S. Department of Justice.

Reschly, A., \& Christenson, S. (2006). Prediction of Dropout Among Students With Mild Disabilities. Remedial and Special Education, 27(5), 276-292.

Riccards. P. (2014). Eduflack: It's time to reframe the k-12 policy debate. Education Week, 34(4), 22-25.

Robinson, V. (2011). Student-centered leadership. San Francisco, CA: Jossey-Bass.

Rose, T., Joe, S., Shields, J., \& Caldwell, C. (2014). Social integration and the mental health of black adolescents. Child Development, 85(3), 1003-1018.

Ross, J., Berger, M.J. (2009). Equity and leadership: Research-based strategies for school leaders. School Leadership and Management, 29(5), 463-476.

Rumberger, R.W \& Losen, D.J. (2017). The hidden cost of California's harsh school discipline. K-12 racial disparities in school discipline. UCLA: The Civil Rights Project/ Proyecto Derechos Civiles. Retrieved from: http://escholarship.org/uc 
/item/0x36s2wf, 6/13/17

Russell, V. J., Ainley, M., \& Frydenberg, E. (2005). Student motivation and engagement. Schooling Issues Digest of the Australian Government Department of Education, Employment, and Workplace Relations. Retrieved from http:/web.archive.org/web /20120110214153/http:/www.dest.gov.au/sectors/school_education/publications resources/schooling_issues_digest/schooling_issues_digest_motivation_engagement. htm

Safir, S. 2017. The listening leader: Creating the conditions for equitable school transformation. San Francisco, CA: Jossey-Bass.

Saji, P. (Writer), \& Cropper, A. (Director). (2017, October 3). Juneteenth [Television series episode] In K. Barris, A. Anderson, B. Dobbins, J. Groff, \& H. Sugland (Executive producers), Black $\bullet$ ish. Hollywood, CA: American Broadcasting Company, Inc.

Saji, P. (Writer), \& Richardson-Whitfield, S. (Director). (2019, January 15). Black like us [Television series episode] In In K. Barris, A. Anderson, B. Dobbins, J. Groff, \& H. Sugland (Executive producers), Black $\bullet$ ish. Hollywood, CA: American Broadcasting Company, Inc.

Schlechter, M., \& Milevsky, A. (2010). Parental level of education: Associations with psychological well-being, academic achievement and reasons for pursuing higher education in adolescence. Educational Psychology, 30(1), 1-10. doi:10.1080 /01443410903326084

Singleton, G. \& Linton, C. (2006). Courageous conversations about race: A field guide to achieving equity in schools. Thousand Oaks, CA: Corwin.

Senge, P., Cambron-McCabe, N., Lucas, T., Smith, B., Dutton, J., \& Kleiner, A. (2012). (Rev Upd). Schools that learn. A fifth discipline fieldbook for educator, parents, and everyone who cares about education. New York: Doubleday.

"SFUSD Board of Education Policy 71-23Sp1"; San Francisco Coalition of Essential Small Schools, 2006. Retrieved from http://sfcess.org/wp-content/uploads/2018/05 /SSDPolicy_final_011207.pdf

Sheridan, S. M., Buhs, E. S., \& Warnes, E. D. (2003). Childhood peer relationships in context doi: http://dx.doi.org.libaccess.sjlibrary.org/10.1016/S0022-4405(03)00049-9

Sirin, S. R., \& Rogers-Sirin, L. (2004). Exploring school engagement of middle-class african american adolescents. Youth \& Society, 35(3), 323-340. doi:10.1177 /0044118X03255006 
Skiba, R. J., Horner, R. H., Chung, C. G., Rausch, M. K., May, S. L., \& Tobin, T. (2011). Race is not neutral: A national investigation of African American and Latino disproportionality in school discipline. School Psychology Review,40(1), 85.

Skiba, R. J., Michael, R. S., Nardo, A. C., \& Peterson, R. L. (2002). The color of discipline: Sources of racial and gender disproportionality in school punishment. Urban Review, 34(4), 317-342.

Solomon, R. C., \& Flores, F. (2001). Building trust. Business, Politics, Relationships, and Life. Oxford University Press.

Solórzano, D. G. (1997). Images and words that wound: Critical race theory, racial stereotyping, and teacher education. Teacher Education Quarterly, 24(3), 5-19.

Solórzano, D. G., \& Ornelas, A. (2004). A critical race analysis of Latina/o and african american advanced placement enrollment in public high schools. The High School Journal, 87(3), 15-26. Retrieved from http://www.jstor.org.libaccess.sjlibrary.org /stable/40364293

Spegel, K. M. (2016). A case study of adolescent girls transitioning from juvenile correctional facilities into community schools (Order No. 10196179). Available from ProQuest Dissertations \& Theses A\&I; ProQuest Dissertations \& Theses Global: The Humanities and Social Sciences Collection. (1848961130). Retrieved from http://search.proquest.com.libaccess.sjlibrary.org/ docview $/ 1848961130$ ? accountid $=10361$

Stephan, W. G., Ybarra, O., \& Morrison, K. R. (2009). Intergroup threat theory. In T. D. Nelson (Ed.), Handbook of prejudice, stereotyping, and discrimination (pp. 43-60). New York, NY: Psychology Press.

Storer, H. L., Mienko, J. A., Chang, Y.-L., Kang, J. Y., Miyawaki, C., \& Schultz, K. (2012). Moving beyond dichotomies: how the intersection of race, class and place impacts high school graduation rates for African American students. Journal of Sociology \& Social Welfare, 39(1), 17-44. Retrieved from http://link.galegroup. com.libaccess.sjlibrary.org/ apps/doc/A285928116 /OVIC? $\mathrm{u}=$ csusj\&sid=OVIC\&xid $=$ fde 40410

Sue, D. W. (2010). Microaggressions in everyday life: Race, gender, and sexual orientation (1st ed.). Hoboken: John Wiley \& Sons, Incorporated.

Sue, D. W., Capodilupo, C. M., Torino, G. C., Bucceri, J. M., Holder, A. M. B., Nadal, K. L., \& Esquilin, M. (2007). Racial microaggressions in everyday life: Implications for clinical practice. American Psychologist, 62(4), 271-286. 
doi:1037/0003-066X.62.4.271

Sweeten, G. (2006). Who will graduate? disruption of high school education by arrest and court involvement. Justice Quarterly, 23(4), 462-480. doi:10.1080 /07418820600985313

Tennenbaum, Shawn, "Relational Trust within an Urban Public Comprehensive High School District in Northern California" (2018). Dissertations. 21. http://scholarworks.sjsu.edu/etd_dissertations/21.

Thompson, M. S., \& McDonald, S. (2016). Race, skin tone, and educational achievement. Sociological Perspectives, 59(1), 91-111. doi:10.1177/0731121415580026

Togut, T. (2011). The gestalt of the school-to-prison pipeline: The duality of overrepresentation of minorities in special education and racial disparity in school discipline on minorities. The American University Journal of Gender, Social Policy \& the Law, 20(1), 163-181.

Townsend, W. (2000). In Rebore R. (Ed.), The perceptions of special education administrators and high school principals regarding the discipline procedures of students with disabilities ProQuest Dissertations Publishing.

Townsend Walker, B.L. (2014). Suspended animation: A legal perspective of school discipline and African American learners in the shadows of brown. Journal of Negro Education, 83(3), 338-351.

Tschannen-Moran, M. \& Tschannen-Moran, B. (2014). When your school's in a bad mood. Educational Leadership, 37-41.

Turner, E. O., \& Spain, A. K. (2016). The multiple meanings of (in)equity: Remaking school district tracking policy in an era of budget cuts and accountability. Urban Education, doi:10.1177/0042085916674060

UC Davis School of Education (Producer), \& Solórzano, D.G. (2014). Using the tools of critical race theory and racial microaggressions to examine everyday racism [Video file]. Retrieved from https://www.youtube.com/watch?v=6JU4294fZNA

UCLA Civil Rights Project (2017). Retrieved from https://www.civilrightsproject. ucla.edu/

U.S. Department of Education Office for Civil Rights. (2014). Civil Rights Data Collection: Data Snapshot (School Discipline). Washington, DC: Author.

Valenzuela, A. (1999). Subtractive schooling. Albany, NY: State University of New York 
Press.

Value [Def. 3]. (n.d). In Merriam-Webster Online Dictionary. Retrieved August 7, 2018, from https://www.merriam-webster.com/dictionary/value.

Vasquez, Nereida Robles, "Analyzing Student-Teacher Relationships of Cariño and Confianza and Their Impact on Academic Engagement by Latino Males" (2018). Dissertations. 25. https://scholarworks.sjsu.edu/etd_dissertations/25

Voelk1, K.E. (2012). School identification. In S. L. Christenson, A. L. Reschly \& C. Wylie (Eds.), Handbook of research on student engagement (pp. 193-218). US: Springer. doi:10.1007/978-1-4614-2018-7

Walkley, M., \& Cox, T. L. (2013). Building trauma-informed schools and communities. Children \& Schools, 35(2), 123-126. doi:10.1093/cs/cdt007

Wallace, J. M. ,Jr., Goodkind, S., Wallace, C. M., \& Bachman, J. G. (2008). Racial, ethnic, and gender differences in school discipline among US high school students: 1991-2005. The Negro Educational Review, 59(1-2), 47-62.

Weiss, C. C., Carolan, B. V., \& Baker-Smith, E. (2010). Big school, small school: (re)testing assumptions about high school size, school engagement and mathematics achievement. Journal of Youth and Adolescence, 39(2), 163-176. doi:10.1007/s10964-009-9402-3

Winstead, T. L. (2016). Microaggressions in team-based learning groups (Order No. 10118046). Available from ProQuest Dissertations \& Theses Global: The Humanities and Social Sciences Collection. (1803627543). Retrieved from http://search.proquest. com.libaccess.sjlibrary.org/docview/1803627543?accountid $=10361$

Wolf, R.E., Steinberg, A., \& Hoffman, N. (Eds.). (2013). Anytime, anywhere: Studentcentered learning for schools and teachers. Cambridge, MA: Harvard Education Press.

Worley, C.G. \& Lawler, E. (2010). Agility and organization design: A diagnostic framework. Organizational Dynamics, 39, 194-204.

X, M. (1965). In Haley A. (Ed.), The autobiography of Malcolm X. New York, NY: Grove Press.

Yosso, T. J. (2005). Whose culture has capital? A critical race theory discussion of community cultural wealth. Race, Ethnicity and Education, 8(1), 69-91. doi:10.1080/1361332052000341006 


\section{Appendices}

\section{Appendix A: CITI Program Completion Certificate}

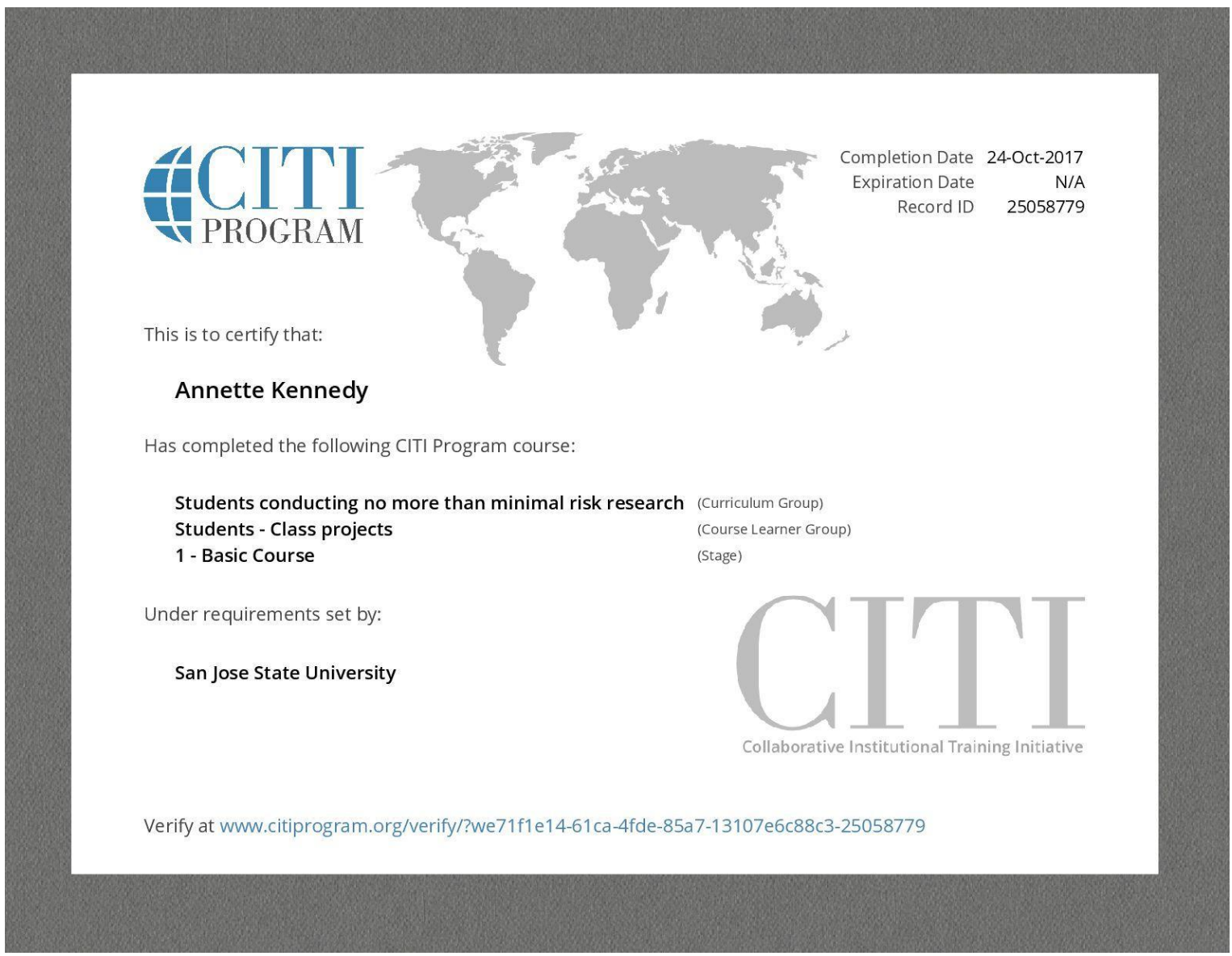




\section{Appendix B: Kohli Approval Letter}

\section{SJSU \\ Annette Kennedy <annette.kennedy@sjsu.edu>}

\section{Request to Reprint a Figure for Ed.D Project}

\section{2 messages}

Annette Kennedy <annette.kennedy@sjsu.edu>

Sun, Jun 17,2018 at 9:41 AM

To: kohli.rita@yahoo.com

Dr. Kohli,

Good morning, I am in my third year as a doctorate student in the Ed.D program at SJSU. My dissertation will focus on the extent to which Black or African American students within my high school district experience racial microaggressions in the classroom setting (from teachers, peers, or both), the types of racial microaggressions experienced, and the human support systems within their school, if any, they rely on if the classroom is not a welcoming place.

I am writing to ask for your permission to use/reprint Figure 1. A model for understanding racial microaggresions on p. 447 of Teachers, please learn our names!: racial micro aggressions and the K-12 classroom in Chapter 2 of my dissertation.

Please let me know if you need any additional information concerning my project or the use of the figure. Thank you in advance for your assistance with this matter.

Respectfully,

Annette Kennedy, M.S.A, M.A

Ed.D Candidate | Educational Leadership

San Jose State University

910-850-6884 (cell)

annette.kennedy@sjsu.edu

Rita Kohli <kohli.rita@yahoo.com>

Sun, Jun 17,2018 at 6:38 PM

To: Annette Kennedy <annette.kennedy@sjsu.edu>

Annette

Nice to hear from you. This should be fine, as long as it's cited properly. Important research! Best of luck!

Warmly,

Rita

Sent from my iPhone

[Quoted text hidden] 


\section{Appendix C: IRB Notice of Approval}

\section{\begin{tabular}{l|l|l|l} 
SAN JOSE STATE & $\begin{array}{l}\text { Office of Research } \\
\text { Division of } \\
\text { Academic Affairs }\end{array}$ & $\begin{array}{l}\text { San José State University } \\
\text { One Washington Square } \\
\text { San José, CA 95192-0025 }\end{array}$ & $\begin{array}{l}\text { TEL: } \\
\text { officeofresearch@sjsu.edu } \\
\text { sjsu.edu/research }\end{array}$ \\
UNIVERSITY &
\end{tabular}}

SAN JOSE STATE UNIVERSITY

HUMAN SUBJECTS INSTITUTIONAL REVIEW BOARD

IRB Notice of Approval

Date of Approval: 8/7/2018

Study Title: Students of Black or African American Ancestry in Grades 10th-12th Perceptions of Their Schooling Experience

Primary Investigator(s): Dr. Amy Leisenring

Student(s): Annette Kennedy

Other Team Members:

Funding Source: None

IRB Protocol Tracking Number: S18105

Type of Review

$\square$ Exempt Registration: Category of approval §46.104(d)()

$\bigotimes \quad$ Expedited Review: Category of approval $\$ 46.110(\mathrm{a})(7)$

$\square$ Full Review

$\square$ Modifications

$\square$ Continuing Review

Special Conditions

$\square$ Waiver of signed consent approved

$\square$ Waiver of some or all elements of informed consent approved

$\square$ Risk determination for device:

$\square$ Other:

Continuing Review

$\otimes$ Is not required. Principal Investigator must file a status report with the Office of Research one year from the approval date on this notice to communicate whether the research activity is ongoing. Failure to file a status report will result in closure of the protocol and destruction of the protocol file after three years. 
Is required. An annual continuing review renewal application must be submitted to the Office of Research one year from the approval date on this notice. No human subjects research can occur after this date without continuing review and approval.

Approved by Dr. Pamela C. Stacks

Associate Vice President

Institutional Official

Office of Research

San Jose State University

IRB Contact

Alena Filip

Human Protections Analyst

408-924-2479

Alena.Filip@sjsu.edu

\section{Primary Investigator Responsibilities}

- Any significant changes to the research must be submitted for review and approval prior to the implementation of the changes.

- Reports of unanticipated problems, injuries, or adverse events involving risks to participants must be submitted to the IRB within seven calendar days of the primary investigator's knowledge of the event.

- If the continuing review section of this notice indicates that continuing review is required, a request for continuing review must be submitted prior to the date the provided. 


\section{Appendix D: Principal Introduction Email Letter}

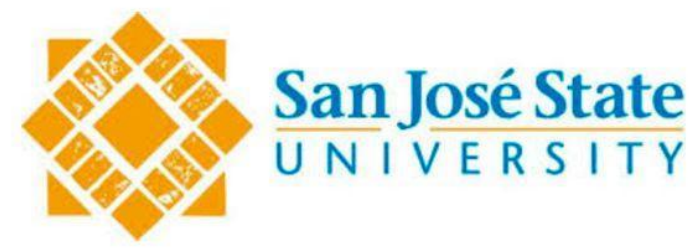

Dear Principal,

I am Annette Kennedy, an Associate Principal within the District. I am emailing you today as a San José State University doctoral student in the Department of Educational Leadership program to ask for your assistance in completing my dissertation. I have been given clearance by the District Office to conduct my research study with the 11 comprehensive high schools. The purpose of this study is to examine the perceptions of $10^{\text {th }}-12^{\text {th }}$ grade high school students' of Black or African American ancestry hold about their classroom and school experiences. The intent is to understand students' interactions with school staff and peers, bring an awareness of the extent racial microaggressions are experienced, and to raise the level of cultural consciousness within the classroom learning environment. Using the input/voices of Black or African American students will be instrumental in all areas of strategic and scenario planning to drive professional development, curriculum needs assessments, and intervention/programs that will be most effective for school leaders, teachers, and students at all levels within the District.

In order to conduct this study with fidelity:

A. The Principal will provide the Researcher with the contact information for the Black Student Union (BSU) Advisor. If the campus does not have such an Advisor, I request the contact information for the Head School Counselor who I can work with directly in recruiting students for the study. [Week of 8/13/18]

B. The Principal or designee will provide a list of their Black or AFAM students who are enrolled in $10^{\text {th }}-12^{\text {th }}$ grades. They are identified by Federal Code 4 and State Code 600 as Black or African American. Also, including Federal Code 7 : Two or more races if one of the racial groups is Black or African American and students who identify ethnically as Hispanic and racially as Black or African American. [Date: 8/27/18]

C. Coordinate with the Principal or designee a date and time between September $17^{\text {th }}-28^{\text {th }}$ to be able to use a computer lab, large space with tables and chairs, or classroom with access to chromecarts for students to complete the online survey. [S ch edule Week of 8/13/18]

The survey, created using SJSU Google Forms, is composed of 35 questions with both closed and open-ended response opportunities. It is estimated to take 30-40 minutes, depending on students responses to open-ended questions. All data collected will be kept confidential. Data security measures will be held with highest regard to include: requesting a dummy login through District IT so no student email addresses can be identified and ensuring no names of students, school district and its employees or facilities will be revealed in any reports related to the study. Active consent (parent/guardian) and assent (student) are required for participation. Students will be provided with food for their participation on the date the survey is administered at your school. For schools who have $80 \%$ of their Black or African American student population complete the survey, they will be awarded a $\$ 100$ to their BSU Club. If no organized BSU Club is present then the funds may be used towards a student diversity inspired activity.

Thank you in advance for your assistance in helping to empower the voices of our Black or African American students we serve in the District. If you have any concerns or questions please contact me. I look forward to working with you and your students.

Respectfully,

Annette Kennedy

Ed.D Candidate | Educational Leadership

San José State University

910-850-6884 (cell)

annette.kennedy@sjsu.edu 


\section{Appendix E: KICK-OFF Phone Blast}

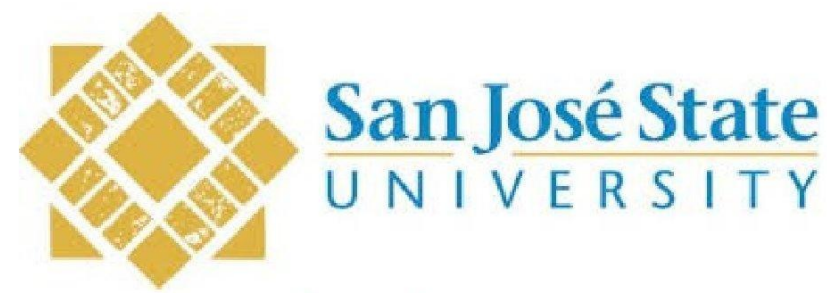

\section{Research Study KICK-OFF!!!}

Happy Labor Day!! I hope you are enjoying your day. My name is Annette Kennedy. I am an Associate Principal within the District. However, I am contacting you today as a Doctoral Student in the Educational Leadership program at San José State University. As an African American woman working in the K-12 education system, it is disheartening to see many of our young people nationally, statewide, and locally constantly faced with what I coin as the Seesaw Imbalance Effect-often hyper visible on the discipline end yet experience invisibility with respect to academic achievement, graduation rates, and being less likely to access honors and AP courses during their high school career. Unfortunately, this trend has lead many Black and African American youth to disproportionally lose out on instructional time, leading to loss of credits and disengagement from school.

As we continue to forge toward a Relationship Centered school district, there is much work to be done according to the results of our Spring 2018 School Climate Survey that revealed Black students expressed higher levels of dissatisfaction across the board including "Sustaining positive relationships between staff and students" (LCAP Next Steps, May 17, 2018). The intent of this Research Study is to dig deeper as to why our students feel disconnected to their schools and district as a whole by understanding from their perspective what their schooling experience is like. For some students this may include recalling some not so pleasant instances experienced at school.

During the month of September, I will be administering a survey entitled, Students of Black or African American Ancestry in Grades $10^{\text {th }}-12^{\text {th }}$ Perceptions of Their Schooling Experiences. The survey requires active consent from parent/guardian as well as the student to participate. Your student will receive more information about the survey this week. Please remind your student to be on the lookout to receive a packet and to bring it home and share with you. It is important that our young people share their experiences to impact decision-making that directly affects them. Student voice is about empowering youth to express their opinions, thoughts, and beliefs in order to influence their educational outcomes.

All information obtain will be confidential and no names of any participants will be named in any reports generated from the analysis of this study. My contact information will be included in the packet. I want to thank you in advance for encouraging your student to participate in this survey for such a worthy purpose- improving the quality of their educational experiences.

Sincerely,

Annette Kennedy

Doctoral Candidate

SJSU Dept. of Educational Leadership 


\section{Appendix F: Parent/Guardian Informational Flyer}

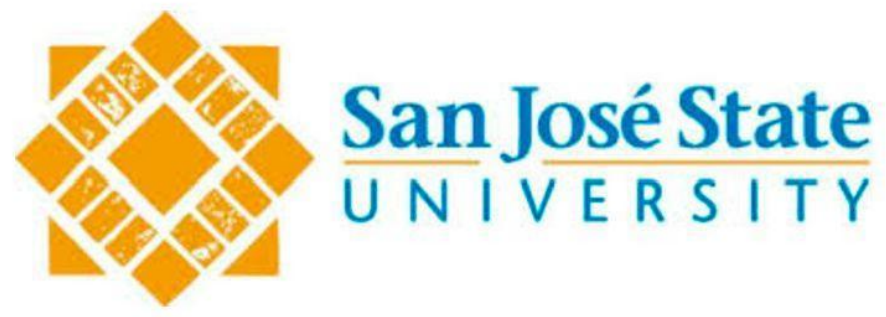

Dear Parents and Guardians,

I am Annette Kennedy, an Associate Principal within the District. I am writing you today as a San José State University doctoral student in the Department of Educational Leadership program to ask for your assistance in completing my dissertation. I have been given clearance by the District Office to conduct my research study with the 11 comprehensive high schools. The purpose of this study is to examine the perceptions of $10^{\text {th }}-12^{\text {th }}$ grade high school students' of Black or African American ancestry hold about their classroom and school experiences. The intent is to understand students' interactions with school staff and peers, bring an awareness of the extent racial microaggressions are experienced, and to raise the level of cultural consciousness within the classroom learning environment. Using the input/voices of Black or African American students will be instrumental in all areas of strategic and scenario planning to drive professional development, curriculum needs assessments, and intervention/programs that will be most effective for school leaders, teachers, and students at all levels within the District.

In order to conduct this study with fidelity:

A. I will work with your student's school Black Student Union (BSU) Advisor or Head School Counselor during the recruitment phase of the study beginning the first week of September, 2018.

B. Because this study requires active consent, I will need to receive all Consent (parent/guardian) and Assent (student) forms signed and returned preferably as soon as possible but no later than September $14^{\text {th }}$ in order for your student to participate in the study.

C. The survey will be administered to your student on the designated date/time set by the school between September $17^{\text {th }}-28^{\text {th }}$

The survey, created using SJSU Google Forms, is composed of 35 questions with both closed and open-ended response opportunities. It is estimated to take 30-40 minutes, depending on students responses to open-ended questions. All data collected will be kept confidential. Data security measures will be held with highest regard to include: requesting a dummy login through District IT so no student email address can be identified and ensuring no names of students, school district and its employees or facilities will be revealed in any reports related to the study. Active consent (parent/guardian) and assent (student) are required for participation. Students will be provided with food for their participation on the date the survey is administered at their school. For schools who have $80 \%$ of their Black or African Am erican student population complete the survey, they will be awarded a $\$ 100$ to their BSU Club. If no organized BSU Club is present then the funds may be used towards a student diversity inspired activity.

Thank you in advance for your assistance in helping to empower the voices of our Black or African American students we serve in the District. If you have any concerns or questions please contact me. I look forward to working with you and your student.

Respectfully,

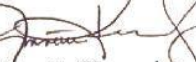

Annette Kennedy

Ed.D Candidate | Educational Leadership

San José State University

annette.kennedy@sjsu.edu 


\section{Appendix G: Student Infographic}

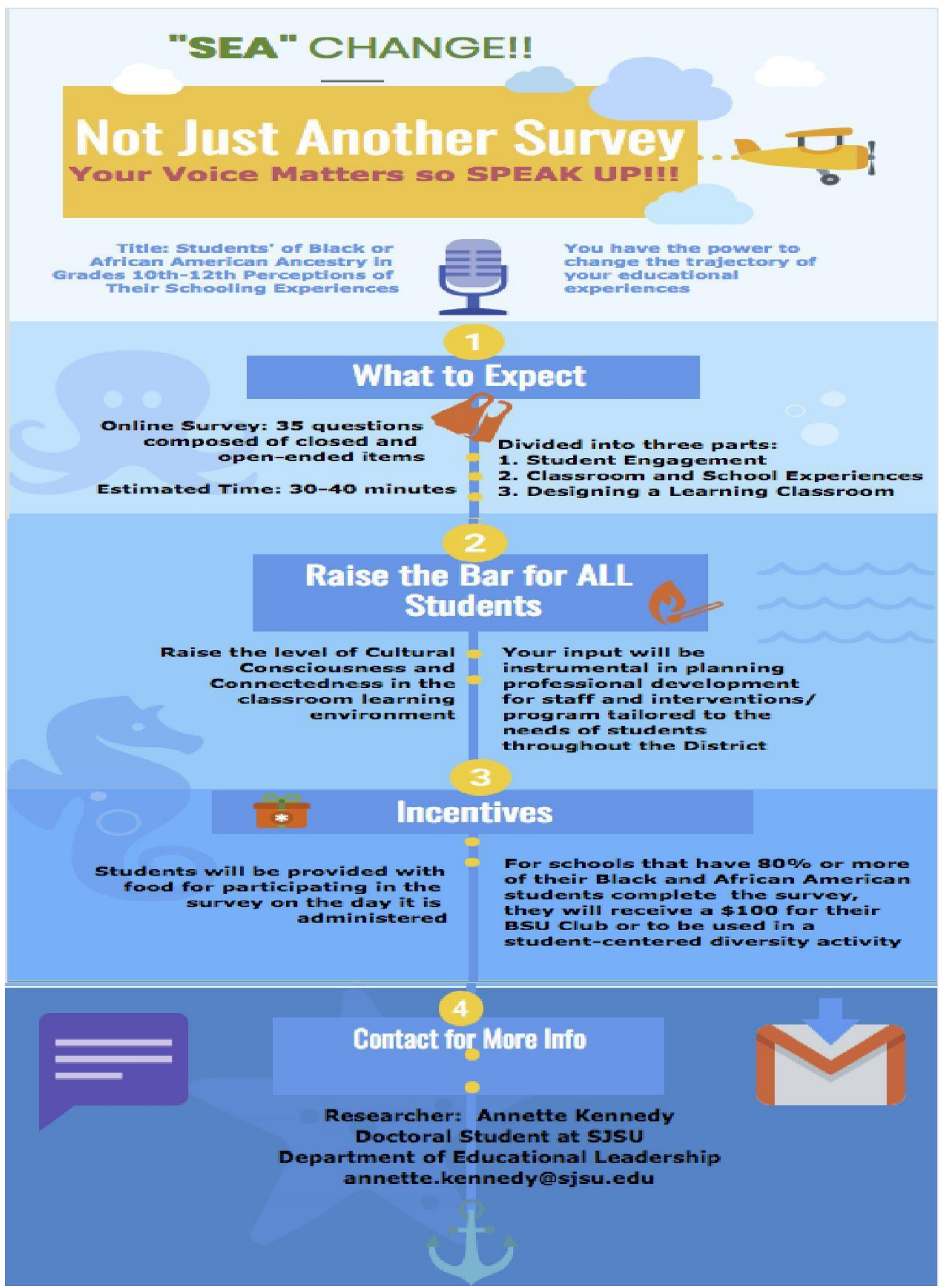




\section{Dear Student,}

I just want to say thank you in advance for taking part in this survey. I cannot stress enough how important it is

to have your voice heard through your survey responses. I assure you that all information collected will remain confidential and your name will not appear in any report in relation to this project. Please Remember these KEY DATES:

Return CONSENT (parent/guardian) and ASSENT (student) forms back no later than

The online survey will be administered on the following:

Date:

Time:

Location:

I look forward to working with you in this study.

Sincerely,

Ms. Annette Kennedy

SJSU Doctoral Candidate 


\section{Appendix H: Parent Consent Form}

\section{Parent or Guardian Permission Form REQUEST FOR YOUR CHILD'S PARTICIPATION IN RESEARCH}

TITLE OF THE STUDY: Students of Black or African American Ancestry in Grades 10th12th Perceptions of Their Schooling Experiences

NAME OF THE RESEARCHER: Annette Kennedy, Ed.D Candidate, San José State University

Annette Kennedy is a high school Associate Principal in the Bay area of California. She is originally from North Carolina. Ms. Kennedy received her undergraduate degree in Sociology and African American Studies from the University of North Carolina at Chapel Hill (1999). She further received a Master of Arts in Sociology from North Carolina Central University (2002) and a Master of School Administration from Fayetteville State University (2010). Research areas of interests include alternative instructional pedagogies, equity, school discipline, and student engagement.

\section{PURPOSE}

The purpose of this study is to examine the perceptions of $10^{\text {th }}-12^{\text {th }}$ grade Black or African American high school students' have about their classroom and school experiences. The goals are to understand students' interactions with school staff and peers, bring an awareness of racial microaggressions (subtle, stunning, often automatic, and non-verbal exchanges which are put downs [Sue et al., 2007]), and to raise the level of cultural consciousness by informing professional development and instructional practices impacting the classroom learning environment.

\section{PROCEDURES}

If you allow your child to participate in this project, your child will be asked to complete an online survey that is composed of three sections: Student Engagement, Classroom and School Experiences, and Designing a Learning Classroom. The survey consists of 35 closed and openended questions. The online survey will take approximately 30 - 40 minutes to complete based on your child's comfort level with technology and depth of their responses to the open-ended questions. The survey will be administered at your child's school site and will have access to a computer. Paper copies of the survey will also be made available to students who have difficulty manipulating a computer, request a hardcopy, or in the event of technological failure resulting in a need to switch to paper-based administration. The survey will be administered in September.

\section{POTENTIAL RISKS}

This study poses minimum risk to your child. A potential risk includes experiencing some discomfort from recalling incidents directed toward them. If the experience of recalling instances of such behavior is stressful, your child may take a break or choose to end the survey. If your child chooses to end the survey early any data collected will be retained as part of the 
study's analysis.

The Researcher will make a referral on behalf of the participant to the school site Social Worker who is trained in providing social emotional and mental health counseling. The Researcher will also contact the parent/guardian to inform them of any discomfort their child has experienced while completing the survey.

\section{POTENTIAL BENEFITS}

Students may feel good about participating in research that may help their school or may help other Black and African American students. Your child's participation will contribute to the knowledge about students' experiences in school and may help society.

\section{COMPENSATION}

Food will be provided to your student for taking part in the study.

\section{CONFIDENTIALITY}

Security measures will be employed to ensure confidentiality of study participants. The Researcher will request a generic/dummy login for students to use to avoid having to use their school email logins to minimize risk of identification. No student names or personal student identification numbers are asked on the survey instrument. Your child will be given a specialized survey ID code to enter on the online survey that will be crossed referenced with a secured document that contains confidential information of your child accessible only to the Researcher. The secured document will be destroyed once the data collection is completed. No names of students or school district or its employees or facilities will be revealed in any reports related to the study. PLEASE NOTE: I am a Mandated Reporter. A Mandated Reporter is someone who is legally required to report abuse, neglect, or a person's intent to harm self or others to the appropriate authority.

\section{PARTICIPANT RIGHTS}

Your child's participation in this study is completely voluntary. You may refuse to allow his or her participation in the entire study or any part of the study without any negative effect on your relations with San Jose State University or this district. This consent form is not a contract. It is a written explanation of what will happen during the study if you decide to allow your child to participate. You will not waive any rights if you choose not to allow your child to participate and there is no penalty for stopping your child's participation in the study. Your child may also decide to stop at any time. Any data collected at that time will be used as part of the study's analysis. The data may be used in future research after identifiers are removed. The district may benefit from the findings of this study. The information collected from this study will be used for a chapter of the Researcher's doctoral dissertation. All school districts in the state of California as well as throughout the nation who desire to improve the educational outcomes of Black or African American students may benefit from this study. The data may be used in presentations and the writing of subsequent white papers and publications.

\section{QUESTIONS OR PROBLEMS}


You are encouraged to ask questions and to have your child ask questions at any time during this study.

- For further information about the study, please contact Ms. Annette Kennedy at 910850-6884 or annette.kennedy@sjsu.edu.

- Complaints about the research may be presented to Dr. Arnold Danzig, Chair of the Department of Educational Leadership, at 408-924-3722.

- For questions about participants' rights or if you feel your child has been harmed by participating in this study, please contact Dr. Pamela Stacks, Associate Vice President of the Office of Research, San Jose State University, at 408-924-2479.

\section{SIGNATURES}

Parent/Guardian Signature

Your signature indicates that you voluntarily agree to allow your child to be part of the study, that the details of the study have been explained to you and your child, that you have been given time to read this document, and that your questions have been answered. You will be given a copy of this consent form, signed and dated by the researcher, to keep for your records.

Name of Child

Relationship to Child
Parent or Guardian Name (Printed)

Parent or Guardian Signature

\section{Researcher Statement}

I certify that the minor's parent/guardian has been given adequate time to learn about the study and ask questions. It is my opinion that the parent/guardian understands his/her child's rights and the purpose, risks, benefits, and procedures of the research and has voluntarily agreed to allow his/her child to participate. I have also explained the study to the child in language appropriate to his/her age and have received assent from the child.

Researcher Signature

Name of Researcher (Printed) Date 


\section{Appendix I: Adolescent Assent Form}

\section{Assent Form for Adolescents \\ REQUEST FOR YOUR PARTICIPATION IN A RESEARCH STUDY}

TITLE OF THE STUDY: Students of Black or African American Ancestry in Grades 10th-12th Perceptions of Their Schooling Experiences

NAME OF THE RESEARCHER: Annette Kennedy, Ed.D Candidate, San José State University

Annette Kennedy is a high school Associate Principal in the Bay area of California. She is originally from North Carolina. Ms. Kennedy received her undergraduate degree in Sociology and African American Studies from the University of North Carolina at Chapel Hill (1999). She further received a Master of Arts in Sociology from North Carolina Central University (2002) and a Master of School Administration from Fayetteville State University (2010). Research areas of interests include alternative instructional pedagogies, equity, school discipline, and student engagement.

\section{WHAT THE RESEARCH IS ABOUT}

The purpose of this study is to understand students' interactions with school staff and peers in high school and how these interactions may relate to their level of engagement in school.

\section{WHAT YOU WILL BE ASKED TO DO}

You will be asked to complete an online survey that is composed of three sections: Student Engagement, Classroom and School Experiences, and Designing a Learning Classroom. The survey consists of 35 closed and open-ended questions. The online survey will take approximately 30 - 40 minutes to complete. The survey will be administered at your school site and you will have access to a computer. Paper copies of the survey will also be made available to you if you have difficulty using a computer, request a hard copy, or in the event of technological failure resulting in a need to switch to paper-based administration. The survey will be given in September.

\section{POTENTIAL RISKS}

This study poses minimum risk to you. A potential risk includes experiencing some discomfort from recalling incidents directed toward you. If the experience of recalling instances of such behavior is stressful you may take a break or choose to end the survey. If you choose to end the survey early any data collected will be retained as part of the study's analysis. The Researcher will submit a referral to the school site Social Worker who is trained in socio-emotional and mental health counseling. The Researcher will also contact your parent/guardian to inform them of any discomfort you have experienced while completing the survey.

POTENTIAL BENEFITS

You might enjoy helping others understand how to create a better learning environment for 
students at your school and other Black and African American students in society.

\section{COMPENSATION}

Food will be provided to you for taking part in the study.

\section{CONFIDENTIALITY}

Security measures will be employed to ensure confidentiality of study participants. The Researcher will request a generic/dummy login for students to use to avoid having to use their school email logins to minimize risk of identification. No student names or personal student identification numbers are asked on the survey instrument. You will be given a specialized survey ID code to enter on the online survey that will be crossed referenced with a secured document that contains confidential information about you accessible only to the Researcher. The secured document will be destroyed once the data collection is completed. No names of students or school district or its employees or facilities will be revealed in any reports related to the study. PLEASE NOTE: I am a Mandated Reporter. A Mandated Reporter is someone who is legally required to report abuse, neglect, or a person's intent to harm self or others to the appropriate authority.

\section{PARTICIPANT RIGHTS}

Your participation in this study is completely voluntary. You may refuse to participation in the entire study or any part of the study without any negative effect on your relations with San Jose State University or this district. This assent form is not a contract. It is a written explanation of what will happen during the study if you decide to participate. You will not waive any rights if you choose not to participate and there is no penalty for stopping your participation in the study at any time. Any data collected at that time will be used as part of the study's analysis. The data may be used in future research after identifiers are removed. The data may be used in presentations and writing of papers and publications.

\section{QUESTIONS OR PROBLEMS}

You are encouraged to ask questions at any time during this study.

- For further information about the study, please contact Ms. Annette Kennedy at 910850-6884 or annette.kennedy@sjsu.edu.

- Complaints about the research may be presented to Dr. Arnold Danzig, Chair of the Department of Educational Leadership, at 408-924-3722.

- For questions about participants' rights or if you feel you have been harmed by participating in this study, please contact Dr. Pamela Stacks, Associate Vice President of the Office of Research, San Jose State University, at 408-924-2479.

\section{ASSENT}

Student Signature

Your signature indicates that you voluntarily agree to be part of the study, that the details of the 
study have been explained to you, that you have been given time to read this document, and that your questions have been answered. You will be given a copy of this assent form, signed and dated by the researcher, to keep for your records.

Student Signature

Name of Student (Printed)

Date

\section{Researcher Statement}

I certify that the child's parent/guardian has been given adequate time to learn about the study and ask questions. It is my opinion that the parent/guardian understands his/her child's rights and the purpose, risks, benefits, and procedures of the research and has voluntarily agreed to allow his/her child to participate. I have also explained the study to the child in language appropriate to his/her age and have received assent from the child. 


\section{Appendix J: Survey Instrument}

\section{Students of Black or African American Ancestry in Grades 10th-12th Perceptions of Their Schooling Experiences}

Thank you for participating in this survey. The survey is divided into three parts: Section 1: Student Engagement, Section 2: Classroom and School Experiences, and Section 3: Designing a Learning Classroom.

* Required

\section{Survey Code ID}

Please enter your Survey Code ID given to you by the Researcher.

1. *

\section{Section 1: Student Engagement}

To what extent do the following statements relate to your high school experiences?

\section{My School}

Mark only one oval per row.

a. Overall, I feel good about being
in this high school
b. I care about this school
c. I feel safe in this school
d. My opinions are respected in
this school
e. There is at least one adult in
this school who knows me well
f. Teachers engage me in
classroom discussions
g. I can be creative in classroom
assignments and projects
h. I am comfortable being myself
in this school
i. I am an important part of my
high school community
j. This school's rules are fair
k. This school's rules are applied
and enforced consistently
I. If I could choose a high school
right now, I would choose this
school


3. Respond by selecting yes or no.

Mark only one oval per row.

a. Have you ever repeated a class
or course for credit in high school?
b. Do you believe you might have
to repeat a class or course taken
this year?

4. How much do each of the following classroom activities and assignments interest or engage you?

Mark only one oval per row

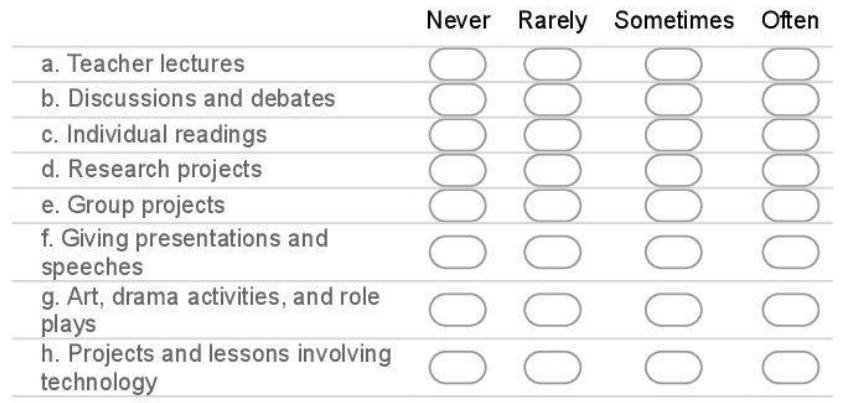

5. Please answer the following questions based on your high school experience Mark only one oval per row.

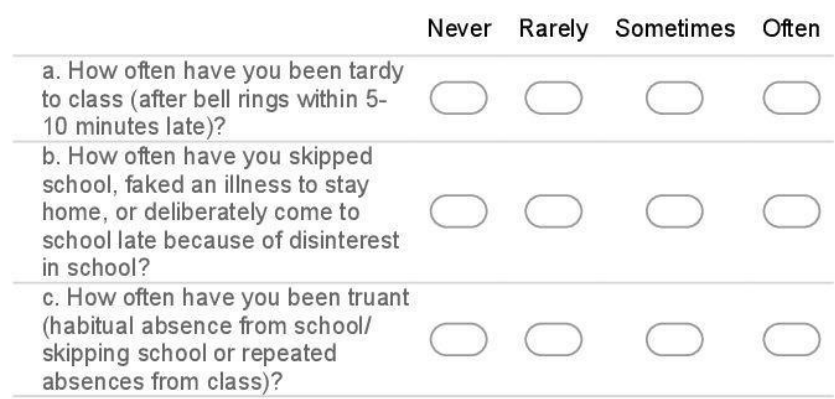

6. At any point in your high school career:

Mark only one oval per row.

No Yes: 1 time Yes: 2 or more times

a. Have you been suspended?
b. Have you ever been put up for
expulsion or expelled from
school?


7. In a typical 5-day week during the school year, about how many hours do you do the following? (Number of hours per week)

Mark only one oval per row.

0-1 $\quad 2-3 \quad 4-7 \quad 8$ or more

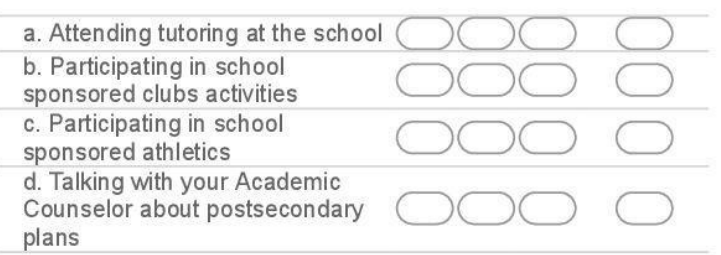

plans

8. Have you ever been bored in class because...

Mark only one oval per row.

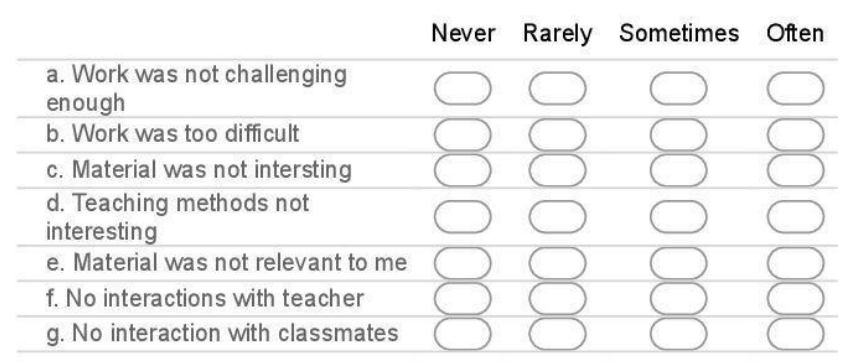

9. Have you ever considered transferring from this school to any of the following? Mark only one oval per row.

a. another school in the district
b. a public school outside of the
district
c. charter school
d. private/ independent school
e. online high school

10. If you selected any of the above options, please explain why you have considered those options. 
11. Have you ever considered leaving this high school because...

Mark only one oval per row.

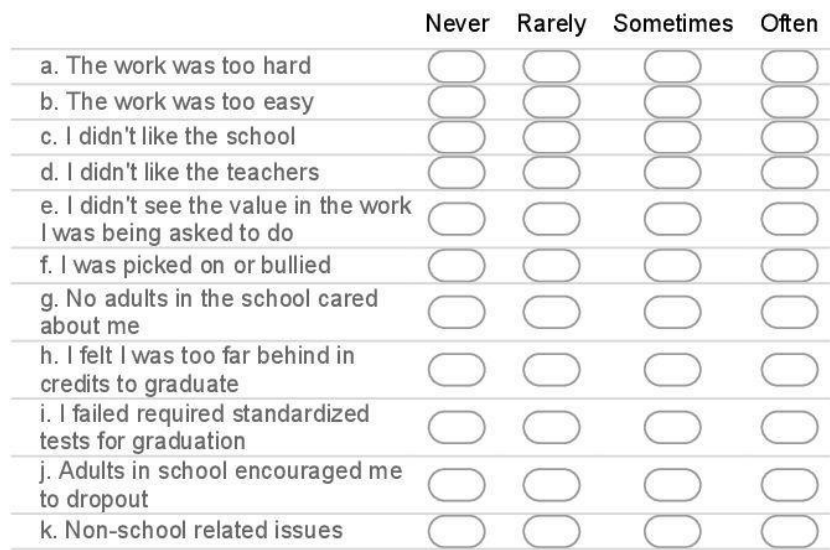

\section{Section 2: Classroom and School Experiences}

Please read the question and determine if it is something you have ever experienced with a teacher, peer, both or neither that you believe was due to your race. If it something you have experienced during your high school career please provide an example of the incident.

12. Have you ever experienced this based on your race...

Mark only one oval per row.

Teacher Peer Both Neither

a. had your name mispronounced

and continued to be after you

provided the correct

pronunciation?

b. felt like low expectations were

held of you in the classroom?

c. felt like a second class citizen in

the classroom?

d. felt singled out in class to respond to a question because of

your racial or ethnic background?

e. felt discouraged from working

on a project that explored your

social identities/(racial heritage)?

g. experienced negative

comments about immigrants?

13. If you have experienced these behaviors or incidents please provide EXAMPLE(S) and indicate by WHOM--[Do NOT Write the actual Name of the Person(s) only indicate "teacher" and/or "peer"]. 
14. Have you ever experienced this based on your race...

Mark only one oval per row.

a. had your hand raised in class
first to answer a question but
instead a student of a different
racial/ethnic group was called on
to respond?
b. been called a derogatory term
or racial slur?
c. been told you were dumb or
stupid?
d. received a write up or sent to
the office for a "subjective" reason
(e.g. disruption or defiance)?
e. heard or experienced
inappropriate racial/ethnic jokes
made in the classroom?

15. If you have experienced these behaviors or incidents please provide EXAMPLE(S) and indicate by WHOM --[Do NOT Write the actual Name of the Person(s) only indicate "teacher" and/or "peer"].

16. Have you ever experienced this based on your race...

Mark only one oval per row.

a. heard someone in class say
they are "colorblind" with respect
to seeing no differences between
racial/ethnic groups?
b. had someone make you feel
like you were not trusted or
believed about something in
class?
c. heard someone say race is no
longer a topic that should be
discussed in schools?
d. felt upset or experienced a
physical reaction (e.g. headache,
dizziness, nausea, stress, etc.)
related to an inappropriate
racial/ethnic comment or behavior
that occurred in a classroom?
e. Have you ever made a
statement or comment in class
that was not acknowledged only to
have another student of a different
racial/ ethnic group say the same
thing afterwards and is praised for
it?


17. If you have experienced these behaviors or incidents please provide EXAMPLE(S) and indicate by WHOM-[Do NOT Write the actual Name of the Person(s) only indicate "teacher" and/or "peer"].

18. Directions: Please read the question and determine to what degree you have ever experienced it in your high school career by selecting never, rarely, sometimes, often

Mark only one oval per row.

\section{Never Rarely Sometimes Often}

a. Do you see pictures or posters

in your classrooms that are

pictures of role models from your

racial or ethnic group?

b. Are most of the students in your

classes from the same racial or

ethnic background as you?

c. Do you observe people in

prominent roles (e.g. teacher,

counselor, administrator) in your

classroom or school that are of the

same race or ethnic background

as you?

d. Ever felt you were treated

differently by your teachers

because of your race or ethnicity

than your classmates?

e. Have you ever felt like you were

not welcome or treated like a

foreigner inside the classroom?

f. Have you been suspended from class (e.g. In School Suspension or Benched in the Office)?

g. If you are absent from class

does your teacher or classmate

contact you or follow-up with why

you were absent when you return

to class?

h. In your high school experience

have you always felt your teachers

graded all students fairly in the

classroom?

i. Have you ever felt like you were invisible or ignored in the

classroom?

j. Do you have classrooms with poor lighting?

k. Do you have classrooms with

peeling paint or damage (eg

holes in wall or graffiti) to the

walls?

I. Do you feel like discipline is fair

in the classroom? 


\section{Social Identity}

Please answer each question.

19. What makes you feel good about yourself?

20. Do you have any insecurities about school? If so, explain.

21. In the 2017-2018 school year, who were your top three go to staff members in your school that you trusted to talk to for emotional support and/or academic encouragement? (NOTE: You may check less than three if you did not have at least three people to identify)

Check all that apply.

Teacher

Administrator

Academic Counselor

Social Worker

Student Advisor

Custodian

Librarian

Parent/ Community Specialist

Secretary/ Clerk

Campus Monitor

Coach

Other Support Staff

I did not have an adult in the school who I felt I could trust to share personal information with or served as a motivator for me in the 2017-2018 school year

22. Do you have friends who belong to racial groups other than your own racial group? Mark only one oval.

Yes

No 
23. How would you describe your skin tone?

Mark only one oval.

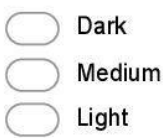

24. Check the boxes that best describe your hair style

Mark only one oval per row.

a. Natural (afro, braids, dreds,
twists, etc.)
b. Wavy
c. Straight (natural or relaxed)
d. Weave Wig

25. Do you believe that people at your school treat other people good or bad based on the color of their skin?

Mark only one oval.

$$
\begin{aligned}
& \text { Yes } \\
& \text { No }
\end{aligned}
$$

26. In your high school experience, have you ever felt like you were judged based on your skin color and/or hair style in the classroom?

Mark only one oval per row.

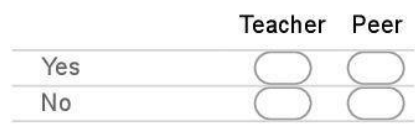

27. If you answered "yes" to any part of the previous question, please share in what way you felt judged? How did it affect your sense of belonging in the classroom? How did you deal/cope with it?

\section{Section 3: Designing a Learning Classroom}

Directions:

If you had a chance to design your ideal school learning environment what would it look like with respect

to academics, community, and equity? Please be as detailed as possible in your responses.

\section{ACADEMICS (Courses/ Instructional Practices)}


28. What types of courses would you like to see offered that you are interested in taking not currently offered at your school?

29. How would teachers teach their lessons (Think about your learning style-- e.g. more hands-on, direct instruction, etc.)? Grading Practices? How would technology be incorporated?

30. How do students interact with one another inside this classroom? Describe how they help each other learn?

\section{COMMUNITY (Physical Layout/ Connectedness)}

31. What is the maximum number of students in an ideal classroom? How would the classroom be arranged/setup? How would Black or African American culture be included in the classroom?

32. How would Black or African American families feel welcomed and integrated into the school? 


\section{EQUITY (Fairness)}

33. What are some ideas/ways on how Black or African American student voices can be empowered in the classroom and school?

34. What would discipline look like in the classroom/school?

35. How would students be made to feel cared for in the classroom?

\section{Thank you for completing the survey!!}

Powered by

Google Forms 


\section{Appendix K: Staff Paper Survey Directions}

Dear School Staff Member,

Thank you for your assistance with this project. I have included paper-based versions of the survey for the students who missed the administration date at your site.

The packets are sealed and only to be opened by the student. They need to complete it in school, in a quiet space. They will need a pencil to complete it. Once they finish they need to place it in the white envelope, seal it, and write their name across the seal and return it to you.

I need to have ALL completed surveys (as well as any unopened packets) back by Friday, October $5^{\text {th }}$.

Thank you again,

Annette Kennedy

Caveat:

To ensure the fidelity of the survey and the data collected please note: As with any other survey/ assessment administered in the District, I am asking that students not discuss the questions asked in the survey or be asked by school staff and/or peers questions pertaining to the survey content. 


\section{Appendix L: Student Paper Survey Directions}

Dear Student,

Sorry I missed you on the date the survey was administered at your school site. However, you still have an opportunity to take part in the survey. In the sealed envelope you will find:

1. A paper version of the survey

2. A white sealable envelope

If you receive an envelope not sealed or tampered with PLEASE contact Ms. Kennedy immediately!!

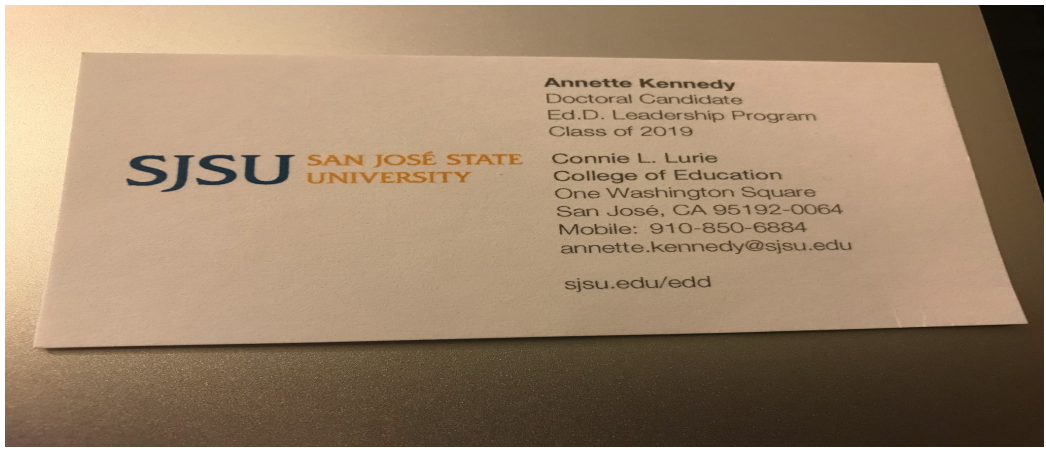

You will need to complete the survey at school. Please do not let anyone see the questions.

Once you answer the survey please place it in the white envelope and seal it. The write your name across the seal.

Return it to the School Staff Member who provided the envelope to you so they can return it to me.

Thank you again for participating in this survey to empower your voice in decisionmaking!! 


\section{Appendix M: Desire to Leave Current School Open Responses}

If you do not know, I just got here from the [public school outside of the district] in "_ ", that is really the only time [I] thought about switching. I always thought online high school would be easier because I do not like being in small rooms with a lot of people in it.

I would like to have a more diverse school.

There are too many past history bullies in my school, but other schools besides the one I'm in are too far away to get to.

Because at times this school doesn't respect students. Or the teachers always putting in assignments late. My parents get angry when they see zeros in schoolloop. I turned those zeros in the teacher doesn't put in the grade

Some private school would probably get me to a good college because they would probably put me out there better.

[I] did think of going to another high school that is a higher level.

I have considered these options because the students are very childish and some of the teachers teaching is hard for me to understand.

Because the school was becoming a dangerous environment

Because the administration here in my opinion is horrible ... and [I] choose private school so [I] can be challenged more and to play more competative [sic] sports

Situations going on at home, and for a better future.

[I've] thought about moving to a private school because [public school in the district] doesnt [sic] offer many good AP classes. Also, I dont [sic] like [current school in the district].

They would be better for me sports wise

Because [I] wanted to go to [public school in the district] 
I wasn't sure this school was gonna be able to give me what I need from it in order to successfully go to college.

I sometimes think what [if] [I] went too [another school in the district] what would that be like as well as online high school [I] could stay home do my work go to sleep dont [sic] have to be bothered by anyone

I've only considered moving schools simply because I thought they had courses that interested me, but I came to [current school in the district] specifically for Forensics and I hope I am able to do the course next year.

I don't like being with people much it's uncomfortable. I also liked my old high school because [I] had friends. really close and great friends.

I have seen other schools with more exceptional art programs and with different learning curriculum (individualized learning).

Honestly, I'd like to stay and leave at the same time. In some classes I'm not able to enjoy them because they are taken too seriously. So in that way I don't like that about this school.

To be in a magnet program.

I had depression and considered online school because, I felt isolated and like I wanted to give up but, eventually got help.

To see what its [sic] like

Because, I feel nothing at this school anymore, and I have nothing left to lose, I care about nothing now, and I want to go back to [private/independent school].

$[T]$ he sports teams softball, I have many friends over there

I selected the top two because my freshmen/sophmore [sic] year I felt like an outsider and didn't fit in. All of my friends left to other schools and I was basically a "loner" for two years.

This school has its perks but it's different from the rest. It feels low income at times and less safe.

because people say the teachers are good there. 
Because most of my friends are at another school and sometimes this school can get boring.

I don't like this school.

[Private/Independent] high school was the school I first liked a lot but I couldn't go so I had to go to the nearest high school.

Some schools get easier criteria. I'm not saying im [sic] dumb I can learn things pretty quickly but its [sic] the way the teach at the school it makes things difficult to understand, plus I have a lot of things going on at home.

Because sometimes I feel like I don't belong here but my teacher's are cool so that's makes me feel ok.

I've considered another school in the district because sometimes I just felt like moving schools because to much was going on.

1. I feel like other schools would be better. 2. Talked with a Counselor. 3. I liked doing online instead of going to school.

I've considered going to [another school in the district] because I have more friends \& I think I would like it there. I've thought about going to [public school outside of the district] because I think about living with my dad \& it's a good school. 


\section{Appendix N: Like About Self Open Responses}

Nothing really, other then posative [sic] comments here or there

My color makes me feel different from all the students here.

My grades and doing good in class.

My grades, my appearence [sic], my family and friends. Me playing football or any sport makes me feel good.

Knowing that I am helping someone else

I'd like to think I'm fairly smart.

What makes me feel good about myself is how independent [I] am and how [I] dont [sic] let many things get to me or tare [sic] me down.

one thing that make me feel about myself is me being happy.

When I get another good, high GPA (for example: a 4.0)

Everything, Im always feeling good

When tell me in [sic] intelligent or good at a certain thing 
Everything. I'm just like a perfect person.

that [I] believe in myself and what i'm doing

having friends that support me for me

being able to acknowledge when [I] wrong.

The power of my words and how [I] expresss [sic] myself

How I treat and protect my friends

good things coming from me

my friends and family.

When [I] do something good or do something right

My looks and family

when [I] get question right

compliments,[I] guess

what makes me feel good about myself is the fact that i'm weird(in a good way)and i'm privileged to be in a school like this and also being kind and grateful.

Me. I make myself feel good about myself

Being with people who relate to me and I can relate do without judgement.

when $[\mathrm{I}]$ make others feel good, my smiles, ad my family and Friends.

I look at myself and thats what makes me feel good about myself 
Sleep

I like my nationality and I'm just proud of myself because I'm not disrespected

Knowing who I am and what I stand for. I am proud of my ethnic backgrounds and I want justice/peace for both of them. I love my hair and when people praise me for showing it off. I think my skin is very pretty but it is a shame others don't.

My family cheering me on

My art

what makes me feel good about myself is that [I] know that [I] will try things over and over until [I] get it right.

My abilities in music and my willingness to learn and lead.

Knowing that other people feel emotionally good after I talk to them, basically helping people.

my pride and courage

I feel good when i look good you feel me.

I'm creative.

Making others laugh and listening to music

knowing i'm doing well in class and taking pride in my hair and ethnic background.

having friends that care about me

Drawing and being the best me. 
When I'm told I can do things

my friends

When I get compliments, called smart, good grades

When someone I don't know geniunlly [sic] compliments me.

I play football, I get good grades

I feel good when I get good grades and do well on assignments. I feel good when teachers make the effort to know who I am. I feel good when my peers compliment me.

When I get good grades

that I can still goto [sic] school with friends

I know I am a leader and an advocate and I love how I make my voice matter

When I succeed in something and are praised for it

that i'm funny and on most days nice. other then that not much. My eyes make me feel good.

The fact that I'm my own person with my own personality and there is no one out there like me.

When I am with my friends

My culture, my hair, and my achievements.

My personality and how i'm easy to talk to 
Im [sic] a confident person and I love my family and Also, I like video games these things make me feel good.

I feel good about myself cause I was raised by two lovely parents and I am surrounded by people who love and care about others.

What makes me feel good is knowing that I've made it far and am about to graduate.

Knowing that I'm here today to see my family and how I make my family and mostly my mother happy that i'm doing good this year.

That I am a unique individual and it doesn't matter how people look at you, just be your own person

that $[\mathrm{I}]$ am myself

My weight, height, hair, face, how i act, how others THINK [I] act. these are all things [I] worry about constantly

Sometimes when I am one of, or the only, African American students in my class I am very aware of that.

yes [I] have actually. we took a class picture and [I] was the darkest one in the photo that your probably couldn't see me. I always thought things like that wouldn't effect [sic] me, but once [I] experienced it myself it really did. Not to an extent but it did at the time. I am also very insecure about my body and the size of my face. sometimes [I] feel others are attracted to me only because [I] have nice curves and a big butt, but dont [sic] actually want to get to know me as a person.

The bathrooms have improved, but most of the time its [sic] filthy (not to blame anyone, but some people are just nasty).

not rally [sic] just racist comments around school

that they always follow me $\mathrm{n}$ [sic] my brother around campus after school and just watch us the whole time ( kinda find it disturbing )

That I don't excel in math or other engineering classes 
When it comes to asking questions about something everyone else in the class understands besides me.

I'm insecure about math because i'm in an advanced math class and sometimes don't fully understand what is taught and then end up having one of the lowest grades in my class :(

tests i'm scared of test even if [I] studied for it

not being accepted or being ignored

The jokes people make about being African especially from African Americans. Sometimes, I admit it's funny but sometimes it's just too much and below the belt

Not going to a good college, because I feel like the whole point of me doing anything is to go to a good college.

fights in school people talking crap and spreading rumors.

Drama because it's over stupid rumors.

Being accused of something [I] didn't do.

[I] wish there were more people who looked like me

I don't like talking upfront.

As of now my classes are not exactly following protocol, so I am struggling. I am also insecure about the fact that I can no longer be Valedictorian.

I'm insecure that I will have a seizure at school, but other than that I am insecure that I will start failing and my parents will start distancing themselves from me.

yes this 19 almost 20 year old keeps coming to the school trying to fight and one of these days im [sic] gonna hurt him cuz [sic] he wont [sic] leave me alone

for sure $[\mathrm{I}]$ need a haircut 
I don't have the energy level required to focus on my work. I'm 'lazy'.

Sometimes I feel isolated for being the only black girl in my class but other wise [sic] I'm confident.

my grades

Yes, I am insecure about literally everything, but I never show it because I hide it with a class clown facade.

One of my biggest insecurities is how little the racial problem is adressed [sic]. The amount of students who say the "N word" is disparaging.

People think that I can't get good grades because of my race; they think i'm a bad student

I used to be very insecure about my skin and hair, people always made fun of it and i've always felt excluded for it.

I feel insecure about my weight, size, build, looks, voice, eyes, everything.

I don't like to fail so I don't try.

I HATE MATH \& Physics.

This school has stupid rules.

As in with peers always have since I was a little girl in preschool and I still sort of do now. But education wise, I still kind of do because failure scares me.

Being judged I feel if I was born in a different ethnic group I'd be treated differently because I'm not only black but I'm also gay and Ive been told that those are 2 taboos.

The fact that this is on the "E" Side is cautionary 


\section{Appendix 0: Feeling Judged Open Responses}

Cope with it

My riends [sic] picked me to be on there team because they think all black people are good at sports.

I felt like just because I had a darker complexion than other people that I was considered "ugly or too dark". It made me seem unwanted in the classroom. I just ignored it and never addressed it.

Once again when my peers called me the "n word" almost every time I had that class. This isn't really too bad of a thing but when people see how long my hair is they automatically just assume its a wig. Black girls can grow long hair too!!

They expect me to tell them the answers to all questions they have (if they didn't do their assignment) because I look innocent.

the teacher might think you are not smart enough to answer a question but another person from a different race can answer it

when [I] get my hair braided students will always look at me weird, they will always ask questions and laugh when [I] tell them that [I] dont [sic] wash my hair everyday.

As if it was their business to know if my hair is authentic or not

It wouldn't let me press no for both

People just expect me to be shady so ignore them

they be like your hair hella nappy

I felt like I didn't want to speak up in the classroom or in conversations anymore because they always put me down or made me feel inferior.

[I] felt judged by my hair [I] have a Afro and [I] dont [sic] like my curly natural hair sometimes because kids can be means and say its ugly or your big ugly hair is in the way.

I feel the same way every time, like I don't belong 
Maybe because they go to a school with people who mainly look like them and they do not know what to do

The [sic] always asked if [I] had a weave when my natural hair was out and why it felt weird or gross. They would also call me a chocolate or a shadow. The only way to cope was to ignore it.

I got judged because of racial stereo types [sic]. [I]t made me feel like [I] didn't belong anywhere anymore. I just told myself that people are just jealous or insecure about their racial appearance.

It was mainly because it seemed like I didn't want to have straight hair, which offended some, especially after suggesting that I do so. It didn't really affect my sense of belonging, and I just shrug it off as people wanting to conform to standard expectations of beauty.

because [I] was black she did not think [I] wanted education

My hair was hella smoove and the teacher was hatin

I get weird looks because my hair type and skin tone don't match. Sometimes people touch my hair without asking even if I tell them to ask first.

I felt like people thought I was not approachable or would not get along with me just because, I'm black.

Because of the color of my skin

Its just jokes like for example when we did the swimming unit, some of my peers wondered if I could swim.

I feel like people can make assumptions about me before they know me because of my hair.

They told me when they first seen me, they didn't think I cared about school \& grades.

My Counselor helps me all the time with school, academics, SAT, and one of my friends said they believed it was because I am black

People have low expectations especially teachers. They think I am trouble. Or peers have crazy high expectations. 
I've always been judged by my color. Whether people speak or not you see the reaction they give when you walk in a room. I cope horribly. I either mostly keep to myself or once in a while tell my mom.

It felt as if I had a target on my back one way I cope is secluding myself or making jokes out of everything.

I got upset

I feel not sad our anything but just like how you going to make fun of me when you have the same thing as me in your hair 


\section{Appendix P: Microinsults Open Responses}

\section{Racially-Based Microaggressions Microinsults Experienced}

People can't really tell what I am from my looks but they know i'm not white so that means im [sic] 'not from here'.

My math teacher last year automatically thought [I] would sit in the very back of the class where the students who didn't do anything productive with the class time sat. When my first test was graded she was in disbelief that [I] produced work that was on the test and was hesitant to give it back to me due to it. So [I] took it from her hand.

A teacher at "_ " has strong opinions about things and often makes comment that are unnecessary; comments about students' intelligence, standing for pledge of allegiance, women's rights, etc.

Told my teacher I want all grades she looked weird at me like it was impossible

Last week my class was talking about beauty and how men don't find women attractive due to their size so I disagreed \& said your color has something to deal w/it to \& one of my classmates said, "I would like to get back on topic" as if what I said had no meaning.

didnt [sic] feel respected because of my racial background

Like when we talk about black people stuff, everybodys [sic] always asking me stuff, and looking at me, and I get it, but its [sic] just uncomfortable.

I heard negative comments about immigrants by peers while walking around school.

Since elementary it sort of has/had been a struggle with people saying rude comments about blacks. Although I don't hear it to often from my peers anymore. But I struggled with who I was and I took my a while to accept myself.

Well teachers do this a lot like my peer never do anything like that but some questionable stuff sometimes

Peer asked me if the class topic offended me. Both makes me seem dumb. Peers use me and don't talk to me.

I've experienced it in elementary school and middle school by students. 
A lot of times people can't pronounce the name "__ " they tend to say "_ " almost all subs get it wrong and teachers take awhile to adjust.

On the first day of school the teacher asked what my name was and I told him and then they still pronounced it wrong.

Teachers often assume because of my race that I always have an attitude towards them or a project.

Anytime the subject of black lives matter or our history of African Americans is brought up, I get starred [sic] at by both the teacher and my peers and often when we talk about it, my voice is shut out.

A teacher would call on me and ask my opinion on a video or documentary we watched about someone who African American.

My last name has always been mispronounced my when ever [sic] roll is being taken my last name is being pronounced wrong i correct the person but still pronounces it wrong.

By pronouncing my last name wrong.

Most of my teachers and peer pronounce my last name incorrectly

If [I] were in a classroom and we were talking about African culture or something and [I] would be the only black person in the class they would always ask me questions like [I] would know the answer or they'd want to know what it feels like from a "blacks perspective"

My appearance was judged and I appeared to look...unintelligent and lazy until I proved the teacher wrong.

My [E]nglish teacher throughout my freshman year didnt [sic] really care [I] aske [sic] for help and stuff she really didnt [sic] care.

I didn't experience anything thing like that but [I] seen it. One of my teachers told a kid to shut up by accident and she bowed to the kid and the kid was Asian.

[I] had a teacher my freshmen year who [I] kept telling my name too her and she kept getting it wrong not trying to get it right and she finally said something when [I] stood my ground. [I] was in PE and a person said [I] thought black people were supposed to be fast. [I] did not [sic] really get any posts for things because my teacher would never call on me in the middle of the year and [I] already knew it was because [I] was black and she was racist. ive [sic] herd [sic] many teachers talk about immigrants the worst teacher was last year my junior year [I] hated the teacher and her racial ways of 
thinking.

when I first came here my name was mispronounced thousands of times,sometimes [I] would tell them to call me any way they like.

I'm African so people say stuff to me like how was the jungle or Wakanda or just make "African" gestures most of the places they ask about i've never been there or most of the things they've asked me if i've seen like lions, [I] haven't and it's mostly students.

I felt like my teacher didn't expect much of me because I was the only black person in the class and once I started not doing great she seems more validated as well as my classmates.

An earlier classmate and I had a discussion involving immigration and legality of crossing the border seeking asylum. He was against doing so without doing so and had a couple of words regarding Latinos in general which I found to be a bit offensive. In many circumstances, with peers and teachers alike, people will ask me of my ethnicity and race due to my very unique features. I have yet to see it in a negative light.

My teacher of this year was discussing the Martin Luther King Jr. speech and all throughout it the students were asking questions about if they could use the word " $n$ " with $o$ at the end because he uses it in his speech, since we were writing a mini essay on it, and he said yes but not to use it because it was a derogatory term. All I could do was sit and listen. Then he told a story on how he was called a " $n$ " word with the $r$, but he flat out said the word two times, with out [sic] caring. And may I say he even said to the class that he isn't black and that he told the person to say it louder. In my head I was mad because he was off topic and he had to say another offensive word. The icing on the cake was when a student asked on the same day "What if someone is mixed" my teacher responded with " mixed? that's disgusting, they can't be mixed with black and white. Your family thinks you're white, and the world thinks you're black. If you're mixed you're just black" after he said that I was just mad and sad because I could relate to that. I'm pretty sure he couldn't tell that he couldn't tell that I was even black and white but the whole incident made me mad, although I don't know if he was talking about the times of when Martin Luther King Jr. was alive. Talking about all of this while doing an essay on the Dr. King speech. And then after that hearing the students laugh while saying the word or hearing the teacher talk about how all of those words like Negro and Nigger don't mean the same thing as Nigga just was ignorant to tell the class. He was able to say those two words but the last one he told the students "don't say the n word." I just found it uncomfortable but I looked at it as he isn't educated. And this was only last week. Also I don't think my name is mispronounced because of my race. 
I have experienced racial profiling, racism, and exclusion because of what people thought about me. In a classroom I noticed everyone else had been favored but me, only because I liked to talk about serious topics. When I inform people of my races, they always have something to say. Whether it has to do with my Black side or my Mexican side, and they expect me to laugh. People are so quick to stereotype me and think I don't care about BLM movement or ICE deporting immigrants and are quick to dislike because of that.

It is weird talking about slves [sic] in the class because everyone looks at you

A Spanish teacher [I] have mispronounces my name regardless of my corrections. When working on projects that explore more on my race my peers tend to say racist comments or laugh at the images of slavery and such.

When it came to talking about a book discussing the life of a black women I felt sorta uncomfortable saying and adding certain things to the discussion in front of my teacher but, mostly peers.

Peers sometimes miss pronounce my name on purpose

One time my teacher kept mispronouncing my name even after [I] told him countless times how to pronounce it. And then always at the beginning of the year the teachers and peers thimk [sic] im [sic] stupid and [I] dont [sic] know anything. 


\section{Appendix Q: Microassaults Open Responses}

\section{Racially-Based Microaggressions - Microassaults Experienced ( $N=35)$}

They think its funny to have very dark skin and full lips. I'm relatively light but my friends who are dark get teased sometimes.

Teacher adressed [sic] students as stupid when they couldn't answer question being asked and often implied things were "basic knowledge"

They just say racial jokes, peers

"Nigger" was written on a desk, a baby dolls head was snapped and the caption was, "a typical day in the South" The N word is constantly utilized.

This " _ " teacher who works at _ and his last name starts with G called all the black kids the "back of the bus" group.

Peer called me "Nigger Trash"

Till this day people still make racial jokes but try to keep it on the low because they don't know how I may react to the joke. But most know I don't tolerate it and say it when i'm not present.

Alot [sic] of students do it today calling people names that would offend someone without thinking. Alot of my peers use alot of derogatory language.

I would be the first person to raise my hand and still get called last.

I had my hand raised for a long time. Other peers get attention. Peers call me "nike" (I substitutes it from the n-word).

Jokes and slurs by my peers in elementary and middle school

When a friend say what's up they said the $\mathrm{N}$ word to me.

someone called me the $\mathrm{N}$ word.

Many of my "peers" say the N word a lot and when I confront them they always say "Why cant [sic] we say it" because they are unaware of the history that's behind that word. Some of my teachers would assume they know what they are talking about when they talk about African Americans and often would joke around about it. 
My peers would purposely say the "n word" in front of me just to draw a reaction out of me.

Not been called on to answer a question even though my hands was raised first.

Yes by calling you the $\mathrm{n}$-word.

the teacher would always write me and my friend up for "being disruptive" when we didnt [sic] sit near each other, never talked to each other in class, and when other students were being loud and running around the teacher wouldn't do anything. me and my friend were the only black people in the class. also when my mom would email the teacher about it the teacher would never respond.

Students always have the reaction of, "You have Ebola! Don't touch me," when told that I went to Africa.

Peers around school say the" N" word with a hard R.Peers also call us black "B" some make jokes about our dad leaving our family.

A kid would use the hard "r" as a joke but knew he shouldn't be saying it period

There was a time were the " " " teacher was talking about slavery and racism. and when he talked about how whites and blacks couldn't be in the same schools or bathrooms and stuff like that a student behind me leaned to his friend and tried to whisper- "No niggas allowed"

Me and some former friends (also african american) were a few minutes late to class and the teacher said," oh looks like the three black girls are late" and that made me really upset.

One time when [I] raised my hand [I] had it up for about 30-45 seconds and than another student raised their hand and the teacher called them instantly after ive [sic] been waiting for almost 1 minute.

[I] had friends that called me the $\mathrm{N}$ word once and [I] was not too happy about that. when [I] was in class that used to happen to me a lot [I] raise my hand first and they go too [sic] the white kid.

Students have literally said to my face "What are you doing in this math class, you're black." Insinuating that I'm dumb because I'm black.

In Modesto high school a peer called me the $\mathrm{n}$ word and would say racial jokes and slurs to me everyday. 
Not in high school, but in middle school, one of my teachers happened to be a bit melodramatically stubborn and was very adamant about her opinions, one of which being my lack of respect in the classroom. The only time this was ever brought up was during a class presentation and, while transitioning between speakers, I was helping my classmate catch up to what was going on so far, which the teacher took as an insult and told me to be quiet or she would put me in detention. So I kind of left. Peers often like to say rude or demeaning things about all races in general as a form of humor.

Honestly I don't know if anyone can even tell my race, most of the time when people think of [A]frican-[A]merican they think of someone who is darker skinned and has a different hair texture. I have dreads so you really can't see, light skin, and freckles. So I don't know how to answer these. I remember a guy in my class always used to call me racists stuff in class during 8th grade and I wouldn't do anything about it because at first we were kind of friends until that happened. Also I have heard racist jokes before, you'll always hear them it's not like you can stop them.

Nowadays people will try to offend you to see how you react. They want to know what type of person you are and label you from the reaction you give. I've been called a racial slur and I have been racially profiled by a teacher. It is so frustrating when you think a teacher will be there for you only to dismiss you because of an opinion or because they think you are being disruptive or a distraction, all because of stereotypes.

Many people in my school say the "n" word even thought [sic] they're not black

My peers always say the various $\mathrm{N}$ words that are used towards African Americans. The always ask or say that black people like watermelon grape soda and fried chicken to me or any other black student.

My peers say the n-word, and offend me out when it comes to talking about things related to black people.

By a student

One of my teachers on the first day of school said they didnt [sic] have time to teach stupid kids or something like that and they looked directly at me. 


\section{Appendix R: Microinvalidations Open Responses}

\section{Racially-Based Microaggressions - Microinvalidations Experienced ( $N=24)$}

Sometimes being "colorblind" is used as an excuse not to talk about racism.

My peer indicated that race doesn't matter and that were all just humans

Student in government class makes comments about things he doesn't necessarily understand: once said they didn't believe institutionalized racism existed.

My peer said that we talk about black history too much instead of focusing on other races however I get what she is saying but I didn't agree with the first part.

There is this real SJW white girl and we were just joking around and I made a "because im [sic] "black" joke and she started tripping and making a big deal out of it.

heard peer in class say it

I was left out of things more in Elementary and part of middle school. So, by a teacher my hand being raised was dismissed and given to another student.

I heard some teachers say there are racially colorblind because of all the different ethnic backgrounds.

I remember raising my hand to say something or answer a question and I was told I was wrong someone else said the same thing and they were right.

Peer claims colorblind so can't see race.

Anytime someone would mention the $\mathrm{N}$ word and their interpretation of it, I would get upset because they never knew what they were talking about and assumed I was "overexaggerating"

I felt upset when my peers said the "n word" in front of me even though I knew they were just saying it to get me upset.

I have felt underestimated by a teacher junior year and [I] felt she treated me differently. There was also this incident where students had to do satire comedy and my teacher played the role of the white supremacist and there was a black man being shot on the screen and my class thought it would be funny to laugh. Where being the only black girl in the class did not find it funny at all. 
I was walking down the hallway and one of my peers said that.

Sometimes I would say something out loud repeatedly and then another student will say the same thing then (in one incidence) they got extra credit!

Peer say racist things in class during history

the teacher asked for the answer for the question [I] said the answer and he ignored me another student answers with the same exact answer using the same words and stills the glory.

A teacher who was pretty old had told us that racism should no longer be discussed because when they were in school it was okay to call someone the $\mathrm{n}$ word in school, and since that is no longer okay, racism must not be a problem anymore to discuss in school.

In middle school a peer would say the n word not towards me but it was offensive

Yes, that happens quite frequently in which I will give the answer first, the teacher will look at me weird because I haven't written anything, and say that I don't know what I'm talking about. We will then do a ten-minute cover of the exact problem, going through step-by-step and asking another student who has completed this extraneous process and reached my exact same conclusion.

It is hard to be African-American/Mexican-American and be dismissed when topics involving your race are being ignored. I have asked teachers if we could talk about these things and they have the audacity to tell me no and that it isn't worth it.

My English teacher during freshman year made that comment that she doesn't see color and it's ignorant.

I have had peers and once a teacher make racial jokes and slurs that made me cry and gave me a headache.

One time [I] said this joke and [I] said loud enough for my table to hear and they chuckled then one kid at my table said it louder an everybody laughed and [I] was just staring at him because he stole my joke. 


\section{Appendix S: Males Desired Instructional Strategies Open Responses}

Probably hands on, and visual teaching.

they use smart boards and chrome books

More hands on, more interactions between students and the teacher.

hands on, [I] guess like how math teachers teach.

they do direct instruction

Slow Down, and make sure every kid is caught up.

Hands on because [I] am an active learner

use more computers

movies

[I] believe that it should be more hands on and not really technology used.

hands on

sports medicine would be a hands on course with powerpoint presentations and journalism would be trying to dig up evidence or something.

With group projects, lectures, or fun activities

more hands on and technology would be used for recipes

hands on, mild technology

hands-on, technology will help with courses

they do it like the other teachers do

More involved with the students. Check up on each during work time to ensure the individual student is on the right track.

I would want them to be more hands on and have the lessons be interesting.

show us how to do it, hands on 
Instead of teachers moving on they could ask if everyone understood the lesson and some kids are sly so their [sic] could be a sheet their internet you could fill out at home.

It would be much better if it had more hands on learning but it is more like direct instructions told. 


\section{Appendix T: Females Desired Instructional Strategies Open Responses}

Hands on, technology has always been incorporated [I] think

Well more hands up

More hands on

Teachers would actually teach as in they would speak to the class on a daily basis instead of relying on the internet to teach for them. Grading would be based on their understanding of the topic and their own progress, not the progress of another student.

They would have a hands-on approach meaning they would physically show the students how they want work done. The teachers would give visual instructions.

I would like more hands on type of activity. Technology can be incorporated watching movies.

Teach the lesson thoroughly before giving homework. For instance, a teacher of mine gives homework that hasn't been taught yet, then teaches it the next day sometimes.

lecture, or they do a problem and you watch them then you have to figure out how do it on your own

yes but each day would be a different assignment for my biology class

I would like teachers to be more hands on and technology will be incorporated regularly.

more hands on and technology shouldnt [sic] be used all the time

with a little bit of fun

Teachers should assign class captains to help them with their work and also in class.

More direct instructions some teachers will just make something up or say a bunch of words or big grammars and expect you to understand what they're saying. They have to be more specific and some teachers need to go take lessons on how to use their technology. I've had teachers who just got a technology didn't even bother to learn how to work around it and wasted the whole class period trying to work the thing when i should be gaining knowledge.

Filed [sic] trips, Group Project, Lectures, This Day in African History (everyday on computers). 
[I] think there should be more hand on stuff to make [I] more fun and more fun projects dealing with the subject

Teachers teach there lessons while the students listen and the students are paying attention

Direct Instruction, Projectors, and More hands-on

direct instructions and technology would be used to research but also play games as a stress reliever.

Technology would be a huge part in the learning and it would be a more hands-on learning approach. We'd use real life examples to convey the message of a lesson.

By telling instructions and making us take our own notes.

Teachers would teach slower, be more patient and adapt to the student. Less homework so that we have time to focus on things we like and sleep. I'm not sure about technology.

by bringing in guest speakers, documentaries, etc

hands on

Teachers would teach more hands-on using more technology.

technology [I] would perfer [sic]

They would do more group projects. Also have test be less apart of there grade.

Lessons should be as unbiased as possible and accessible for all students. Offering a variety of teaching methods (visuals, hands-on, auditory) would be beneficial. Grading should be reflective of the students' twe ability (not just tests) Technology, in our expanding world, should be more present.

Actually teach \& explain, connection with their students

patience, hands on

Lectures.

Teachers would teach hands on. You wouldn't really need technology.

A lot of talking 
Teachers would have more hands-on learning styles and technology can be used for easier access. Also, to make cool and learning things you can't get of a book.

giving breaks during class, playing games because the end of class

Most of my teachers use direct instruction and just have everything planned where they know what they teach that day. 


\section{Appendix U: Course Preferences}

\begin{tabular}{|c|c|}
\hline $\begin{array}{l}\text { What types of courses would you like to see offered that you are } \\
\text { interested in taking not currently offered at your school? }\end{array}$ & Categories \\
\hline $\begin{array}{l}\text { A sports course, something athlets [sic] can join to better their } \\
\text { athleticism. }\end{array}$ & Physical Education \\
\hline African American History & Culture/ History \\
\hline $\begin{array}{l}\text { African American Studies, American History form the Africa [sic] } \\
\text { American Perspective, African History(Not African American), } \\
\text { History of White Colonization, African American College } \\
\text { Preparatory Classes. }\end{array}$ & $\begin{array}{l}\text { Culture/ History; College } \\
\text { Readiness }\end{array}$ \\
\hline $\begin{array}{l}\text { African American Studies, Mental Health, Cooking, Beauty/ love } \\
\text { yourself }\end{array}$ & $\begin{array}{l}\text { Culture/ History; Life } \\
\text { Skills/Vocational; } \\
\text { Health/Beauty }\end{array}$ \\
\hline Animation; mindfulness/therapy & STEM, Health/Beauty \\
\hline $\begin{array}{l}\text { At our school I would like to see theater, hip-hop dance groups, } \\
\text { STEP, and more classes that help with future jobs or readiness } \\
\text { classes. }\end{array}$ & ART; Life Skills/Vocational \\
\hline Cinematography & Theater \\
\hline Cooking & Life Skills/Vocational \\
\hline $\begin{array}{l}\text { Cooking, How taxes work, How to get a job, Driving, Real world } \\
\text { issues }\end{array}$ & Life Skills/Vocational \\
\hline Drama/theater classes, and/or ASL & ART; Foreign Language \\
\hline $\begin{array}{l}\text { Financial Literacy, Music Theory (extensive), Social Structure, } \\
\text { Constructs and Perceptions, African History and Culture. }\end{array}$ & $\begin{array}{l}\text { Life Skills/Vocational; ART; } \\
\text { Social/Political; } \\
\text { Culture/History }\end{array}$ \\
\hline Forensic Science & STEM \\
\hline French & Foreign Language \\
\hline
\end{tabular}




\begin{tabular}{|c|c|}
\hline I would like Basic Technology to be offered in my school & STEM \\
\hline I would like more language classes & Foreign Language \\
\hline $\begin{array}{l}\text { I would love to see a sign language class at school. I also know } \\
\text { that ethnic studies started being offered this year, but the way } \\
\text { students act at "__" it should be a requirement. }\end{array}$ & $\begin{array}{l}\text { Foreign Language; } \\
\text { Culture/History }\end{array}$ \\
\hline $\begin{array}{l}\text { I would really love to have philosophy cause am [sic] thinking of } \\
\text { being a lawyer }\end{array}$ & Social/Political \\
\hline $\begin{array}{l}\text { I would want to take cooking class cause I know how to whip up } \\
\text { some smackleables [sic]. }\end{array}$ & Life Skills/Vocational \\
\hline Language like foreign (Twi) & Foreign Language \\
\hline Law enforcement & Life Skills/Vocational \\
\hline Lifeskills & Life Skills/Vocational \\
\hline $\begin{array}{l}\text { More Language options. The only language class we have is } \\
\text { [S]panish. }\end{array}$ & Foreign Language \\
\hline $\begin{array}{l}\text { More classes that would keep you on track to more/different } \\
\text { types of college majors }\end{array}$ & College Readiness \\
\hline More languages, less euro-centric [sic] history classes. & $\begin{array}{l}\text { Foreign Language; } \\
\text { Culture/History }\end{array}$ \\
\hline My school has all the courses I like such as engineering and art. & ART; STEM \\
\hline $\begin{array}{l}\text { Other Foreign Language classes. Psychical education for juniors } \\
\text { and seniors }\end{array}$ & $\begin{array}{l}\text { Foreign Language; Physical } \\
\text { Education }\end{array}$ \\
\hline Thinking like how to become a music producer or cooking & ART; Life Skills/Vocational \\
\hline Workshop & Life Skills/Vocational \\
\hline
\end{tabular}




\begin{tabular}{|c|c|}
\hline a class that studies around Black history & Culture/ History \\
\hline about other cultures and races of people & Culture/ History \\
\hline$[\mathrm{A}]$ frican $[\mathrm{A}]$ merican club & Culture/ History \\
\hline cooking classes & Life Skills/Vocational \\
\hline dance and Arabic language & ART; Foreign Language \\
\hline drivers ed or health class & $\begin{array}{l}\text { Life Skills/Vocational; Physical } \\
\text { Education }\end{array}$ \\
\hline driving course & Life Skills/Vocational \\
\hline Forensics & STEM \\
\hline french, drama & ART; Foreign Language \\
\hline $\begin{array}{l}\text { [I] would like to have an African american studies class at my } \\
\text { school. }\end{array}$ & Culture/ History \\
\hline [I] would like to take a engerneering [sic] class. & STEM \\
\hline $\begin{array}{l}\text { kinesiology because I want a class about sports other than physical } \\
\text { education. }\end{array}$ & Physical Education \\
\hline life skills or driving classes & Life Skills/Vocational \\
\hline maybe classes like acting & ART \\
\hline more AP classes and electives. & College Readiness \\
\hline $\begin{array}{l}\text { more foreign language classes, AP classes as well as more } \\
\text { engineering }\end{array}$ & $\begin{array}{l}\text { Foreign Language; College } \\
\text { Readiness; STEM }\end{array}$ \\
\hline
\end{tabular}




\begin{tabular}{|l|l|}
\hline more languages instead of Spanish & Foreign Language \\
\hline $\begin{array}{l}\text { perhaps courses on languages other then [sic] Spanish, like } \\
\text { Japanese, Chinese, [K]orean, anything really. }\end{array}$ & Foreign Language \\
\hline Rap & ART \\
\hline Sculpting & ART \\
\hline $\begin{array}{l}\text { there should be a sports medicine class a journalist class a cooking } \\
\text { class }\end{array}$ & $\begin{array}{l}\text { Physical Education; } \\
\text { Social/Political; Life } \\
\text { Skills/Vocational }\end{array}$ \\
\hline
\end{tabular}




\title{
Appendix V: Ideal Peer-to-Peer Interactions in the Classroom
}

\author{
Labeling Key \\ Cooperative Learning \\ Academic Support \\ Group Work \& Discussion \\ Racial Identity
}

\begin{tabular}{|l|l|}
\hline Label Name & Extracted Text \\
\hline $\begin{array}{l}\text { Leoperative } \\
\text { N=12 }\end{array}$ & $\begin{array}{l}\text { We collaborate with each other } \\
\text { They will help each other by collaborating to complete } \\
\text { assignments } \\
\text { Most people help each other in class while some don't. } \\
\text { Students are pretty helpful to each other sometimes just a little } \\
\text { rude } \\
\text { They help each other by sharing their ideas and dictating } \\
\text { mistakes } \\
\text { We all work together for the most part } \\
\text { they are welcoming but understand that some kids don't like } \\
\text { social interactions } \\
\text { It is necessary to interact with each other because you have to } \\
\text { use the information that others research in order to better } \\
\text { understand your topic. } \\
\text { The students don't really help each other, it depends the class. If } \\
\text { math nope, if psychology they will talk but if they know each other. } \\
\text { That's kind of how it is. } \\
\text { Students don't make racist/homophobic/transphobic jokes. } \\
\text { Get along, help each other make meals, } \\
\text { Every one [sic] at school interact good with each others, and in } \\
\text { the class rooms [sic] they are good everyone works together } \\
\text { nicely. }\end{array}$ \\
\hline $\begin{array}{l}\text { By helping them in explaining more } \\
\text { They would support each other and keep each other acountable }\end{array}$ \\
\hline
\end{tabular}




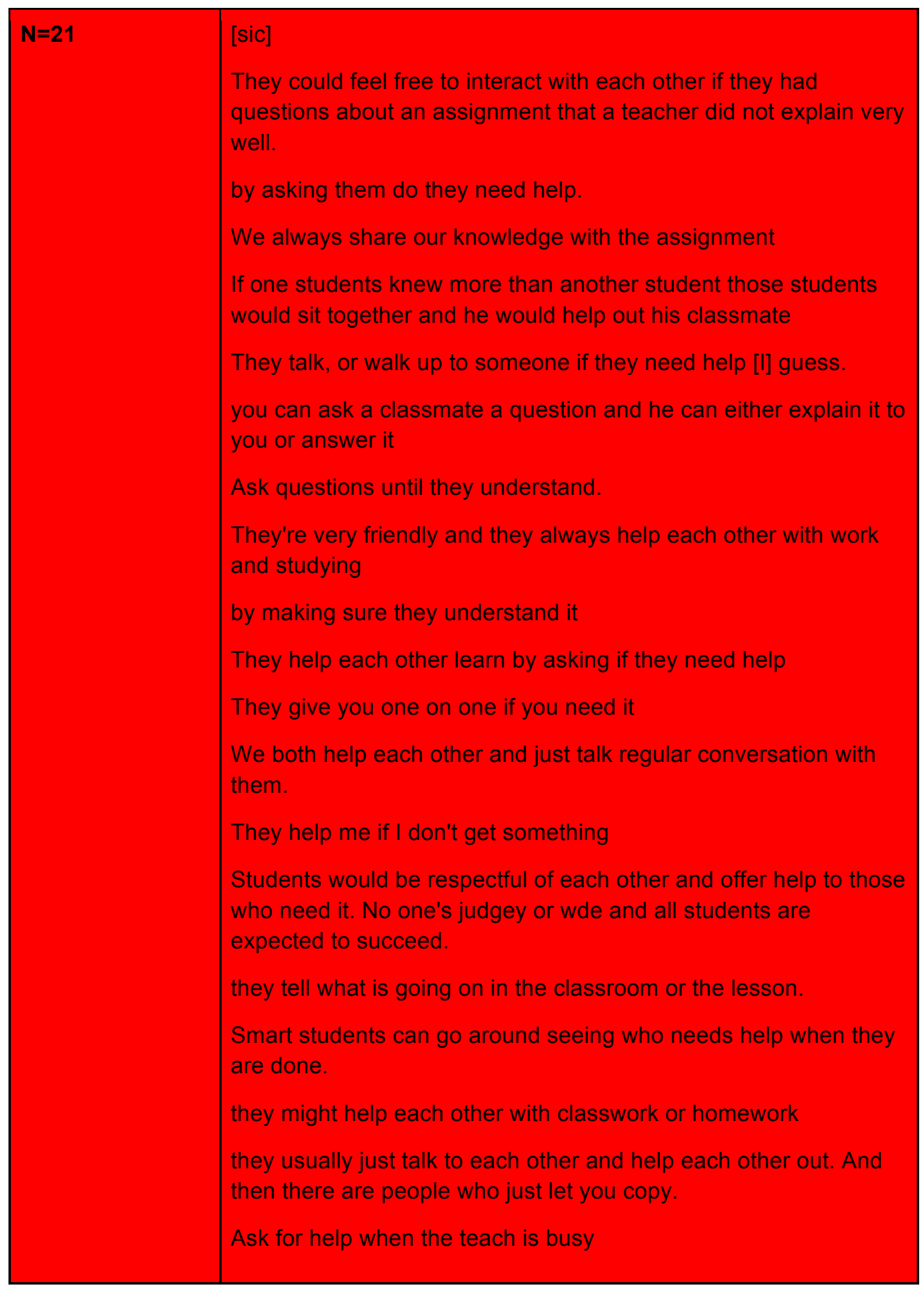




\begin{tabular}{|c|c|}
\hline & $\begin{array}{l}\text { I sometime text each other to ask question or go over to them } \\
\text { They try to break things down so it's easier. } \\
\text { When one student asks, the other student helps and interacts with } \\
\text { the student. }\end{array}$ \\
\hline $\begin{array}{l}\text { Group Work \& } \\
\text { Discussion } \\
\mathrm{N}=15\end{array}$ & $\begin{array}{l}\text { they talk and lay out there [sic] personal opinions } \\
\text { they sit next to each other sum talk and work sum goof off or sum } \\
\text { just don't work at all } \\
\text { everyone carry's [sic] there [sic] own weight when it comes to } \\
\text { group assignments } \\
\text { talk about homework and stuffs } \\
\text { you can work in groups more and get too [sic] know each other } \\
\text { they would read about a event in black history and make a project } \\
\text { on it. } \\
\text { it would be a fun environment and everybody would help each } \\
\text { other in groups } \\
\text { They learn by either hands on, visual, or listening to the activity in } \\
\text { class } \\
\text { comparing notes, asking questions, debating. } \\
\text { verbally support each other } \\
\text { They support each other by creating study groups. } \\
\text { talk to classmates } \\
\text { Group projects help each other on what they know, and others } \\
\text { don't. } \\
\text { They net pretty well with each other unless you don't like them. As } \\
\text { a new tech school students work in group and learn from each } \\
\text { other and come up with new ideas on how to complete stuff. } \\
\text { We talk to each other }\end{array}$ \\
\hline $\begin{array}{l}\text { Racial Identity } \\
\mathrm{N}=6\end{array}$ & $\begin{array}{l}\text { Students would interact simply be connecting with other students } \\
\text { of their ethnicity it is much easier that way because we struggle } \\
\text { with the same thing and problems in this society because of our } \\
\text { color differences and racial backgrounds. We'd help each other }\end{array}$ \\
\hline
\end{tabular}


learn simply by interacting with one another.

we interact like a family. we always help each other out with school work

In this class, we are a family...there is not much african american students at this school so we made a promise to always look out for each other.

More BSU events, Fashion Show!!!- Help learn about other cultures, and A GEOGRAPHY LESSON!!!

Students see no difference in one another. They are all treated equally by teachers and all staff members. It would be a calm and collected community and environment.

Students usually communicate regardless of their skin color 


\title{
Appendix W: COMMUNITY - Ideas to Include Black Families and Student Integration
}

\author{
Labeling Key \\ Treated Fairly \\ Invited/Welcomed to Events \\ Racial Identity Acknowledged/ Voice Empowerment \\ Student-centered Integration
}

\begin{tabular}{|l|l|}
\hline Label Name & Extracted Text \\
\hline Treated Fairly & $\begin{array}{l}\text { Equally } \\
\text { when staffs can learn to treat everyone the same way and with } \\
\text { respect } \\
\text { like every other family } \\
\text { Keep it cool with them } \\
\text { As long as there is no racist people they will be fine } \\
\text { The would feel welcomed into the school when they notice that } \\
\text { their children's races are not discriminated } \\
\text { they would feel welcomed by seeing how the are all treated the } \\
\text { same way } \\
\text { Honestly just treat them like you treat everyone else or they will } \\
\text { feel different. If you treat them better or worse they will still feel } \\
\text { different. } \\
\text { Just treated with kindness and equality like all the other families } \\
\text { should be. Check beforehand if a translator is needed so there's } \\
\text { no stress put on their child. } \\
\text { If they are treated the same } \\
\text { by being assured that the teachers and faculty have been } \\
\text { checked prior to their job being given to them. } \\
\text { they would feel the same as families from another other race } \\
\text { I think any family should be welcomed no matter race so Black or } \\
\text { African Americans should feel welcomed. } \\
\text { I think African families can feel welcomed if are treated the same }\end{array}$ \\
\hline
\end{tabular}




\begin{tabular}{|c|c|}
\hline & $\begin{array}{l}\text { as other guardians/parents and also, if there were more African- } \\
\text { American parents. Even black staff. }\end{array}$ \\
\hline $\begin{array}{l}\text { Invited/Welcome } \\
\text { d to Events } \\
\mathrm{N}=11\end{array}$ & $\begin{array}{l}\text { They would be invited to events, the school and etc. } \\
\text { They would feel welcomed because every Friday we will have } \\
\text { activity where well [sic] bring in food and any one and everyone } \\
\text { can come. } \\
\text { meetings } \\
\text { we could have coffee things just for black parents or bring in food } \\
\text { and talk and have fun } \\
\text { Meetings } \\
\text { During Back-to-School Night, we would use the time to celebrate } \\
\text { and welcome the parents to the school with a barbecue in my } \\
\text { classroom and give them thoughts to take home about their } \\
\text { culture. } \\
\text { There would be meetings to address any concerns } \\
\text { After-school event } \\
\text { Black families can feel welcomed by giving them a rundown of the } \\
\text { school. (e.g. facts, purpose, goals, environment.) } \\
\text { They would be welcomed and pleased to be here } \\
\text { If they speak with the principal } \\
\text { welcomed. }\end{array}$ \\
\hline $\begin{array}{l}\text { Racial Identity } \\
\text { Acknowledged/ } \\
\text { Voice } \\
\text { Empowerment } \\
\mathrm{N}=10\end{array}$ & $\begin{array}{l}\text { having an Black student union or some other event where they } \\
\text { could feel proud to be who they are } \\
\text { Black families would feel welcomed by being free to express their } \\
\text { culture without having to worry about potentially being judged for } \\
\text { it. } \\
\text { have meetings with just black families and a black administrator } \\
\text { and discuss school issues or events. make sure there student is } \\
\text { welcomed and adjusting properly } \\
\text { black would be portrayed as beautiful } \\
\text { by learning thier [sic] culture and talking about it to them }\end{array}$ \\
\hline
\end{tabular}




\begin{tabular}{|c|c|}
\hline & $\begin{array}{l}\text { If they are invited to events that doesn't exclude them from any } \\
\text { thing, or they are put on boards of school and any other decision } \\
\text { making group when it comes to school activities } \\
\text { Their culture would be more openly represented. } \\
\text { They could make whatever food they want and no one will judge } \\
\text { them. } \\
\text { just be known to the fact that they have a diffrent [sic] race } \\
\text { Black families are very welcomed because it adds more black } \\
\text { culture to the school. }\end{array}$ \\
\hline $\begin{array}{l}\text { Student- } \\
\text { centered } \\
\text { Integration } \\
\mathrm{N}=16\end{array}$ & $\begin{array}{l}\text { By allowing more blacks or African Americans into schools } \\
\text { my allowing more black students in school } \\
\text { They will know that there is a good percentage of black people } \\
\text { who go to the school } \\
\text { The black students will feel like they are in a second home. } \\
\text { Parents will not have to worry about their students interacting with } \\
\text { others and they will know that there is always someone looking } \\
\text { out for their child at school. } \\
\text { They would feel more welcomed because there are more races } \\
\text { Some might feel welcomed based on the students in school. } \\
\text { BSU Welcome Day- First Week of School, call all black students } \\
\text { in and tell them what to expect, get them to join BSU, etc. Also, } \\
\text { upper class-man-lower class-man buddy/ mentor system that help } \\
\text { new students make friends and feel more comfortable navigating } \\
\text { and enjoying the school. } \\
\text { They would look around and think that there are barley [sic] any } \\
\text { black kids } \\
\text { it would be an all black period and then a regular integrated } \\
\text { period } \\
\text { everyone will say hi } \\
\text { If more black people attend the school. } \\
\text { Black students would be treated equally as everyone else, and } \\
\text { they would have the necessary resources to succeed. }\end{array}$ \\
\hline
\end{tabular}




\begin{tabular}{|l|l|}
\hline $\begin{array}{l}\text { Because they would know that there is way more than just one } \\
\text { African American but many. } \\
\text { They can be welcomed based on how you carry yourself around } \\
\text { school. } \\
\text { They would feel welcomed by everyone not treating them less } \\
\text { than a human being because of our background and make us feel } \\
\text { equally because we are all in school for one thing like getting that } \\
\text { diploma and going to college if you choose to do so. }\end{array}$ \\
\hline
\end{tabular}


Appendix X: EQUITY - What are Some Ideas/Ways on How Black or African American Student Voices can be Empowered in the Classroom and School?

\author{
Labeling Key \\ Media \\ Speaking Up \\ Clubs \& Organizations \\ Other
}

\begin{tabular}{|l|l|}
\hline Label Name & Extracted Text \\
\hline Media & $\begin{array}{l}\text { Talkshows } \\
\text { talkshows } \\
\text { by making posters and debate } \\
\text { posters } \\
\text { have the courage to empower your voice through art or music }\end{array}$ \\
\hline Speaking Up & $\begin{array}{l}\text { They can voice their opinions and ask any questions they need to } \\
\text { ask. } \\
\text { Some ways that their voices can be heard by choosing and calling } \\
\text { on them if they raise their hands versus overlooking them. } \\
\text { our voices can be empowered simply be letting us speak without } \\
\text { being interrupted and giving out opinions. } \\
\text { If we present our ideas or problems in front of a group of staff } \\
\text { members. } \\
\text { participating in class all times } \\
\text { other people just need to be willing to listen } \\
\text { Having less restriction on discussions in classrooms } \\
\text { I feel like participation and procrastination has a big part in it. } \\
\text { more people need to speak up on how they feel. Have meetings } \\
\text { and make presentations. } \\
\text { if they had more black kids inside the classroom then we could } \\
\text { benefit off of each other. }\end{array}$ \\
\hline
\end{tabular}


just equal right to speak

They can show and tell there [sic] ideas empowered in class or in general

By allowing them to say their own opinions or ideas

By voicing out their discrimination and letting everyone hear what they have to go through as a black student.

they can make a speech about how they feel about everything.

I feel that with knowledge comes power, and all you need to do is push them to absorb the knowledge they are presented with and use it to see the change in your surroundings.

There really isn't a way. You just gotta have the adults and their parents speak to them about stuff like that, because the reason why I am able to speak about my teacher problem is because my dad taught me how to speak up for myself.

be confident on what say

Listen and take us seriously when we speak.

Talk more about Black History

Black students starting discussions and getting the ball rolling on issues they want discussed can help inspire others to discuss things. Teachers also should be honest about topics that need discussing.

By letting them speak.

Have a day of the month dedicated to black students going into classes and sharing their high school experience so far.

they could raise their hands more and participate

Stand up for ourselves

It can be empowered by being allowed to free their minds anytime anywhere.

African American can feel empowered at school or even in the classroom by having more activities in which they are able to learn more about their ancestries and history of them. They could 


\begin{tabular}{|c|c|}
\hline & $\begin{array}{l}\text { have a open mic on what they feel in their heart and what is real. } \\
\text { I don't know...speak up? } \\
\text { They would be heard }\end{array}$ \\
\hline $\begin{array}{l}\text { Clubs \& } \\
\text { Organizations } \\
N=13\end{array}$ & $\begin{array}{l}\text { Frequent talks in clubs or sports about the topic } \\
\text { Run for ASB because no black students are in it right now } \\
\text { by having a B.S.U that will have the freedom to voice there [sic] } \\
\text { opinions } \\
\text { BSB- Black Student Body, governing class for the wants and } \\
\text { needs of all Black students with representatives. } \\
\text { Gatherings } \\
\text { Bigger Bsu/ more black kids } \\
\text { joining clubs or sports outside of school } \\
\text { By having a get together of black students to form an event } \\
\text { therefore creating a community. } \\
\text { More black people in ASB. } \\
\text { Teaming up with other black students, treat everyone fairly, more } \\
\text { equity courses } \\
\text { They can make BSU more known and incorporate things such as } \\
\text { STEP into there union. While helping students understand their } \\
\text { history. } \\
\text { Have our own clubs where anyone can go to and understand } \\
\text { what it's like to be Black. } \\
\text { if we start our own club or something }\end{array}$ \\
\hline $\begin{array}{l}\text { Other } \\
\mathrm{N}=7\end{array}$ & $\begin{array}{l}\text { removing the mentality of all blacks being unfriendly and violent } \\
\text { Teachers should make sure to deal with any student that doesn't } \\
\text { agree to anything. } \\
\text { more opportunities given to us } \\
\text { That African Americans are great and wonderful people and that } \\
\text { we shouldn't be judged on what we eat or how we act, and } \\
\text { especially what we look like. }\end{array}$ \\
\hline
\end{tabular}


Just treat them like everyone else

read more African-American literature

Maybe for the older grades, when your done taking all required history classes you should be able to take African American history, even freshman because I know the only option for freshman history at "_ _ is ethnic studies but that covers all races so it sorta rushes through all the ethnicities. 


\section{Appendix Y: EQUITY - What Would Discipline Look Like in the}

\section{Classroom/School?}

\section{Labeling Key \\ Warning \\ Respect \\ Fair \\ Other}

\begin{tabular}{|c|c|}
\hline $\begin{array}{l}\text { Label } \\
\text { Name }\end{array}$ & Extra \\
\hline & $\begin{array}{l}\text { If someone broke a classroom code the teachers would give them a warning } \\
\text { first. If they continued, the teacher would confiscate the students phone and } \\
\text { after class have a civilized conversation about the events that took place in } \\
\text { class and try to understand why it happened. } \\
\text { you get } 2 \text { warnings then you get sent to the office with a referal [sic] } \\
\text { being sent to the office, or out of the class. or getting warnings and owing } \\
\text { the teacher time } \\
\text { Waring [sic] } \\
\text { At first it would be easygoing, but three strikes and it would be strict for a } \\
\text { month } \\
\text { Points getting taken, talking to your teacher or going to the office. } \\
\text { Discipline won't be harsh and it would just have the student sit out and } \\
\text { someone can talk to the student to understand how they actually feel. } \\
\text { they would get three strikes depending on what they did } \\
\text { go to Ms. "- } \\
\text { sent to the office or a warning } \\
\text { life lessons showing what can go wrong if they continue on this path and } \\
\text { help them become better. } \\
\text { sit downs and talks recognizing the problem } \\
\text { Discipline in classroom looks like warning and then after the third you will get } \\
\text { a referral for the consequence and will be sent to the office to have a talk } \\
\text { with principal. }\end{array}$ \\
\hline
\end{tabular}




\begin{tabular}{|c|c|}
\hline & $\begin{array}{l}\text { Respect for one another } \\
\text { respect for one another } \\
\text { no cursing, respect is key teachers respect students and students should } \\
\text { return the favor } \\
\text { what we are doing now for that is fine with me as long as it is in a non violent } \\
\text { way } \\
\text { By being honest with the students and respecting their various perspectives } \\
\text { No talking/ be respectful } \\
\text { students who use any racist slur would be expelled determining which words } \\
\text { are used writing a paragraph why you said a comment that offended } \\
\text { someone or disrupt class } \\
\text { Students would be asked why, and talked to like young adults to discuss the } \\
\text { root of the issue. } \\
\text { Discipline would be similar to the disciplines given now. But, a little bit } \\
\text { different making it so that jokes about races aren't made. (All races). } \\
\text { if everyone respected each other }\end{array}$ \\
\hline & $\begin{array}{l}\text { Discipline would be fair in the classroom. People would be held accounable } \\
\text { [sic]. } \\
\text { Fair among each student, no matter skin color or background } \\
\text { Equality in punishments } \\
\text { discipline would be the same just like any other school. } \\
\text { fair punishments and rewards } \\
\text { Everyone being treated the same } \\
\text { Discipline would be fair and equal, and no student would feel singled } \\
\text { out. Frequent troublemakers would get the necessary things they need to } \\
\text { help them be successful. } \\
\text { Just fair discipline to everyone. } \\
\text { They should give students a fair chance before always resulting to calling on } \\
\text { sending out of class. }\end{array}$ \\
\hline & $\begin{array}{l}\text { students get sent to the office or get suspended from school. } \\
\text { Sometimes if the student is deemed/judged as troublesome, the teachers }\end{array}$ \\
\hline
\end{tabular}


will discipline them with rather odd undone actions. Otherwise, it's fair.

say something or send them to the office

Sent to the office.

to write a thousand word of what ever [sic] the class does for example if the whole class was cheating they would write "[l] would never cheat again" a thousand times.

Getting sent to the office. Calling parents and etc.

Suspension and detention would stay the same but expulsion is something we would avoid having to take into consideration. We like to know the root of the problem before cutting down the tree to see if maybe we can help it grow once more.

detention “"”

Detention

Sent to the office or detention 
Appendix Z: EQUITY - How Would Students be Made to Feel Cared for in the

\section{Classroom?}

\section{Labeling Key \\ Treated Kindly/Welcomed \\ Communication/Listened to \\ Other}

\begin{tabular}{|c|c|}
\hline Label Name & Extracted Text \\
\hline $\begin{array}{l}\text { Treated } \\
\text { Kindly/Welcomed } \\
\mathrm{N}=24\end{array}$ & $\begin{array}{l}\text { They would get the extra help that they need. The teachers } \\
\text { would make the students feel welcomed. } \\
\text { They would be made to feel cared for because if they broke a } \\
\text { class rule, the teacher would not get upset initially but they would } \\
\text { try to understand what was going on and why the student } \\
\text { "misbehaved." } \\
\text { by helping them and care for them. } \\
\text { by getting help from the teacher if they don't understand anything } \\
\text { if the teacher checks up on em[sic] and doesn't act like the } \\
\text { students isn't there } \\
\text { when theyre [sic] being respected like everyone else, and being } \\
\text { treated like everyone else } \\
\text { To have patience with students and more tutoring time } \\
\text { involved more and not looked at differently } \\
\text { answer there questions just make them welcomed } \\
\text { the teacher gets to know the student even if they have a lot } \\
\text { There friends will make them feel welcome or comfort them. } \\
\text { students will feel cared by getting treated the same. } \\
\text { when the teacher does not give up on them even when they hard } \\
\text { headed } \\
\text { the work in a way we can understand. } \\
\text { Just by being treated with respect. }\end{array}$ \\
\hline
\end{tabular}


Teacher asking how our day was

Treat them with respect

Ask how they are on a daily bases [sic]

Teachers who take the time to make their students feel cared for and treated fairly. Teachers who make the effort to be kind and find out about students' lives would produce happier and more caring students.

By teachers telling them everyone learns different, \& helping them.

they would get 1 on 1 help from the teacher if needed

Maybe if teachers where [sic] more kind towards student, although some are, students would be kind.

The teachers are welcoming.

Teachers would get to know each student

Having a teacher that is actually willing to help them.

Communication/ Listened to $\mathrm{N}=15$ they be cared for in the classroom and feel cared before each week we will would speak on something that was bothering and the class would only consist of black students so what is wouldn't be something you'd need to worry about

If the teacher would listen to their excuse for whatever reason.

everyone will have time to talk to me and [I] will actually listen

class will feel like a family making strong relationships with the teachers and students. That being said teachers will not accept all late work because the students should know there expectations and the teachers should know if the students have something going on that will get in the way of school work

teachers should make sure they contact every student and parent to ask about the well being of the family.

I would hope that they would see me or other instructors as a source of advice and an open person to consult with for anything. I'm a pretty unbiased person and [I] genuinely love listening to the concerns of others and helping them. 


\begin{tabular}{|c|c|}
\hline & $\begin{array}{l}\text { the adults in school talking more with the students with their } \\
\text { mental health, because I know that in } 10 \text { th grade my grades went } \\
\text { down because of that. And trust me I did bad things to myself } \\
\text { because of the stress of school. } \\
\text { by being heard } \\
\text { to have a voice and speak up } \\
\text { Have our voices matter. } \\
\text { Teachers can check up on each student when possible. If that's } \\
\text { hard, councilors [sic] can walk in to check up on the student. } \\
\text { By always helping them out and finding out when they are sad if } \\
\text { they have any issues. } \\
\text { Students would feel cared for in classroom when they are heard } \\
\text { and the learning environment seems to be positive. } \\
\text { Maybe a talk with the teacher or a Advisor } \\
\text { Be more collaborative and speaking }\end{array}$ \\
\hline $\begin{array}{l}\text { Other } \\
\mathrm{N}=8\end{array}$ & $\begin{array}{l}\text { By meeting the needs of every student } \\
\text { safe and secure } \\
\text { They will know they are learning something to benefit them in the } \\
\text { future } \\
\text { food } \\
\text { MORE BLACK FACULTY- Here to help students and navigating } \\
\text { them through school. } \\
\text { comfortable and safe } \\
\text { when people trust u [sic] } \\
\text { More interaction with students. }\end{array}$ \\
\hline
\end{tabular}




\section{Appendix AA: Researcher Epistemology}

Mertens (2007), founder of the Transformative Paradigm, infuses a social justice lens with mixed methodological practices in order to conduct research that is culturally responsive and empowering to oppressed and marginalized communities under study. She identifies the basic philosophy of the transformative paradigm. Specifically she notes:

To know realities, it is necessary to have an interactive link between the researcher and the participants in a study. Knowledge is socially and historically located within a complex cultural context. Respect for culture and awareness of power relations is critical (p. 216).

In order to utilize the transformative research paradigm with fidelity to guide this study and to build trust among the participants, it is imperative that I, the researcher, authenticate this work by sharing my lived story as an African American woman and as a former high school student who experienced instances of racial microaggressions, subtle slights and slurs, during my schooling career.

My DNA. I always wanted to know the various ethnicities that combined to make up who I was growing up but unfortunately the extent of unraveling my ancestral history often did not go beyond the memories of the few relatives that my father and mother could recall. As my maternal grandparents had long passed before I, or most of my siblings, had been born as well as my paternal grandfather. Although I did know and interact with my paternal grandmother, she passed the night before the first day of my junior year of high school and I always felt a void at not having asked more about her recollection of ancestral roots. Despite doing online searches and meeting with some 
glimpses of success, I decided that I wanted more information to where my ancestors originated from. A few years ago, I decided to use genetic testing and to put an end to wondering and begin the journey of exploring who I am on a grander scale.

Figure 23. My dna provides my ethnic and racial breakdown. I am 94\% of African bloodline with the three largest heritage origins stemming from Cameroon/Congo (44\%), Benin/Togo (30\%), and Mali (14\%) (AncestryDNA, 2019). I had always suspected some cultural traces of Asian based on comments from parents and phenotypical characteristics of family members. I am not surprised that I would have some European descent as a manifestation of the miscegenation that took place during the slave trade and institutionalization of slavery in this country.

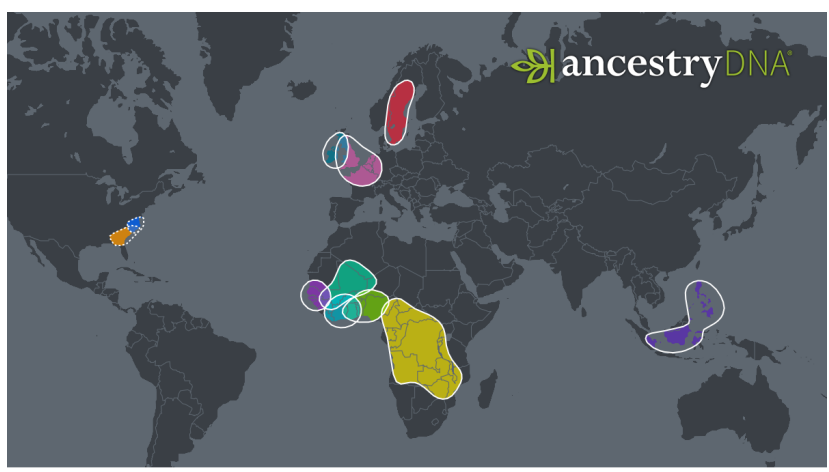

DNA Story for Annette

$\begin{array}{lr}\text { Cameroon/Congo } & 44 \% \\ \text { Benin/Togo } & 30 \% \\ \text { Mali } & 14 \% \\ \text { Ivory Coast/Ghana } & 4 \% \\ \text { Ireland \& Scotland } & 2 \% \\ \text { Philippines } & 2 \% \\ \text { Senegal } & 2 \% \\ \text { Great Britain } & 1 \% \\ \text { Sweden } & 1 \%\end{array}$

Figure 23. My dna. 
Because of the diaspora of black people involuntarily taken from their homelands off the continent of Africa and transplanted around the world, tracing ancestry origins had always been a challenge for African Americans in the United States unlike other racial/ ethnicities who have a greater sense for the intactness of their familial tree. Thanks to modern day genetic testing, such companies as AncestryDNA and 23andMe have opened up a whole new world for many Black people of African descent to be able to gain a greater sense of their cultural and ethnic heritages that have long been hidden due to the intentional stripping techniques used to destroy connectivity to homelands and morale of black people in order to enslave them. Thus, I chose to include my DNA findings to acknowledge my racial consciousness and identity and because it centers and connects my story as part of a peoples who have historically, socially, and politically been subjected to a marginalized membership yet, have often found the courage, determination, and voice to exceed and excel well beyond expectations of their conditions through persistence and resilience. Operationally, for this research study, I utilize Derrick Bell’s (1995) definition for marginalized which he positioned as, “...we see such identification as one of the only hopes of transformative resistance strategy" (902). Marginalization is not a status of pity but one that propels advocacy and action. In "Pedagogy of the Oppressed," Freire (2000/1970) emphasized that freedom will be the result of informed action when a balance between theory and practice is achieved. Oppressors create a culture of silence that propagates a negative self-image of the oppressed. A person must undertake a critical conscious awakening to realize that this culture of silence is created to oppress. I firmly believe that once you know who you are, 
you can no longer allow yourself to be denied or silenced and your voice carries more power in leading transformative changes for human rights.

My Story. I am an African American female who grew up in a stable, yet economically disadvantaged home for most of my childhood in a rural area of North Carolina. Looking back now, I realize I was a high-risk student with the odds of graduating high school stacked against me. Although my epistemology is extensive, from the early beginnings of navigating the K-12 public school system through my senior year of high school, I will pay homage to my high school years as it aligns with the focus of this study.

High School Alma Mater. Western Harnett High School located in the western half of Harnett County in North Carolina is home of the Eagles. It is a rural, low-wealth (Title I) school with $4 \%$ of the student body identified as LEP, $8.9 \%$ IDEA (receiving services through the Special Education program) and less than one percent receiving accommodations via a 504 Plan. I would say most of the demographic makeup of the school has remained the same since I attended during 1991-1995 school years. The school has always been predominantly White with Black and African American students being the largest minority group and only small percentages of Hispanic/ Latino, Asian, American Indian, and other groups. However, recent data has shown a large increase in the percentage of Hispanic/Latino students. Using the survey data from the Office of Civil Rights (OCR) in 2013 the total student body consisted of 1,378 students. Whites constituted 55.6\% of the population, Black/African Americans represented 21\% of the student body, Hispanic/ Latino 16\%, Two or More Races was 5.5\%, American Indian 
consisted of $0.9 \%$, and Asians and Hawaiian/ Pacific Islander each comprised $0.5 \%$ of the student population. Slightly more males (52.6\%) than females (47.4\%) were enrolled (2016).

High School Career. Early in my educational career I felt slighted and wronged because when I was younger (2nd grade) I was not allowed to be tested for the Academically Gifted (AG) program as gatekeepers of the school only reserved that type of testing opportunity for white students. I even remember going to the Assistant Principal's office to ask if I could be tested. I do not recall what she said but obviously she did not take me serious given I was never tested despite being academically capable. However, the summer before my freshman year, I contacted the high school and district office to find out what needed to be done in order for me to be tested for the program. I was finally able to get someone to respond and they explained the process to my mom and she signed for me to be tested. I sat in the Principal's conference room during the summer at the high school I would be attending that fall (Western Harnett High School) and took the test. The results revealed that I was indeed gifted in mathematics and was right on the cusp for reading. Thus, I officially qualified in the area of mathematics. In high school it equated to ultimately taking honors and Advanced Placement (AP) courses. However, as a teenager, I felt it was a necessary accomplishment for me to show that I was just as smart as my peers who qualified years ago and that it was important as an African American student to be recognized for such an achievement and to gain access to additional educational resources and opportunities. 
During my high school years, I had a lot of caring and strong teachers. I grew up in truly what one may consider a neighborhood school where many of the teachers were from the area and lived in the community with very little turnover as most teachers stayed till retirement. Most of my teachers were white females. One of my favorite math teachers was a white male, Mr. Harrington, who was my geometry teacher my 9th grade year. He was my go to snack guy at break on a daily basis. He would automatically have a pack of whatever he was eating waiting for me. The snack supply carried on through my sophomore year.

During my entire high school career I only experienced being taught by two teachers of color, a Biology Teacher who was an African American female and a P.E. Teacher who was a Native American female. As I recall in my entire K-12 experience, I had five total teachers of color (4-Black Females; 1-Native American Female). My second and fourth grade classroom teachers and my eighth grade English Teacher were all black females. In none of my K-12 schooling did I see Administrators or Counselors who looked like me. The few Blacks who worked in schools were often in Custodial or Cafeteria roles.

In The Autobiography of Malcolm X, he wrote about his schooling experience and the feeling he had of a sense of oddity that was placed on him in his classes composed of mostly white peers. The notion that black students who rise above the low expectations held of them in class are seen as unique and almost non-human in the eyes of their white peers. In essence, the black student is assigned an ascribed status referred to as a pink poodle, an object to marvel (1965). Because I was in the honors and advanced classes, I 
was often either one of two or the only black student in the classroom and at times was made to feel like a mascot or pink poodle with having to represent or speak on the behalf of all black students (X, 1965; Kelly, 2007). I often felt the classroom makeup was not a true reflection of the many other smart black students I knew who could easily have done the work but either were not encouraged to take the more advance classes or felt embarrassed if someone knew they were really smart if they took those classes.

Being engaged in various activities outside of the classroom, I felt was essential in order to be a balanced and successful student. Although I was not a big sports person, I would occasionally go to games. I was often involved more with academic events. I was a member of the Beta Club, Science Club, SADD, and Debate (although I never competed). I took part in the History Bowl in the County and my team won first place and we received trophies and a picture in the newspaper. I received other rewards and plaques (e.g. recognized as a high performing student in the County by United Way) throughout high school for being an outstanding student. I was an aide in the library. I was selected and trained a few days over the summer before my senior year to be a Peer Tutor and had the opportunity to lead mediations between peers who had conflicts.

I was an active member in my church as well as a member of the Youth NAACP in Harnett County and received a small scholarship from the organization to help with books during my first year in college. During my sophomore year, I was selected to take part in a math team competition held at North Carolina State University. I was the only female and African American student apart of the high school team. Even though we did not win, I felt it was a great experience to meet other high performing students, 
particularly in math, from around the state and to spend a day on a college campus. I also served as the Historian for the Junior Class and worked on prom committees and was often granted other leadership roles.

I was identified as number seven in my Junior class and was selected as a Junior Class Marshal for the 12th grade graduation. I remember a white male peer, who I had known since elementary school who was also identified as one of the top 10 students of the Junior class, saying to me to the effect that although I was black, I was different. I never forgot how awkward that made me feel. To know him, I knew he was coming from a sincere place and trying to make a compliment but at the same time it reminded me how as an African American student I often felt like I had to work twice as hard to get the same academic recognition. Unfortunately I knew he was not the only White peer who allowed their minds to hold stereotypical, preconceived notions that to be black somehow equates to not being as smart as "them" so I had to be seen as different for him to justify why I deserved that honor. I continued to excel my senior year and I graduated as the top African American student in my class (and essentially the top performing Black student in the school at that time).

Being one of the top-graduating seniors, I had the honor of doing the prayer for the Convocation event preceding the graduation. I remember so many people later commenting of how great of a job I did. I remember that same white male classmate saying I sounded like a Southern Baptist Preacher. Also, I was the student who had the best school attendance as I had perfect attendance from third grade through my senior year of high school and was recognized and received a plaque during Senior Awards 
Night for that accomplishment. Unfortunately, I remember my paternal grandmother passed away the night before the first day of my junior year of high school but my parents did not want me to miss going to school despite having a long, hard night. But I always felt my grandmother would have wanted it that way so I found the strength to go to school the next morning. I remember cousins, friends, and teachers were very supportive during that time. In my entire K-12 schooling I missed nine days of school.

I attribute my high school success to a variety of factors from having supportive parents who encouraged me to do well, maintaining perfect attendance, strong academic ability in both math and reading, actively engaged in extracurricular activities both in and outside of school, friends who also cared about making good grades, having a strong spiritual foundation, having several caring teachers who supported my growth and success, and never having a discipline infraction nurtured me from falling prey to becoming a high school dropout statistic.

However, it is not to say that my K-12 experience was all roses along the way. Early on I realized growing up in a rural school system in a predominantly White community where everybody knows your name, still teachers and peers held dispositions and preconceived notions of Black students that led to instances of being discounted and overlooked for educational opportunities. I recall my freshman homeroom teacher who constantly mispronounced my name as Anita despite clearly that was not what was on his attendance roster or the many times I corrected him to no avail. Despite some glitches of oddities in the classroom experienced from teacher and/or peer, I was lucky in a sense I suppose that I had more going for me than against me. The reality is that many African 
American students quickly stamped with labels as future dropouts or as future menaces to society, particularly African American males, may not have the necessary tools to endure or persevere against the fight of the heart of darkness and thus are overcome and fall prey to the self-fulfilling prophecy if they do not have the support from within the classroom or outside of it to sustain. 


\section{Appendix BB: Kindezi Inspired Structured Schools (K.I.S.S. Model)}

The classroom is an example from the inside out of how students of color and those who are apart of marginalized groups are often made invisible to educational opportunities yet become hyper visible as recipients of behavioral consequences. I coin this behavior the Seesaw Imbalance Effect (SIE) (see Figure 24).
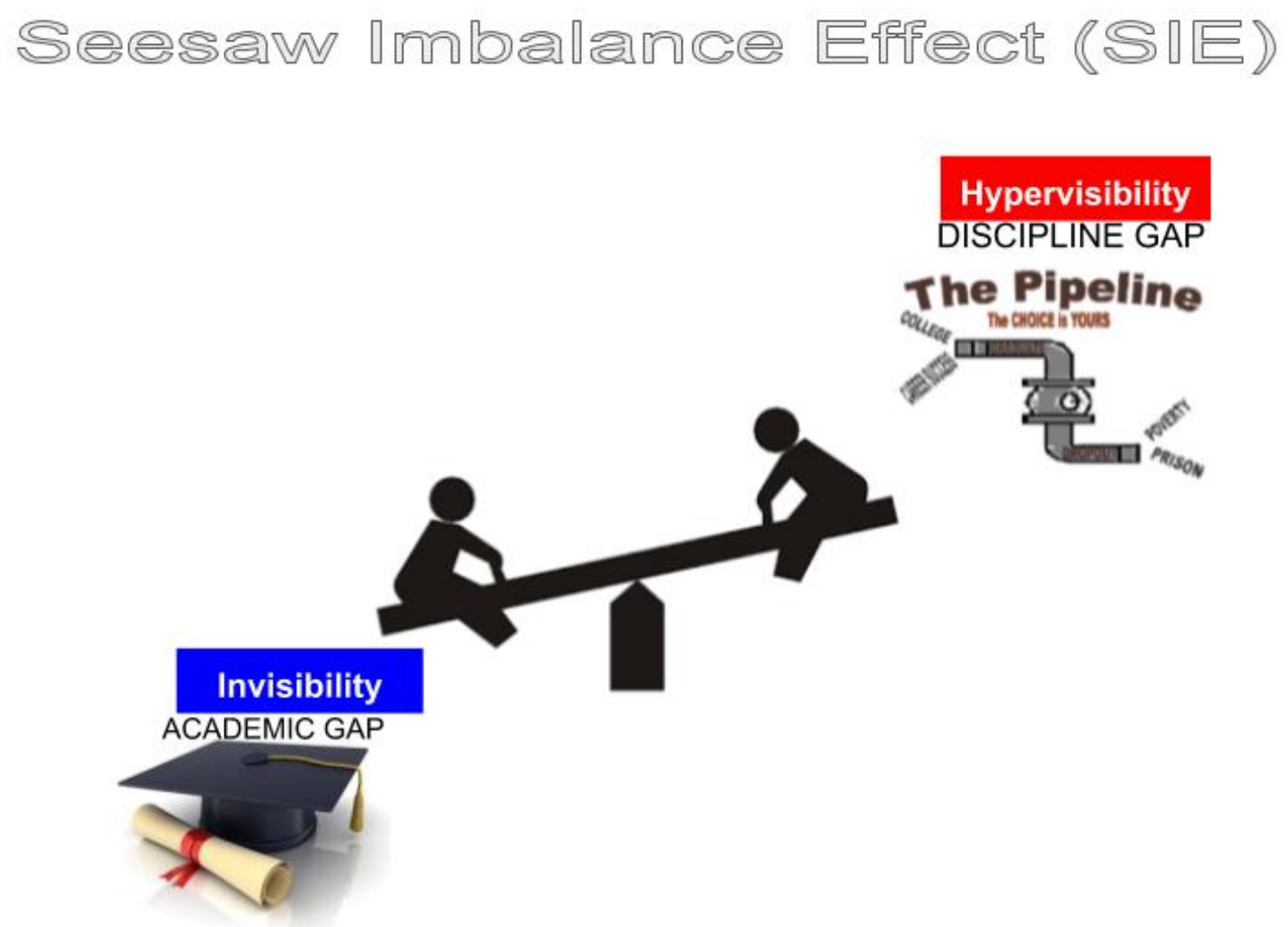

Figure 24. Seesaw imbalance effect.

School climate contributes to the success of students and supports the concept of SIE (Pringle, et al., 2010). Carter Andrews (2012) referred to the experiences black students 
encounter in the classroom such as over magnification as racial spotlighting and the invisibility as racial ignoring.

According to Kunjufu (2002), African Americans are classified as involuntary minorities and they see school as a majority meaning the academic achievement it promotes often serves to challenge their group loyalties and ethnic identities. He recommends cooperative learning classrooms because it is student centered and encourages students to work together promoting confidence and self-esteem as well as academically enhancing student learning. Kunjufu (2002) further noted competitive, grade oriented classrooms leave many low achieving and disadvantaged students to finish last and to feel demoralized. This sentiment is echoed by Ford (2012) who pointed out that African Americans are involuntary minorities because their ancestors were brought to this country as slaves for the financial benefit of the slave-owners and were stripped from their culture and had Western culture impressed upon them unlike other immigrant groups who have come to the United States freely to pursue economic and educational opportunities.

Ladson-Billings \& Tate (1995) coined the phrase culturally relevant pedagogy as a way to train new teachers how to use best practices that value the African American learner. Academic success (intellectual growth), cultural competence (appreciation of one's culture), and sociopolitical consciousness were the defining domains. LadsonBillings (2014) pointed out that over the years teachers have been successful at implementing the first two but were failing at raising the consciousness of students. She defined sociopolitical consciousness as "the ability to take learning beyond the confines 
of the classroom using school knowledge and skills to identify, analyze, and solve realworld problems" (p. 75). Teachers need to create and seek out opportunities to engage students in learning beyond the textbook or worksheet by utilizing real-world, meaningful issues and topics by which students can become action oriented thinkers and doers as well as take part in service learning projects and other meaningful learning opportunities.

If the Black or African American Student Value Exclusion Model (BOAASVEM) speaks to the general, norm experiences of Black or African American students in most traditional high school classrooms, then it is certainly time to restructure the learning environment. Kindezi Inspired Structured Schools (K.I.S.S.) is an ideal transformative framework or school model that aligns with a Bantu cultural practice called Kindezi that highly values students utilizing an Afrocentric approach. Kindezi, an African term descended from the Bantu, is referred to as the art of babysitting. However, the idea of babysitting takes on a more profound meaning than what one may typically associate with an Eurocentric, Western perspective. Kindezi is about taking special care and providing attention to a child whether it is by parents, siblings, or extended relatives within the community. It is further defined as, “...the art of touching, caring for, and protecting the child's life and the environment" (Fu-Kiau and Lukondo-Waamba, 2000, p. 1). Childrearing is held in high regards within African communities because it not only allows for the growth and nurturing of the child by helping to develop and shape their future but, is considered to be therapeutic and an enlightening experience for the caregiver as well. 
Fu-Kiau and Lukondo-Waamba (2000) pointed out "all social relationships that work to tie all these societal elements together (parents, ndezi, and children) are in the interest of personal growth and community betterment" (p. 31) which is consistent with Freire (2000/1970) comment, "what the educator does in teaching is to make it possible for the student to become themselves" (p. 47). The epitome of academic freedom and liberation is realizing that education is a living, selfless process of finding one's true self to in turn empower others (see Figure 25).

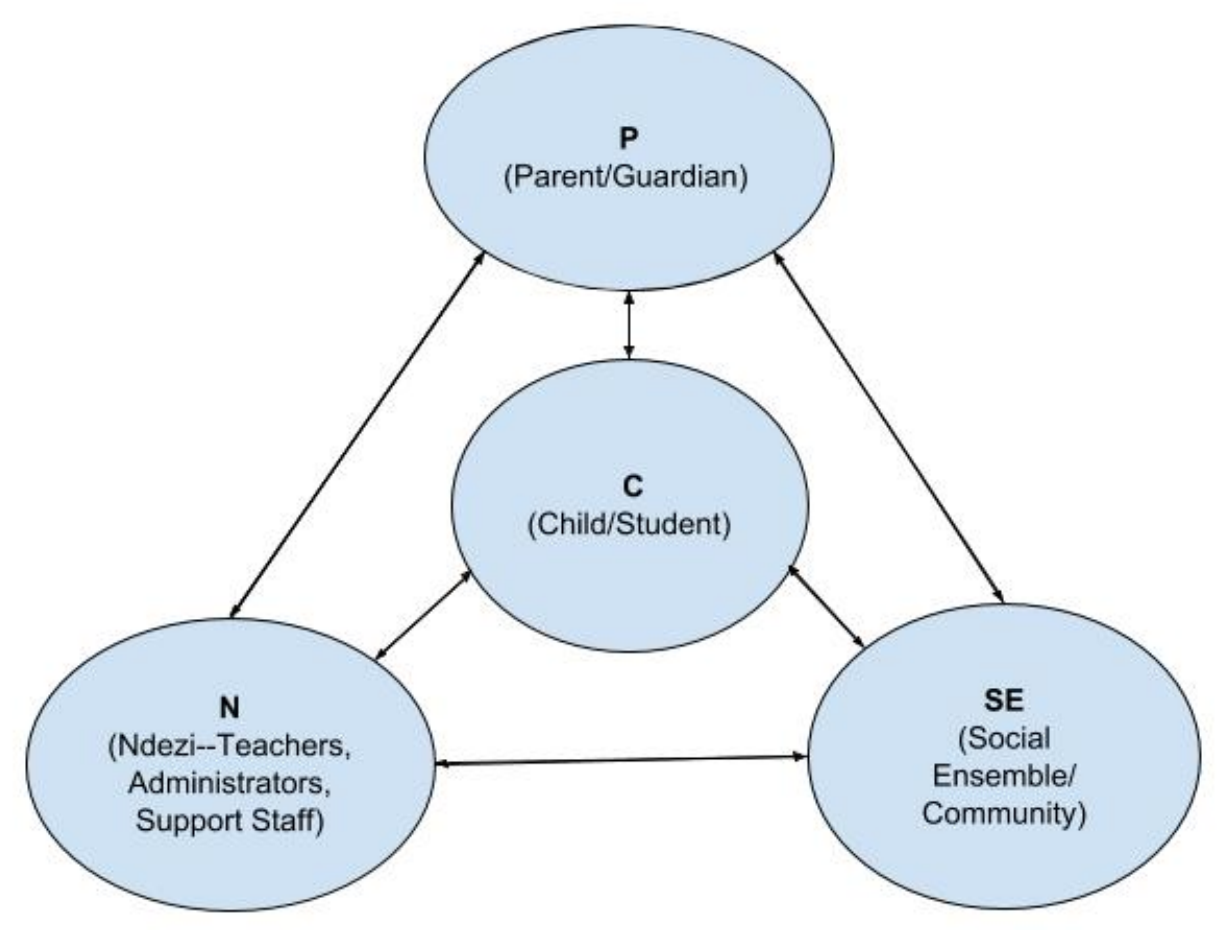

Figure 25. Kindezi--a process of collectively nurturing and rearing a child for success. Adapted and modified from Fu-Kiau and Lukondo-Waamba (2000). KINDEZI: The Kôngo art of babysitting (p. 32). Baltimore, MD: Inprint Editions. 
Visually Figure 25 shows how Kindezi principles can be situated in an educational context and the social responsibility of all in the sâdulu (learning environment) contribute to the caring and nurturing of the student. Specifically sâdulu is "a moving school" meaning learning is not restricted to 4-walls of a classroom but allows for interaction, collaborative learning, and authentic experiences to occur in various settings (p.19). The social ensemble includes peers as well as the greater community served by the school. Ndezi, teacher, is one of many adults students are able to gain knowledge from in a school setting. All elements are critical in the ability for students to thrive and obtain educational freedom.

Although the diaspora may have led to the displacement of African descended people around the world, many of the adages of this mentality can be witnessed within African American culture in the United States. The idea of nurturing one's young and the strength of family bonds/kinship continue to be deeply rooted within the daily lives of Blacks in America transcending social class. An example can be seen in the mother of former First Lady, Michelle Obama, who moved with the family to the White House to help care for the children.

The Kindezi African philosophy promotes smaller/ family-like classrooms often with six to eight students per teacher at the elementary level. In the proposed K.I.S.S. model targeting high school age students small groups of 12 for academic core classes and up to 20 for elective courses are ideal. The holistic model stresses academics and socioemotional learning through three main approaches: Socratic tutorial, supporting all students to meet high expectations, and develop healthy relationships. The Kindezi 
model further taps into the right-brain thinking strategies as noted by Kunjufu (2002) and utilized Ladson-Billings (2014) framework of cultural relevance and sustainability pedagogy fostering student centered learning through art integration, differentiation, and project-based learning.

The principles of KINDEZI have often been centered and implemented in early childhood education from kindergarten through middle school with such models in existence in Atlanta, GA (The Kindezi Schools) and Indianapolis, IN (Kindezi Academy). However, the same concepts with respect to collective caring and nurturing the child and emphasizing key instructional and learning strategies within nontraditional environmental arrangements continue to be a necessity at the latter half of the k-12 educational experience in shaping future leaders. The model can sustain as a selfstanding school, be incorporated into a traditional school setting within a freshman academy or embedded throughout the school through course offerings and classroom practices. The K.I.S.S. Model presents a unique opportunity to explore the potential positive impacts such principles will have on high school students, particularly students of color whose learning needs are best met through the incorporation of a KINDEZI framework. At the core of Kindezi Inspired Structured Schools are three principles: community, equity, and excellence (see Figure 26). A foundational understanding of roles (see Figure 27) and a list of sample courses (see Figure 28) are provided for the draft model. 
Core Values

\section{Community, Equity, Excellence}

Equity: Subgroup needs-outreach/ interventions (both human and technology infused learning opportunities, address educational inequities,

wrap-around

services--ACCESS FOR ALL

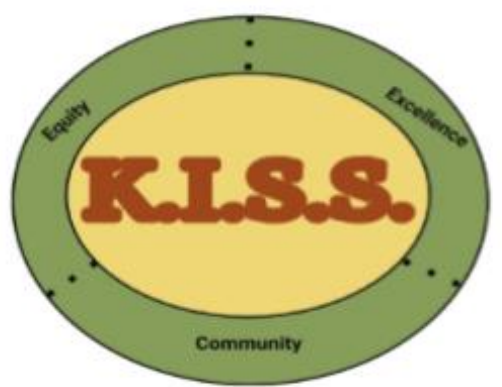

Excellence: Assessment and Data-- What teachers need to learn to promote student learning? Pedagogy/

Curriculum, PLCs (Open to

Learning Conversations OLCs); standards/rigor; student centered, project based--inquiry learning opportunities

Community: Building

Relationships--Kindezi

influence, Peer to Peer, Staff

to Peer and Staff to Staff;

Service Learning Projects,

Parents/Guardians, Potential

Agencies and Business

Partners

Figure 26. Framework and self-sustaining model of kindezi inspired structured schools (K.I.S.S.) core values. 


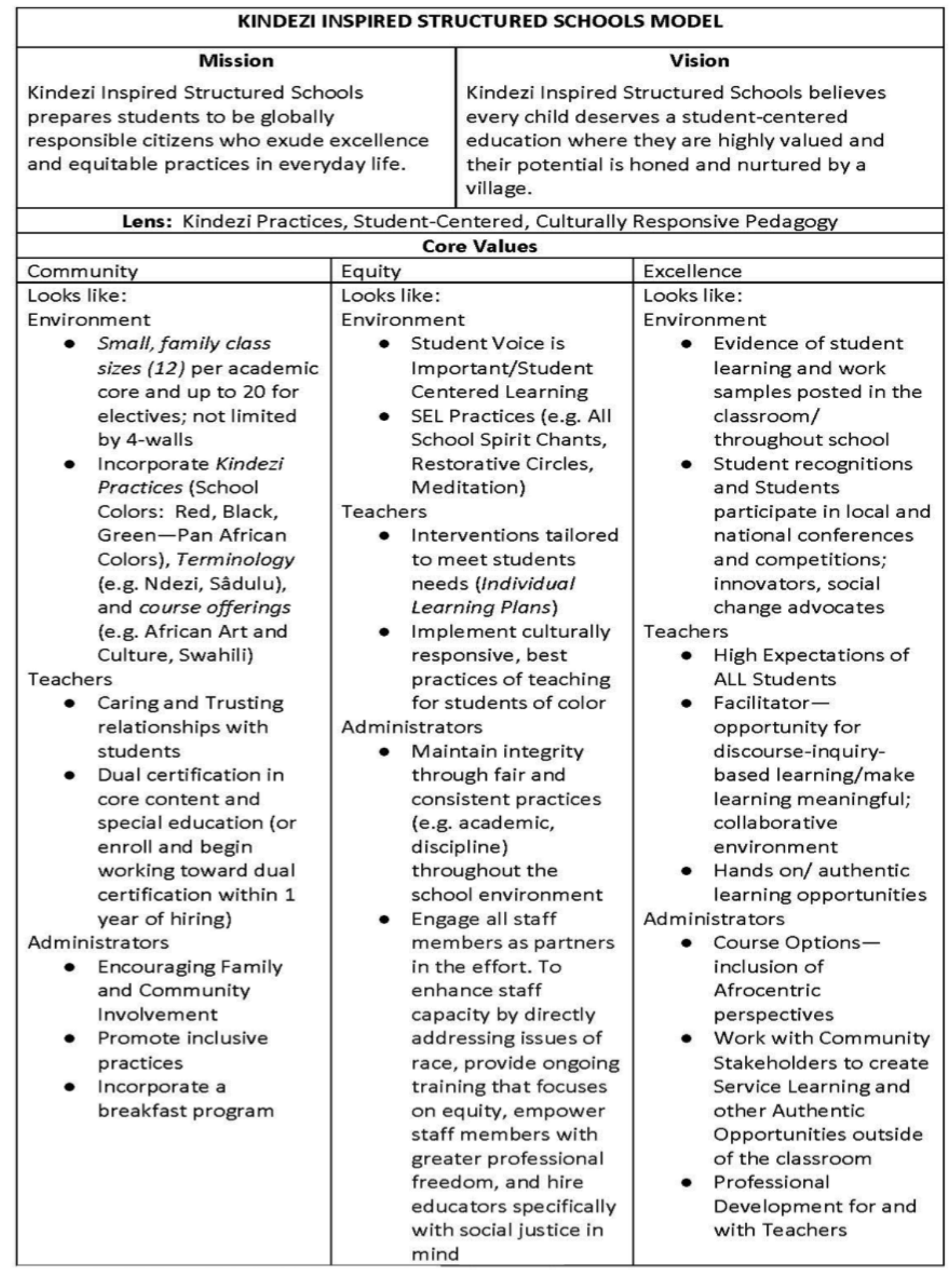

Figure 27. Roles within K.I.S.S. core values. 


\begin{tabular}{|c|c|c|c|c|c|c|c|}
\hline Required Elective & Choice Elective & $\begin{array}{l}\text { Clubs [work with local } \\
\text { businesses and colleges } \\
\text { (recruit college student } \\
\text { volunters) to assist in } \\
\text { creating authentic } \\
\text { learning experienees] }\end{array}$ & Core Academics & $\begin{array}{l}\text { School and Class } \\
\text { Structures }\end{array}$ & $\begin{array}{l}\text { All Grades--Service } \\
\text { Learning }\end{array}$ & CORE VALUES & Bantu Culture \\
\hline African Art and Craft & Social Justice & Robotics/ Engineering & English & $\begin{array}{l}12 \text { students per core class; } \\
\text { up to } 20 \text { students per } \\
\text { elective }\end{array}$ & Community Project 1 & $\begin{array}{l}\text { Community, Equity, } \\
\text { Excellence }\end{array}$ & $\begin{array}{l}\text {-Languages commonly spoken by } \\
\text { the Bantu Peoples: English, } \\
\text { Spanish, French, Portuguese, and } \\
\text { Swahili }\end{array}$ \\
\hline African Dance & $\begin{array}{l}\text { Debate/ Creative } \\
\text { Writing }\end{array}$ & Math & Math & Incorporate technology & Community Project 2 & & Bantu means "people" \\
\hline Hip Hop Dance & Cultural Diversity & Science & Science & All School Meetings & Community Project 3 & & $\begin{array}{l}\text { http://wwww } \\
\text { newworldencyclopedia. } \\
\text { orgefentry/Bantu }\end{array}$ \\
\hline History of Jazz & Physical Education & $\begin{array}{l}\text { Arts (performing and } \\
\text { visual) }\end{array}$ & History & Advisory & Community Project 4 & & \\
\hline Civil Rights I (before 1960) & Drama & $\begin{array}{l}\text { Journalism (work on } \\
\text { creating a school } \\
\text { newspaper) }\end{array}$ & & Inclusion Model & & & \\
\hline Civil Rights II $\left(1960^{+}\right)$ & Coding & Martial Arts & & $\begin{array}{l}\text { Core Teachers to be or } \\
\text { work to be dual certified } \\
\text { in content and special } \\
\text { education }\end{array}$ & & & \\
\hline Gospel Choir & Band & $\begin{array}{l}\text { Business in Practice } \\
\text { (Encourage } \\
\text { entrepreneurship such as } \\
\text { using Crowdfunding or } \\
\text { Kickstarter, work with } \\
\text { Junior Achievement, etc.) }\end{array}$ & & PBIS & & & \\
\hline Roots Cooking & Photography & Stepping & & $\begin{array}{l}\text { Mediation Moment (Calm. } \\
\text { org and other Mindfulness } \\
\text { strategies) }\end{array}$ & & & \\
\hline Tap Dance & Keyboarding & Automative & & Student Centered Learning & & & \\
\hline Swahili** & Marketing & & & Project-Based Learning & & & \\
\hline \begin{tabular}{|l} 
Independent Studies \\
Course:Diaspora--project \\
can focus on any aspect of \\
the dispersion of African \\
descendants from their \\
original homeland
\end{tabular} & $\begin{array}{l}\text { Spanish,* French,* } \\
\text { Portuguese* }\end{array}$ & & & & & & \\
\hline
\end{tabular}

Figure 28. Sample course offerings. 